Leslie Kaplan

Jane Sautière

Henri Raczymow

Philippe Fusaro

Pascal Commère

Baptiste-Marrey

Dominique Fabre

François Salvaing

Jacques Séréna

François Bon

Emmanuelle Pireyre

Jean de Breyne

Sylvie Gracia

Mouloud Akkouche

Nicolas Fargues

Alice Ferney

Fabienne Swiatly

Lucien Suel

Christine Détrez

Aurélie Pétrel

\title{
Tours et détours en bibliothèque carnet de voyage




\section{Tours et détours en bibliothèque. Carnet de voyage}

Leslie Kaplan, Jane Sautière, Henri Raczymow, Philippe Fusaro, Pascal Commère, Baptiste-Marrey, Dominique Fabre, François Salvaing, Jacques Séréna, François Bon, Emmanuelle Pireyre, Jean de Breyne, Sylvie Gracia, Mouloud Akkouche, Nicolas Fargues, Alice Ferney, Fabienne Swiatly, Lucien Suel, Christine Détrez et Aurélie Pétrel

DOI : 10.4000/books.pressesenssib.1844

Éditeur : Presses de l'enssib

Année d'édition : 2012

Date de mise en ligne : 20 juillet 2017

Collection : enssib2012

ISBN électronique : 9782375460245

\section{QbOOOKS}

http://books.openedition.org

\section{Édition imprimée}

ISBN : 9782910227975

Nombre de pages : 272

Référence électronique

KAPLAN, Leslie ; et al. Tours et détours en bibliothèque. Carnet de voyage. Nouvelle édition [en ligne]. Villeurbanne : Presses de l'enssib, 2012 (généré le 01 février 2021). Disponible sur Internet : <http:// books.openedition.org/pressesenssib/1844>. ISBN : 9782375460245 . DOI : https://doi.org/10.4000/ books.pressesenssib.1844. 
Leslie Kaplan

Jane Sautière

Henri Raczymow

Philippe Fusaro

Pascal Commère

Baptiste-Marrey

Dominique Fabre

François Salvaing

Jacques Séréna

François Bon

Emmanuelle Pireyre

Jean de Breyne

Sylvie Gracia

Mouloud Akkouche

Nicolas Fargues

Alice Ferney

Fabienne Swiatly

Lucien Suel

Christine Détrez

Aurélie Pétrel

Tours et détours
en bibliothèque
carnet de voyage 
Une journée à la bibliothèque Sainte-Barbe 00

Marguerite (Yourcenar) 00

Canaan en vue: Prolégomènes à une tentative d'approche de la BU Paris 7-Diderot 00 Le pas de l'autre 00

Sortir des forêts 00

L'impasse des verbeuses ou la rivière enfouie ${ }^{00}$

À Paris 8 Saint-Denis 00

Lueurs sur l'incendie méconnu de la médiathèque de Lorient 00

Elle est ici chez elle (La bibliothèque de la Roseraie à Angers) 00

De haut en bas 00

Nettoyer une phrase de Marguerite Duras 00

Lire et lire, Écrire le lire, et lire ici-même 00

Au hasard l'Alcazar 00

Larguer les amarres! 00

Trafalgar à Austerlitz 00

J'aime/J'aime pas: Carnet de route vers la médiathèque d'Alfortuille ${ }^{00}$

À portée de main 00

Trois petits tours avec L'Albatros 00

De fil en aiguille 00

Trombe 00

Bibliographie des auteurs 00

Présentation d'Aurélie Pétrel 00 


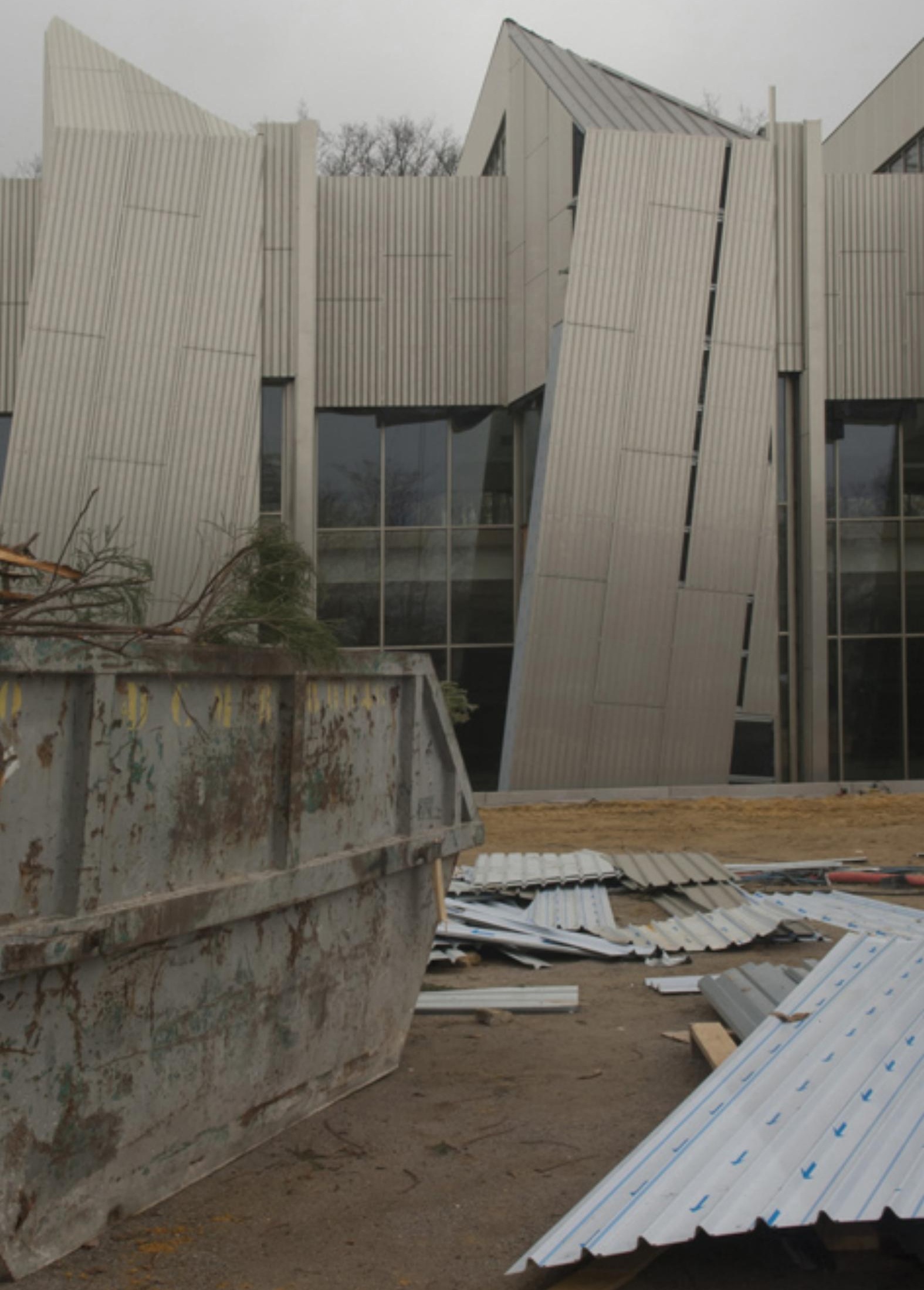




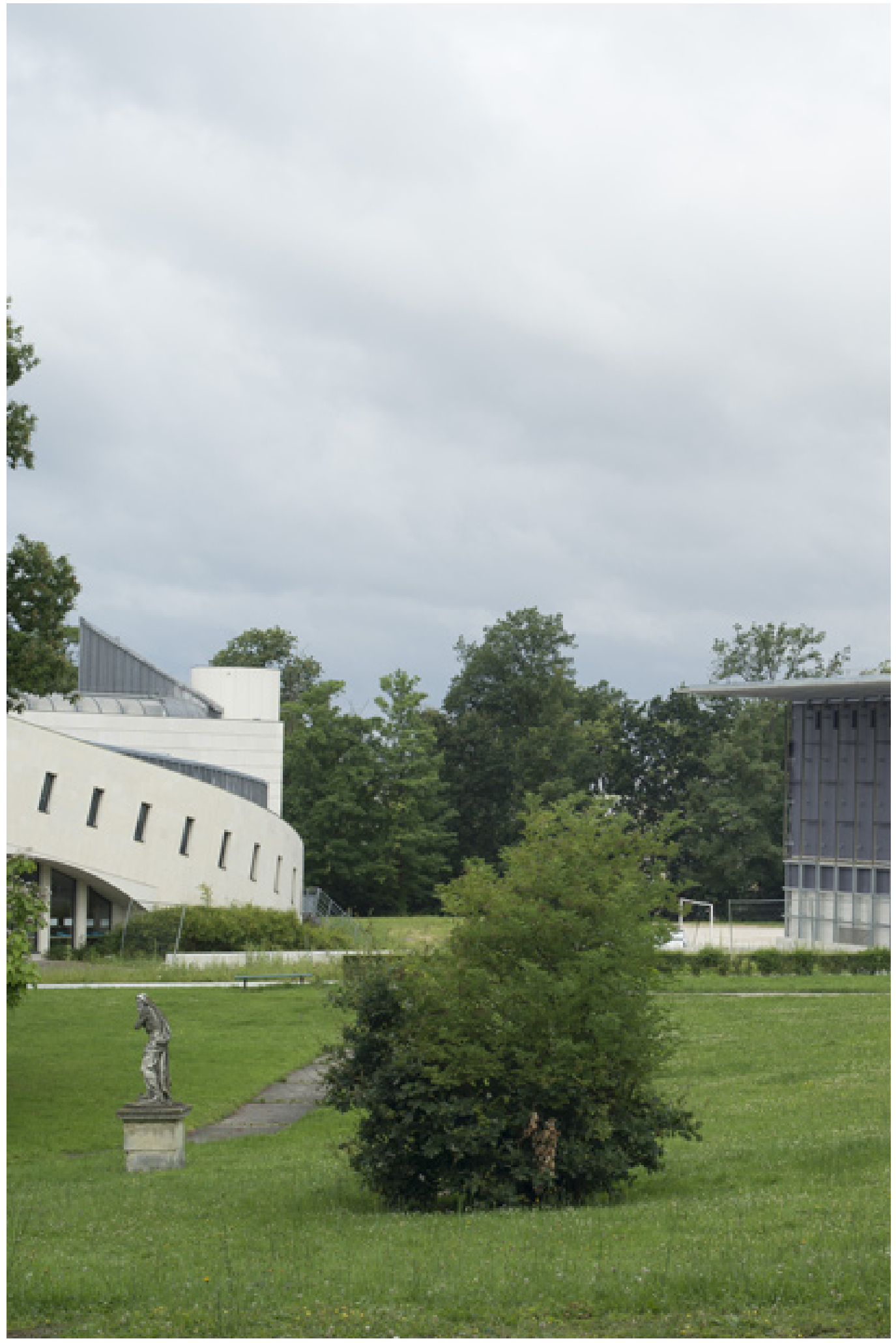



Cette publication a été réalisée

dans le cadre des 20 ans de l'enssib.

Les autres ouvrages édités à l'occasion des 20 ans de l'enssib

Lire, écrire ou comment je suis devenu collectionneur de bibliothèques par Jacques Roubaud.

Version numérique disponible gratuitement:

< http://roubaudlireecrire.enssib.fr >

[ISBN 978-2-910227-95-1]

Imaginaires des bibliothèques: «Mondes lettrés:

fragments d'un abécédaire" par Christian Jacob,

«< http://www.fonds-thorez.ivry94.fr/thorez >»

par Annette Wieviorka.

[ISBN 978-2-910227-96-8]

Architecture et bibliothèque, 1992-2012: 20 ans

de constructions, ouvrage collectif réunissant des architectes, des conservateurs de bibliothèques, des élus et plus de vingt bibliothèques. L'illustration de l'ouvrage a été confiée à Frank Bonnefoy.

[ISBN 978-2-910227-98-2]

à renseigner

ISBN 978-2-910227-97-5/ prix : 55€

Dewey:

Rameau 


\section{Tours et détours en bibliothèque carnet de voyage}

littérature \& photographie PRESSES DE L'enssib 


\section{Écrire la bibliothèque}

Pourquoi demander à des écrivains, ainsi qu'à une plasticienne-photographe d'aller à la rencontre de bibliothèques? Les bibliothèques sont des objets complexes: lieux ouverts à tous, fréquentées par certains, de tailles et d'architectures variées, gratuits, payants pour certains services, espaces collectifs pour des usages singuliers, établissement municipal ou service commun de l'université; leurs personnels sont visibles dans les espaces, présents pour les publics, invisibles parfois. Institution ancienne, en révolutions successives, l'image de la bibliothèque est lourde d'idées reçues, de représentations, de fantasmes peut-être. Geste architectural pour les uns, lieu emblématique de l'éducation ou de la culture pour d'autres, elle est aussi l'objet d'enjeux politiques, sociaux et économiques.

Une des activités régulières pour les bibliothécaires s'incarne dans leur attention aux auteurs : écrivains, musiciens, plasticiens, penseurs..., ceux-ci sont présents dans les collections proposées, invités en résidences, associés à des expositions, des rencontres, des festivals.

\section{La commande}

Une bibliothèque pour faire quoi? C'est la question que nous avons posée à la vingtaine d'artistes invités, pour qu'ils proposent leurs voies de lecture/écriture dans le paysage des bibliothèques. Chacun d'entre eux a choisi, dans une sélection de bibliothèques construites entre 1992 et $2012^{1}$, un établissement en particulier. Dedans, dehors, de près, avec, de loin... l'écrivain était alors invité à aller à la rencontre de ces lieux de vie, de passages, d'offres et de demandes, de présences physiques et virtuelles. De son côté, Aurélie Pétrel est partie saisir, en photographe, les différentes bibliothèques choisies par les auteurs. Sa série d'images en cartographie le parcours.

\section{Un double portrait}

Il est toujours risqué de faire commande à des auteurs; impossible d'anticiper les textes qui arriveront, les photos qui seront choisies. 
Bien heureusement chacun n'en a fait qu'à sa tête. Mais tous ont joué le jeu de la commande. Le portrait fragmenté que ce livre esquisse est double: c'est celui des univers-bibliothèques, opérant une traversée entre réalité institutionnelles et scène fictionnelle, autant qu'un portrait d'écrivains en activité, au travers d'un condensé de formes littéraires, de la nouvelle au poème en prose en passant par la contrainte de type oulipienne. Plusieurs textes interrogent le service-bibliothèque, questionnent son évolution, d'autres y mettent le feu ou font le ménage, beaucoup témoignent d'une réappropriation de l'expérience-bibliothèque et leurs auteurs ont pris le risque de se livrer à un corps à corps avec l'opacité symbolique de l'institution.

Une des bonnes surprises, pour un éditeur essentiellement au service des professionnels des bibliothèques a été les nombreux croisements entre les préoccupations actuelles des bibliothécaires et nombre de sujets abordés par les auteurs. Exemple convaincant de la capacité réflexive de la littérature et de l'art.

\section{La familiarité du dépaysement}

Le bibliothécaire trouvera dans ces textes matière à construire des liens avec le corpus des ouvrages qui traitent du compagnonnage littérature et bibliothèques ${ }^{2}$; l'esprit curieux découvrira la richesse thématique d'un

1. Voir la base de données qui recense la majorité des constructions de bibliothèques de ces dernières vint années, sur le site de l'enssib:

Constructions de bibliothèques françaises depuis 1992 $<$ http://www.enssib.fr/ constructions-debibliotheques/liste> 2. Se reporter à Écrire la bibliothèque aujourd'hui, sous la direction de Marie-Odile André et Sylvie Ducas (Cercle de la librairie, 2007), qui traite et met en perspective la représentation des bibliothèques dans la production littéraire pour la période moderne. objet aussi hybride que la bibliothèque et un état actuel de sa représentation en littérature; l'amateur de littérature, pour sa part, sera sensible à la diversité des formes d'écritures contemporaines et aux manières par lesquelles les artistes appréhendent leur objet.

Pour nous, école et éditeur, cet ouvrage s'inscrit au cœur de nos missions: élargir l'horizon des bibliothèques.

Et nous voilà, peut-être, devant un nouveau courant artistique: la géo-bibliothéconomie?

\section{Catherine Jackson}





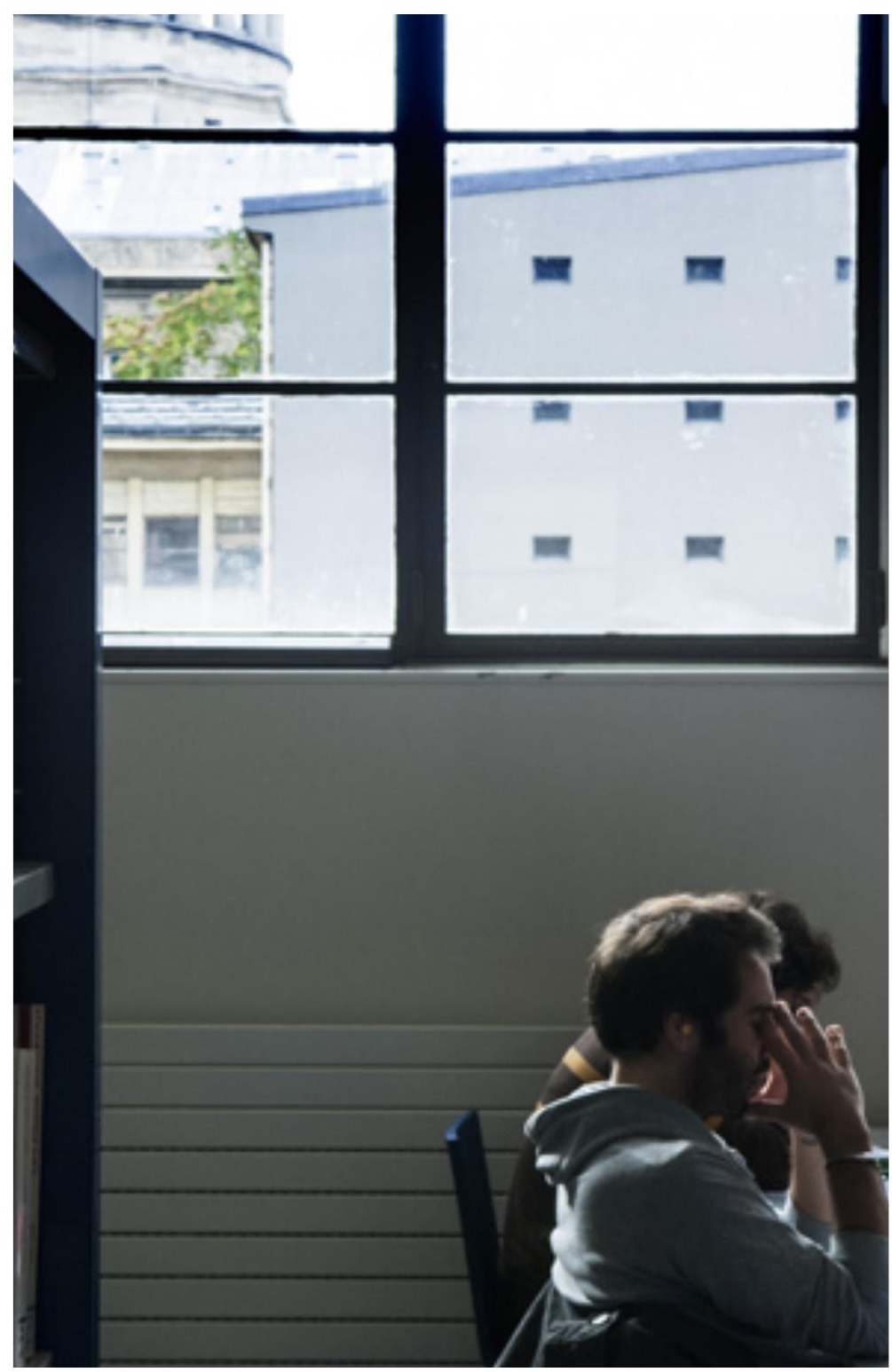


Bibliothèque Sainte-Barbe, Paris

Une journée à la bibliothèque

Sainte-Barbe 
Je suis allée passer une journée à la bibliothèque SainteBarbe qui se trouve près de chez moi.

Dans la rue, devant l'entrée, beaucoup de jeunes gens, souvent hilares, souvent inquiets, fumant, buvant des cafés, discutant sans arrêt, par deux ou en petits groupes.

C'est une bibliothèque interuniversitaire, 800 places de lecture, installée dans les murs de l'ancien collège SainteBarbe, le plus ancien collège de France, fondé en 1460 sur la montagne Sainte-Geneviève, à côté d'autres grandes bibliothèques (Sainte-Geneviève, Cujas, la Sorbonne). La bibliothèque est ouverte pour les étudiants de niveau licence et master, de Paris et de l'île-de-France. Aménagée depuis peu, moderne, agréable, pleine de lumière et d'ordinateurs, elle est rattachée administrativement à l'université Sorbonne Nouvelle-Paris-3. Droit, sciences politiques, sciences économiques et sociales, langues, littérature.

J'ai eu de la chance, j'ai fait une rencontre, une vraie, exemplaire pour moi de ce que c'est, une bibliothèque: l'accès aux livres et à l'amour des livres, bien sûr, et aussi la possibilité d'échanger, de partager, de penser avec la présence radicale, tranchante, d'un texte.

Jérémie, je l'ai d'abord vu de dos, assis la tête dans les mains, entouré d'une pile de livres de chaque côté, il lisait de façon intense, et de temps en temps, c'est ce qui m'a frappée, il était secoué de rire. Je me suis approchée, il lisait Bouvard et Pécuchet.

J'ai engagé la conversation, il m'a dit que le livre était aux concours, agrégation, capes, bonheur pour lui.

Et il m'a expliqué, très content d'essayer sur moi les idées qui lui étaient venues pendant ses lectures, comment pour lui c'était un texte qui annonçait, anticipait, notre société de consommation.

Je le relis pour la nième fois, m'a dit Jérémie, et à chaque fois il me fait rire, mais rire. En même temps c'est un livre tellement sérieux. Il me semble toujours me parler à moi personnellement, et de nous, de maintenant.

Regardez, là je suis dans le chapitre IV, quand ils deviennent archéologues. Quand ils se mettent à tout ramasser. 
Quand leur maison ressemble à un musée. C'est ce que dit Flaubert.

Le petit mot musée.

D’emblée il nous fait réfléchir à ce que c'est, un musée, le rapport au passé, donc bien sûr à nous, aujourd'hui, à qui nous sommes, comment nous nous situons.

"Quand on avait franchi le seuil, on se heurtait à une auge de pierre (un sarcophage gallo-romain), puis les yeux étaient frappés par de la quincaillerie».

Trois mots, discordants, trois domaines hétéroclites, auge, sarcophage gallo-romain, quincaillerie. C'est déjà tout le chapitre, et même tout le projet.

L'énoncé de la quincaillerie est si drôle, c'est littéralement n'importe quoi, une bassinoire, des flambeaux, des serrures, des boulons, des écrous, la carcasse d'un bonnet de Cauchoise, deux urnes d'argile, des médailles, une fiole, jusqu'au morceau de cotte de maille, et la "pièce unique», une hallebarde.

La description continue, on arrive aux «deux noix de coco (appartenant à Pécuchet depuis sa jeunesse)»...

L'ensemble est donné sous le signe de ces noix de coco, qui résonnent avec l'expression «à la noix» «à la noix de coco », c'est-à-dire: sans aucune valeur. Folie douce...

Et la hideuse statue de saint Pierre... Total kitsch, bien sûr, mais pas pour eux.

Après ils partent en campagne, dit Flaubert, ils visitent, ils ont l'amour des bibelots, ils accumulent...

C'est-à-dire, commentait Jérémie, on peut y voir le n'importe quoi «consommateur» comme on dirait aujourd'hui, qu'on trouve dans la société maintenant.

Alors ils se passionnent pour le style, «bientôt ils furent capables de distinguer les époques, et dédaigneux des sacristains, ils disaient: "Ah! une abside romane! Cela est du xil siècle! Voilà que nous retombons dans le flamboyant!" » «Nous retombons »... Façon d'embarquer le lecteur, mais ironique en même temps: qui, mais qui, est dupe de cette classification, eux bien sûr. 
Ils adoptent tout de suite les façons de voir, de décrire et de juger des historiens de l'art (médiocres, médiocres...) qu'ils lisent, consultent.

Et ils achètent, ils achètent.

Je trouve, dit Jérémie, qu'on voit les boutiques de gadgets à la sortie de n'importe quel musée, les foulards, les assiettes, les cendriers, les tasses, les mugs, avec des reproductions de tableaux...

Et les interprétations, «cela prouvait que nos ancêtres avaient chéri la gaudriole»... Pure projection, bien entendu...

Mais tout de suite après, vient la phrase, "ce défaut de certitude les contrariait».

Jérémie s'arrêta, tout d'un coup sérieux.

En un sens, il reprit, ils sont idiots, trop bêtes, "des cloportes", c'est Flaubert qui parle d'eux comme ça, moi je pense à La Métamorphose et à Kafka, ils cherchent n'importe quoi, n'importe comment, ils accumulent, sans aucun discernement, bric-à-brac total, et en même temps, ils sont touchants, ils sont poussés en avant par l'angoisse, comme tout le monde, comme nous, comme moi... Flaubert ne réduit jamais à la caricature, même s'il invente des types, des modèles, des stéréotypes, crac, il les ouvre, il les complexifie...

D'ailleurs ils ont un côté enfantin, ils sont comme des enfants, ce qui les rend, aussi, universels. Je pense à moi, enfant, dans le grenier d'une maison à la campagne, l'amour sans discernement du passé, de ce qui était «avant», avant nous, avant qu'on arrive au monde, ce passé qui est plein de mystère, inimaginable. Et comme les enfants ils adorent se déguiser, se déguiser est la façon la plus simple de s'approprier, de comprendre, ils se déguisent en Moyen Âge, en colporteurs... et comme tous les enfants ils se demandent «d'où on vient»...

Mais en même temps, plus loin: "Ce défaut de certitude les contrariait» (à propos de la non-concordance entre le style d'un monument, et la date qu'on lui suppose).

C'est-à-dire, de nouveau, l'inquiétude, l'angoisse. 
Flaubert épingle ces deux insectes, si on veut, il les traite, maltraite, avec ironie, et pourtant, non, en tout cas pas seulement: il maintient une dimension où l'on peut s'identifier à eux, ils sont comme nous, «madame Bovary c'est moi ", et ça, insistait Jérémie, c'est parce que Flaubert ne leur refuse pas l'angoisse, l'inquiétude. Chose dont les autres protagonistes, les notables etc. sont complètement dépourvus.

Je me suis demandé pourquoi c'est si drôle, dit Jérémie, rêveur, je veux dire: de quoi est fait le comique dans ce chapitre, dans ce livre.

L'ironie épingle le ridicule, le distingue, le souligne, et se détache, se dégage de ce qui est montré, critiqué.

L'humour fait voir l'insolite, le bizarre, il nous implique tous. Et l'humour marque aussi l'importance du hasard, ce «maître de l'humour» comme dit Max Ernst...

Est-ce que Flaubert a de l'humour, au-delà de son ironie? Le comique flaubertien est "objectif », pas intérieur comme celui de Kafka... L'angoisse est un moteur pour les personnages, mais pas un point de vue.

Mais, Jérémie réfléchissait, un écrivain comme Flaubert, qui a un rapport tellement fort au réel, doit bien aussi avoir un rapport au hasard, et donc à l'humour...

Je me suis dit, Jérémie souriait, que Bouvard et Pécuchet auraient pu proférer certains des aphorismes de Lichtenberg, peut-être...

"Il s'émerveillait de voir que les chats avaient la peau percée de deux trous, précisément à la place des yeux».

Ou Flaubert aurait pu dire de l'un ou l'autre de ses héros des choses comme «Il faisait toutes ses découvertes à peu près comme les sangliers et les chiens de chasse trouvent les sources salées et les eaux minérales» ou encore "Cet homme travaillait à un système d'histoire naturelle, dans lequel il classait les animaux d'après la forme de leurs excréments. Il distinguait trois classes: les cylindriques, les sphériques et ceux en forme de tourte »... Enfin, dit Jérémie, peut-être... 


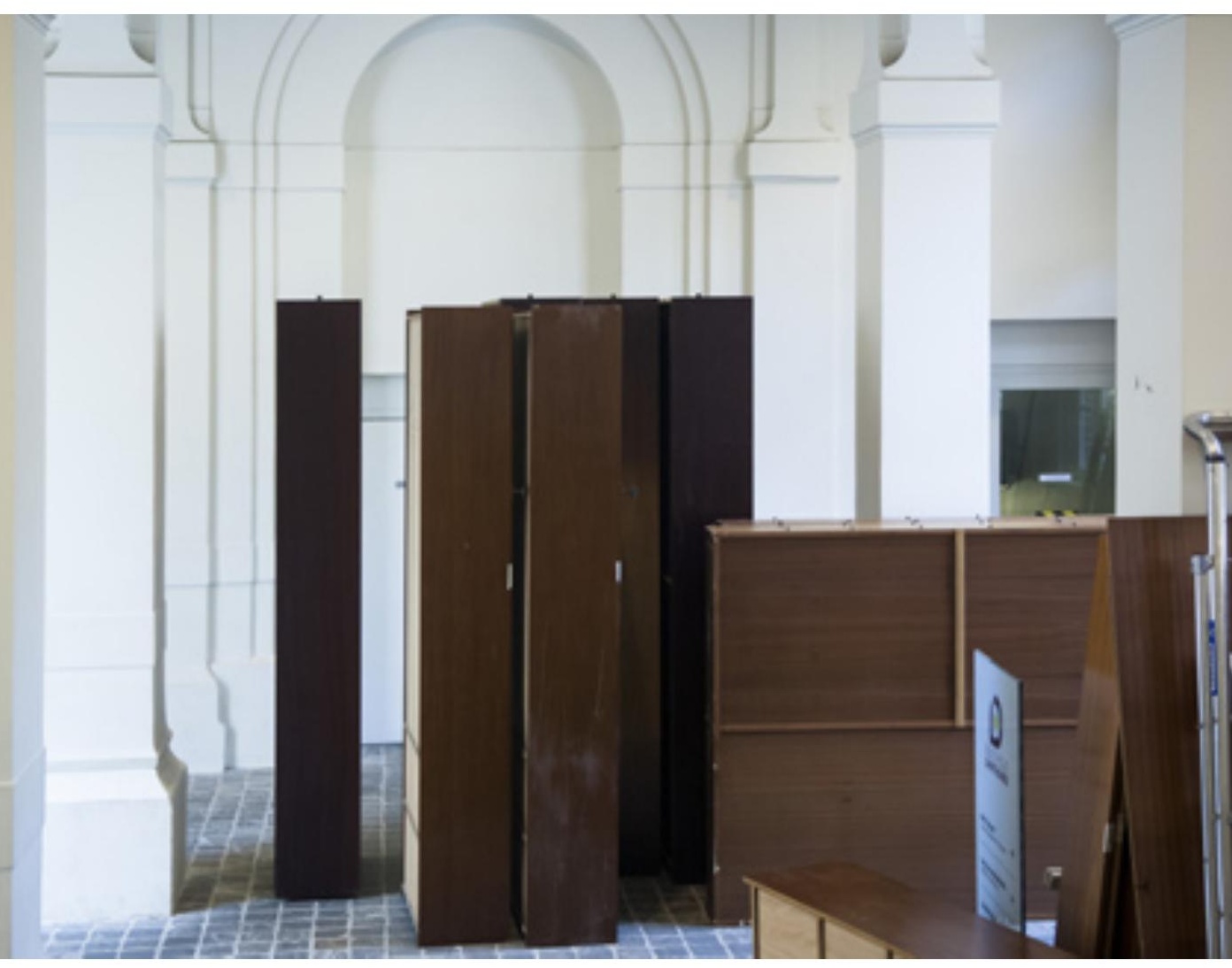


Le chaos du réel, continuait Jérémie, décrit dans ce chapitre, mais aussi bien dans tout le livre, c'est le chaos de la condition humaine.

J'ai souvent pensé à Vladimir et Estragon, dit Jérémie. Il prit un livre dans une de ses piles, c'était En attendant Godot, l'ouvrit et lut:

«Étant donné l'existence telle qu'elle jaillit des récents travaux publics de Poinçon et Wattman d'un Dieu personnel quaquaquaqua à barbe blanche quaqua hors du temps de l'étendue qui du haut de sa divine apathie sa divine athambie sa divine aphasie nous aime bien à quelques exceptions près [...] et attendu d'autre part qu'à la suite des recherches inachevées n'anticipons pas des recherches inachevées mais néanmoins couronnées par l'Acacacacadémie d'Anthropopopmétrie de Berne-en-Bresse de Testu et Conard il est établi sans autre possibilité d'erreur que celle afférente aux calculs humains...»

Il rit, moi aussi bien sûr, et il ajouta, Ce discours se termine avec les pierres:

«Les pleurs les pierres si bleues si calmes hélas la tête la tête la tête la tête en Normandie»...

Beckett aurait pu penser à ce moment où Bouvard et Pécuchet «pleins d'ardeur » étudient successivement la Pierre du Post à Ussy, la Pierre Couplée au Guest, la Pierre du Darier, près de Laigle...

Moi, continuait encore Jérémie, je trouve que ce livre parle de maintenant, de la "culture», du tourisme, enfin, ce qu'on appelle la culture, le tourisme, soi-disant de masse... «après les églises ils étudièrent les châteaux forts »... ils passent d'une chose à une autre, tout les émerveille, et en fait très vite, tout les ennuie, ils ont des mauvaises raisons pour s'intéresser, ils s'intéressent parce que c'est vieux, ce n'est évidemment pas une raison!

Ils sont bien sûr à l'opposé de l'énoncé flaubertien, «le style est une manière absolue de voir les choses », pour eux le style, ce sont tous les styles, des choses mortes, il n'y a aucun enjeu, c'est ce qui les rend si pathétiques. Pour eux la culture ce n'est pas une recherche de sens, c'est un 
moyen pour ne pas s'ennuyer, pour ne pas être confronté au vide de leur existence.

J'ai pensé au film de Jean-Luc Godard, Les Carabiniers, dit Jérémie. Ce que les deux paysans imbéciles rapportent de leurs voyages, de leurs conquêtes, c'est quoi? Des cartes postales. Même si évidemment Flaubert n'a pas connu la société de consommation, la société marchande il la connaissait très bien. Une société où l'accumulation de n'importe quoi, y compris des connaissances, tient lieu d'expérience, où la recherche, infinie par définition, se rabat sur des bribes de savoir, d'un savoir fait plutôt de préjugés.

Où la culture est une forme parmi bien d'autres d'aliénation. L'histoire de France défile en images d'Épinal, clichés, énumération «de problèmes, de points curieux à éclaircir».

Confrontés au réel, à l'infini du réel, à l'infini des choses, des idées, des opinions, au réel infini de la pensée, les deux n'ont aucun point de vue, tout est réduit à des «curiosités ", et ils sont littéralement avalés par le réel, ils passent leur temps à tomber dans des trous, au propre et au figuré, ils vont de déconvenue en déconvenue.

Flaubert a trouvé une tension, un système contradictoire, où d'un côté Bouvard et Pécuchet s'intéressent à tout, à n'importe quoi, ils glissent à l'infini d'une chose à une autre, et on est pris de vertige avec eux, c'est vraiment un infini concret, qui se déploie, et qui angoisse, et d'un autre côté il y a le contraire, mais c'est complémentaire, leur entourage ne s'intéresse à rien, mais alors à rien, ou alors quand les gens autour d'eux s'intéressent, c'est uniquement pour des raisons personnelles, en ramenant tout à eux-mêmes, totalement égocentrés.

Et méchants.

Les deux héros sont dans le rêve, l'illusion, trois trous dans un vieux chapeau signifient que le chef des voleurs s'est pris une balle, eux croient tout ce qu'on leur raconte pour leur vendre n'importe quoi, mais c'est beau, romanesque, etc., et à l'opposé Mme Bordin: «Tant mieux, on a bien fait», quand ils racontent qu'on a tué le chef des voleurs supposés. 
Portrait d'une femme atroce, violente, égoïste, avare, et surtout, comble de la bêtise: sans aucune curiosité, ramenant tout à elle, pleine de préjugés, etc.

Les autres notables sont à la même enseigne.

Flaubert note le comique qui vient du manque absolu de curiosité. Trouver du sens suppose toujours une invention, pour sa vie, qui comme toute vie est unique. Au contraire eux à la fin du livre, dans le plan laissé par Flaubert, «ils s'y mettent», c'est-à-dire: à copier, c'est la «bonne idée», et cette solution n'est rien d'autre que leur incapacité à passer ailleurs, à faire, imaginer autre chose que ce qu'il y a...

Ce qui est émouvant, presque tragique, chez Bouvard et Pécuchet, c'est que leur recherche du savoir est une recherche de sens, mais ils ne le savent pas.

Le savoir rassure, alors que le sens est une construction, est toujours en train de se faire, jamais fermé (tant qu'il y a de la vie). Et l'angoisse est inévitable.

Flaubert nous le fait sentir par le négatif, en creux.

La pure accumulation conduit bien entendu au néant. Et, dans ce chapitre, au "tout devint phallus».

Le comique vient de ça: une idée devient tout ou tout se réduit à une idée.

Il y a cette blague bien connue, dit Jérémie, sur les grandes conceptions du monde, Jérémie riait en racontant: d'abord est venu Jésus-Christ, pour lui, tout est amour. Ensuite vint Marx, tout est économie. Après Marx, Freud, alors pour lui, tout est sexe. Et enfin, Einstein, qui dit, tout est relatif.

Jérémie fit une pause.

Je voulais qu'il continue, je dis, Vous n'aimez pas le moment mnémotechnique? Pour moi c'est un des moments les plus comiques, quand ils font le tour des méthodes qui soi-disant aident la mémoire, mais qui sont elles-mêmes impossibles à garder en mémoire...

Oui, le moment mnémotechnique est trop, trop drôle, dit Jérémie, c'est l'absurde poussé à l'extrême. La proximité 
de ce qui est le plus humain, ce qui définit l'humain, la parole, le langage, avec le non-sens, l'absurde.

"Pâris frappe l'imagination au moyen de rebus; un fauteuil garni de clous à vis donnera: Clou, vis - Clovis; et comme le bruit de la friture fait «ric, ric», des merlans dans une poêle à frire rappelleront Chilpéric ».

Au-delà de l'absurdité évidente, à savoir que c'est sûrement aussi difficile de se souvenir des clous et de la poêle à frire, que de Clovis et de Chilpéric, c'est la joie des sons, encore l'enfance, ric et ric, clou et clou...

Mais ils découvrent que jamais l'Histoire ne sera fixée, «C'est triste», pensaient-ils.

Pour moi ils sont tristes parce que passifs, c'est la position du consommateur, passive, triste, Flaubert anticipe l'insatisfaction de la société de consommation.

Leur solution (très provisoire) à la fin du chapitre: écrire la vie du duc d'Angoulême. C'est Louis-XIX, j'ai cherché, a dit Jérémie, il a régné le temps d'abdiquer, vingt minutes...

«Mais c'est un imbécile!

- Qu'importe!»

Et ils redoublent l'imbécillité.

«Détails intimes, traits du prince:

Au château de Beauregard, dans son enfance, il prit plaisir, avec son frère, à creuser une pièce d'eau que l'on voit encore. Une fois il visita la caserne des chasseurs, demanda un verre de vin et le but à la santé du Roi.»

Ces «détails intimes », soi-disant passionnants, sont en fait nuls, répétitifs.

«Son style valait sa parole. Ses proclamations dépassaient tout. »

«Soldats, j'arrive». "Je suis arrivé», «J'arrive»...

C'est sans fin, dit Jérémie, souriant largement. Ce livre, je veux dire. Les livres, ajouta Jérémie, en montrant les rayonnages tout autour.

Je lui souhaitai bonne chance pour ses concours, et je le laissai travailler, ravie de cette rencontre surprenante et de ma journée à la bibliothèque. 
Jane Sautière

Médiathèque Marguerite Yourcenar, Paris

Marguerite (Yourcenar) 
Si elle avait gardé son nom de naissance, ça aurait été un peu compliqué, Marguerite Antoinette Jeanne Marie Ghislaine Cleenewerck de Crayencour, c'est long. Même lorsqu'on ne garde qu'un des prénoms, Marguerite Cleenewerck de Crayencour, c'est long. Long comme les histoires nobiliaires, les noms arcboutés sur les pays, la possession de la terre, de son nom, de son histoire. Corps du seigneur et territoire fusionnés. Comme elle a fait de Crayencour son nom de Yourcenar, ce que ça fait d'écrire avec un autre nom que le sien, Crayencour, on pense à craie, à crayon, c'est cette part de son nom qu'elle a livrée à la transformation en nom d'écrivain, elle a gardé Marguerite, elle n'a pas gardé ni cherché à transformer Cleenewerck, elle n'a pas choisi Antoinette, ni Jeanne, ni Marie, ni Ghislaine. Antoinette Yourcenar, Jeanne Yourcenar, Marie Yourcenar, Ghislaine Yourcenar.

Donc, Marguerite Yourcenar for ever. On ne peut pas imaginer un temps où on ne lira plus Yourcenar. Peut-être arrivera-t-il. Peut-être, un jour, les immensités qui nous fondent ne nous fonderont plus, parce que, ici et toujours, place aux vivants. Mais nous ne serons plus là, nous non plus, jusqu'à ma mort, au moins jusque-là, on lira Marguerite Yourcenar. Peut-être Duras disparaîtra-t-elle avant, ou pas de la même façon, dans la moquerie et le quolibet, avec la violence spécifique qu'on met à l'assassinat des femmes qui écrivent. Tandis que Yourcenar mourra comme meurent les langues anciennes, un grand paquebot coulant dans le silence et la lenteur, son erre à peine visible.

J'aimerais tenir l'idée de faire ce texte sur Marie de Crayencour ou sur Jeanne Cleenewerck. Sur une femme de Flandre, sur une femme pâle dans un velours bleu nuit.

Dans ma bibliothèque, d'elle: Mémoires d'Hadrien, Feux, L'CEuvre au noir, Conte bleu. Je ne souviens plus du recueil de Conte bleu, dont je vois qu'il a été publié après sa mort, bien que les textes qui le composent datent de ses 24 ans. 
Qui choisit le nom des bibliothèques? Pourquoi Marguerite Yourcenar, ici dans le $15^{\mathrm{e}}$ arrondissement de Paris? Là, dans la rue d'Alleray, où, si je tourne à angle droit, face à la médiathèque, dans la rue Corbon, je tombe, après avoir traversé la rue de la Convention, dans la rue de Cronstadt, où j'ai vécu, sans à aucun moment m'abonner à cette médiathèque, qui, tout simplement n'existait pas encore, ou d'ailleurs à aucune autre. Je commençais à me constituer ma propre bibliothèque, quittant peu à peu le livre de poche pour m'acheter des livres, des vrais, avec mon salaire et avec cet indiscernement brouillon lié à l'absence relative d'ouvrages de littérature chez mes parents. Non, là, rue de Cronstadt, je vivais dans la solitude noire des amours passionnelles, j'allais boire des coups, dans un bar tenu par un ancien boxeur, me sentant bien dans cet univers d'hommes fanés et marqués, étrangère et donc sans recours à mes malheurs volontaires et adorés. Pas de médiathèque, donc. Mais dans ce studio, boîte bétonnée qui donnait de la claustrophobie à mon chat, nanti d'une baie vitrée occlusive, (niveau zéro de l'architecture), qui n'ouvrait sur aucun extérieur, ce qui allait comme un gant à ma souffrance, ton sur ton, comme on dit, la soulignant et la prolongeant, là, oui, j'ai acheté et lu Mémoires d'Hadrien, j'en suis à peu près sûre pour avoir trouvé dans les pages du livre ré-ouvert, une lettre brève, un brouillon de ma prose accablante à mon amant absolu. Les longs moments de cette écriture, je m'en souviens si parfaitement, la recherche du mot à la mesure de l'excroissance du sentiment, cette quête fébrile d'où il ne sortait aucun apaisement et qui me conduisait à aller boire des coups au bar du vieux boxeur. Là, au milieu des hommes vaincus, je reprenais un peu de forces, suffisamment pour rentrer chez moi. J'aurais été mieux inspirée de placer la lettre, ou plutôt son avorton, le brouillon, dans Feux, qui l'eût peut être contenue avec plus de prévenance. Car ça, ces mots de petite femme amoureuse dans Mémoires d'Hadrien, non, ça ne se peut pas. Je mesure l'indécence, je sens le glacis de la misogynie "yourcenardienne» me plaquer net, au sol, comme au rugby, plof. Me plaquer, en tant qu'amoureuse pour la faiblesse de ma constitution face à l'immensité de mon sentiment, et en tant qu'auteur, pour le 
rabattement de l'écriture à une œuvre «au blanc» - si j'ose défaite par le noir non assumé. «La nuit était tombée, sans qu’il put savoir si c'était en lui ou dans la chambre: tout était nuit.../... les ténèbres s'écartaient pour faire place à d'autres, abîme sur abîme.../... 1». Voyez l'écart. Comme cette Marguerite-là est loin de mon pauvre moi, si faible, si pathétiquement féminin (pléonasme), si parfaitement renversé par la jouissance (cul par-dessus tête, enfin) dans le grand appartement de l'homme de Montparnasse, qu'il fallait bien tout ce malheur pour ne pas follir, renversée sur le grand lit et dépouillée comme un lapereau, baisée par l'amant, toute la lumière de ma vie, l'éblouissement sexuel, noir absolu, puis retour à la baie vitrée, aux hommes fatigués du bar du boxeur (il faut dire aussi que je travaillais en prison, grise plaine des hommes vaincus). J'aurais dû lire Duras. Mais Hadrien, un empereur... La possession, non plus de la terre, mais du monde. Duras m'aurait montré l'empereur de la jouissance des femmes, l'amant, si on veut, et la douleur qui s'en suit.

Donc, on l'appelle la médiathèque Marguerite-Yourcenar. Qui et pourquoi? Y a-t-il un vote en conseil municipal? Est-ce un maire qui suggère? Impose? Un fonctionnaire de la mission «Livre» du ministère de la Culture? Y a-t-il une liste d'attente des auteurs en voie d'être «nominés»? On me dit que dans le $3^{e}$ arrondissement de Paris, il y a eu vote des lecteurs de la bibliothèque pour désigner Marguerite Audoux.

Mon ancien quartier, à l'époque, ce n'était pas la mairie du 15e, balladurienne jusqu'à la quintessence, la caricature. Surtout le bar du boxeur, alors là, pas balladurien pour un dessous de bock, bar proche de la rue des Morillons, rue des objets et des amoureuses perdues (pléonasme). Pourquoi Yourcenar, et pas Calet, Henri Calet, promeneur infatigable, mais lui, plutôt du 14e, c'est vrai, plus que du 15e. Sauf qu'il ne faut peut-être pas raisonner au nom du lieu de naissance de l'auteur, de l'endroit qu'il a arpenté. Mais plutôt de son territoire mental, espace politique, affectif, sensible, sinon il n'y aurait que peu

1. L'E Euvre au noir, Marguerite Yourcenar, Gallimard, 1968. de noms d'écrivains au fronton des bibliothèques de Seine-Saint-Denis (Paul Éluard, Didier-Daeninckx). 
Alors qu'il y en a, des bibliothèques, appelées Louis-Aragon séparé d'Elsa-Triolet (plusieurs fois nommés mais chacun dans des communes différentes), Boris-Vian, Robert-Desnos, Paul-Éluard, André-Breton (imaginez que j'ai rencontré un directeur de prison qui s'appelle André Breton, j'ai cru à une plaisanterie), HenriMichaux, Saint-John-Perse, Michel-Simon, Guy-de-Maupassant, Georges-Brassens, Georges-Pérec, Guillaume-Apollinaire. Parfois, un concept, médiathèque Avenir. Il y a une bibliothèque Marguerite-Yourcenar, place Nelson Mandela à Sevran.

Je suis donc venue la voir, elle est belle, hospitalière, grande, si parfaitement au service des lecteurs, auditeurs, amateurs de vidéo, qui la traversent.

Moi, qui suis venue le sandwich à la main et qui ai mangé devant l'entrée, réalise que je pouvais tout à fait le faire dans un espace jouxtant le patio où mon appareil photo peine à garder trace des fleurs si légères de quatre jeunes prunus, fleurs inconscientes de cette fin janvier qui garde ses griffes d'hiver en réserve. Partout de jolis sièges contemporains, orange, rouille, brique, rouge basque, causeuses, tulipes ou fers à cheval tordus pour faire dosseret. DVD rangés par genres et par réalisateurs. Bel escalier où, sur un palier, une femme lit, luxueusement, posée au bon endroit comme un chat. Partout, comme des petits salons où se poser et lire.

Je cherche si j'y suis (toxique curiosité), tape «Sautière » et trouve un traducteur de manga prénommé Laurent. Mais Nullipare est chez Marguerite D. dans le $20^{e}$.

Au rayon de Marguerite (Yourcenar). J'ouvre Souvenirs pieux, intriguée par le titre. Installée sur une banquette corail, je lis, page 346, l'aventure littéraire avec son père, nommé par son prénom «Michel», aventure et liaison, car quoi de plus incestueux («une intimité désinvolte», dit-elle) que cette histoire du manuscrit paternel confié par lui à elle, sa fille, qui l'endosse et le signe, sous le titre de Premier soir, histoire d'un homme du monde et homme à femmes, emmenant sa toute jeune et fraîche épouse en voyage de noces, c'est-à-dire, au seuil de la 
faire passer de cet état virginal à l'état matrimonial, celui de toutes les petitesses de la vie conjugale.

Je m'apprête à emprunter ce livre, ce que je ne fais pas, partant plutôt avec Petits contes de printemps de Sôzeki, décidée immédiatement par une phrase de quatrième de couverture: "Je vais aborder des sujets si ténus que je dois bien être le seul à m’y intéresser ». Sous le soleil d'hiver, qui, ce jour-là, est si doux, si vulnérable (il faudrait l'inconscience des prunus pour penser l'hiver fini), il me faut absolument aller lire au parc Brassens. Après avoir longé mon ancien logement et observé sa façade triste, immuable, tandis qu'il me semble que tout s'est bellement patiné autour, jusqu'à l'existence d'un «bar à jus » à l'entrée de la rue de Cronstadt, je pousse vers le bar du boxeur, qui s'appelle en réalité Aux sportifs réunis et je demeure stupéfaite du décor qui m'accueille, un décor, oui, comme dans un film noir, rideau tiré sur une salle pittoresque, "mythique» comme indiqué sur la vitrine, dont j'entrevois à peine les anciennes photos. Décor dans le jus, plus vrai que vrai, sans doute ce que Barthes aurait appelé «l'effet de réel». Je n'ai pas osé rentrer, intimidée par cette atmosphère, plus que je ne l'avais été par le fait d'entrer dans un bar d'hommes à l'époque, où mon arrivée provoquait toujours un petit moment de silence et d'indécision. Je commandais un cognac, j'aurais dû demander un rhum, j'étais reçue avec une affection distante, la seule que je pouvais supporter. J'aimais la boxe. Le boxeur s'appelait Walczak, il est mort d'une crise cardiaque à son comptoir l'hiver 89. J'avais quitté le quartier depuis quatre ans.

Elle, la belle médiathèque Yourcenar, existe depuis février 2008, plus de 3000 mètres carrés, 165 personnes peuvent s'asseoir sur ces sièges corail et rouge basque, les prunus sont donc vraiment jeunes, sans expérience face au faux printemps. La bibliothèque de mon quartier s'appelle Flandre, le pays natal de Marguerite Y., toute proche des tours éponymes, dans le 19 . Mais maintenant, elle a été rebaptisée Claude-Levi-Strauss, depuis qu'elle a été agrandie, mais on l'appelle toujours Flandre (700 mètres carrés, des sièges ordinaires, pas de prunus). 


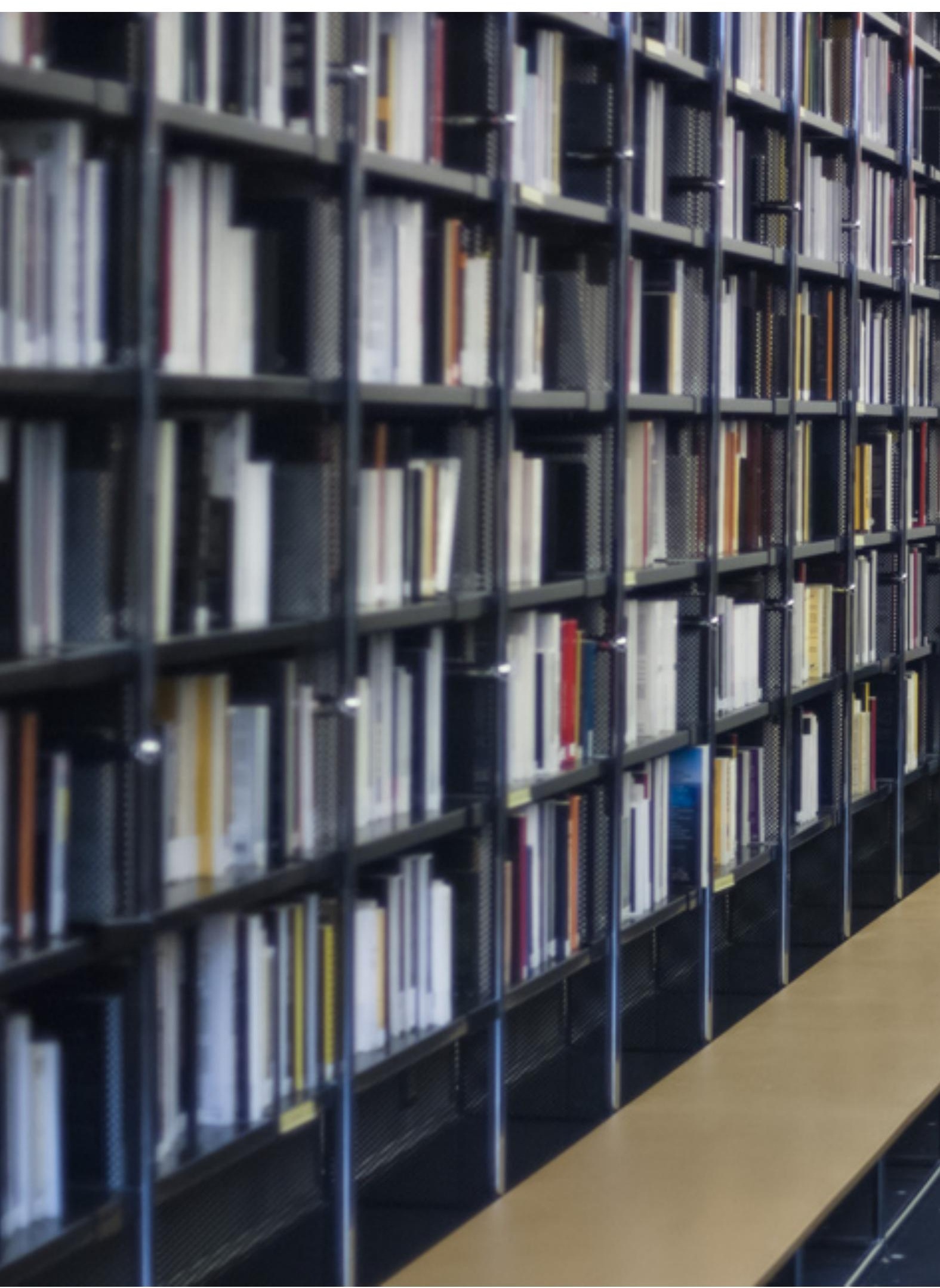




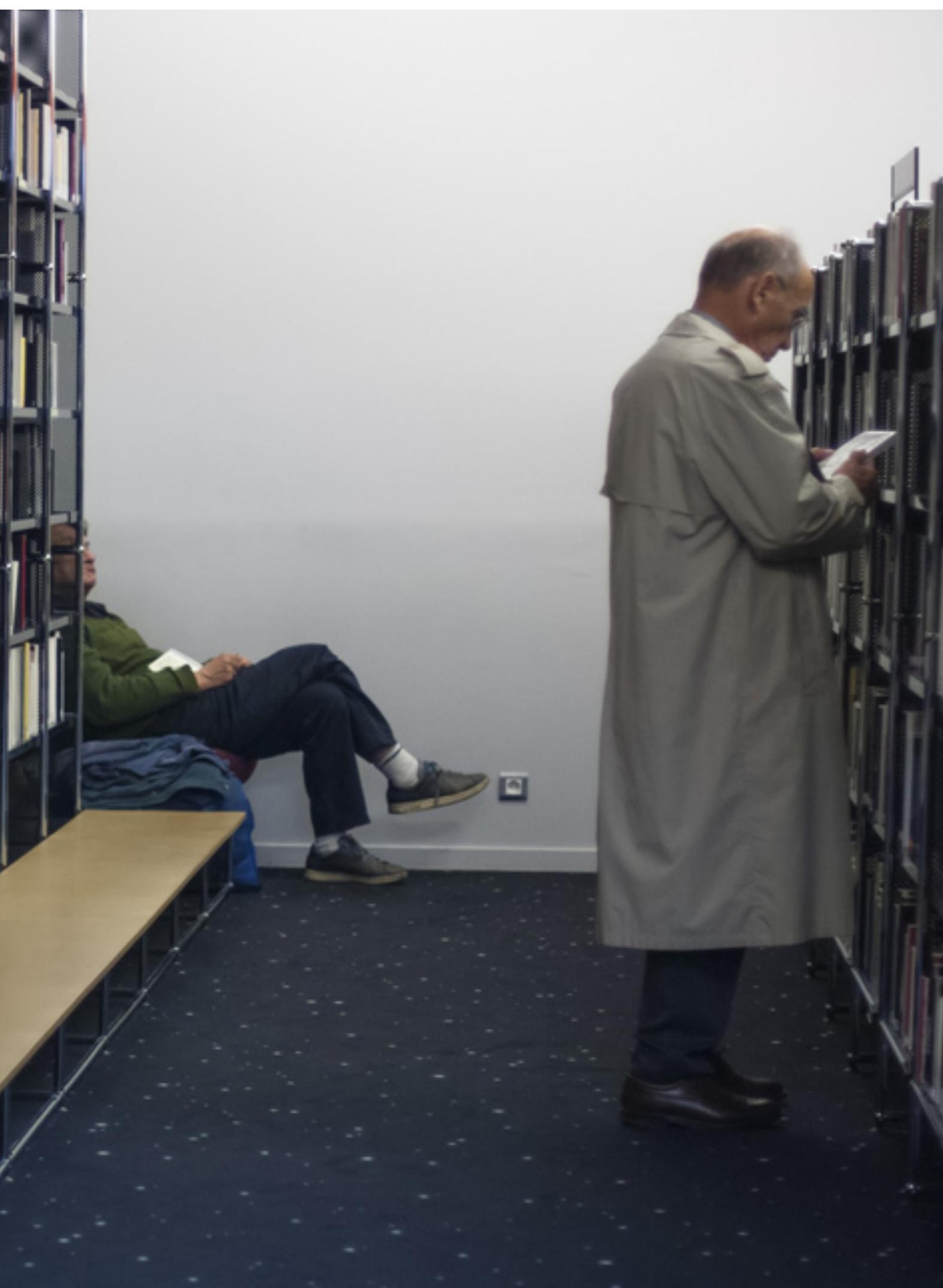




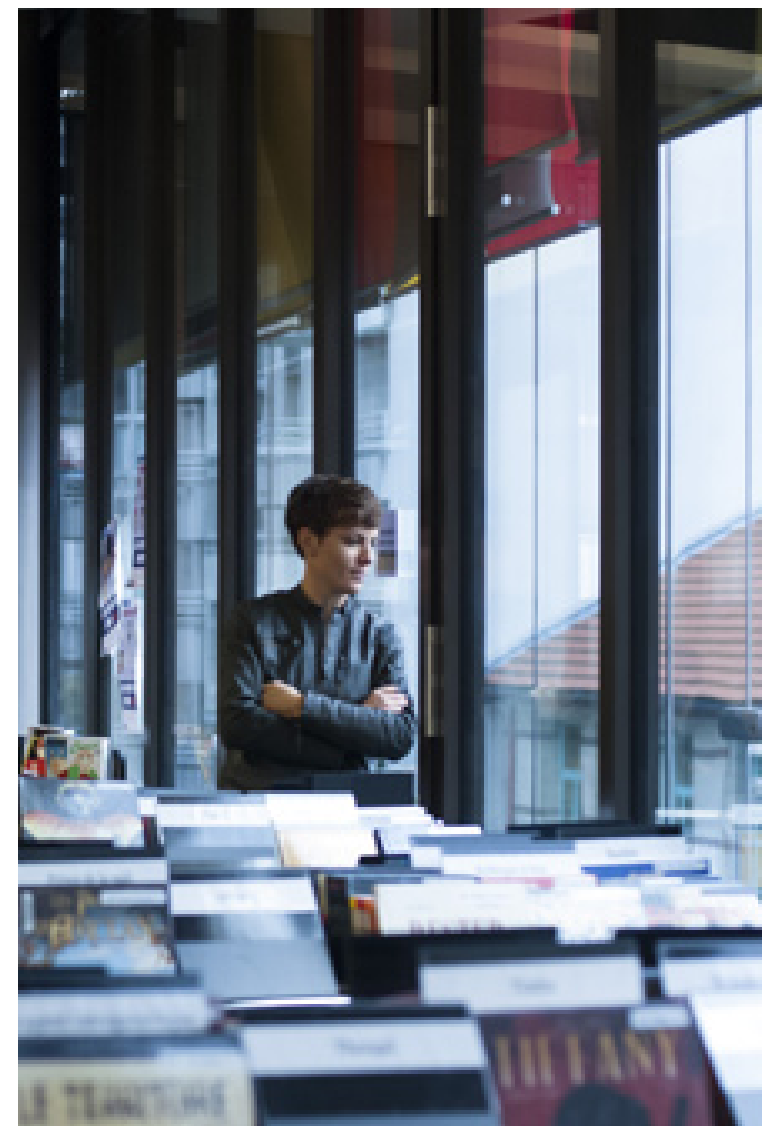


Je reviens chez Marguerite Y. un samedi de février, après quelques semaines de glaciation ternaire, voir si les prunus ont survécu et rapporter mon Sôzeki. Grisée par cette joie que j'éprouverai toujours à l'idée qu'on me prête des livres et qu'on le fasse avec autant de prévenance, et, plus fort encore, dans tous les arrondissements de Paris, même les riches, à charge pour moi de rapporter mon ouvrage, donc, tant qu'à faire avec ma gaieté, autant en rajouter et prendre le bus, traverser tout Paris, gris comme il se doit (du nord-est au sud-ouest, en pensant à Calet qui allait lui en bus également, du sud à l'ouest). J'arrive un peu tard pour flâner, c'est samedi, il y a beaucoup de monde, je prends à la hâte À la recherche de Shanghai d'Anyi Wang, pour le titre, pour son nom, pour ces mots en quatrième de couverture: "Les cent années de ce siècle sont passées pour Shanghai comme un rêve, laissant des bribes de cauchemar et de belles illusions. Derrière nous, le fleuve poursuit sa course vers l'Est. » Saisir ce qui vient, surtout depuis quelque temps, de cet Orient extrême, qui écarte absolument tout sens critique, tout rattachement à une proximité, tout implicite situationnel, tout exotisme. Ce qu'en somme, toute littérature doit pouvoir provoquer. Disons que là, le fleuve est plus large pour accéder à cette suspension, cette indécision de la lecture, ce ravissement. Les prunus vont bien, mais je n'en compte que trois.

Lorsque je reviens rapporter mon Wang, je marche derrière une ravissante petite personne de cinq, six ans, qui se rend également à la médiathèque, plus jolie et fraîche qu'une jonquille, coiffée d'un chapeau rose et jaune, et je me dis que c'est le printemps soi-même que je viens de croiser, sa grâce, sa sève, sa bouleversante mortalité.

Je m'assois sur un fauteuil tulipe à un demi-étage, oscillant comme une nacelle, et puisque je ne reprends pas de livre, je flâne, regarde les pixels jaune et rouge de la façade que le soleil transforme en vitraux, m'installe au point écoute et choisis d'entendre Chemirani, un ensemble persan de percussion zarb. Coule dans mon oreille le son précieux de la langue de mon enfance. Joie et nostalgie se mêlent aujourd'hui dans mon trajet 
et mon séjour vers Marguerite (Yourcenar), comme fait le printemps, faisant surgir chaud et froid en couches non homogènes, distinctes, nous détachant et nous reliant dans le même mouvement à ce qui fut et ce qui sera et que, peut-être nous connaissons déjà, parce que nous sommes vieux. Le printemps me rend vieille, pensai-je, dans le bus qui me ramène, où, dans mon dos, un jeune homme à mèche, dont j'aperçois le reflet dans la vitre, et dont j'entends très distinctement les larmes et les mots, suppliant son amoureuse de ne pas le quitter, intense, fébrile. Jeune silhouette en palimpseste des rues animées aujourd'hui, et de l'amoureuse de Cronstadt dont j'hésite à regarder le reflet vieilli dans la vitre.

En fait, les prunus, qui ont conservé quelques fleurs, ne sont ni quatre ni trois, mais six. Trois en triangle dans l'atrium et trois en ligne sur un côté.

Dans le bus qui me ramène à mon Est relatif, ma Flandre parisienne, dans cette glissade de la ville livrée au gris qui lui va comme un gant long à une pierreuse, j'applique la fine résille de mes marques anciennes, là où j'ai vécu, aimé, lu sans aucun discernement jamais, avec ce qui souvent, comme aujourd'hui, justifiait la promenade, aller à la bibliothèque, plaisir de cueilleur, plaisir de promeneur, comme on irait voir la Seine, le bassin de la Villette ou quoique ce soit qui justifie qu'on passe la porte de chez soi, heureux et confiant. 


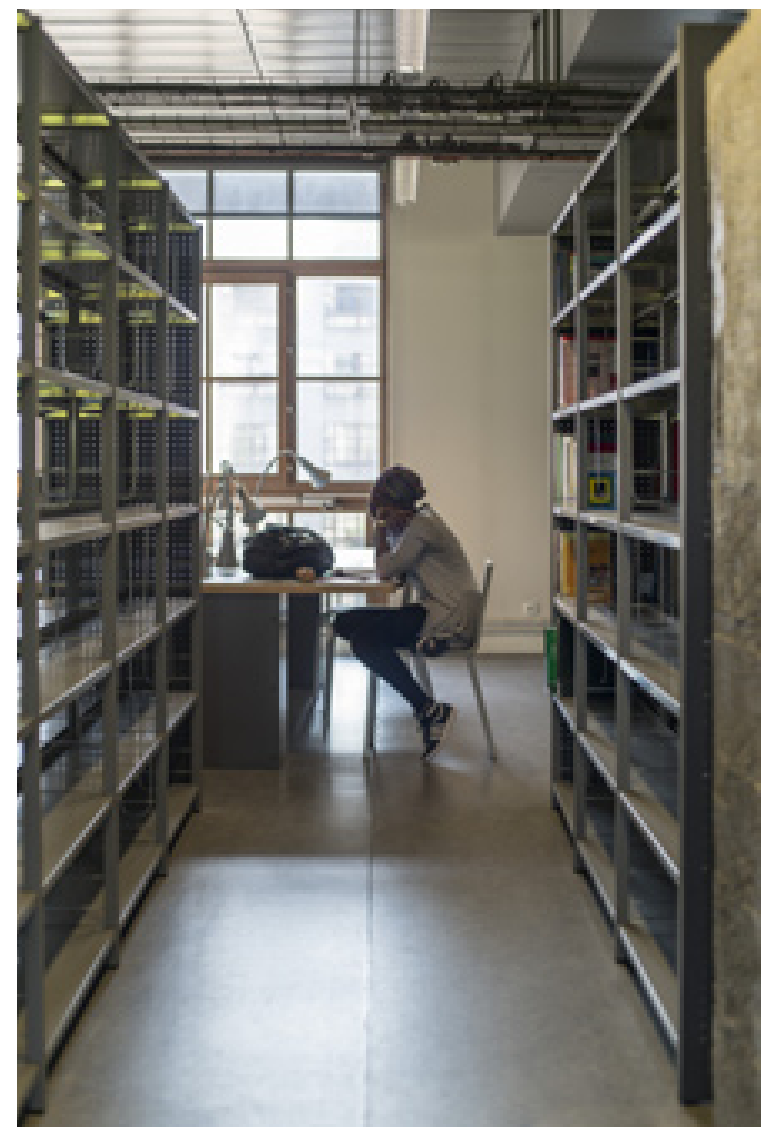




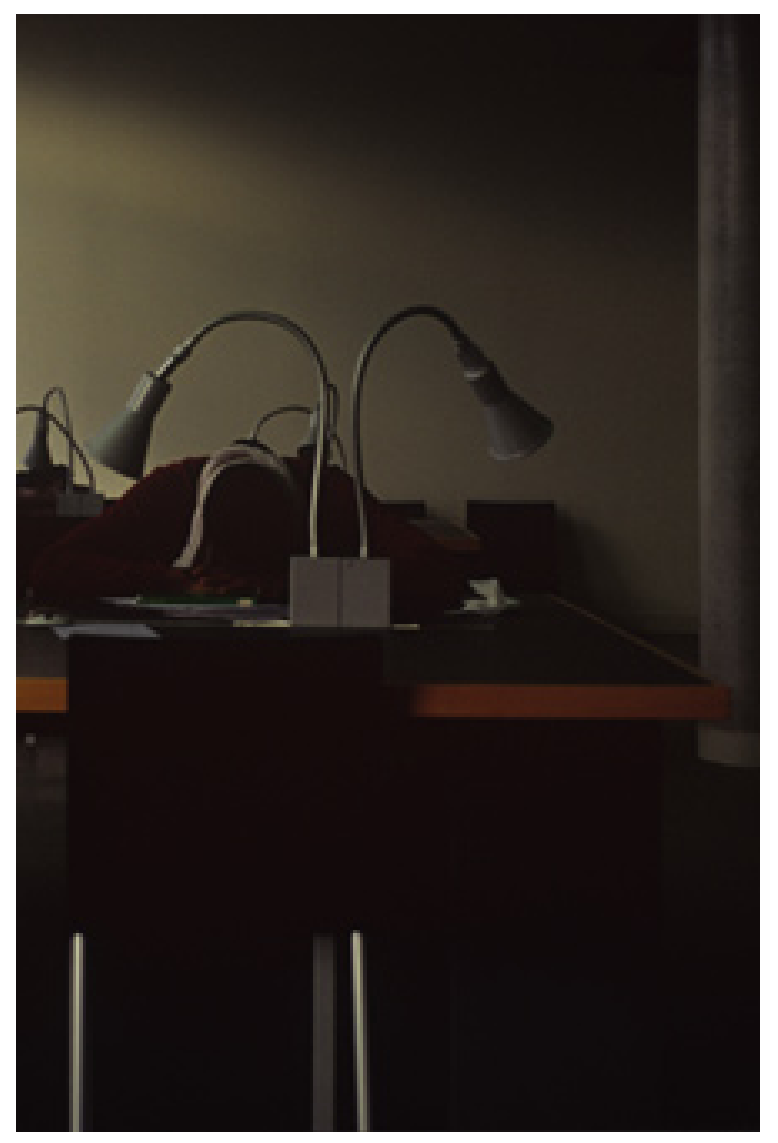




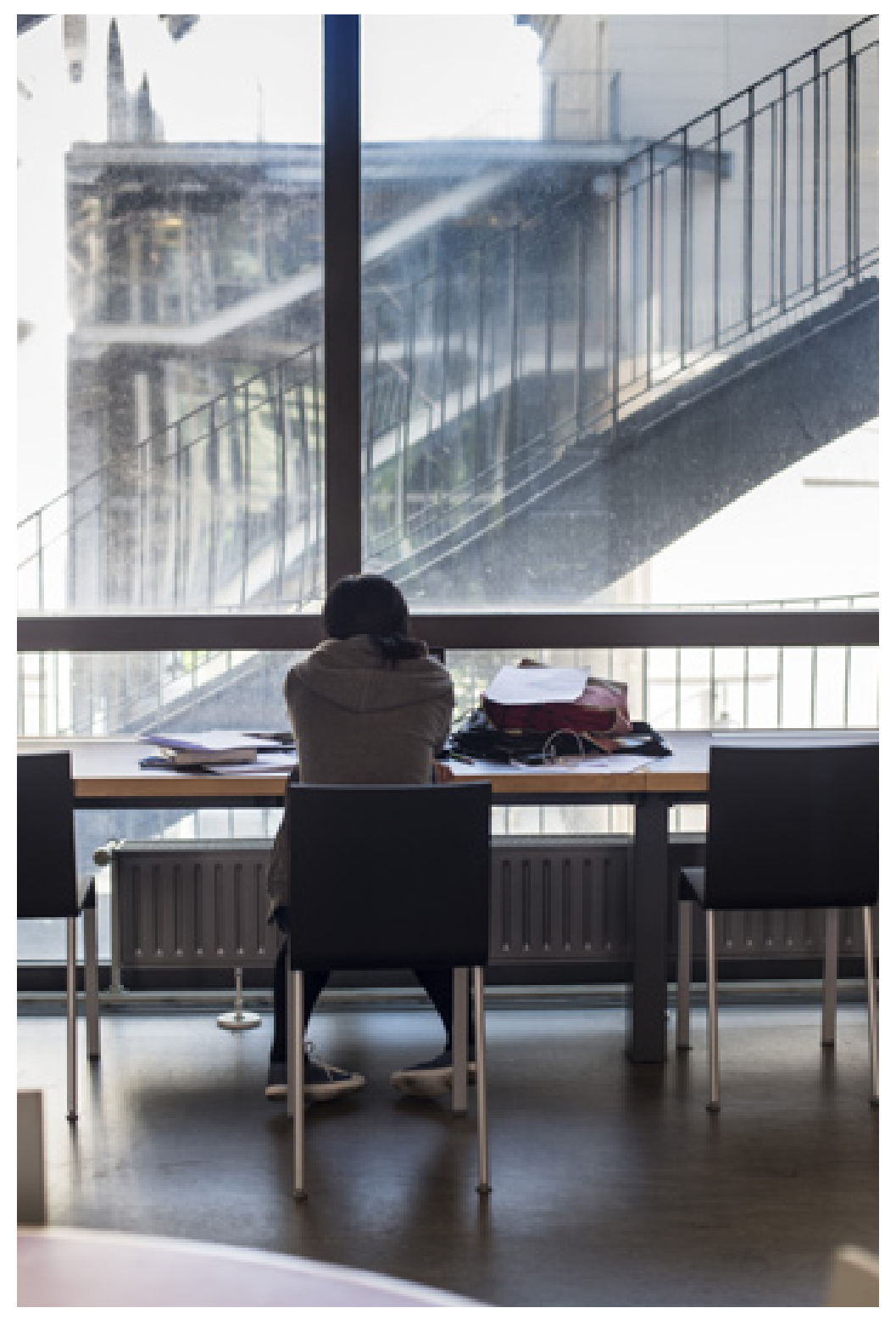




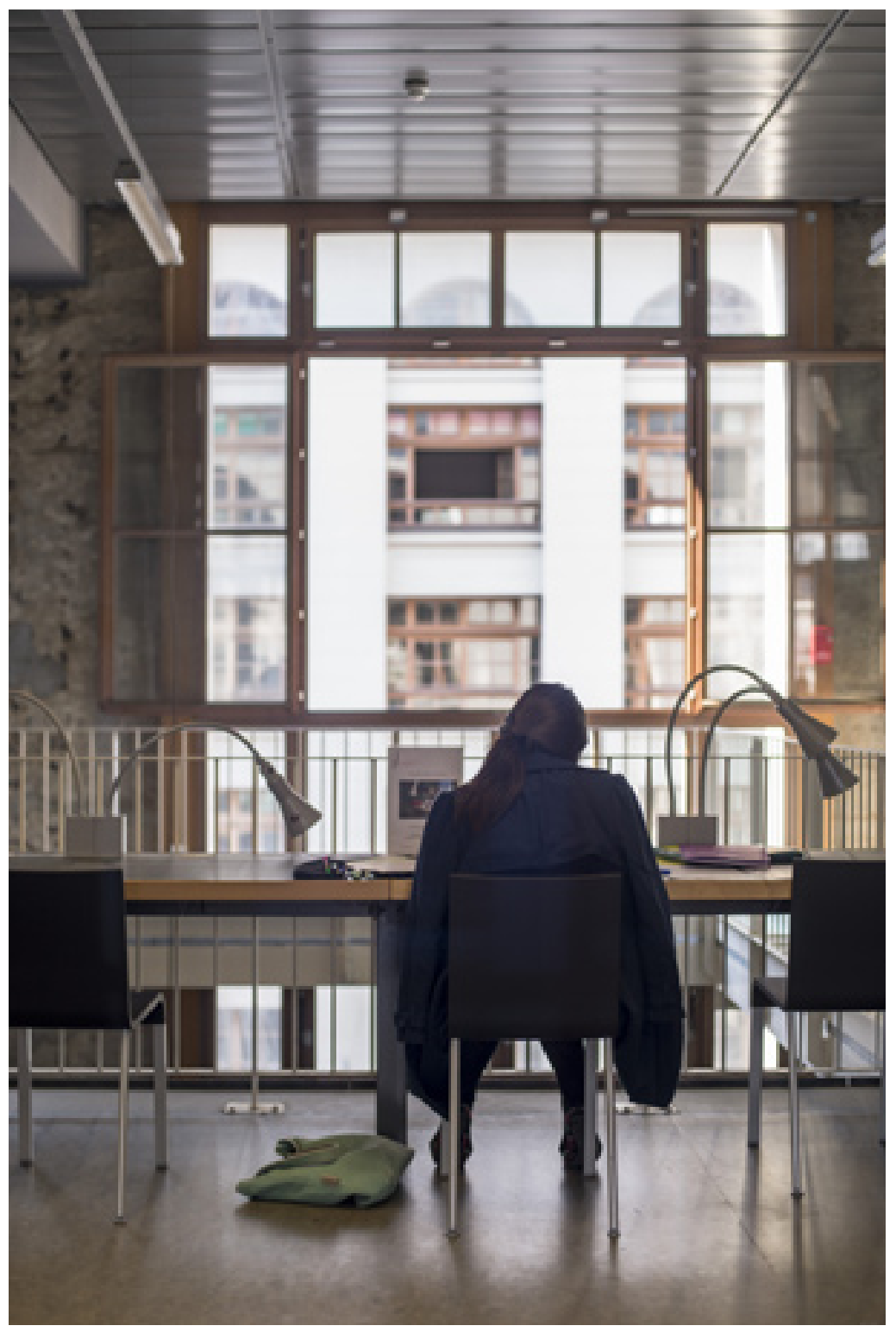




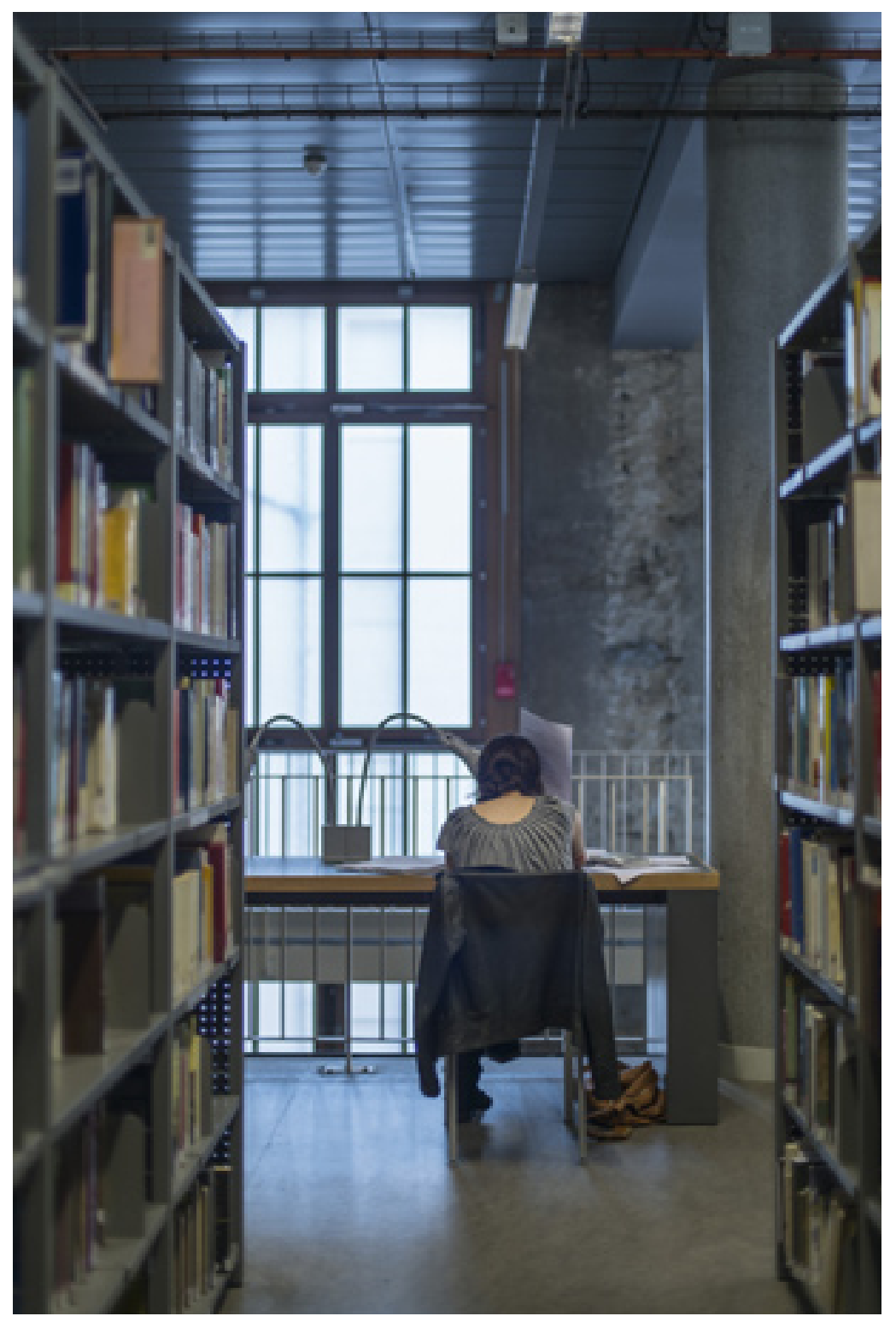


Henri Raczymow

Bibliothèque centrale de I'Université Diderot, Paris

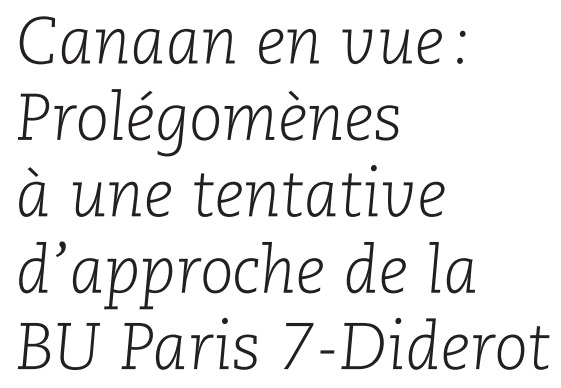


Alors je me suis décidé à sortir, malgré la grisaille et l'air vif. Ce n'était pas quand même comme d'aller en Sibérie. Quoique. La démarche, sortir, me fut facilitée: je devais me rendre à cette boutique Afflelou pour y retirer une paire de lunettes, gracieusement offertes par la maison, et dont j'avais choisi moi-même la monture. Pourquoi cette aubaine? Pourquoi moi, qui ne porte de lunettes que pour lire? Allez savoir.

Je me suis donc rendu à pied rue de Turbigo puis attrapai le bus 47 qui devait me conduire place d'Italie, lieu assez éloigné du reste de ma destination réelle. Mais c'était comme si je devais semer d'étranges poursuivants, multipliant les embûches, les zigzags et les leurres. (Peutêtre après tout était-ce moi-même que je comptais perdre, au propre et au figuré.) Ou bien j'entendais seulement différer l'échéance et réfléchir à la chose, à son halo vaguement jaunâtre. Ah! j'avais grand besoin de réfléchir, de prendre quelques notes conjuratoires, propitiatoires. La pensée, dans le bus qui m'emportait vers l'Aventure, me frappa de la concomitance entre mes nouvelles lunettes à la monture avantageuse (je m'étais observé dans un miroir) et cette visite à la bibliothèque. Où je ne me rendais pas en vue de lire quoi que ce fût. Mais sait-on jamais? Des fois que... Moi qui adore lire tout ce qu'il y a d'écrit dans les rues, à Paris, en province, à l'étranger, y compris les plaques des médecins \& dentistes \& avocats à la cour \& experts-comptables agréés \& masseuses-détente complète. Et qui n'aime pas la campagne à cause de cela même: il n'y a rien à lire, sauf la pluie dans les nuages.

J'ai descendu le boulevard Vincent-Auriol, pas si sinistre que ça, et puis, sur la droite, voilà, la rue du Chevaleret où habita naguère ma bien-aimée, avant notre rencontre qui nous changea la vie et les idées. Je ne l'imaginais pas si longue, cette rue. (Anne m'avait dit que ce que je cherchais, 
rue Thomas-Mann, était au bout). J'allai donc au bout, ou quasi. J'ai dévalé vaille que vaille une centaine de numéros. Cela devenait de plus en plus provincial à mesure que les immeubles "bourgeois" se faisaient plus rares, puis cela s'embourgeoisa à nouveau à mesure qu'on approchait du quartier résidentiel autour de la BNF. C'était Ivry, ici, avant, il y a longtemps. Il en restait quelque chose, très peu en vérité. Au numéro 119, sur la droite, se tenait l'hospice des Sœurs de la Charité, alias l'Euvre Saint-Casimir, créé en 1860, et où s'était jadis réfugié un barde polonais, poète mystique à plein temps, Cyprian Norwid. Anne, qui connaissait cet endroit, me dirait que ses jardins sont immenses et splendides. On se serait cru revenu au temps où Jean Valjean, je veux dire M. Madeleine, confiait Cosette aux bonnes sœurs du quartier de Picpus, de l'autre côté de la Seine. Ou bien à Angers, ou à Angoulême ou à Nantes, enfin par là. Ivry... Ivry... L'hébreu, le passeur, le passage... Je me promis pour une prochaine fois de suborner une bonne sœur afin qu'elle me laisse entrer... Et puis sur la gauche, j'escaladai des marches au haut desquelles se trouvait le fameux square Cyprian-Norwid. Nous nous retrouvions, cet homme et moi, lui que mes aïeux ont pu croiser peut-être, il était une fois, du côté de Varsovie. C'était un jardin parsemé de simples, paradoxalement sophistiquées pour certaines d'entre elles, avec des écriteaux portant leurs noms latins et leur provenance exotique, sinon c'était le tout-venant de par chez-nous: romarin et lavande. Je ne me suis pas attardé. Car la BU de Paris 7-Diderot, un peu plus loin, de l'autre côté de la belle avenue de France, m'attendait, sans m'attendre vraiment bien sûr. Mais là, de l'ancien temps, des anciennes choses, il ne restait plus rien. Ils avaient tout arasé. Rien, vous disje, ni Ivry, ni rien d'autre. Si bien que le visiteur étranger n'est en ces lieux la proie d'aucune reconnaissance, au sens qu'Aristote, je crois, donnait à cette fonction poétique qui autorise la catharsis: oui, reconnaître, s'y reconnaître, lire sous un texte nouveau quelque chose d'un ancien, et 
sous l'autre, inconnu et inouï, quelque chose de soi-même, si vous voyez ce que je veux dire, fût-ce à demi-mot.

Une deuxième fois que je vins là, ce fut par le métro, la ligne 14 précisément. Châtelet, Gare de Lyon, Bercy, Cour Saint-Émilion, Bibliothèque François-Mitterrand, on descend, ou plutôt, on remonte à l'air libre, et même très haut, sur la venteuse avenue de France au pied des immeubles de laquelle, par petits groupes, des jeunes gens fument et boivent un noir breuvage dans un gobelet de carton blanc. J'avais ce jour-là rendez-vous avec deux conservatrices, Mmes Géraldine Moreaud et Janie Philipps ("L'une pareille au cygne et l'autre à la colombe»), au sixième étage, bureau 649 B, à 10 heures pétantes. Entrevue pour laquelle je m'étais préparé, non en me formulant les questions très précises que je me fusse apprêté à leur poser, car je n'en avais pas, mais en me rasant de frais, justifiant mon apprêt: pour être grand clerc, on n'en est pas moins homme!

C'était un matin, donc, à l'heure où les gens vont à leur travail. Debout ou assis, le visage baissé sur leurs journaux gratuits, figés, totalement figés. Ils ne se connaissent pas, ils sont encore ensommeillés. Ils m'apparurent tels des comédiens sur scène, avant la représentation, laquelle débuterait à quelque signe d'un invisible chef d'orchestre, et qu'ils guettent de tous leurs sens, immobiles, silencieux, concentrés, anticipant ce qu'ils auraient bientôt à faire, chacun pour soi, le rôle de l'employé compétent, diligent, attentif, soucieux de l'entreprise commune ou c'est tout comme. Dans le vaste hall de la station François-Mitterrand, fichés dans le sol et donc impénitemment piétinés par les voyageurs, des médaillons dorés portant des phrases d'auteurs prestigieux. J'ai aimé celle-ci, de Malcom Lowry: "La maison pommelée, de cette lumière brumeuse qui tombait, douce, à travers de jeunes feuilles. » Maison pommelée, je ne savais pas trop 
ce que c'était, mais je trouvais ça bien joli. Et puis cette autre, de Stendhal: "Comme une dissertation obscure sur quelques phénomènes relatifs à l'oranger. " J'étais certain, dans le catalogue en ligne de la BU, de trouver la thèse correspondante, mais je m'illusionnais sans doute, c'eût été trop beau.

Et puis, laissant s'éteindre en moi l'incendie violent de ces pensées, cela m'est apparu: LES GRANDS MOULINS DE PARIS. Quelle sorte de grains aujourd'hui y mouline-t-on? Bâtiment B, c'est là, celui des Grands Moulins justement. De l'autre côté de l'esplanade, c'est un autre bâtiment de béton, la Halle aux farines ${ }^{1}$. L'ensemble du quadrilatère est délimité par les rues Marguerite-Duras, FrançoiseDolto et le quai fluvial Panhard et Levassor où stationnent des péniches industrieuses aux ventres ensablés. Côté Grands Moulins, donc, quatre étages de salles de lecture. Je ne gambadai qu'aux deux premiers, les ouvrages généraux et les études littéraires, caressant au passage les nobles piliers de béton, "droits et majestueux », vestige de l'architecture industrielle qui, dans ce bâtiment, avait précédé l'aménagement de la bibliothèque. Les périodiques, les thèses... C'est ce que j'ai vu en premier, les thèses, les plus récentes en tout cas, les autres sont remisées en réserve. Reliées en peau noire. Elles m'ont ému, de même qu'un manuscrit-tapuscrit m'émeut plus qu'un livre édité. Sans doute parce que le lien avec l'auteur n'est pas complètement rompu, que l'auteur a tenu entre ses mains cet objet qui lui coûta tant, encore un peu sanguinolent et amniotique, portant d'abondantes traces d'ADN, chair de sa chair, tout glaireux et morveux. J'ai parcouru un peu leurs titres, parfois grandiloquents, mais c'est la loi du genre non? Je n'ai pas osé en ôter un de l'étagère et l'ouvrir, et le feuilleter.

1. Où avais-je déjà rencontré blutage, minoterie, meunerie? Voilà: dans un tableau de Courbet, les Cribleuses, qu'on peut voir au Musée de Nantes. Deux jeunes femmes y passent des grains au tamis. Et aussi un troisième personnage, un petit garçon en sabots, qui inspecte une grosse boite en bois qui s'appelle un tarare, instrument ventru qui entre aussi dans le traitement des graines. Ce vieux coffre qu'il ouvre semble tout noir, et vide. Que regarde-t-il au juste? Quel mystère cherche-t-il à percer? De ce coffre, l'enfant ouvre le ventre. II l'inspecte, comme pour vérifier, pour comprendre quelque chose. Mais quoi? Ce ne peut être un mystère lié au traitement des grains, car l'enfant voit ce tarare à cet endroit, depuis toujours, depuis sa naissance. Eh bien c'est sa naissance même qui fait pour lui mystère. Qui diable met les petites graines dans ce ventrelà? Autrement dit: D'où viennent les bébés? Première question, comme on sait, que se pose l'enfant-scientifique, et qui fait que plus tard, s'il persévère dans l'être, il fréquentera les bibliothèques, celle de I'Université Paris 7-Diderot, par exemple, sise rue Thomas-Mann Paris $13^{\mathrm{e}}$ arrondissement. CQFD. 
C'eût été comme de zieuter les viscères de son auteur. Pourtant, je fus bien tenté d'extirper celui au titre affriolant: «Étude logico-grammaticale, énonciative et rythmique de la ponctuation. » Prends-en de la graine, me suis-je dit un instant. La graine. N'étions-nous pas aux Grands Moulins? Mais non, je n'en eus pas la force de conviction. Alors, je suis allé dans la salle des périodiques. Dans une travée, sur quoi tombé-je? On ne me croira pas: The French Review et French Studies. J'ouvre la première au hasard. Et mon regard distrait s'arrête sur la critique (en français) d'un livre dont l'auteur m'est connu, un mien ami pour tout dire.

«... Si le texte de l'auteur prétend à l'humour, il n'en demeure pas moins erratique. Il contient bien des lourdeurs, et la drôlerie verse parfois dans le Grand-Guignol, comme si son inconfort patent devant son objet ne pouvait se traduire que par des quolibets, d'ailleurs approximatifs. Ces sarcasmes récurrents relèvent davantage de la plaisanterie de potache que de l'intellectuel éclairé. On dirait que c'est à partir de son entour qu'il rend compte du lieu qu'il s'est donné pour objectif de peindre, comme si le vide qui semble lui agréer davantage devait se rendre visible sur le fond du plein. Portons pourtant au crédit de l'auteur quelques mises en abymes de bon aloi où il manifeste non sans talent son insigne prétention... »

Lecture faite, je suis redescendu assez vite, j'avais chaud. L'excitation, sans doute, ou l'angoisse, ou le réchauffement climatique, quand on ne sait pas on ne sait pas. Dans l'ascenseur, un panneau didactique expliquait l'origine des Grands Moulins, la création de l'entreprise à Nancy, son installation à Paris au début du xx siècle sur le quai Panhardet-Levassor (première voiture à essence en 1910; voir «Je t'attendrai à la porte du garage » de Charles Trenet, chanson que de mauvaises langues et/ou de mauvaises oreilles ont entendue comme: «Je tâte André à la porte... »), la création 
en 1929 de la première école de boulangerie à Paris. Je n'en lus pas davantage, j'étais arrivé ${ }^{2}$. Après tout, depuis la création de la bibliothèque inaugurée en 2007, y avait-il eu un seul étudiant ou professeur qui ait lu ce panneau, je veux dire in extenso? Cette pensée me disculpa d'interrompre ma lecture. Je fis un tour aux toilettes du rez-de-chaussée. Des graffitis. L'un d'eux, d'une écriture enfantine: «Mon honneur s'appelle fidélité». C'eût été encore mieux en allemand, en allemand du III Reich.

Une minoterie sous la fac, pensais-je. Un lieu sous un lieu. Mais tous les lieux n'ont-ils pas un autre lieu sous eux? Tous ne sont-ils pas des palimpsestes? N'y eut-il pas quelque chose sous la Tour Eiffel? Et tenez, l'endroit précis où je me trouve, là, chez moi, à ma table. N'y eut-il pas jadis et naguère quelqu'un à ma place, et quelque chose avant cette table? Et quelque chose avant ces murs, et ce sol, et ce plancher? Ah, qu'on arrête, j'ai le vertige.

Fort de ce fort devisement intérieur et tout estourbi, je me suis retrouvé sur l'esplanade Pierre-Vidal-Naquet (1930-2006), entre Grands Moulins et Halle aux farines. Ah! une cafétéria, une machine qui rend la monnaie sinon heureux. Un café court. Un banc de pierre, le dos au soleil, je sirote en paix. Devant la cafète, un type en toque blanche de grand chef fume une clope. Une inscription au sol, en capitales noires tracées au pochoir:

\section{LA RÉPUBLIQUE DES BÂTARDS \\ EST NÉE DU SANG DES COMMUNARDS}

En 68, on était plus inventif, non? Ça n'avait pas plus de sens, mais c'était plus drôle. C'était mieux avant, de mon temps? Bah voyons. Tout de même, j'étais heureux que ces deux octosyllabes de bonne facture trahissent encore une faible

2. Un seul voyage en ascenseur ne suffisait pas à une lecture in extenso du panneau. L'ascenseur allait trop vite et on était d'autant plus vite arrivé qu'on n'allait pas bien loin, pas bien haut: il n'y avait que quatre étages. Moi, consciencieusement, je me suis attardé un peu plus. C'est-à-dire que j'ai fait plusieurs fois le trajet, ou plutôt je ne saurais dire combien de trajets j'ai faits. Heureusement, nul étudiant n'était assez fou pour parcourir les mêmes avec moi et être le témoin goguenard ou interloqué de ma déraison, de mes errements ascensionnels. Et puis j'ai renoncé à devoir tout lire. C'était trop. Trop technique, trop historique, trop tout, trop pour moi, pour ma petite appétence. Dans une autre cage d'ascenseur, évidée, suspendues à des filins d'acier, d'antiques machines à traiter la farine. C'était bien instructif. (Ce sont Géraldine et Janie qui, un jour de novembre, me servant de guides et d'éclaireuses, me les ont montrées.) 
faille de tremblotement en ces lieux, et me rendissent ce sol même un peu moins étranger.

Je ne voulais pas repasser par où j'étais venu, alors je me suis perdu dans le quartier. J'ai croisé la rue MargueriteDuras puis Primo-Levi. Il ne manquait plus que moi comme grand écrivain, ça viendrait plus tard, nul doute. J'ai longé la rue des Frigos avec ce bâtiment qui datait d'avant, laissé sciemment à l'abandon et voué à des ateliers d'artistes. D'anciens entrepôts frigorifiques, comprenait-on. Puis ce fut la Seine. J'ai traversé un pont, ne me demandez pas lequel, cherché en vain un bus ou un taxi, retraversé le même pont sans davantage retenir son nom, longé la BnF célèbre pour ses coups de vent quasi marins et, à la station Quai de la Gare, en face de chez Truffaut (la boutique des plantes), j'ai ouvert la porte d'un véhicule noir comme les enfants poursuivis, à la récré, font mine de rentrer chez eux en faisant clic-clac d'un geste du poignet. Bastille, République, Magenta. Home sweet home. Quand on est écrivain, qu'on emploie tout son temps à écrire des livres et souvent à en lire, on n'est pas en manque, je crois, d'avoir sous la main et devant les yeux des kilomètres linéaires de livres. Malgré Borges.

Oui, Canaan n'est jamais qu'en vue. Moïse n'y accède pas, comme on sait. Et si lui, qui donna le décalogue au monde, n'y accède pas, alors pour moi y réussirais-je mieux? La chair est triste, hélas... 
Philippe Fusaro

Médiathèque du Tilleul, Gérardmer

Le pas de l'autre 
L'auteur se réveille avec la sensation d'avoir les jambes mouillées, la peau froide et fripée de celui qui reste trop longtemps dans l'eau.

Ce sont les jambes qui, dans le songe, sont entrées dans le lac, foulant un gravier de silex et d'algues. Au-dessus de l'eau, de ses hanches pour être plus précis, l'auteur, blouson rouge imperméable, pousse la barque et l'accompagne sur plusieurs mètres avant de prendre appui sur les avant-bras, de tirer son corps hors de l'eau et de s'installer sur le banc.

C'est l'aube d'une saison indéterminée. La pluie fine habille le visage de l'auteur d'un masque en plastique. La brume donne des airs de Louisiane à ce lac qui, dans le songe, n'a pas de nom.

L'auteur, en rouge imperméable, improvise les gestes lents et sûrs de celui qui possède la maîtrise des rames. Il avance, traverse le rideau de pluie, assuré qu'au milieu du lac, son nom

L'auteur, rames en main, les paumes qui ressentent la brûlure mais ne lâchent pas leur rythme, murmure à la surface de l'eau et pour Dieu sait qui ces vers d'une poétesse polonaise lus avant de s'endormir.

«Et se taire en même temps - au nom d'un lac qui n'a jamais pu obtenir un nom quelconque.»

L'oreiller tâché de salive, une longue mèche de cheveux filtre la lumière grise de pluie qui peine à dire le jour dans cette chambre d'hôtel au bord du lac, l'auteur s'étire dans cet entredeux, convaincu pour quelques secondes encore que les jambes sortent tout juste de l'eau.

De la bibliothèque, on n'aperçoit pas le lac.

L'immeuble semble avoir été construit dans les années 1930. Il s'agirait des bureaux d'une ancienne usine de lin.

Le lecteur gravit des marches jusqu'au premier étage s'il veut lire. 
Le lecteur gravit des marches jusqu'au second étage s'il veut y amener ses enfants, ou s'il veut emprunter des disques, des films.

L’auteur s'arrêtera au premier étage.

Sans avoir une idée préconçue de ce qu'il est venu chercher jusqu'ici, loin dans l'est, à part des images heureuses d'un passage éclair dans son enfance, à la manière d'un vieil album photo qu'on feuillette les jours d'ennui, l'auteur se dirige tout droit vers le rayon poésie. Il veut comprendre, sortir de sa poche le mètre et calculer, combien de haut, combien de large, compter le nombre d'étagères et définir la place du poète dans la cité, dans la mémoire d'une ville. Pourquoi la production conséquente de livres de poésie et la diversité des éditeurs d'aujourd'hui ne trouvent qu'un pâle écho dans ces murs, pourquoi l'intérêt fort que ce rayon suscite en librairie ne passe pas le portique à l'entrée de la bibliothèque? Que ce soit ici ou ailleurs, l'auteur le vérifie à chaque rencontre et déplacement.

La poésie, son histoire sont représentés. Les grands poètes, les poètes populaires gonflent le torse. Entre deux volumes, l'auteur s'étonne des perles. Il lit la date du dernier emprunt sur la fiche à l'intérieur de l'ouvrage. Il lit l'absence, la misère de la fréquence.

Dans le recueil d'un prix Nobel polonais - une star en Italie dont il n'existe plus qu'un ouvrage disponible en français sur deux recueils traduits, l'auteur lit ces vers qui en disent long sur le statut du poète:

«Poètes et écrivains

c'est comme ça qu'on dit

c'est-à-dire les poètes c'est pas des écrivains, alors quoi... »

L'auteur referme le livre. No comment.

Parmi les perles, allez savoir pourquoi, la main retire ce livre plutôt qu'un autre. 


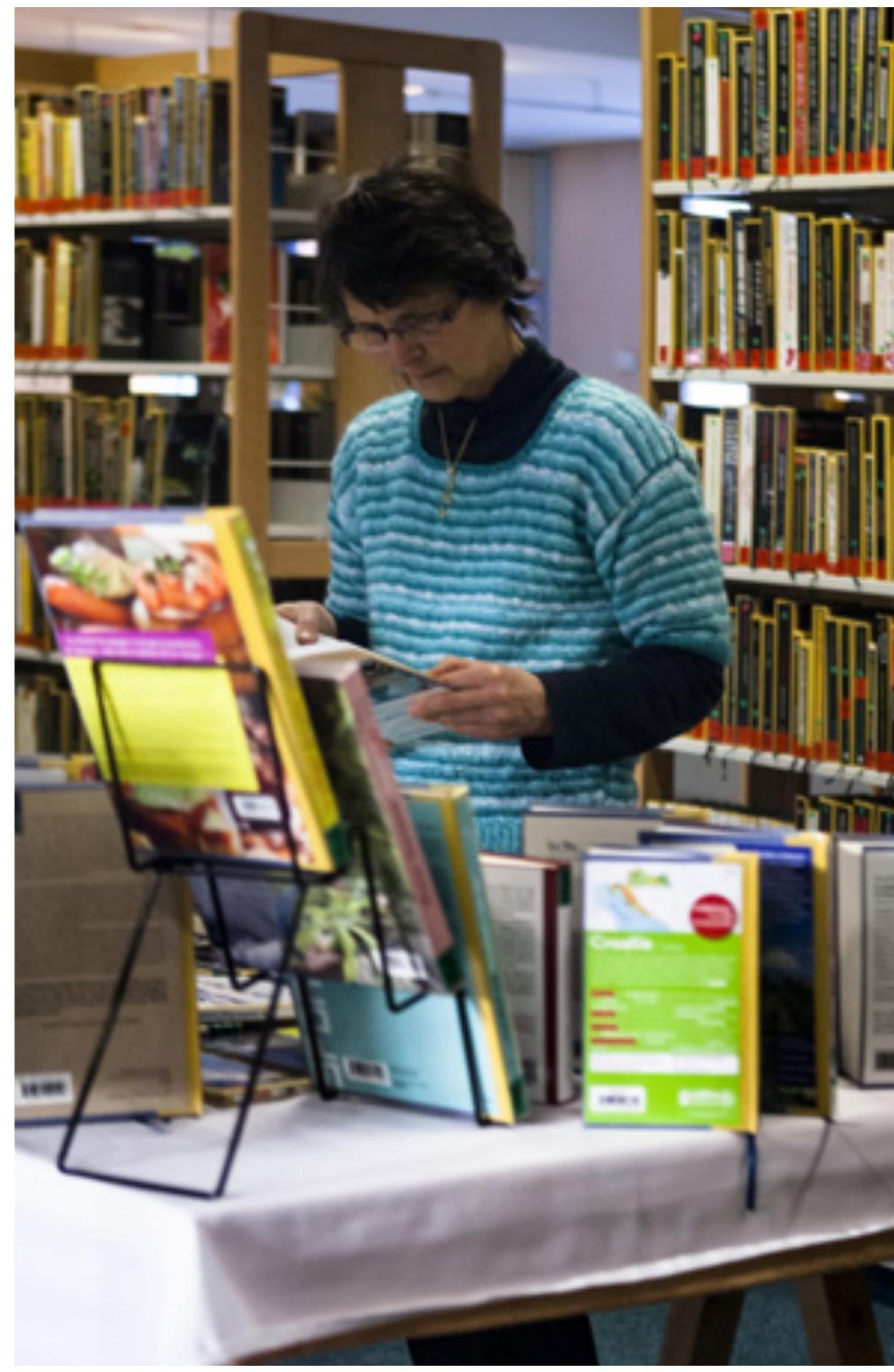




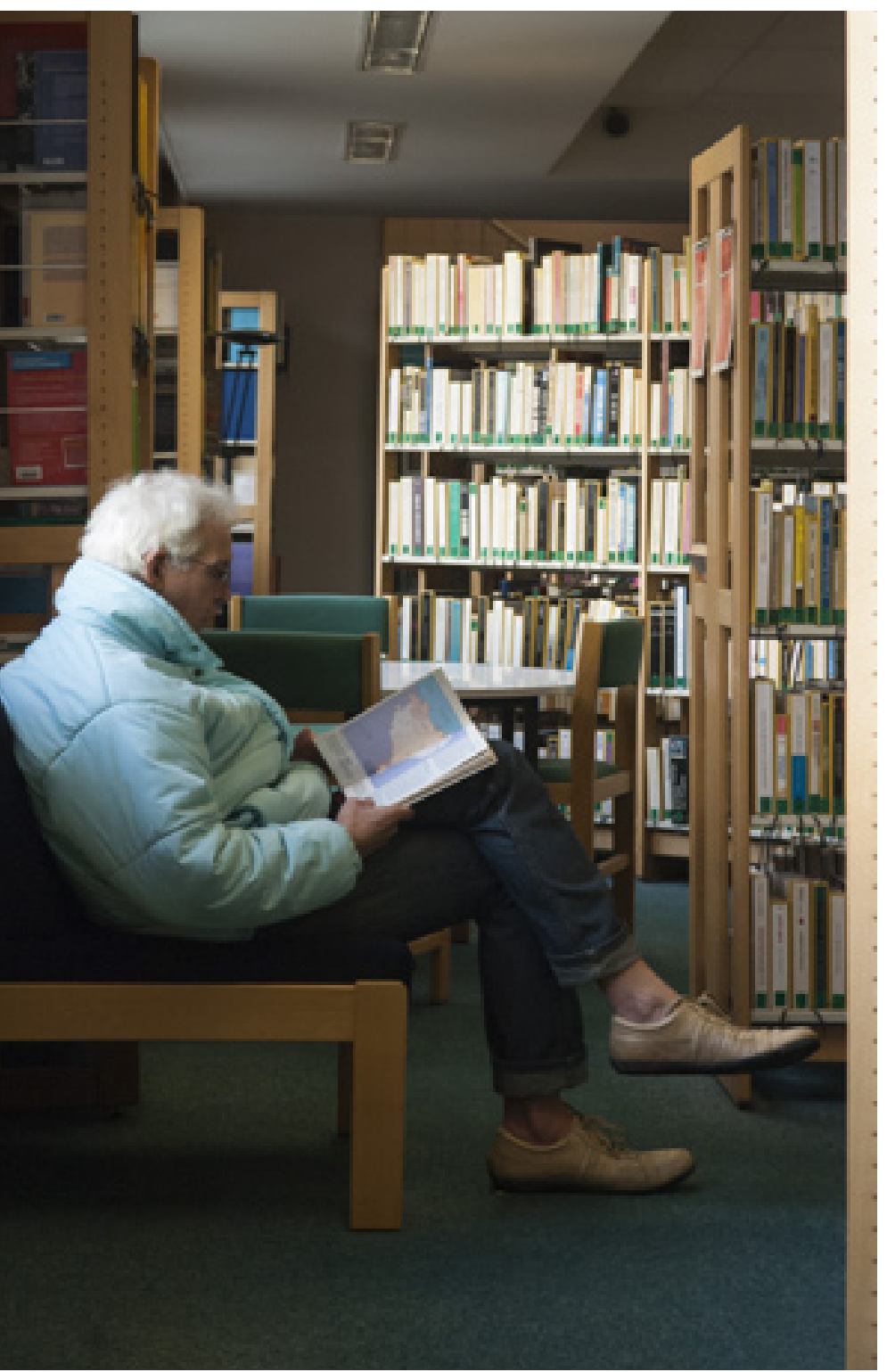


Un livre fin.

Un auteur - Gilbert Vautrin - inconnu.

Date de publication: 1991.

Sur la fiche d'emprunt figurent trois dates:

11 mars 92

5 Sept. 92

14 Av. 93

et l'auteur, aujourd'hui, appose la sienne: novembre 2011, installé dans le fauteuil de la bibliothèque, sous la fenêtre qui donne sur le parking, au moment où il referme le court livre qu'il vient de lire.

Il me semble que l'auteur, en venant jusqu'ici, loin dans l'est, savait que dans le fond, c'était la rencontre avec un poète qui motivait son voyage.

Une rencontre avec un titre, avant même un nom.

L'HIVER, UN AUTRE

Allez savoir pourquoi celui-ci retiendrait sa curiosité de lecteur. Lorsque l'auteur le lit, il sait aussitôt que son intuition est la bonne.

Que ce titre sera à la hauteur du contenu du livre.

Que dans ce titre, tout comme dans une photographie, ce punctum que décrit Roland Barthes dans La Chambre claire, ce point qui le touche, sans pouvoir lui donner un sens, c'est cette virgule après le mot «l'hiver», la saison, « un autre » ou le paysage qui s'ouvre.

Un titre en deux temps

L'Hiver,

un autre 
pour deux acteurs d'un même livre

le poète

une peintre

Marie-Claude Vicario

- inconnue -

trace

des signes

à l'encre rouge,

un rectangle

aux trois coins appuyés

le quatrième

point final

sans lever le pinceau du papier buveur,

un $\mathrm{M}$ aux allures de griffe

penchant vers l'est

une montagne timide, 
un cercle fragile avec ces blancs que l'œil comble

des trous

le cercle est perméable,

jamais ces signes discrets ne veulent prendre la place du poème,

jamais les signes ne sont l'ombre du poème,

ils sont une lecture,

ils sont l'œil d'une lectrice

qui a su percevoir ce qui échappe au poète

parce que les mots ne suffisent pas toujours,

ils reprennent à leur façon les vers du poète

«comme le vide

tient

dans le blanc»

ou encore

«c'est un paysage aussi,

que le papier vide.» 
L'Hiver, un autre

ou la connivence des vieux amis,

on marche main dans la main sur les sentiers à l'ombre des sapins

on n'échange plus les mots inutiles,

ceux qui veulent faire croire que,

à qui d'abord?

l'un sait ce qui se trame dans le cœur de l'autre

l'un est là pour porter l'autre

et la boucle est bouclée,

même si plus tard, les chemins divergent

malgré l'absence

les blessures qu'on veut épargner à l'autre

qu'on garde pour soi

le temps

de dire le chrysanthème 
entre elle et lui

les signes avaient lu la chronique de cette mort annoncée

et l'éloignement qui s'en suit

pas un hasard s'ils sont rouges

s'ils ont la couleur du sang

flamboyant sur la neige

je n'ai jamais cessé,

non, de disparaître

elle l'avait lu, ça

la page 13 fut pour eux

le constat d'un échec

elle en avait été le témoin

de cet échec...

pas un hasard si la peintre choisit le rouge

la seule arme pour lutter contre le froid

dont le poète se plaint

ce froid

terrible. 
sur la peau de celui,

qui erre dans la montagne

entre elle et lui

les signes sont l'écharpe autour du cou,

le long manteau qui recouvre les épaules rougies.

L'Hiver, un autre

ou l'espoir d'un recommencement,

du pas dans la neige qu'on veut poursuivre

et redescendre de la montagne fragile,

chasser la saison,

passer à l'autre

plusieurs autres

parce qu'il n'y a aucune raison de ne pas y croire

que le prochain

hiver

sera plus doux. 
L'auteur, au volant de sa voiture, longe le lac, puis il poursuit la route bordée de sapins. Il suit les indications de Marie-Claude, peintre et compagne, le temps d'un livre, du poète. À la bibliothèque, on connaît Marie-Claude, on confie à l'auteur son numéro de téléphone et celui-ci l'appelle depuis sa chambre d'hôtel. Il explique la raison de sa venue jusqu'ici, loin dans l'est, il décrit avec des mots simples ce qui l'a touché en découvrant leur livre à tous les deux, il aimerait en discuter avec elle.

L'auteur, au volant de sa voiture, sur la route de la maison de Marie-Claude, se dit que le livre est un sésame extraordinaire, qu'il permet la rencontre parce qu'on parle la même langue dans le fond, la langue du sensible. Nul besoin de passeport. On peut être noir, jaune ou rouge, la porte est grande ouverte.

Elle dit, je suis peintre, et à cette époque, je m’intéressais beaucoup à la calligraphie, je créais mon propre papier aussi, tenez, je vais vous montrer, je les ai dans mon atelier, dans une boîte, si je la retrouve, buvez votre thé en attendant, et moi, je caresse le chien qui cherche un compagnon de jeu, je discute avec son mari, d'origine italienne lui aussi, décidément, ça me poursuit, toujours un Italien dans l'ombre, je l'ai cherché, après tout, pas un hasard non plus si, en tirant le livre de son étagère, en lisant le titre sur la couverture, je vois ce nom italien, Vicario, ça a dû jouer, c'est sûr, et Marie-Claude revient, les originaux en main, ceux qui ont servi pour le tirage de tête, le papier a son épaisseur, du relief, du corps, ce dont le livre ne peut pas rendre compte, même si le résultat est splendide, les œuvres, faut les voir, les toucher, les soupeser, la pulpe des doigts en contact, et là, elle me raconte le livre, une histoire ancienne, vingt ans déjà, vous imaginez, comme si c'était hier, elle dit, Gilbert, je ne le connaissais pas, je travaillais dans un lycée professionnel, avec l'éditeur, il enseignait aussi, nous étions amis, puis un jour, il me parle de ce texte, 
veut que je le lise, donne mon avis, peigne mon avis si d'aventure et là, je suis surprise, jamais fait ça auparavant, et je pars avec le texte, ce long poème dans mon cabas, je dis, d'accord à condition que ça me plaise, que ça m'évoque des images, sinon, ce ne sera pas bon, ça ne fonctionnera pas, et je rentre à la maison, je lis une première fois, ne rentre pas de suite dans le texte mais ça, je le savais, il faut du temps pour lire un poème, et ainsi, je le lis, je le relis, je le lis à n'en plus finir pendant des semaines jusqu'à ce que le rouge s'impose, que le rouge devienne mon écriture, ne pas répéter le blanc, la neige du poème, non, je ne suis pas une illustratrice, je suis une lectrice et mon langage se traduit par des images, par des signes, et là, il se voulait rouge, peu de rouge, ne pas négliger le blanc de Gilbert, le blanc, est là, dans le vide, le rien, dans l'autour, et c'est seulement là, ma proposition entre les mains, ma lecture que je rencontre Gilbert, son regard, il m'a compris lui aussi, parce qu'il fallait que ça lui parle, sinon, on laisse tomber, un livre comme celui-ci, c'est un dialogue entre deux écritures, une rencontre autour d'un même univers, les mains liées, c'est une relation, et puis nous avons défendu ce travail, bec et ongles, nous l'avons lu en public, nous avons vaincu nos timidités, et nous nous sommes perdus de vue, chacun prenant le chemin comme il vient, avec ces tours, ses détours, ses blessures, celles qui font qu'on change du tout au tout, qu'on aille voir ailleurs si jamais, vous voyez ce que je veux dire...

À son retour de cette petite ville, loin dans l'est, l'auteur apprend de la bouche de l'éditeur, au téléphone, que ce fameux livre, L'Hiver, un autre, est partie en fumée et plutôt deux fois qu'une. Un premier incendie avait entamé le stock, un second incendie l'a achevé. Il en reste un original dans la bibliothèque personnelle de l'éditeur. "Je vais vous le recopier pour que vous ayez au moins une trace du texte. Sinon, voyez avec Gilbert Vautrin, je vous donne ses coordonnées. Il vient de sortir un second livre.» Presque vingt ans après L'Hiver 
dans lequel l'auteur avait lu, là-bas, loin dans l'est, l'annonce d'une saison à venir, d'un recommencement. De Plain-pied.

Sur son carnet, inscrit au feutre noir, le numéro d'un poète parti sans laisser de trace. Disparu dans la neige. Un homme du silence. Un poète qui devenait mythique à ses yeux.

L'auteur a mis plusieurs mois avant de l'appeler.

Il ne s'agissait pas, en se déplaçant jusque dans une bibliothèque, loin dans l'est, de se lancer dans un exercice de snobisme qui consistait à dénicher dans un rayon le poète obscur, lui dépoussiérer le smoking, lui arranger le nœud papillon, un coup de blush sur les joues et ranimer un visage un peu jaune qui souffrait du manque d'air.

L'auteur s'interroge plutôt sur son attirance envers certains écrivains qui publient peu. Non pas qui écrivent peu. Quoique.

Jean-Jacques Schuhl, par exemple. Il publie deux romans, Rose poussière et Télex $N^{\circ} 1$ en trois ans, puis on n'entend plus parler de lui pendant trente ans jusqu'à ce qu'il revienne, tel un fantôme sorti tout droit d'un film expressionniste allemand, avec Ingrid Caven. La presse, le public, les libraires, tout le monde est stupéfait, crie au génie, on lui donne le Goncourt, un malentendu, un prix populaire pour un livre qui exige un lecteur actif, instruit, rock'n'roll. Silence radio à nouveau pendant dix ans. Entrée des fantômes - titre shakespearien qui lui va comme un pantalon de cuir - sort alors qu'on ne l'attend plus...

De 1968 à 2010, quatre romans à se mettre sous la dent. C'est peu mais le résultat impressionne. Il n'y a pas une visite dans une bibliothèque sans que l'auteur se rende à la lettre $\mathrm{S}$ du rayon littérature française avec l'espoir de trouver un jour l'introuvable Télex $N^{\circ} 1$. 
Au bout du compte, un soir de février, une saison qui sied au poète, l'auteur prend son téléphone. Il compose le numéro de Gilbert Vautrin. Une voix de femme répond. Elle appelle son compagnon. L'auteur bafouille en se présentant. Tout reprendre depuis le début. Le voyage jusque dans cette bibliothèquelà où l'on travaillait le lin, l'odeur du lac, son poème lu un jour de pluie dans son format cartonné parce que tous les livres dans cette bibliothèque sont reliés, cartonnés, protégés afin qu'ils durent, passent de main en main, même si la poésie, ce n'est pas ce qu'on recherche d'abord. L'auteur lui parle du thé chez Marie-Claude. De ses doutes quant au résultat de sa quête parce que, dans le fond, qu'est-il venu chercher là-bas, loin dans l'est? Un poète, était-ce une raison suffisante? Une raison pour divaguer. Se pencher sur la forme d'un récit, mais qu'il soit sensible. Juste. Qu'il soit celui d'un lecteur entré dans un espace conçu pour lui, en réalité.

Un matin de neige, l'auteur et le poète se retrouvent devant la bibliothèque pour une marche athlétique autour du lac.

Gilbert, la soixantaine, jambes moulées dans un pantalon fuseau conçu pour cette pratique, baskets de compétition, écharpe de laine et bonnet bleu marine, tend la main à l'auteur, en survêtement rouge vintage Adidas et baskets de ville usées, écharpe de laine, pas de bonnet à cause du gel dans ses cheveux.

Gilbert lui confie que tel Tennessee Williams qui nageait chaque jour avant d'écrire, lui marche, mais lui, mieux que Tennessee, écrit en marchant, j'écris sans le vouloir, dit-il, à cause du paysage, de la neige en hiver, de l'odeur des sapins, de la brume sur le lac, quel que soit le temps.

Gilbert est bavard et l'auteur en oublie ses joues écarlates, l'effort qu'il fournit si rarement, la douce sensation de brûlure 
lorsqu'il respire. Gilbert partage ce moment d'intimité. L'incursion d'un autre dans son univers n'est pas fréquente. Il accueille l'auteur dans son atelier, en somme. Celui qui le protège de «notre soi-disant monde» dont parlait Cummings. Un atelier en mouvement. Une fenêtre ouverte sur l'extérieur avec un panorama à 360 degrés. Gilbert évoque ce besoin de mettre son corps, sa peau sur la table, chaque jour. Le poème est rare. Il réclame de l'effort, beaucoup de sueur.

L'auteur et le poète s'entretiennent ainsi une matinée entière, ils en oublient de compter le nombre de tours du lac. Ils échangent ensemble sur l'écriture, ils se découvrent une passion commune pour les poèmes de Richard Brautigan - Journal japonais est définitivement le plus beau long poème américain du xx siècle - et de Sandro Penna, ils aiment tous deux la boxe et se promettent d'écrire un jour sur Carlos Monzón. L'auteur lui propose de l'emmener voir Palerme. Il lui dit que la neige ne suffit pas. Que ces paysages du sud devraient l'inspirer. Le poète émet des doutes. "Pourquoi pas, dit-il. Je me sens bien ici, tu sais, mais promis, je réfléchis à ta proposition...» 


\section{Pascal Commère}

Bibliothèque multimédia intercommunale Épinal-Golbey

\section{Sortir des forêts}


À trop consulter cahier des charges et feuilles de route on se perd, ce à quoi un tropisme tenace m'a de longue date prédisposé. J'allais vers les forêts. Pour dire vrai, j'en venais, ayant choisi un itinéraire buissonnier, et roulant à couvert, maintenant que l'obscurité trouée par les faisceaux de mes phares était quasi-totale, infinie, telle une phrase d'un seul souffle inscrite depuis l'origine dans le ballant du monde, dans la nuit. Cependant que me revenait une échappée extra-muros, quelques semaines auparavant, où le hasard avait voulu qu'à Madrid (où l'on me vola papiers et portefeuille - mais c'est une autre affaire) la Bibliothèque nationale d'Espagne fêtât son tricentenaire par une exposition à laquelle, profitant de mon séjour écourté, je ne manquai pas de me rendre, et dont je feuillette aujourd'hui le somptueux catalogue édité à cette occasion. Léonard de Vinci (Códices Madrid I y II), Rabanus Maurus (De laudibus Sanctae Crucis), Dante Alighieri (Commedia), et, surprise, qui n'est pas pour me déplaire, Charles Perrault (Courses de testes et de bague faites par le Roy et par les Princes et Seigneurs de sa Coeur en l'année 1662) pour ne citer que quelques-uns des trésors un temps sortis de l'ombre. De là à céder au démon de l'inventaire pour ce qui me concerne ici, mémoire folioté, bachoté et rendu dans les temps, rien de cela. Pas plus qu'à la fiction du reste, blanc ou noir pour le genre, du moins pour ce qui est du texte à rendre, espérant qu'il prenne forme, sorte de l'ombre. Encore que je ne sais rien à son sujet, pas plus que je ne connaissais Épinal, la bibliothèque pas davantage où je m'apprêtais à ancrer mon écritoire, ayant décidé de mon déplacement la veille, sans plus d'apprêts, à peine j'en avais relevé l'adresse, un temps trompé par l'ancienne, désormais obsolète, et cherché l'itinéraire, ainsi qu'on sait à l'écran.

Je reviens aux forêts. À vrai dire je ne sais pas trop où je veux en venir. Si, un peu. Pressentant dès l'abord le lien, certes antagonique, qui les rattachent à l'écrit. Au Livre. Bien que celui-ci ne soit pas nommément au cœur de ma requête. Outil de connaissance, le livre à mes yeux désigne bien davantage. Compagnon de vie, et plus encore. À tel point que j'eus besoin 
très tôt de les avoir à moi, souci de possession non pas tant que pour être avec, m'y perdre, m'y retrouver, et les interroger, les toucher, creuser dans leur sillage un chemin, dès lors que peu enclin à les emprunter, je les faisais miens aussitôt, incapable par là de m'en séparer dans les délais. C'est dire. Mais je n'ajouterai rien au contentieux aimable que j'entretins de longue date avec les établissements publics chargés de leur gestion. Cela nous éloignerait d'Épinal. Où j'arrivais pour la seconde fois, me souvenant qu'à la première j'avais pas mal erré avant de me décider à me procurer un plan de la ville, égaré peu après. M'en remettant dès lors aux ponts sur la Moselle, quand un monument aux morts de la Première Guerre avait accroché mon regard. Des noms dans la pierre, plus de mille cinq cents, un poids d'ombre et de nuit que la mention conjointe des batailles prolongeait durablement. Les Vosges, La Fontenelle, Alsace, Le Linge, La Chipotte, Hartmann, Grand Couronné...

J'étais tout près, en fait. Rue Entre deux portes, ne dit-elle pas qu'on sort. De quoi, c'est une autre affaire à laquelle la rue Saint-Michel, qui file vers Saint-Dié, n'apporte qu'une réponse évasive. Sinon par le quartier qu'elle inaugure, reconstruit sur les lieux d'une ancienne friche industrielle et, plus exactement, pour ce qui est de la bibliothèque, à l'emplacement des bâtiments de la société des transports des Hautes-Vosges. Quartier affecté désormais aux loisirs, à la culture. Galerie d'art, cinéma, patinoire - ses bleues chamarrures en façade, quand la B.M.I. (Bibliothèque Multimédias Intercommunale) s'enveloppe dans les ocres. Parkings spacieux à l'avenant, vides pour l'heure - leurs arbres pas d'ici qui peinent côté racine. J'ai repéré l'entrée.

Et d'abord le grand hall qui ne manque pas de surprendre, habitué qu'on est malgré soi aux anciennes images et d'autant plus tenaces qu'elles s'attachent à des souvenirs riches en émotions. Telle salle de lecture, inscrite dans la mémoire bibliothèque de Strahov à Prague, visitée naguère, murs tapissés de livres, de dos le marocain, et le bois et les ors, le stuc 
des moulures, les fresques du plafond et leurs allégories hommage à l'instruction, parquets luisants, globes terrestres, toutes cartes et estampes. Et voici qu'à la rime le vers suivant répond. Ah! que le monde est grand à la clarté des lampes! Ce dont je douterais quelques instants plus tard, lorsque, midi passé, bistrot près du marché, deux hommes à une table voisine, l'un d'eux: "Ah, mais vous dites toujours: «Il y a vingt ans...»», quand l'autre, moustache de sapeur, tout aux événements meurtriers du moment, n'en démordait pas, «vous verrez, la Marine gagnera cinq points aujourd'hui», qu'il était prêt à parier, tiens, rameutant du même coup l'ombre des forêts anciennes. La peur.

Petit tour du propriétaire en sorte, parler du bâtiment. Sa conception, due au cabinet d'architectes Chabanne \& partenaires, lequel présente son projet en quelques lignes, avant de préciser son propos: "Une bibliothèque est un lieu chargé de sens. C'est un lieu de vie et d'échanges, un lieu de culture, un lieu de passions. » Voilà qui est dit. Et que le Livre occupe la place centrale semble assez naturel. Conforme à l'idée que l'on se fait généralement d'une bibliothèque. J'ai tenté un pas vers l'accueil, bredouillé quelques mots. Pour demander... Euh... MM. Elle, la directrice. En vain. «Madame-M. est en réunion". La veille déjà, alors que je souhaitais prévenir de mon arrivée... "Mais il y en a tous les jours des réunions... ». Une question, toutefois. "Qui êtes-vous? » Un silence. Vu qu'il n'est pas question pour moi de présenter une carte professionnelle (ainsi qu'il est d'usage dans les romans du genre), étant sans papiers depuis l'épisode madrilène! À l'accueil, on ne m'en précise pas moins son emploi du temps. Oui oui... la directrice sera là cet après-midi. Tandis qu'à travers la cloison latérale je découvre ce qui constitue le cœur de l'édifice, fautil dire le sanctuaire, cette Salle des boiseries dont on reparlera avec Elle, et qui n'est autre que la reconstitution d'une de ces anciennes bibliothèques dont j'ai dit tout à l'heure le mythe qu'elles relaient aux yeux de quelques-uns. À savoir la continuité du savoir à travers le temps, ainsi qu'on peut le lire dans une plaquette de présentation, mais plus encore, et je 
ne pouvais l'oublier, les regards qui s'étaient succédé au fil des siècles, de page en page, et dont la fixité marquait le souvenir d'une suie impalpable, savoir et temps mêlés, lorsque la nuit venue, les livres sous les reliures consentent à dévoiler les premières lignes d'un secret jalousement gardé; les vocables, souffle retenu, ah cette haleine qui sent le chou; le rauque ânonnement de qui découvre l'écriture, s'y confronte; l'épaisse salive aux lèvres, le doigt aux engelures interrogeant le signe, et quel tremblement accompagne la quête transgressive, quand la question taraude les esprits enfiévrés. Bibliothèque! Dont je ne tarderai pas à saluer le mot qui inaugure un sigle devenu familier au point qu'il le supplée, dans une coulée de langue qui, négligeant les points entre les lettres, fait de nous qui cherchons, béhèmi, bohémiens, et tous gens de bohème. Errants, et défricheurs.

Mais pourquoi Épinal, pourquoi une seconde fois? Sinon pour quelques questions demeurées sans réponse. Du fait même que j'avais oublié de les poser. À commencer par celle-ci: que vient-on faire dans une bibliothèque, que vient-on y chercher? Mais n'est-ce pas à moi d'abord que la question s'adresse? De là à ce que j'interroge les usagers... Car j'y avais pensé bien sûr. Mais le hall était vide, ou quasi, ce jour-là, hormis quelques lecteurs de quotidiens retranchés dans un mutisme fermé à toute enquête. Ce que je voulais, non, c'était l'adolescent branché, la petite dame aux cheveux teints qui pour rien au monde n'eût manqué une animation, dieu sait si elles se succédaient. Elle existait du reste, la petite dame, on me le confirma. Quant à Elle, la directrice, nous avions bavardé l'après-midi, dans ce qui me parut être un bureau - le sien, sans doute. Un peu sombre, pour tout dire. Quelconque. Avec des grilles aux fenêtres qui ne s'ouvraient pas, trouvaille de l'architecte. Le hall alors, comprenez, un lieu où chacun faisait le plein de lumière. Quand une question m'était venue, presque brutale. Qui n'avait pas semblé la surprendre. Sans doute y avait-elle répondu maintes fois. Comment devient-on bibliothécaire? Ce qui revenait à demander: pourquoi. Eh bien voilà. "Quand j'étais petite je numérotais les livres, dès 
qu'un nouveau arrivait je recommençais la numérotation ». Une affaire de chiffres seulement? Ou si les livres... Présents dès l'enfance, bien sûr, et pour cause: des parents profs de lettres... Qu'en était-il ici?

D'un temps qu'elle dit partager entre les relations avec les lecteurs, ajoutant: ce qui est le plus valorisant, et la gestion interne de l'établissement. Avait-elle seulement encore celui de lire? Elle, souriant alors. Quand plus tard, évoquant un auteur finlandais dont j'ai à peine le temps de citer le nom, Elle dit Paasilinna. Comme quoi. Budgets et réunions ne l'ont pas dévorée! Ou s'en remettait-elle aux oscillations de la raison, comme je l'avais fait moi-même pour définir notre vrai lieu, cette rue Saint-Michel qui s'éloignant du centre nous rapprochait de l'essentiel, et, par là, d'une altérité dont témoignait l'emplacement même du bâtiment, entrée de ville, et comme tournant le dos, pour s'ouvrir à la proche périphérie, cette intercommunalité (ainsi qu'on dit) qui ne dépasse pas ici 45000 habitants. Aux forêts j'avais dit, ronces et épines (spina) dont provient le nom de la ville, sans que je consente à me départir du rôle du Livre, là ou ailleurs, au point de faire du bâtiment un rempart contre les ténèbres qui guettent l'humanité depuis toujours, la noirceur des halliers, toute forme de repli sur soi, enfermement, quand le hall dès l'entrée proposait accueil et lumière, échange, ce que les noms de SaintLoup, qui avaient attiré mon regard la première fois à l'aller, niaient à leur façon, lesquels n'étaient pas sans signification, pas davantage que les mots qui envahissaient mon esprit au retour, creusant de leur falot la nuit que le Livre n'éclairait pas encore, jeté que j'étais soudainement parmi les ombres, avec les premiers hommes, par les essarts, en fuite. Ou si déjà une histoire m'entraînait dans sa suite, avant que d'apercevoir la masse blottie au sol de formes ployées d'ombre, et la boue qu'on sait, là où quelques mois auparavant, fin de journée, j'avais surpris, de dos, un homme s'éloignant à pas lents sous la pluie, fatigué, un outil sur l'épaule, espèce de croc, tel qu'on n'imaginait pas que semblable instrument pût servir de nos jours. Être de chair et d'os, bien réel, si tant est que je n'avais 
pas rêvé, mais non, rien d'un être de papier, tout droit venu de quelque image de Goya (figurant au catalogue de Madrid naturellement), de ceux dont on voudrait douter qu'il en existe encore et dont la présence parmi nous, à trois pas, assombrit l'histoire à laquelle nous sommes mêlés. Comment ne pas remarquer alors les signes et caractères graphiques qui ornaient la façade et les vitrages du bâtiment, l'éclairant en quelque sorte, et dont j'apprendrais qu'ils tiraient leur origine des pages d'un très ancien manuscrit du viII siècle, répertorié sous le nom de Glossaire d'Épinal, et provenant, comme les boiseries de la salle éponyme, de la bibliothèque de l'abbaye de Moyenmoutier. À quoi s'ajoutaient, parmi tant de trésors dus aux confiscations révolutionnaires, livres d'Heures, incunables et manuscrits du Moyen Âge, au rang desquels figurait L'Évangéliaire pourpre du chapitre Saint-Goëry, dont la reliure porte en son plat supérieur une plaque d'ivoire de la seconde moitié du XIve siècle. Toutes choses que j'interrogerais à mon retour, prenant mesure d'un patrimoine qui éclairait notre route. Mais je venais tout juste d'arriver.

Du hall, il m'a suffi de quelques regards circulaires pour repérer les secteurs à l'étage, avant que je n'y furète plus longuement dans l'après-midi, découvrant du même coup l'existence de petites loges tournées vers le dehors, les «carrels", dont les adolescents, adeptes des recherches en commun, aiment à partager l'intimité confortable. Les livres ne constituent-ils pas un terrain de rencontre... Verre et métal pour ce qui est du matériel d'exposition; couleurs, gaies sans plus de tapage, du mobilier. Le gris des matériaux, un rien aérien. De l'espace. Ouvert à tous, le dira-t-on assez, semaine et dimanche après-midi compris, pas mal de monde dit-on, et beaucoup en famille alors, on y vient, on s'installe. On cherche. Comme cela a l'air simple, quand tout semble à portée. On respire. On partage. Chacun pour soi, en esprit, dans un vivre ensemble qui, ménageant une place à tous, contribue à la lumière du lieu. Qu'on eût dit neuve, comme née de l'instant. Et pour cause. L'ouverture datait de 2009. Quand j'avise une étagère, livres: produits d'accueil. Ainsi que ces mots 
venaient de s'imposer à moi, tirés d'un univers mercantile assez peu approprié. Mais! Livres qu'on pose à plat, au sujet desquels il me revenait qu'une fois, jeune emplumé alors, mais déjà habité par la folie du scribe, un homme de lettres, d'âge mur, souhaitait qu'on distinguât les livres des «imprimés ». Qu'en était-il aujourd'hui ? Défunté l'homme de lettres, ses livres oubliés... Ou presque. Parmi BD, mangas et toutes sortes d'albums, films et DVD, livres-audio, numériques, tout matériel ad hoc, y compris adapté mis à disposition (je lis sur la brochure) des personnes handicapées «empêchées de lire», ici, à Épinal, où Jean-Charles Pellerin, toute fin du xviIe, crée les fameuses Images, dont une mémoire collective ressuscite sans tarder les histoires qu'elles colportent, seules du genre à pénétrer l'austérité des temps quand tâches et travaux, en forêt pour partie, s'invitaient à la veillée, chargées d'hiver, de loups. Mais de quoi je parlais? Ah oui, des «imprimés». Lesquels posés à plat, disent tout de ce qu'ils disent sans grand besoin d'auteur. Internet méfiez-vous... Accros aux écrans... La face cachée du Net... Quand soudain: livre rouge, tout petit, l'air de rien - Les origines de la pensée grecque, de Jean-Pierre Vernant. On a changé d'écran.

Période électorale oblige, propos franco-français dans le coin presse au fond, titillés un tantinet par la rumeur du monde. Lumière de l'aujourd'hui. Comme si la forêt lorraine soudainement reculait. À moins qu'elle ne revînt, supports multiples, points de vue divergents, en des informations tous azimuts. Cependant que j'ouvre une brochure (municipale), où il est question de la fête des Champs Golot (lé chan golo, patois local). «Profitant d'un surcroît des eaux dues à la fonte des neiges, les enfants faisaient voguer toutes sortes de bateaux de fortune sur lesquels étaient allumés des bouts de chandelles... ". Écouteurs aux oreilles, un ado à côté, assis, remue des yeux, icônes, petits bonshommes, ça s'agite à l'écran... Peu de monde à cette heure, au sol des pas feutrés. Nulles traces, ni bruits, sinon par instants la sonnerie d'un téléphone sur une banque d'accueil, le crépitement des doigts sur un clavier, une soufflerie légère - climatisation peut-être. 
Tandis que par les baies vitrées je surprends le dehors sous un tout autre aspect, voitures qu'on voit passer sans les entendre, monde insonorisé, comme en retrait de soi, protégés un instant du quotidien auquel nous ramènent les titres en tous genres. Bricolage, sciences pointues, préhistoire. Sondages, déclarations. Et comme une évidence, La Gazette des Communes: Réhumaniser le service public.

En fait, on était passé du xix au xxie siècle. C'est Damien qui le dit, plus de vingt ans de présence, dont une grande partie à la Maison romaine, ancêtre de la BMI depuis 1905, un rien antique à ce qu'il semble, et conforme à ce qu'on attendait alors d'une bibliothèque. Moquette et tout en courbes, il avait dit, alors que maintenant c'est droit, métallique, fonctionnel. Quant à la fréquentation... Disant c'est plutôt mort entre 12 et 14 heures, à d'autres instants c'est la bourre, ça crie. On en resterait là. Parmi les livres, dans leur ombre. Et ce qu'on savait d'eux, sans rien en dire de plus. Ce qu'on en attendait. D'eux et de l'écriture. Après quoi j'avais pensé à la nuit, au sentiment qu'on a de se perdre, de s'enfoncer parfois. Malgré un début de complicité dont j'aimerais retrouver aujourd'hui la trace dans les mots. Autant que ce qui nous sépare, qui reste propre à l'expérience de chacun. Ce que c'était qu'être là au quotidien par exemple, gestion du secteur, classement des livres, retour de prêt, commandes. Lesquelles ne soulevaient pas de problèmes particuliers, selon Elle à qui j'avais demandé des précisions à ce sujet se bornant à dire entre février et novembre, à tous moments, ajoutant: chacun a son domaine, son budget. Mais qu'est-ce que c'était qu'être bibliothécaire, secteur adultes, sinon être au service des livres bien sûr, de la littérature, ah quel mot, qui recouvre tant de genres, sciencefiction polars: rayons à part désormais, sans compter les dictionnaires, les encyclopédies. Ce qu'étaient les lecteurs, leurs attentes. C'est alors qu'il avait souri, tirant d'un rayon une pile de livres lacérés, couverture arrachée. Et moi : tiens, la voilà mon enquête! Elle venait un peu tard. Mais j'avais un indice: tous provenaient du rayon Psycho. On se prend au jeu l'un et l'autre. Dois-je en déduire... «Oui, nous avons un serial killer 
à l'étage!». Sourire. Maintenant que me revenaient les mots d'Isaac Babel au sujet des bibliothécaires... «Ils sont mal habillés, d'une extrême maigreur. On dirait des fanatiques possédés par une idée que personne ne connaît en ce monde». Les temps étaient-ils si différents? De cela il eût fallu parler aussi. Ce que sont les stéréotypes. Sans oublier les livres évidemment, du temps où l'on glissait une fiche dans chacun d'eux. Tampon encreur alors, apposé page 29. On vérifie. Disant: "Avant je faisais ça, maintenant ce sont mes collègues en bas ». Tampon sec, désormais. La page avait changé. Ajoutant qu'à la Maison romaine on envoyait des «ultimatums» aux retardataires. Était-ce vraiment révolu, pas sûr. «Certains collègues ici doivent le faire encore». Il a trouvé la page. Quatre-vingt-dix-neuf il dit, articulant. Une question subsistait toutefois. Mais concernait-elle les principes de classement, évoqués longuement l'instant d'avant, ou bien quelque détail se rapportant à l'enquête, dont je n'étais pas sûr qu'elle avait touché à son objet, au point de ne pas progresser avant que je revienne... Ce que je fais aujourd'hui, en pensée, m'apprêtant à ouvrir comme pour la première fois un livre de Giorgio Caproni où, dès les premières pages, une phrase était venue à ma rencontre. Une phrase que j'avais prise pour un signe, une invite à poursuivre. «Tandis que moi, je me perdais dans un mot: la nuit». 

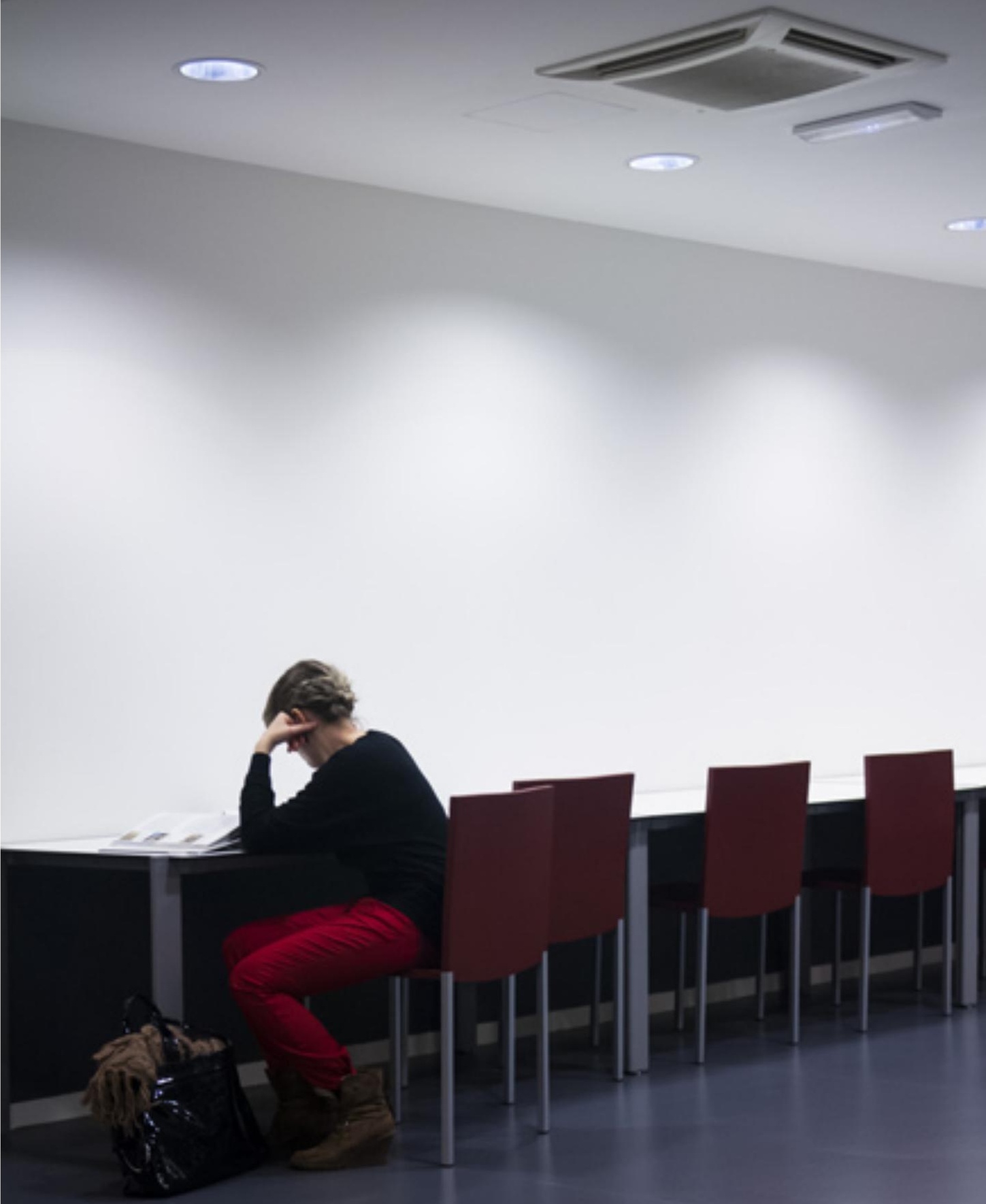

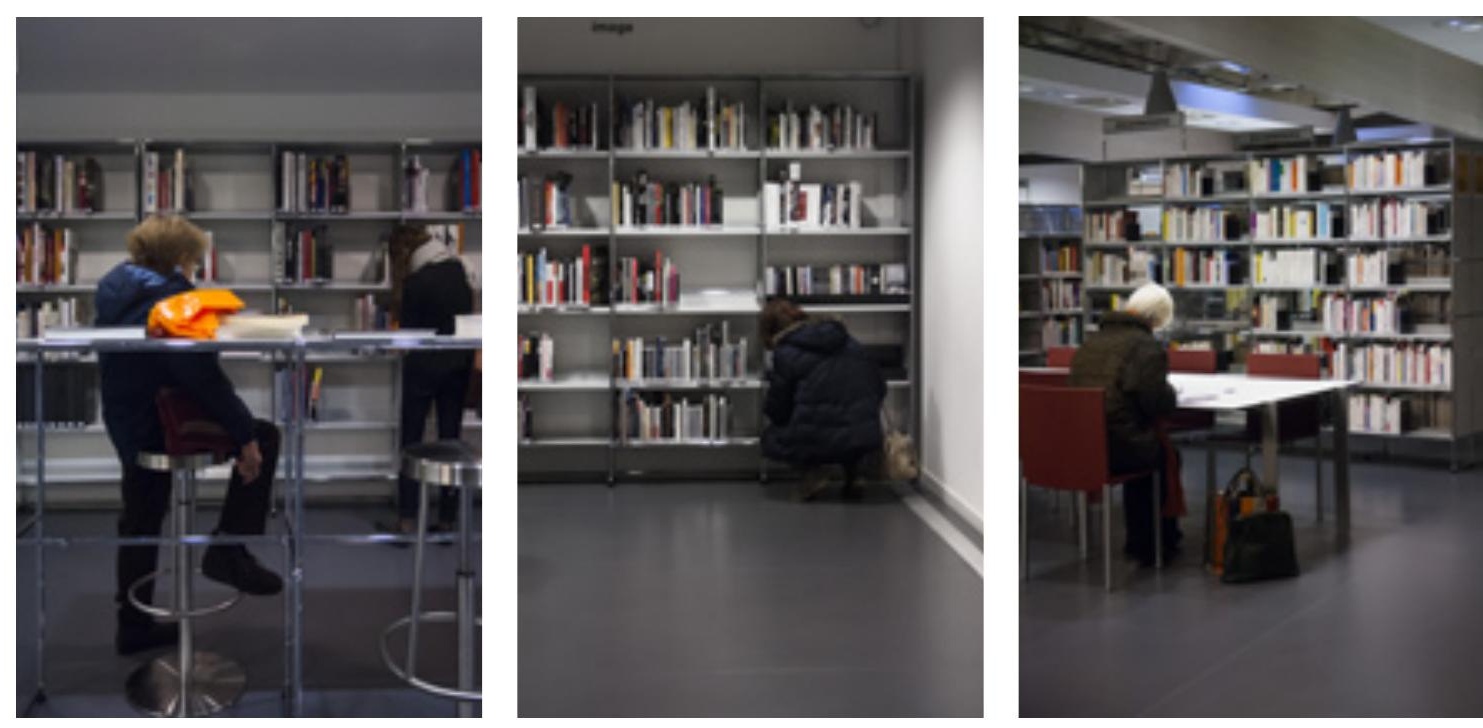


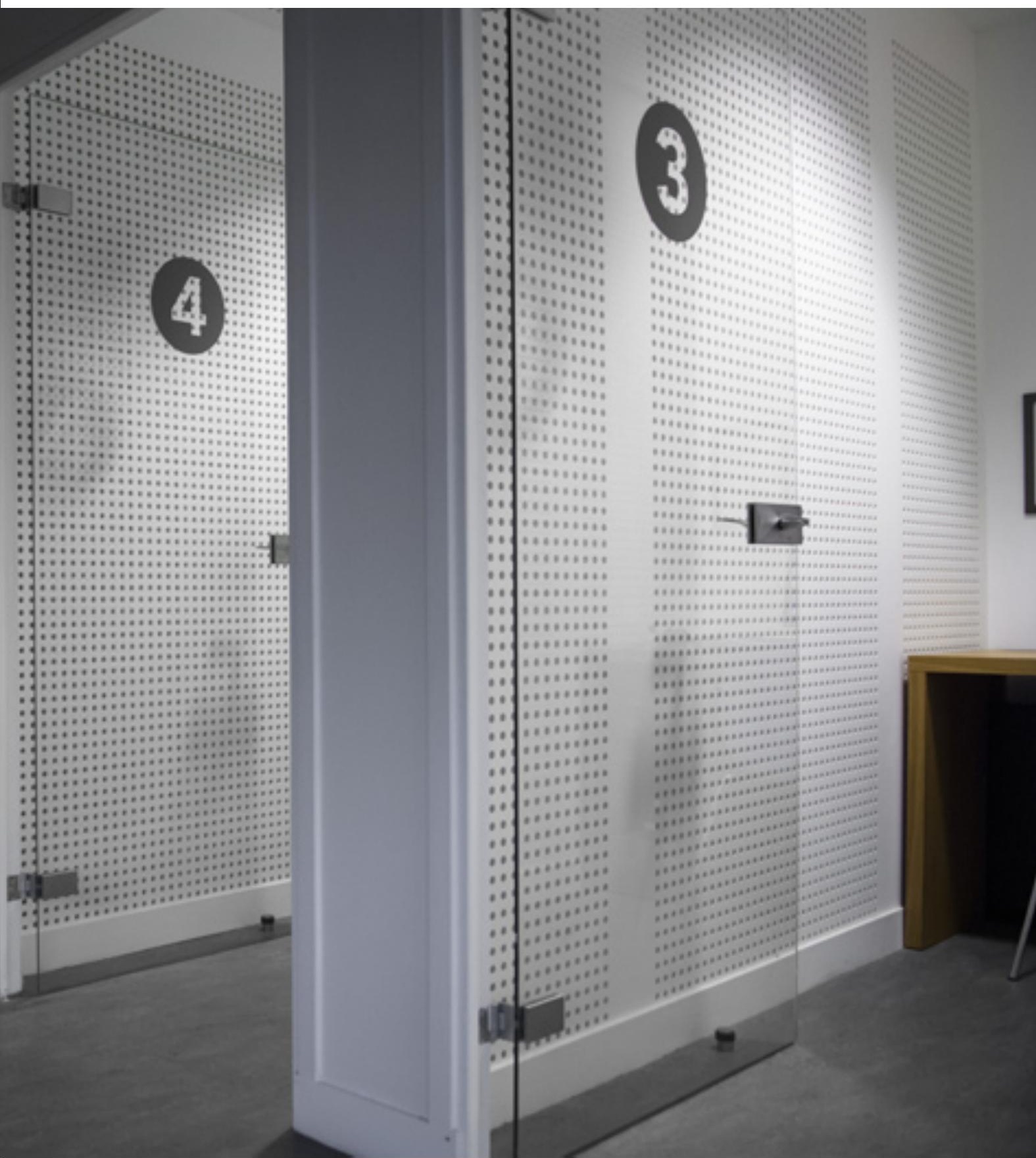




\section{Baptiste-Marrey}

Médiathèque Elsa-Triolet, Villejuif

L'impasse des verbeuses

ou la rivière enfouie 
Cela fait vingt ans que j'habite Gentilly, un demi-siècle que je crapahute dans le Val-de-Marne (on dit aussi le 94), bastion historique du communisme français, dernier conseil général aux mains de ce qui survit du P.C.F. Sur l'autre rive de la Seine, c'est le 94 bourgeois (Nogent, Saint-Maur, Saint-Mandé, Vincennes) et de l'autre côté de ce qui fut la Nationale 10, ce sont les Hauts-de-Seine sarkozystes (le 92).

Villejuif est le siège de la "communauté d'agglomération" (sans s) du Val-de-Bièvre, soit un peu plus de 200000 habitants, répartis sur sept communes: largement l'équivalent de la ville de Lille, le double de celle de Rouen. La Présidente, élue au deuxième degré, pour trois ans est une femme (Patricia, P.C.) : elle a succédé à une autre femme (Claudine, P.C.). L'agglomération dont le quatorzième vice-président a en charge la culture (c'est dire son importance) gère entre autres choses les déchets. Elle s'est donné aussi pour mission «la réouverture de la Bièvre». Cette rivière, devenue, au fil des ans et des tanneries, un égout dont Balzac et Huysmans ont donné des descriptions fameuses, est depuis plus d'un siècle invisible. Mais elle irrigue, poétiquement, par son absence même, ce territoire. On s'agite pour la remettre à ciel ouvert.

Dans cette vaste zone à l'urbanisme continu, Satie a caché longtemps ses secrets (Arcueil); Doisneau photographié les as du cyclo-cross, course à pied vélo sur le dos (Gentilly); Marin continue de vendre couleurs et châssis aux peintres d'Île-de-France (Pincemin, Segui et bien d'autres). À l'est du découpage administratif de l'agglomération, Vitez s'est élancé de son clairsemé public d'Ivry jusqu'à la Comédie-Française; Ivry, justement, en bordure de Villejuif et du quartier des Malassis (cher à Cueco et à ses copains); puis, au fil de la Seine, Vitry: là, règnent, autour du Rond-Point, l'Hourloupe, «peinture monumentée» de Dubuffet, et le Mac-Val, temple chic et choc de la modernité et de la grande prêtresse, ordonnatrice des Nuits Blanches de V.V.P. - Vuitton-Ville-de-Paris: Lénine, Trotzky où êtes-vous?

Ce sont là les derniers soubresauts de la volonté historique du parti communiste de soutenir la création, en tant que telle, fûtce contre le prolétariat. La même volonté politique a impitoyablement raboté ce qui subsistait de rural et de populaire (fermes, ateliers vétustes d'artisans, jardins disparates) au profit de centres commerciaux pyramidaux et pharaoniques, d'immeubles vitrifiés de bureaux à la Levallois-Balkany, d'H.L.M. audacieux à Ivry ou en briques uniformes à Gentilly et alentour. 
Officiellement Villejuif viendrait ${ }^{1}$ de Villa Judea du nom d'un certain Juvius, propriétaire gallo-romain. Pierre Larousse écrit tout à trac que les Juifs possédaient les terres de cette colline au Moyen Âge. Quoi qu'il en soit, Villejuif fut longtemps une modeste bourgade: pas plus de 2000 habitants au XIX siècle (contre près de 55000 aujourd'hui). Le 18 septembre 1870 fut dressée une barricade (canons, pavés, et sacs de sable) contre les Prussiens, reconstituée avec une exactitude photographique par Édouard Detaille (musée de Versailles). Le grand Atget vient en 1901 avec sa grosse boîte en bois $(18 \times 20 \mathrm{~cm})$ prendre des clichés de la ferme, déjà abandonnée, du château de Saint-Roman. Mais il y avait partout des maraîchers et leurs cultures. On en retrouve encore la trace grâce à de nombreuses sentes étroites pour piétons et jardiniers qui, fidèles à l'ancien cadastre, divisent la commune en carrés rectilignes, jadis de choux et de salades, aujourd'hui de pavillons et de garages: ainsi subsistent la voie des Taillis ou celle des Roses, à proximité de la merveilleuse Impasse des Verbeuses. S'y ajoutent, bien sûr Liebknecht (un sentier!), Barbusse, Condorcet etc.

Depuis la fin du siècle dernier, Villejuif est devenue une ville hospitalière: trois gigantesques hôpitaux, véritables villes dans la ville échappent au pouvoir de la commune: Paul-Guiraud (psychiatrie), Paul-Brousse (centre hépato-biliaire) et, visible de toute la banlieue sud, le manhatannesque Institut Gustave-Roussy écrase, au fond de son cul-de-sac de toute sa menaçante hauteur le parc des Hautes Bruyères : ici la science lutte contre le cancer. Combien de lecteurs dans ces lieux de souffrance et d'espoir?

La nouvelle bibliothèque a été construite en 2006 au centre de la commune, dans le carré institutionnel, au voisinage de la mairie, de l'église Saint-Cyr-Sainte-Julitte (fermée en dehors des offices), du centre des impôts et du théâtre Romain-Rolland pionnier avec Aubervilliers du théâtre en banlieue - récemment modernisé avec une scène judicieusement dédiée au bon mimepédagogue Jacques Lecoq.

Les récentes «médiathèques » (je ne m’habitue pas à ce terme technocratique), par le choix de leur emplacement, par leurs dimensions souvent imposantes, par la qualité de leur architecture, jouent aujourd'hui le rôle de signal culturel et politique

\author{
1. Le Patrimoine des \\ communes du Val-de- \\ Marne, Flohic éditions, 1994. \\ 2. Bien que Malraux fût un \\ ministre-écrivain, il n'y eut \\ jamais, même en projet, \\ de "Maison de la Culture \\ du Livre": elles furent toutes \\ centrées sur le théâtre. \\ Une belle occasion de \\ décloisonnement ratée.
}


(même à l'égard des non-lecteurs) que jouèrent avant elles les Maisons de la Culture ${ }^{2}$.

Celle-ci est dédiée à Elsa Triolet. On peut y accéder par la station de métro Louis-Aragon, en suivant l'avenue de Stalingrad, prolongeant le boulevard Maxime Gorki, etc., etc. J'aurais préféré le choix des Jolies Verbeuses à celui de cette mauvaise traductrice de Tchekov. Mais le bâtiment tout en longueur sur deux étages est une réussite. Il est dû à Paul Chemetov et Huidobro, auteurs précédemment de la barre du Comité Central, dit aussi ministère des Finances dans ce qui fut le Bercy (bulldozérisé) de mon enfance. La lumière est partout présente (qu'en sera-t-il quand l'immeuble en construction dans l'espace resté libre sera terminé?), les volumes bien proportionnés, les circulations aisées, la signalisation remarquable de lisibilité. Elle se différencie de la terminologie habituelle: ainsi la salle de lecture du rez-de-chaussée est intitulée «espace des citoyens » (doté - quelle bonne idée - d'un agrandisseur de caractères), et l'espace jeunesse a son «île aux histoires ». Pour le reste, l'indispensable espace multimédias voué aux seuls ordinateurs, le fonds pour adultes au premier étage avec ses livres (bon choix de nouveautés présentées à plat, dont quelques poètes), avec ses disques et ses films (pour l'instant sur DVD, demain sur...?); une salle de lecture «dédiée au travail dans le calme» et une salle d'étude «dédiée au travail dans le silence» (le plaisir de lire semble avoir été soigneusement écarté). Prêt gratuit, 8975 inscrits, près de 20\% de la population. Pas de pénalités de retard, donc pas de régie (traquée par les trésoriers municipaux). Ouverture: vingt-huit heures par semaine avant de revenir à trente et une heures, comme précédemment. À Issyles-Moulineaux, dans le réactionnaire 92, la bibliothèque est ouverte tous les dimanches. Deux annexes de quartier, vouées à la jeunesse, l'une dans la M.J.C., l'autre dans une école - d'où leur fermeture pendant les deux mois d'été, le reste de l'année les enseignants ont pour mission de «développer l'esprit critique dès le plus jeune âge » (plutôt que le rêve ou l'utopie), mais les enfants y apprennent à fréquenter les livres, dès leur entrée à l'école.

Si je me réjouis de l'existence d'un auditorium, dit «salle culturelle», à l'équipement apparemment sommaire, et de la présence du théâtre voisin dans la «salle de l'Églantine» (150 places), je reste perplexe devant le troisième étage voué à l'auto-formation et composé de 
neuf cabines individuelles ou placards avec ordinateur, accessibles sur réservation aux volontaires deux fois une heure par semaine. L'absence de mon logiciel favori ("Comment ne pas mourir idiot», le produit-phare d'Apple) a accentué ma nostalgie de Platon et son Académie, d'Alain et sa classe de khâgne où la formation naissait au sein du groupe de l'échange (en temps réel) et du dialogue (live): ce qui devrait être encore aujourd'hui la mission première des bibliothèques plutôt que le tête-à-tête onaniste avec un écran ${ }^{3}$.

Je suis ressorti de ma visite, par un bel après-midi d'octobre, pensif. Je me suis arrêté à la maison de la presse voisine et ses 8000 titres plutôt bien choisis. Eva Joly était en vedette en vitrine et à l'intérieur. Simple souci d'actualité en cette semaine des primaires socialistes ou peut-être en réaction à Patricia-Claudine? À la question: quelles relations avec Elsa Triolet? Réponse: néant. De même à Points Communs, petite librairie souriante et dynamique installée sur les décombres d'un disquaire (merci la Fnac). J'y ai acheté de la britannique Doris Lessing, c'est ainsi qu'un jeune noir du zimbabwe a volé un manuel de physique supérieure (l'absence de majuscules donnant un air chic de modernité à cette jolie plaquette $^{4}$ où la romancière décrit la misère des bibliothèques dans ce pays qui fut longtemps le sien: "Je me souviens d'un chauffeur de taxi, à Harare, qui en apprenant que j'étais arrivée avec une valise bourrée de livres, avait remarqué: «Ils nous ont appris à lire, mais ils ne nous donnent pas de livres». «Ils», en l'occurrence, c'était le nouveau gouvernement noir, qui avait fait pareilles promesses. C'était l'époque où le prix d'un bon livre de poche britannique dépassait le salaire mensuel d'un instituteur. Il y a là un mystère, un véritable mystère, qui n'a pas de solution simple. D'où venait donc cette véritable faim de livres dans cette ancienne colonie britannique? » Loin du Zimbabwe, dans ma banlieue-sud, il existe une bibliothèque municipale dans chacune des sept communes du Val-deBièvre, mais il n'y a pas plus de trois librairies (pour 200000 habitants) ${ }^{5}$ sans que cela semble inquiéter ni le quatorzième vice-président, ni les bibliothécaires.

3. Ma confiance absolue dans la capacité des «nouvelles technologies " à se perfectionner (pour solliciter de nouveaux achats) me fait penser que ces placards informatisés - même s'ils sont très fréquentés dans certaines bibliothèques seront bientôt obsolètes. 4. Collection Le Cabinet de Lecture, L'Escampette éditions (" avec le soutien en 2010 de la Région Poitou-Charentes"). 5. Début octobre vient de s'ouvrir un «Furet du Nord à la Vache Noire" - drôle de zoo! centre commercial d'Arcueil, le treizième magasin ouvert par le groupe (séparé de Virgin), et le premier dans la région parisienne. Modèle Fnac: 40000 titres (peu de poésie), beau rayon papeterie, rayons de DVD et de disques commerciaux, "réassort" lent, transitant par Lille. Ce qui rend plus qu'aléatoire les commandes virtuelles. 6. Le libraire retraité Charles Le Pailleur, après avoir fermé son échoppe (virtuelle) du Kremlin-Bicêtre, est intervenu dans plusieurs de mes essais sur le livre: Éloge de la Librairie, éd. Le Temps qu'il fait, 1991, Éloge des Bibliothèques, CFD/Hélikon, 2000 , Les boutiques des merveilles, éd. du Linteau, 2007, qui ont avancé plusieurs propositions, reprises depuis avec autorité par Antoine Gallimard (sans mention de source, naturliche) 
Au soir de ma balade à Villejuif, je suis resté planté devant le panneau indicateur ELUARD (poète devenu quartier) entre Hôtel de Police et Centre des Impôts. Tant de provocations (parfois de compromissions) mais d'engagement, mais de talent, pour cette banalisation, cette chosification! Tant d'argent, d'efforts, d'investissement, de personnel, de dévouement, peut-être même de bénévolat (ce mot honni: il faut "professionnaliser» la culture) pour arriver à ce faux monde, tout sourires, toutes promesses, des bulletins municipaux, chantres de la diversité sociale et communautaire (les Portugais ici, les Srilankais là). Avec mes soixante ans de militantisme culturel derrière moi, je doute.

Je m'interroge comme tout un chacun sur l'évolution (les mutations, cela fait plus sérieux) de notre société et de notre culture; plus immédiatement sur celle ${ }^{6}$ du livre (condamné désormais à l'écran?). Mais vivant au cœur de cette agglomération (mot inepte, serais-je un «aggloméré»?), je vis avec le sentiment profond, pathétique, que des «activités culturelles» imposées d'en haut glissent sur la population, ne l'atteignent pas au cœur, à l'âme, là où l'on n'aime pas être touché.

Comment sortir les Verbeuses de leur Impasse? L'essentiel est invisible. L'essentiel est ce qui se vit entre le lecteur et le livre qu'il a choisi, et que certes il doit d'abord trouver plus facilement à Villejuif qu'à Harare, soit en librairie soit en bibliothèque, d'où naîtra la longue conversation d'esprit à esprit (sans abonnement à Internet) qui provoque le plaisir et l'éveil de l'intelligence. L'essentiel est la musique de la mémoire, la musique étouffée de la rivière souterraine qui irrigue les cœurs et les esprits.

Les Verbeuses amoureuses

douces aux enfances,

les Verbeuses rêveuses

entre leurs livres clos

chantent mezzo-voce

endormeuses aux yeux clos

la romance endormeuse

au fil de l'eau qui pour elles

dans leurs rêves murmure.

13 octobre 2011 

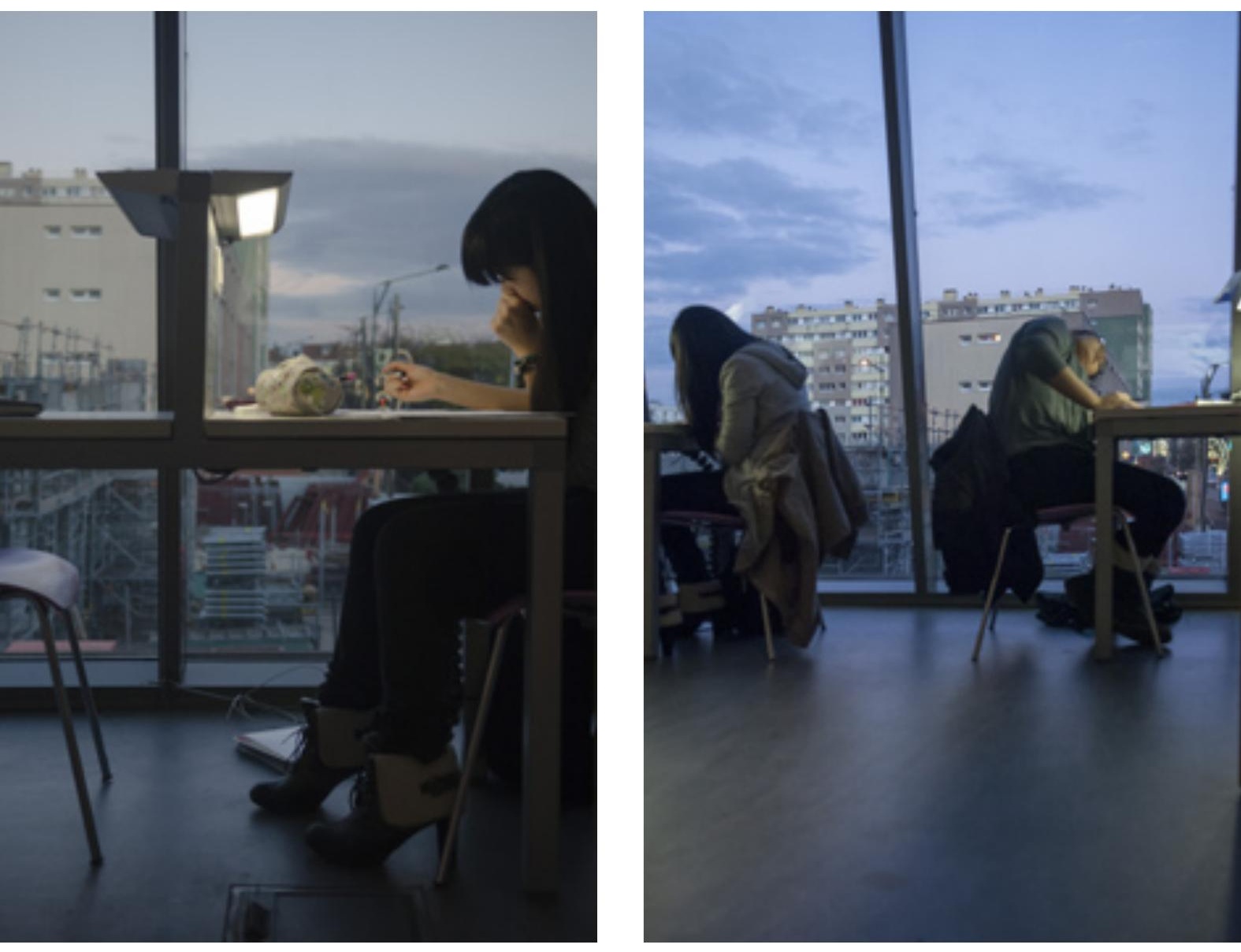


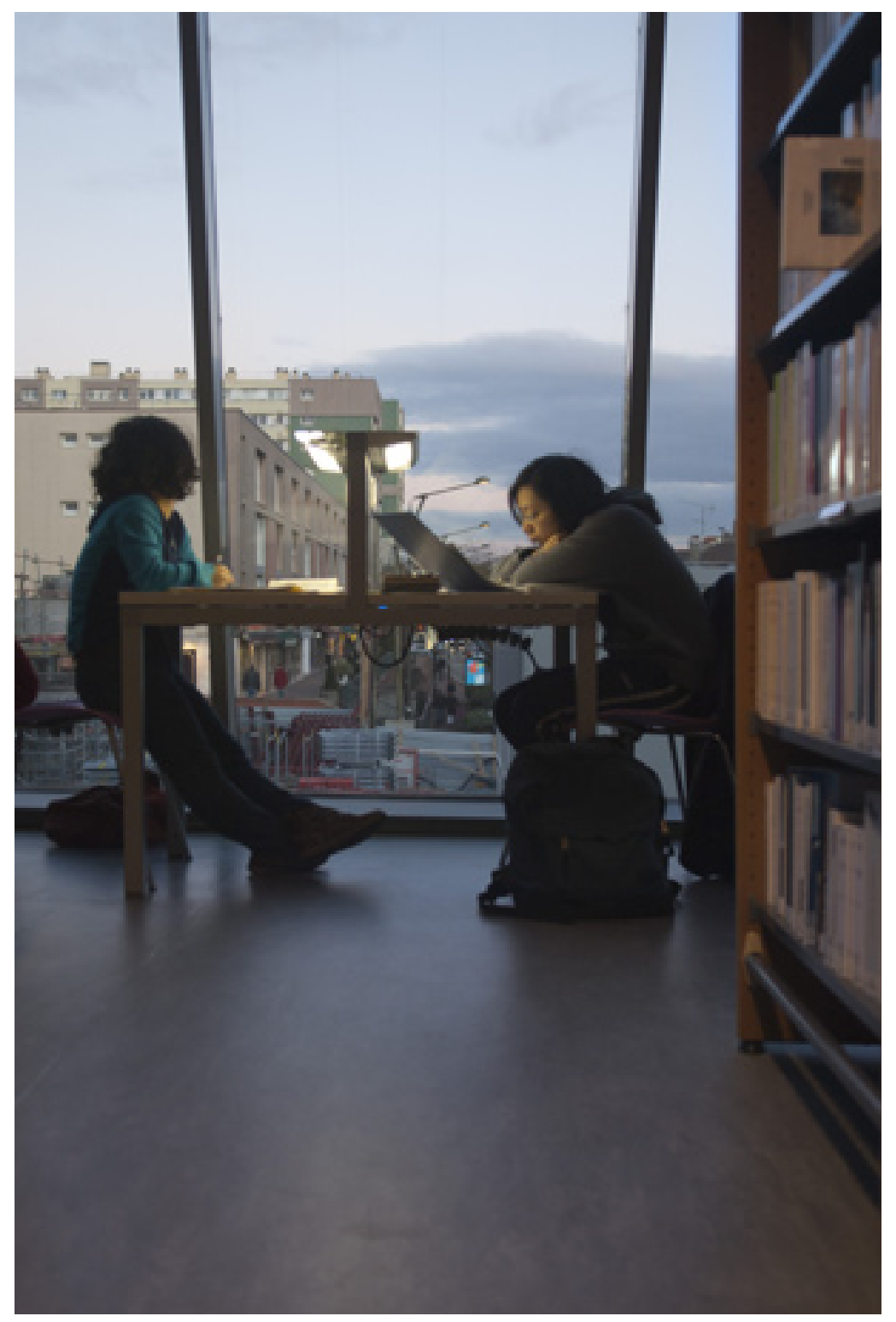




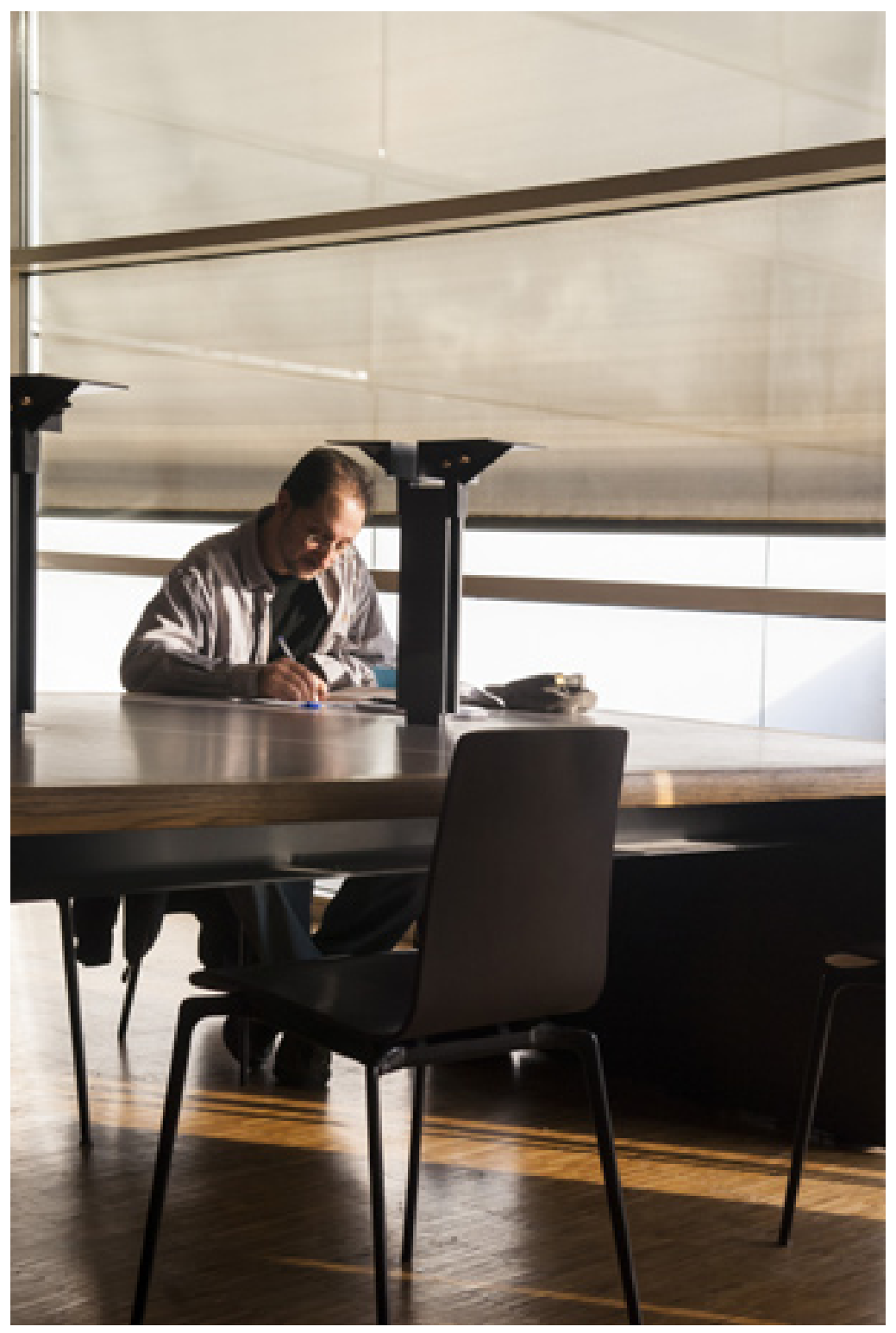



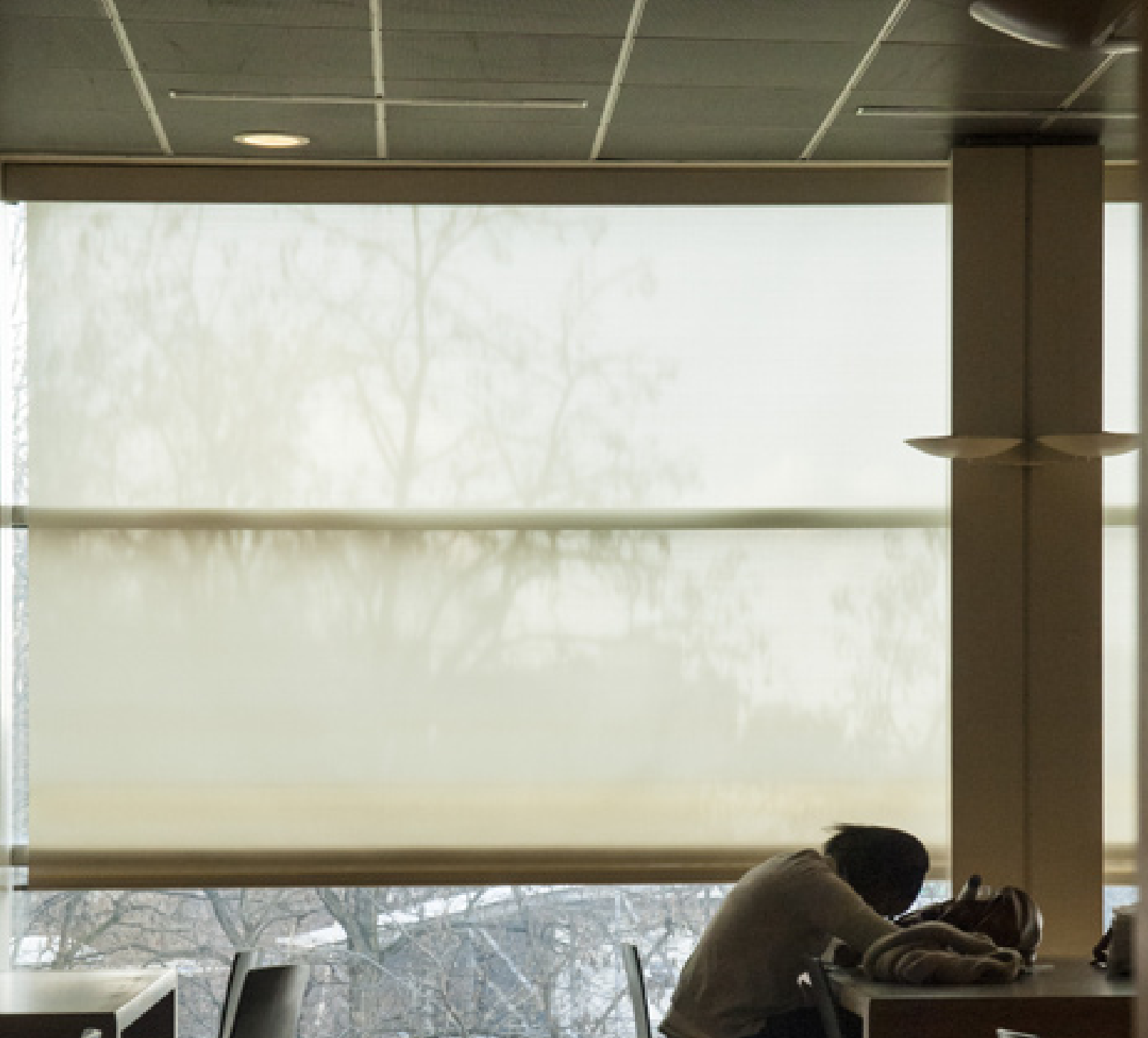


\section{Dominique Fabre}

Bibliothèque de l'Université Paris 8, Saint-Denis

\section{À Paris 8 Saint-Denis}


Jusque tard dans ma vie j'ai eu peur des bibliothèques. Il me semblait que les lecteurs et les personnes qui travaillaient dans ces endroits allaient me percer à jour, je crois bien. Elles allaient se rendre compte que je faisais semblant. En fait, je ne venais pas vraiment pour lire, et, quand j'ouvrais un livre, presque chaque fois, il me semblait qu'au moindre signal, un courant d'air, un rayon de soleil à travers la vitre, une parole entendue, ou ne serait-ce qu'une silhouette s'arrêtant d'avancer dans la rue en contrebas, j'allais me lever et repartir sans même refermer le livre. Je le laisserais sur la table se lire tout seul, au hasard des passages de types comme moi, inoccupés, qui se rendaient adolescents à la bibliothèque municipale d'Asnières pour retrouver leurs copains, s'ils en avaient par là. Ceux dans mon cas voulaient faire une rencontre qui changerait leur vie, et en pensant à ça, changer de vie, je ne veux pas dire tomber sur un auteur de romans, ou sur un grand poète caché dans un rayonnage sans doute éloigné du bureau où d'un côté, ils font les retours, et de l'autre les retraits, exemplaire choisi pour une semaine, prêt renouvelable une seule fois, ou retards avec de petites pénalités, si petites qu'on aurait parfois envie de payer plus, s'il s'agit de livres qu'on a aimés.

Tous ces livres ne finissent-ils pas par tous se ressembler? Un peu comme, à force, dans les motels américains, ces bibles rangées dans le premier tiroir de la table de nuit, parfois avec un annuaire de la ville ou de l'état. Ces bibles vous font un effet un peu différent du phone book dont quelques pages sont inévitablement arrachées. Vous connaissiez quelqu'un ici et vous avez retrouvé ses coordonnées, et peut-être que vous donnerez un coup de fil à cette personne, que cette personne vous répondra, elle se souviendra bien de vous. Dans la grande bibliothèque d'Asnières près de la mairie. Là-bas. Les employés me paraissaient comme fatigués de vivre dans ces milliers de pages cotées, sous les rampes lumineuses, et puis, un jour, la dixième fois que j'allais tuer le temps à la bibli. (j'étais en internat, mais ma mère me demandait souvent de débarrasser le plancher le samedi aussi, d'où le problème de l'accueil, les lieux d'accueil, le plus commun étant le café d'en bas, 
mais je n'en avais pas encore l'âge, bien trop timide aussi pour ça. Et puis il fallait avoir l'argent nécessaire pour acheter un coca) bref la dixième fois, il s'est passé quelque chose pour moi, ensuite j'ai eu moins peur des bibliothèques. On ne rencontre jamais personne finalement, dans les livres. On ne rencontre que des idées de rencontres, on se fait de mignons petits films, et en un sens, c'est bien comme ça. Il nous suffit d'un livre pour commencer, après tout. Ensuite, on n'en finira pas.

En présentant une pièce d'identité, une facture EDF avec une adresse à Asnières, on nous donnait une carte renouvelable, il fallait agrafer sa photo. Chaque emprunt était daté avec un tampon. Dans le livre la bibliothécaire glissait un petit papier où était inscrite la date de retour. Jusqu'à quinze jours plus tard, ou alors huit s'il s'agissait d'un livre très demandé, romans récemment parus ou ouvrages souvent consultés, du fait des examens ou de tel autre moment de la vie des lycées d'Asnières et des environs, puisque la personne à laquelle me fait penser la première bibliothèque venait d'une grande maison de Gennevilliers. J'allais la voir là-bas, eux aussi à Gennevilliers avaient tout le confort possible en matière de prêt de livres et de disques trente-trois tours. Pathé Marconi, la voix de son maître. Deutsche Gramophone, la précision germanique au service de la voix humaine (ai-je emprunté là-bas le premier disque que j'ai entendu de l'anglaise Kathleen Ferrier?), me reviennent toutes ces voix du passé, sur le fond sonore Europe numéro un, on écoutait cette station à la maison. Chez moi on écoutait Max Meynier comme en religion, les routiers sont sympas.

La bibliothèque d'Asnières m'a offert de nombreux samedis qui sont passés plus vite que la moyenne des samedis des années 1975-1980. Cette fille. Elle était bien plus travailleuse que moi. Je faisais semblant du mieux que je pouvais en attendant ses baisers. Parfois elle chipotait: il fallait que j'arrête de la mater ou de bavarder si ça devait servir à quelque chose, les bibliothèques de prêt! Les livres sont toujours là, certains se reposent dans les réserves et d'autres ont été changés, des 
nouveaux exemplaires les ont remplacés. D'autres ont disparu corps et biens. Livres pour toujours oubliés. Je ne suis pas né de la dernière pluie: pourquoi cette idée ne me quittet-elle plus aujourd'hui? Puis, pour moi, il y eut d'autres bibliothèques. Celle de Nanterre n'avait rien à voir avec la même aujourd'hui. La bibliothèque Sainte-Geneviève dont bien souvent, je me sentais rejeté avant même de m'asseoir avec le livre que je voulais.

On remplissait un papier avec le nom de l'œuvre et celui de l'auteur, on présentait sa carte d'étudiant, et lorsqu'on l'avait en mains, il ne fallait pas rester là bayer aux corneilles puisque quelqu'un de payé pour et nettement plus âgé que vous avait pris de son temps pour aller le chercher dans les rayonnages cachés. Puis cette personne avait fait ce qu'il y avait à faire avant de vous tendre l'ouvrage avec un air affairé, parce que les livres se cachent parfois dans des endroits insoupçonnés, surtout lorsqu'on choisit un titre inhabituel exprès pour se justifier d'être là, alors qu'on pourrait être aussi bien ailleurs. Par exemple au stade de foot, assis sur le banc quai B gare d'Asnières à faire le compte des trains qu'on ne prendra pas et des trains qu'on a pris, ou bien, monter dans l'omnibus pour poireauter de la même façon une station plus loin, sur le quai D ou C de la gare de Bécon-les -Bruyères, si proche que le train n'a pas eu tout à fait le temps de prendre une allure normale de train de petite banlieue ouest, et là, plutôt que de lire un livre, ou que de faire semblant de lire un livre en attendant qu'il se passe quelque chose, on fera sans doute semblant d'avoir un rendez-vous urgent, le même train en sens inverse vous mènera sûrement quelque part. Il y aurait une longue histoire à raconter mais justement, il s'agit de ne pas le louper, ce train! Du coup, on passe sa vie dans des livres jamais lus, ou alors trop lus, dans des affaires de trains pas pris et de livres perdus, oubliés, lus et relus, mais en plus, des années plus tard, on s'est complètement égaré au sujet de la bibliothèque de Paris 8 à Saint-Denis, anciennement la fac se trouvait à Vincennes, et justement non, en m'y rendant, je pense à ça. Tout se tient. 

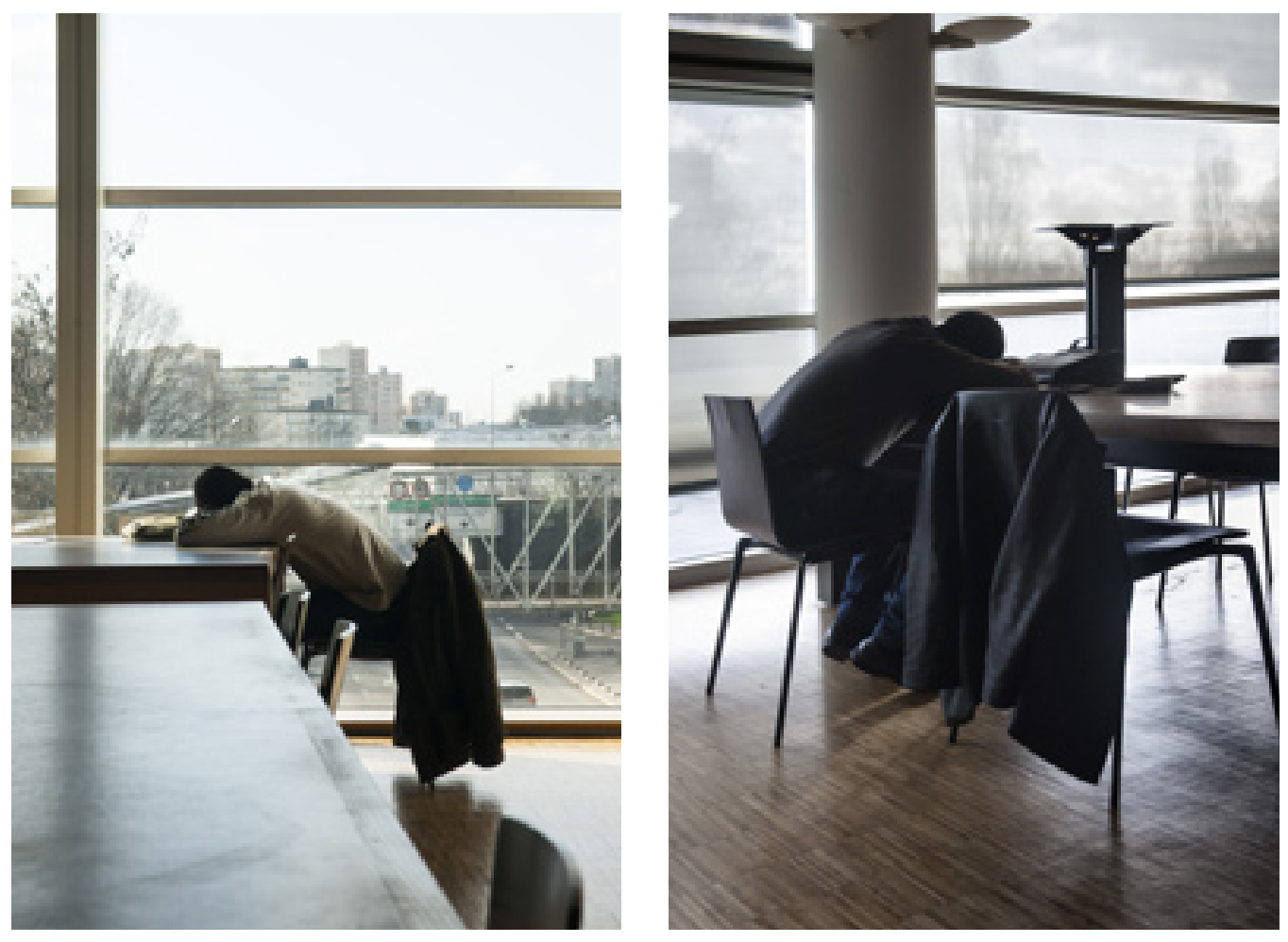


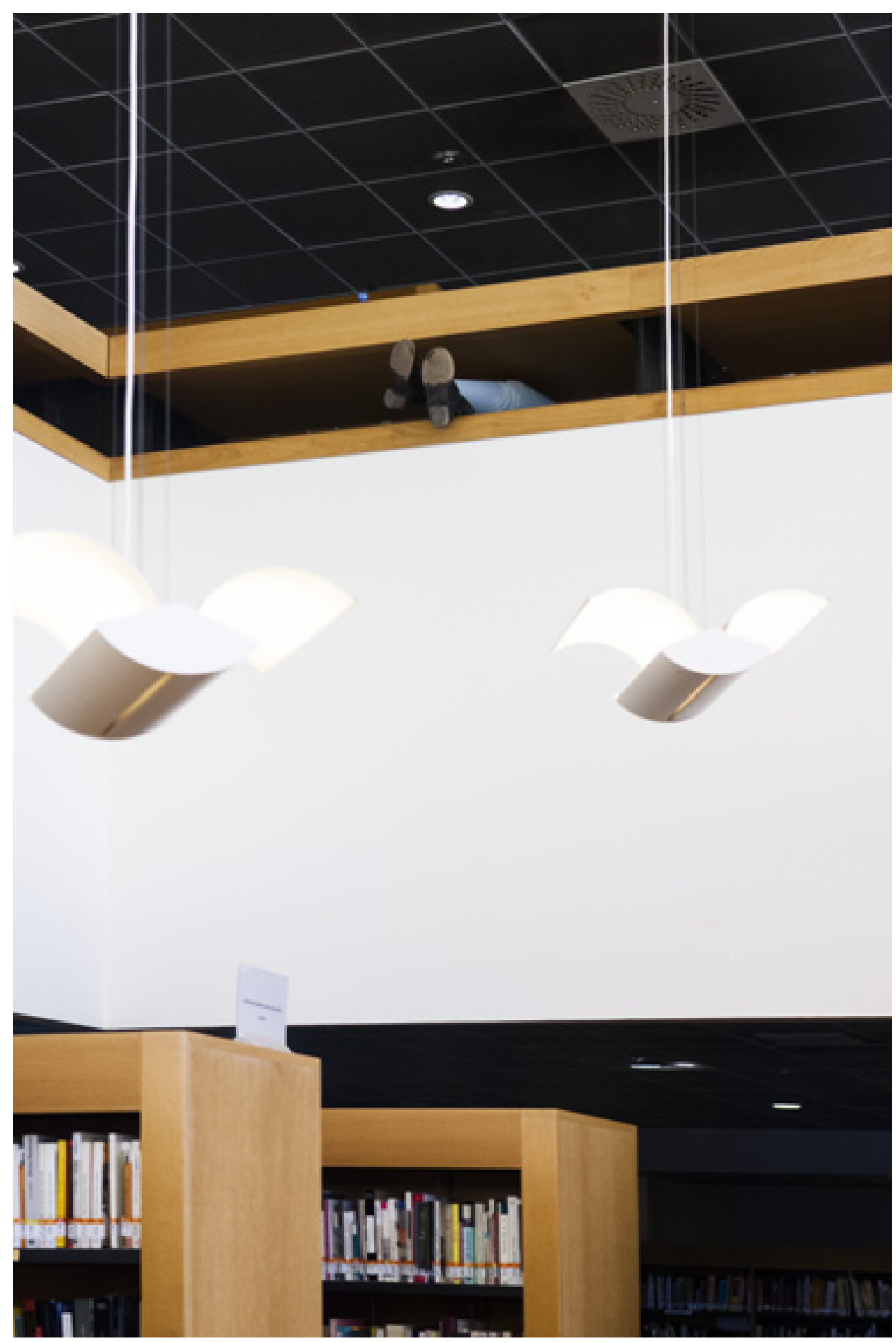




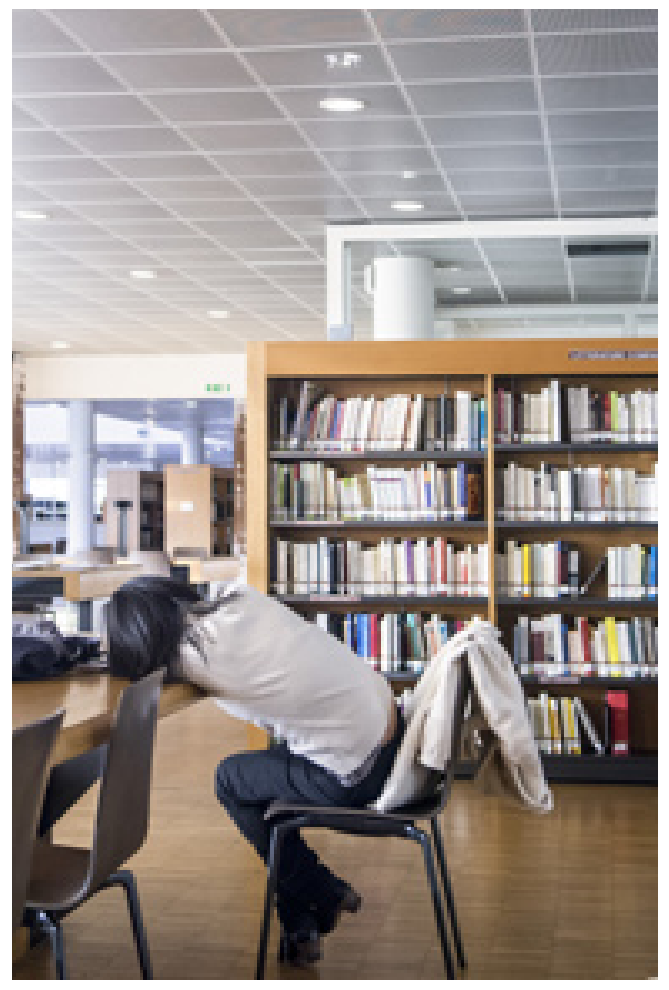




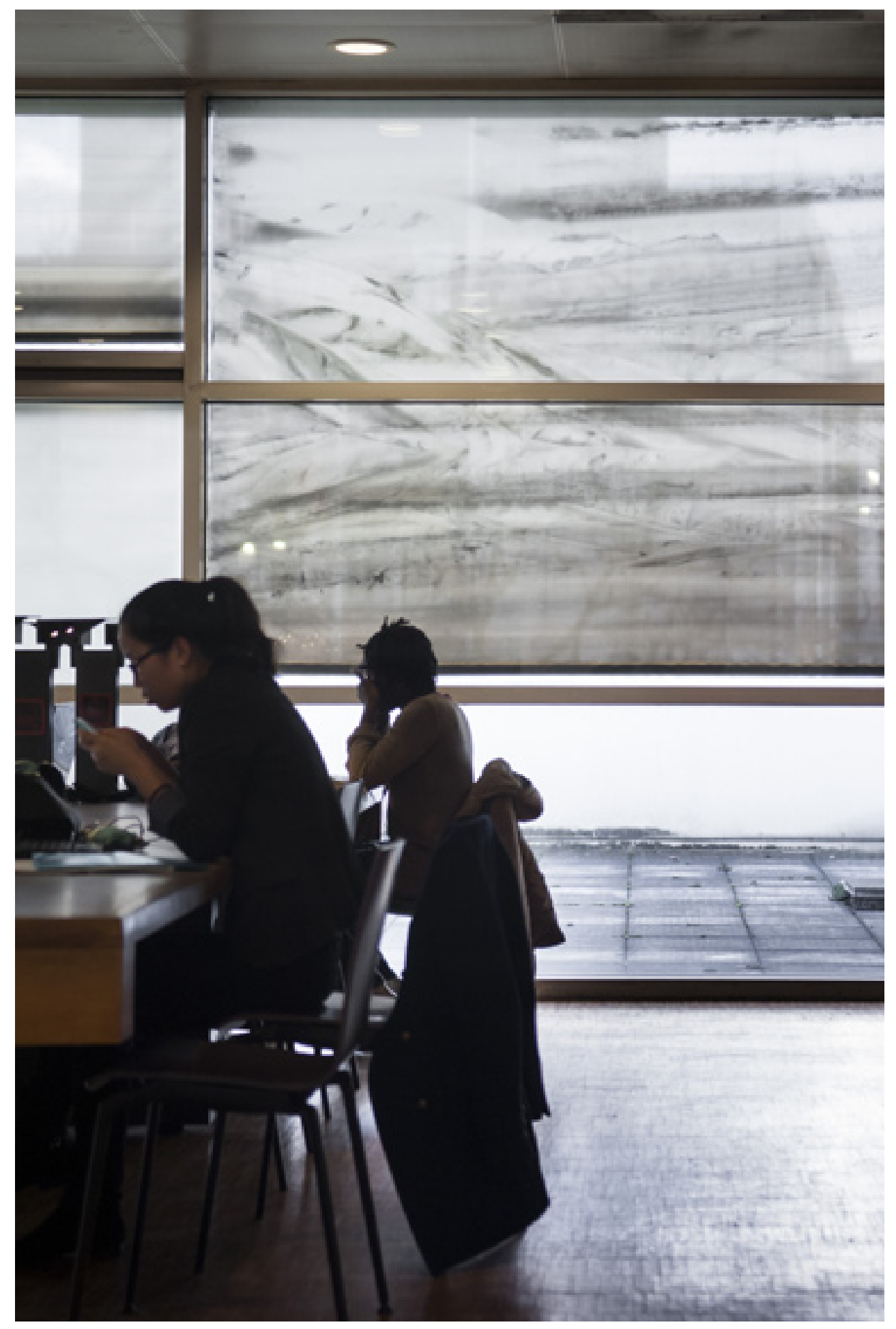


D'autres bibliothèques je me les rappelle aussi, la bibliothèque publique de Santa-Monica (Californie du sud), celle d'Augusta (Maine), des heures et des heures, les bibliobus départementaux, les petites antennes des quartiers lors d'une résidence en Seine-Saint-Denis. Les mercredis des contes pour les enfants, les groupes de paroles de femmes sur les sujets de leurs choix. À l'université de Paris 10, au début des années 1980, les étudiants parlaient à voix haute dans l'entrée, la bibliothécaire leur adressait un petit sourire, avant de leur montrer le panneau: merci de respecter le silence. Le droit de se taire et de lire tranquille, longtemps. Dans les endroits les plus éloignés, certains s'abritent derrière une pile qui déroule des milliers de lignes, des idées pour faire la disserte, ou se raconter de quoi, si l'occasion s'en présente, sur le chemin du RER en direction de Paris.

D'autres, les bras croisés devant eux, avec parfois un petit cahier pour prendre des notes, se sont plongés dès ce matin d'il y a longtemps dans un livre dont ils ignorent qu'il les accompagnera toute leur vie. Ce peut être parfois pour une bonne raison, d'autres fois seulement pour le titre, ou même une jolie couverture... Ils en viennent à bout, dans un état presque hypnotique, ils n'entendent plus le bruit des chaises qu'on tire, le bruit si particulier de qui essaie de ne pas en faire... Ils ne remarquent pas les mouvements des nuages dans le ciel, les nuages de Nanterre s'amassant près des tours rondes de la cité Picasso où, chaque fois qu'on passe par là, les gens se demandent quel genre de meubles peuvent être collés aux murs pas droits dans cette cité? (On ne peut pas s'empêcher de mentir, de dire que les meubles ne sont pas prévus pour les appartements de cette cité-là). Absorbés par un livre ils ne voient pas non plus ceux qui rentrent pour rien, qui pourraient aller ailleurs aussi bien, et ça leur durera toute leur vie. Ils ne matent même plus les belles filles et les beaux garçons qui travaillent sérieusement leurs partiels. Puis, un jeune homme s'en va, il a peut-être des choses à faire, un emploi du soir, quelques heures. 
Azzedine menait de front une maîtrise de droit, un emploi le soir de serveur dans une pizzeria del Arte à Paris, et deux petites amies qui ne devaient surtout pas se rencontrer, car sinon, en plus du reste, il y aurait eu une guerre de clans le soir, dans les rues d'Asnières-Gennevilliers. Alors parfois, Azzedine, quand je le vois à la bibli., a les deux bras croisés devant son livre et ses cheveux bouclés couvrent les pages, ses lunettes qu'il n'a pas eu le temps d'enlever sont tordues, une branche en l'air, comme s'il était vraiment noyé de fatigue sur une table à l'écart, dans le département des sciences humaines. Pendant ce temps, du côté des journaux et des périodiques, les gens qui vont et viennent lisent la presse, à peu près tout ce qu'ils trouvent. Ils fulminent, comparent les gros titres, et, quand ils ont rechargé leurs batteries, ils quittent la bibliothèque avec leur petit cartable qu'ils n'ont pas ouvert aujourd'hui. Mais peut-être ce soir, ou demain, va savoir ce qu'ils y avaient caché de leur vie? Longues années.

Cette mémoire des biblis ne s'efface pas facilement. Elle est accrochée aux livres qui nous ont entourés depuis nos jeunes années. Livres de la primaire, lectures qu'on nous a faites ou pas, quand nous étions des enfants et que nous ne nous couchions jamais tard. Histoires racontées un petit bout chaque soir où j'en étais? ah oui... Livres de chez Gibert achetés d'occasion ou retrouvés neufs, la page de garde en moins. Premiers livres achetés avec votre propre argent qui vous rendent enthousiastes et vous font aimer la vie, elle sera si vite passée. Vous ne pourriez pas en faire un livre mais plutôt dix ou cent, ou aucun. Ensuite, un jour quand tant de livres auront été lus et oubliés, on se dit qu'on ira de nouveau en bibliothèque, avec sa canne et son chapeau. Alors on relira, entre la promenade et l'heure d'acheter le pain à la boulangerie, ces ouvrages qu'on n'aura jamais que croisés dans la vie, dans les bibliothèques de prêt. Il ne sera sans doute pas trop tard? Ceux des grands philosophes qui font «bouger les lignes", sauf qu'on n'a jamais compris pourquoi? Ceux des explorateurs dans des pays qu'on n'a pourtant jamais visités, mais dont on a rêvé souvent, et qui n'ont en fait jamais vraiment existé ailleurs qu'ici. 
Ou, pour les plus chanceux d'entre nous, histoires des pays où on a mis les pieds, mais on avait que le guide touristique et on a seulement effleuré ces légendes qu'on voudrait bien avoir comprises. Livres trouvés sur des bancs, passés par beaucoup de mains, achetés dans des vide-greniers, où on cherche un roman qu'on n'aurait jamais lu avant, comme s'il nous attendait. Auteurs aimés dont on rêve de trouver un inédit, parce que ce fut une telle secousse de les lire. Vieux romans lus dans un train. Entre les pages, on a senti vivre quelqu'un qui a connu les mêmes moments de grâce et les mêmes tourments, nous n'aurions pu le rencontrer ailleurs qu'ici. Livres pour lesquels il faut attendre son tour. Premiers livres interdits lus à la bibli., je me demande encore comment Histoire d'O, Pauline Réage (dévoré), avait atterri près de Romain Rolland (pas fini)? Sur la table de nouveaux arrivages, livres de la collection Terre humaine. Louons maintenant les grands hommes. James Agee Walker Evans. Nos listes personnelles. Comment nous aimons les comparer. Bon, allez hop, la bibli.

La Départementale 29 passe sous la bibliothèque de l'université de Paris 8 à Saint-Denis, mais je ne suis pas venu là en voiture. C'est juste au terminus de la ligne 13, à la station de l'université. Avant, j'habitais aussi ligne 13, mais à l'autre terminus, vers Asnières, la ville où j'ai grandi, il y a une éternité. En tout cas, à part une petite amoureuse (très temporaire) à Saint-Ouen - station Garibaldi - je n'avais jamais eu une occasion sérieuse, en bonne et due forme, de prendre un métro bleu à la station La Fourche, et pas un jaune. Je ne me suis pas dit cette fois-ci, comme souvent ces trente dernières années, qu'il était anormal que les métros bleus soient en général plus prompts à arriver que les jaunes. Je ne suis d'ailleurs pas sûr que ce soit vrai.

Les gens descendent en masse à la station précédente. J'ai assisté à un mini-embouteillage de poussettes, et quelques jeunes personnes en habits, petite coiffe musulmane, teeshirts Nike ou genre de djellaba et grosses chaussures de sport taille 45 se sont occupées de défaire l'embrouille de 
poussettes à deux places serrées dans le même endroit. Ensuite, peu de gens dans la rame, et, sans me tromper cette fois-ci, à la sortie, j'ai emboîté le pas d'une jeune femme vêtue d'une jupe à motifs fleuris, un lourd sac d'ordinateur à son épaule gauche, son pas rapide sur des talons. Tiens oui, l'ordinateur, j'aurais quand même dû venir équipé. D’autres personnes moins estudiantines d'apparence portaient également qui son sac, qui son ordi, qui son pépin, et des variantes des trois. Moi j'étais venu les mains dans les poches, avec un parapluie en torche que j'avais jeté à La Fourche. Quel idiot tu fais, et l'ordi? À vrai dire, n'ayant jamais réussi à travailler vraiment ou à écrire en bibliothèque quand j'avais le temps de le faire, et à peu près certain que je n'avais pas changé tant que ça, je ne me suis dit ça qu'en passant, histoire de me dire quelque chose. Sur le parvis, un restaurant pas cher où on peut manger un couscous, une sorte de brasserie juste à la sortie du métro. Une bonne raison de revenir, je me suis dit, c'est déjà ça! (Ce genre d'informations retient toute votre attention quand il n'est pas loin de midi). Puis, un tabac fermé, la fois suivante aussi il serait fermé, et comme il faisait un temps pourri de pluie personne pour tenir le mur. D'ailleurs, à proprement parler, il n'y a pas de mur à tenir aux abords de l'université et de la bibli. C'est là que j'ai regardé les directions, de part et d'autre de la D 29, qui est donc enjambée par les livres, d'un côté Stains, et de l'autre Villepinte et Pierrefitte, de quoi alimenter une triste chronique des amours banlieusardes, inventées ou sublimées, des années 1980 et suivantes, surtout les suivantes. Un jour, je ne serai plus jamais là. Je n'attendrai plus de bus en me demandant pourquoi? Je ne pourrai plus lire de livres.

La D 29 en cet endroit n'est pas spécialement triste, mais elle est quand même moins poétique que la Nationale 3, par exemple, pour ne pas trop s'éloigner du quartier. Mais ce genre de réflexion vous fait louper l'essentiel, toutes ces routes ne vont nulle part quand il s'agit seulement de visiter la grande bibliothèque de l'université de Paris 8 , à Saint-Denis. Je voudrais ajouter que j'aime beaucoup Saint-Denis, en vrai. 
Du côté de la basilique ils ont fait un très beau travail de rénovation et j'adore les histoires des rois morts de l'histoire de France. Il y a également le stade de France qui me semble l'hommage le plus accompli aux Martiens, extraterrestres ou déjà atterris qu'on a pu leur faire en Europe, à mon humble avis. Sur la passerelle qui enjambe la rue, des phrases sont écrites, avec des mystères à la clé. OÙ AI-JE LU en lettres capitales, et plusieurs énigmes du sphinx, qui est donc passé par ici. Ce n'est pas laid, des jeux de mots de l'Oulipo comme entrée en matière pour ce grand bâtiment. Qui a choisi ces phrases? SEUL ASTRE EXACT UN LIVRE: celle-ci, au sommet, m'a bien plu, on n'est jamais si bien servi que par soi-même, en matière de bouquins.

Dans toutes les visites, il y a toujours un sale bonhomme qui potasse pour poser des colles aux guides. Souvent retraité de l'Éducation nationale, le monsieur ne donne pas non plus de pourboires. J'ai tiré ma langue au chat aux énigmes du sphinx et puis je suis rentré en montrant ma carte d'identité. De manière non conforme à mes souvenirs, les appariteurs et d'ailleurs les bibliothécaires étaient tous unanimement avenants. Et, bien que je n'aie pas hésité à jouer le retraité de l'Éducation nationale, madame la directrice, Carole Letrouit, une jeune femme blonde et énergique, n'a séché sur aucune de mes questions de badaud, bien au contraire. Elle m'a parlé du déménagement de Vincennes, du rôle historique d'Alice Saunier-Séité, de l'engagement de François Mitterrand, des projets d'aménagement en cours, des façons d'ancrer la bibli. dans cette ville bigarrée, d'attirer les gens différents... Il me semblait que j'aurais trop de choses à dire sur la bibli. en en sortant, et plus assez de place pour raconter des histoires sans queue ni tête avec des livres de-ci de-là, qui sont quand même mes préférées! L'architecte, Pierre Riboulet, a aussi tracé les plans de l'hôpital Robert-Debré à Paris, des bibliothèques de Limoges et de Palaiseau, et de plein d'autres bâtiments à usages variés. Il a souvent été imité, ce qui est un gage de réussite, voire parfois de succès. François Mitterrand en a posé la première pierre ou alors est-ce que j'ai rêvé? À l'intérieur 
on se dirige très facilement, grâce à des bannières de couleur pour chaque domaine. Orange, rouge, brun. Ce code couleurs a été repiqué à droite à gauche.

Les tables sont en bois sombre, assez lourd. Des lampes discrètes qu'on peut soi-même éteindre ou allumer. Comme c'est calme! Comment décider où m'asseoir, ici, là, là-bas? Je suis allé regarder sans faire exprès du tout du côté des F, en littérature, exprès pour voir s'ils avaient le dernier ouvrage de Domichnick Fabrazov, l'obscur fameux écrivain turkmène. Je suis désolé de dire que non, mais par contre, d'autres $\mathrm{F}$ de ma connaissance étaient bien présents. Devrais-je en parler à Carole, du Turkmène? Sans oublier, m'avait-elle expliqué, qu'il faut compter avec les grandes réserves de la bibliothèque, laquelle est ouverte à toute personne de plus de 18 ans, et donc, les demandes totalement imprévues, en matière d'ouvrages, mais aussi de films, de documentaires divers, peuvent survenir assez souvent. Impossible de trouver des colles à poser à Carole. 500000 entrées par an. Près de 200000 ouvrages prêtés. J'avais noté comme un studieux apprenti reporter tous ces gros chiffres, mais pas assez soigneusement. À les relire la tête m'en tourne. Je suis ressorti, je suis allé refaire le tour des différentes salles, trouver ma place dans l'une d'elles.

Ici les gens sont plus calmes que dehors, dans la vraie vie. La grande bibliothèque de Paris 8 leur donne à lire, en paix. Ils se tiennent là, il ne faisait pas beau dehors, avec parfois un coup d'œil sur leur portable. Nombre de personnes amènent leur propre ordi, des petits qui tiennent dans un grand sac à main. On n'a pas l'impression que les choses imprimées sont en train de mourir peu à peu, quand on est là. Au contraire, elles nous attendent tranquilles et bien rangées, il suffit de se servir et on voyage. D'autres lecteurs occupaient la rangée d'ordinateurs en prêt gratuit, il n'y avait pas de bruit dans les salles. Je me suis assis seul, à une grande table pour douze, rien que pour moi! J'ai consulté mes notes, mes chiffres tout mélangés, et je n'avais encore rien fait. J'ai essayé pourtant, mais bon, un livre en amène un autre, on en ouvre dix, on en lit une 
moitié, et puis zut il se fait tard, vers la fin. Avant de venir ici j'avais sans doute oublié le luxe d'une après-midi, bien installé, dans les bouquins. J'en ai pris plein les yeux. Je me suis demandé si je ne raconterais pas tout ça d'ici une autre fois ou alors de chez moi? Je n'ai pas décidé. Dans des endroits un peu à l'écart, des petits groupes d'étudiants qui travaillaient vraiment, bien plus qu'on ne le faisait avant, j'allais dire de mon temps, ce qui d'ailleurs est assez irritant à admettre, mais bon. Je serais bien allé me mêler à eux, mais en somme, pourquoi?

Dans le grand couloir d'accès, un écran plat géant annonçait une invitation à rencontrer un cinéaste américain, du genre qu'on applaudit au Sundance festival. Les dates ne collaient pas avec mes activités. On peut passer sa vie dans cette bibli., je crois bien. Ou plutôt, on peut y passer facilement quelques années de sa vie. Cela s'appelle apprendre. On ne le fait pas toujours, mais en tout cas, ici, on le peut. Ça m'aurait plu de le redécouvrir, et d'être de nouveau à l'université. De me mettre à lire comme pas mal d'autodidactes les principales œuvres en partant de A jusqu'à Z. Retrouver les joies les plus durables que nous pouvons avoir, dans cette vie-là. J'y suis retrouvé une semaine plus tard, et là, je n'ai pas hésité sur la table où m'asseoir. J'ai passé une autre bonne après-midi à bouquiner. Au bout d'un certain nombre d'heures, quand je suis ressorti de la bibli. universitaire de Paris 8 à Saint-Denis, je me suis dit qu'un jour, peut-être cet été, je reviendrai lire ici et tenter de répondre aux questions du sphinx peintes sur la passerelle au-dessus de la D29. "Où ai-je lu? »... dans la ligne 13, en attendant la rame, quelques jeunes personnes lisaient un ouvrage emprunté là-bas. Et puis, ils sont montés dans le métro, et en début de ligne, comme il y a des places assises, ils ont rouvert leur livre aussitôt. Alors, la rame a démarré et nous nous sommes éloignés. 


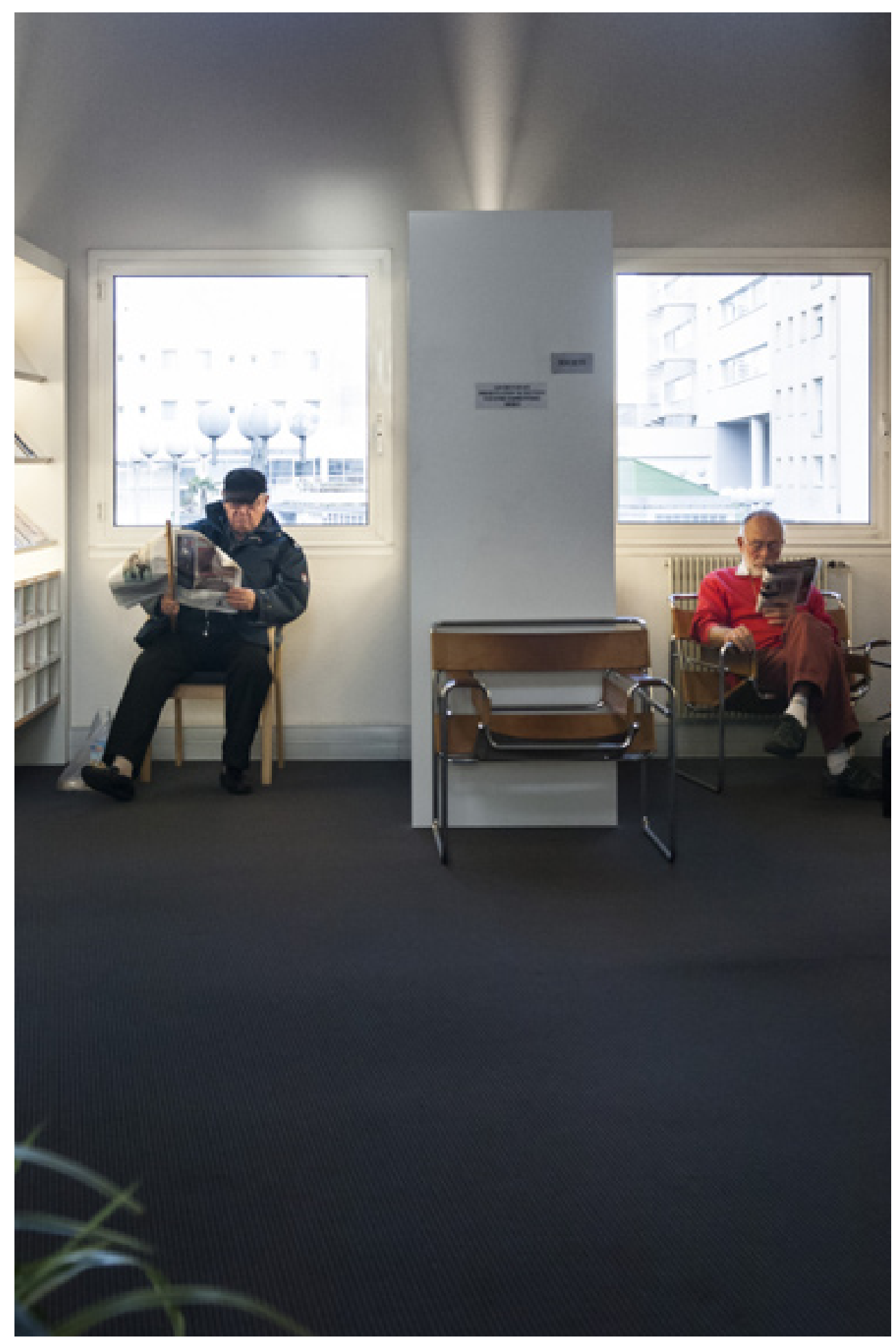




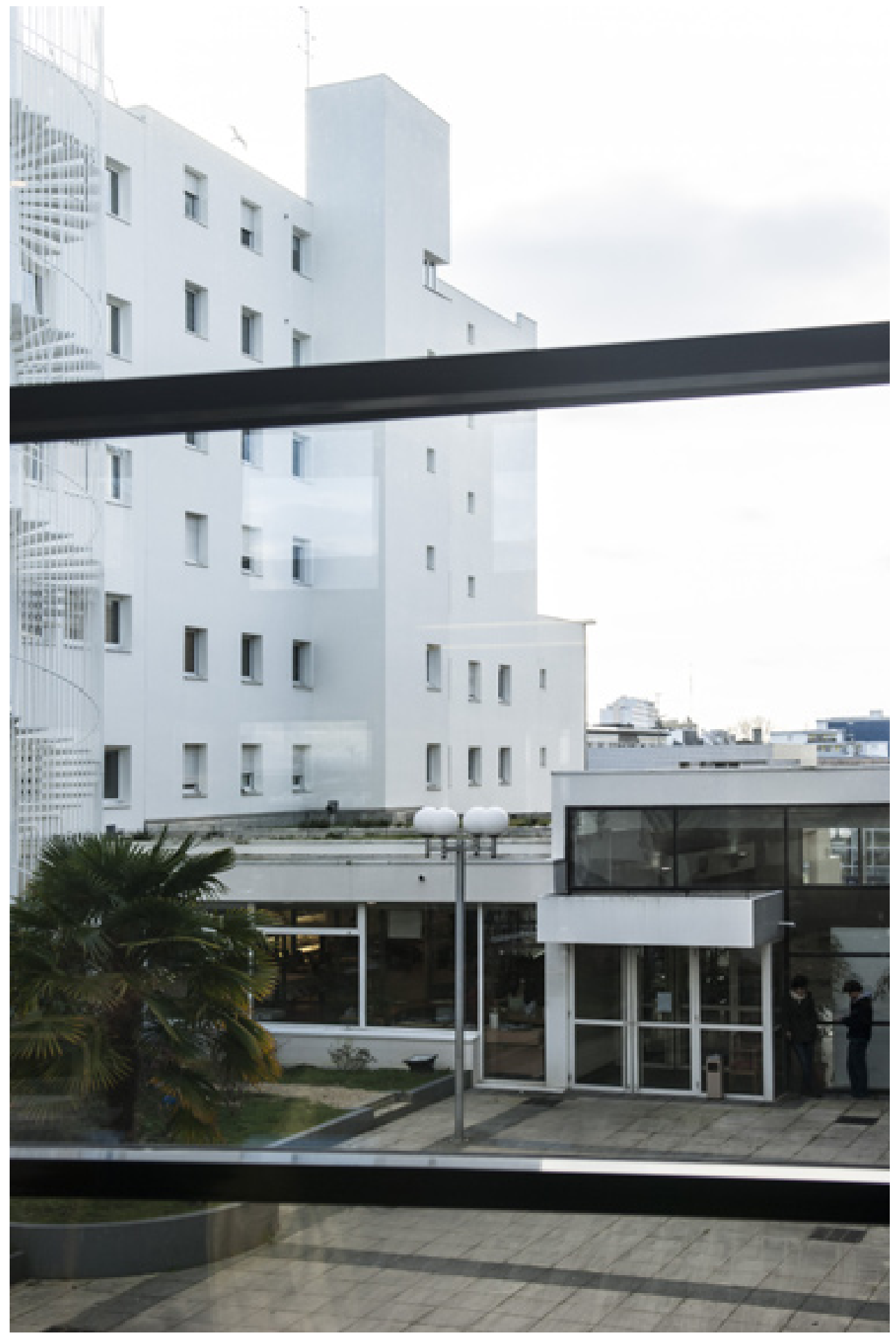




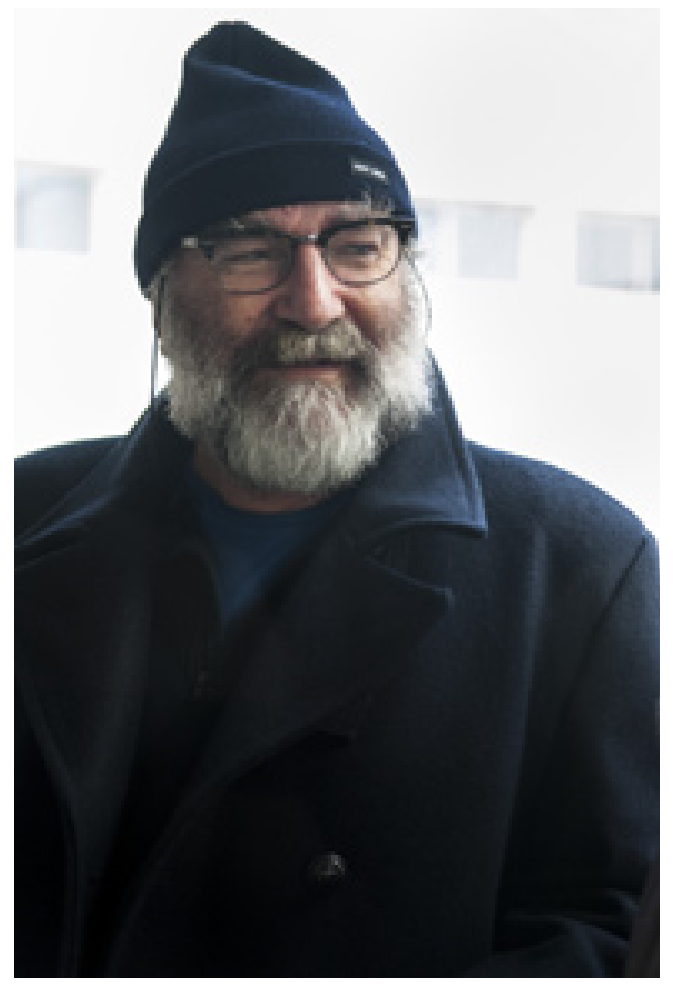


L'homme - ou pourquoi pas la femme? - qui arrachait des pages aux livres, du temps que je travaillais à la bibliothèque de Kervénanec, on n'avait pas réussi à l'identifier. Des lecteurs nous rapportaient, exaspérés, tel des Liaisons dangereuses où manquait la déclaration de guerre de la marquise de Merteuil au vicomte de Valmont, telle un Agatha Christie d'où avait disparu la démonstration finale d'Hercule Poirot, d'autres des livres de recettes de cuisine où ne subsistaient que les alléchantes photos de plats sophistiqués.

Trouver le ou les coupables avait d'abord paru la simplicité même: il suffisait de retrouver sur les fiches qui, précédemment, avait consulté ou emprunté l'ouvrage endommagé. La directrice envoyait une convocation, à laquelle la lectrice ou le lecteur devait se présenter, faute de quoi nous ne pourrions à l'avenir vous confier d'autres documents et nous nous réserverions le droit de poursuivre devant les tribunaux... Les fiches avaient livré les noms les plus improbables: Mme Gosselin, M. Leroy, Mlle Le Guern... fidèles du lieu. Leurs auditions successives n'aboutirent qu'à leurs humiliations. Comment pouvait-on les soupçonner de pareils sacrilèges? Mme Gosselin, en pleine salle de lecture, monta sur une table pour y déchirer, au vu de tous, sa carte d'abonnée. Sans qu'il se livrât à la même véhémente protestation, M. Leroy ne reparut pas non plus. Le plus pénible, en fin de compte, fut la constance de Mlle Le Guern qui continua de venir deux fois par semaine à la première heure et de réclamer Physiologie du goût, invariablement, bien qu'elle se gardât de l'ouvrir, les deux mains parallèles au volume, le cernant sans le toucher, les yeux rouges de larmes qu'elle ne laissait pas couler, jusqu'à midi.

Loin de prendre fin après les renoncements des trois suspects, les déprédations s'étaient multipliées. Nous reçûmes la consigne de surveiller en particulier les lycéen(e) s et les étudiant(e)s, lesquel(le) s butinent dans les rayons et dans les ouvrages pour ne s'emparer que 
d'une phrase par ci, d'un paragraphe par là, pour l'ajuster à d'autres emprunts et composer d'une paresseuse acrobatie leurs devoirs ou leurs dissertations. Mais le ou les vandales procédèrent dès lors de telle façon que les étudiant(e)s et assimilés purent être mis hors de cause: les pages étaient arrachées sans plus aucun discernement, aucune logique, à poignées frénétiques et de toute évidence aléatoires. (Pourquoi supprimer les pages de Moby Dick vouées par Melville à la description de la queue du cachalot? Et pourquoi, dans Hannah Arendt, prélever parmi celles consacrées à d'illustres inconnus comme Waldemar Gurian ou Randall Jarrell plutôt que parmi celles traitant de Rosa Luxembourg ou de Bertolt Brecht?) Nous ne disposions pas hélas à l'époque de ces caméras qui aujourd'hui accompagnent partout tous nos actes et permettent, sinon d'éviter, de reconstituer nombre de nos délits - l'homme, ce délinquant contrarié ai-je lu je ne sais plus où (Cioran? Jean Dutourd? Pascal Bruckner?), et je ne peux que rester persuadée de la pertinence de cette assertion.

Pour autant que je sache, peu après ma nomination à la bibliothèque de Keryado, à Kervénanec les détériorations cessèrent. Je dois avouer que j'étais heureuse de quitter Kervénanec, car l'ambiance s'y était dégradée au sein du personnel. Puisque ni les fiches ni l'observation du public n'avaient permis d'appréhender le, la ou les coupables, nous en étions venus à nous soupçonner les uns les autres. À Keryado, je respirai. Du moins la première semaine.

Parmi les bibliothécaires, j'appartenais à la sous-espèce qui pratique encore la lecture. Le samedi après-midi, juste avant la fermeture, je décidai d'emprunter Le Petit Prince. C'est un livre auquel je voue un attachement béat depuis l'enfance, et que je relisais de loin en loin. Je n'étais pas sans avoir remarqué la médiocrité de son style, mais le charme de ses dessins la compensait largement. Et surtoutj'entendais, 
de page en page, la voix fluette, espiègle et comme désaccordée de mon père qui le premier me l'avait lu.

Le dimanche dans l'après-midi, après avoir fait la vaisselle, je m'installai sur le canapé de mon bow-window, et j'ouvris, pour la centième fois peut-être de mon existence, Le Petit Prince. C'est, chacun le sait, un ouvrage très mince, ce qui sûrement contribue à sa gloire, moins de cent pages dans l'édition que j'avais entre les mains. Quand j'en fus à la page 49, au chapitre XIV, je faillis avoir une attaque. La cinquième planète était très sale, était-il écrit. Or je me souvenais parfaitement de la voix de mon père à cette entame, La cinquième planète était... et comme il détachait le groupe attribut très curieuse. Curieuse et non sale. Sale n'appartenait pas au vocabulaire du Petit Prince, j'en étais certaine, en tout cas ne qualifiait certainement pas la cinquième planète à l'orée du chapitre XIV. J'avançai avec appréhension dans le chapitre qui était celui, fameux, de l'allumeur de réverbères. Le texte ressemblait à celui de Saint-Exupéry, mais en différait scandaleusement.

- Bonjour. Pourquoi viens-tu d'éteindre ton réverbère?

Demande le petit prince. Ceci était conforme. Mais pas la réponse:

- C'est la grève, répondit l'allumeur. Bonsoir.

Dans Saint-Ex, aucune mention de grève. Mais de consigne. Et l'allumeur ici, emploie, le Bonjour et non le Bonsoir qui est pour la réponse suivante. Et l'imposture se poursuivait tout au long de la page 50 en face de la 51 où grâce au Ciel figurait le dessin authentique, si déséquilibrant et si bien équilibré de l'allumeur penchant d'un côté, son réverbère de l'autre, et, comme du ventre de sa planète, le cercle rouge orangé du soleil surgissant à demi, précédé de segments de rayons également rouge orangé.

Je ne vais pas retranscrire toutes ces mutilations. Je n'en donnerai que deux autres exemples.

- Mais le rôle d'un allumeur de réverbère ne consiste-t-il pas à allumer? 
- Précisément répondit l'allumeur. Mais la grève c'est la grève.

Et plus loin:

- Et c'est pourquoi la grève! La planète d'année en année a tourné de plus en plus vite, et la paie n'a pas changé.

Et entre les deux, une cascade de torsions, d'inversions, d'insertions, qui défiguraient la si poétique rencontre imaginée par l'auteur.

J'abordai avec circonspection la page 52, mais plus trace de modification, me sembla-t-il. Et jusqu'au dernier paragraphe du livre:

Regardez le ciel. Demandez-vous: "Le mouton oui ou non a-t-il mangé la fleur? »

Jusqu'au dernier mot: d'importance! Le Petit Prince était tel que dans ma mémoire l'avaient gravé la voix de mon père et ravivé tant de lectures depuis.

Je revins au recto verso des pages 49 et 50. Maintenant que je les savais dépareillées du reste du volume, je remarquai que le papier en était un peu moins gris, l'encrage un peu plus prononcé... Mais c'étaient là des différences si peu prononcées que même des yeux aussi exercés que les miens n'y avaient d'abord vu que du feu. Caractère et corps étaient exactement ceux des autres pages. Les retraits, les espaces tout avait été reproduit à l'identique. Du travail d'expert, je peux l'attester, l'une de mes tâches de bibliothécaire étant, dans la mesure du possible, la réfection des ouvrages.

J'étais à présent sur mon canapé de bow-window la proie de questions vertigineuses. Depuis quand ce Petit Prince avait-il été perverti? Combien d'autres volumes de Keryado avaient subi pareils outrages? Devais-je alerter mes collègues, mes supérieurs sur ma découverte? Ou la leur dissimuler? Et en cas, jusqu'à quand?

J'essayai de me répondre point par point. Impossible de savoir de quand datait la détérioration volontaire de cet 
exemplaire. Sa fiche aurait beau désigner son dernier emprunteur avant moi, comment savoir si lui-même n'avait pas eu entre les mains cette même altération des pages 49 et 50 ? Tout le monde n'a pas disposé d'un père pour lui lire et relire les aventures interplanétaires de ce garçonnet à la tignasse jaune, aquarelles de l'auteur. Tout le monde ne les connaît pas par cœur et ne sursaute pas si l'allumeur de réverbères, au lieu de consigne parle de grève. Plusieurs lecteurs sur plusieurs mois, et qui sait davantage, vivaient avec le souvenir d'un allumeur de réverbères faisant grève au lieu de suivre la consigne.

La première vérification à laquelle je me livrai, dès le lundi, fut si cette détestable version apocryphe du Petit Prince corrompait tous les exemplaires du texte disponibles à la bibliothèque de Keryado (il en existait quatre, dans trois éditions différentes), ou seulement celui que j'avais emprunté. Par un hasard extraordinaire, tous étaient sortis ce week-end-là, et je me dus me résigner à attendre leur retour pour opérer, avec la plus grande discrétion, l'examen des pages 49 et 50 dans une édition, du chapitre XIV dans les autres.

Un nouveau week-end accourut, sans qu'aucun Petit Prince soit revenu. Il est vrai que notre règlement autorise des emprunts de documents d'une durée de trois semaines, très excessive à mon avis, mais qui se soucie de mon avis? Histoire de ne pas perdre de temps, j'empruntai pour vérification L'Étranger d'Albert Camus dans une édition de poche, autre texte à mes yeux très surestimé, mais je n'appartiens pas davantage aux faiseurs de gloire qu'aux faiseurs de règlements.

Comme la semaine précédente, j'attendis le dimanche après-midi et de m'être installée dans le bow-window pour entamer ma lecture. Je n'eus pas longtemps à attendre pour constater que j'avais eu du flair. Première phrase: Aujourd'hui, papa est mort. Et peu après: J'ai reçu un télégramme 
de l'asile: Père décédé. Curieusement, cette fois, ce roman qui m'avait laissée de glace quand il m'annonçait qu'Aujourd'hui, maman est morte... m'étreignit dès l'incipit et je le lus d'une traite. Et quoique le faussaire n'ait pas poursuivi ses méfaits plus loin que la deuxième page, machinalement, en lisant, je remplaçai Maman par papa, ma mère par mon père, et je prolongeai ainsi jusqu'à la dernière ligne l'émotion initiale.

Il me fallut la plus grande maîtrise de moi-même pour résister à la tentation de révéler à mes collègues le lièvre que je croyais avoir levé: quelqu'un à Lorient rectifiait les chefs-d'œuvre officiels de notre littérature. Je ne pouvais être tout à fait sûre de moi que je n'aie pratiqué quelques autres sondages. Le lundi soir j'empruntai Proust, le mardi Madame Bovary, le mercredi Le Rouge et le Noir, et ainsi de suite le jeudi Alcools, le vendredi Andromaque, le samedi les œuvres complètes d'Arthur Rimbaud... Je ne dormis que trois heures par nuit cette semaine-là. J'étais au comble de l'épuisement et de l'exaltation comme de l'indignation.

Mon intuition se vérifia plus qu'abondamment. Longtemps, je me suis couchée de bonne heure, prétendait la narratrice (!!!) d'À la recherche du temps perdu, embarquant sur sa fausse piste dans les quatre premières pages de cette édition qui n'était pas de «La Pléiade», dont le papier bible trop mince n'aurait pas supporté sans de trop visibles dégâts l'arrachage et la réinsertion - je parle d'expérience. Sous le pont Mirabeau coulait la Loire, la joie venait toujours après le boire, et autres monstruosités que je m'arrête là d'infliger au lecteur. Flaubert subissait les coupes que le procureur Pinard aurait voulu que la Justice lui assignât (la scène du fiacre, le détail de l'orteil sur le lit de mort...), Le Bateau iure descendait des fleuves inflexibles, Julien Sorel s'exaspérait d'apprendre que Madame de Rénal avait réchappé de son attentat... Baste. Qu'il me suffise de souligner que la profanatrice (en moi-même je penchais de plus en plus pour l'hypothèse d'une aigre lectrice) ne 
manquait pas plus de culture et d'imagination que d'habileté technique.

Une nouvelle semaine s'ouvrit, où j'entrai à reculons. À qui allais-je donner la primeur du gouffre que je venais de mettre au jour: on pouvait craindre qu'à Keryado, pas un seul monument de la littérature française, ou peutêtre mondiale, n'avait subi d'acte de vandalisme... À quel (le) collègue? Ou à quel (le) supérieur(e)? J'avoue que j'effectuais trop distraitement mes tâches ordinaires du lundi, l'esprit assiégé par les questions. Allions-nous devoir relire tous les livres en stock? Prévenir les lecteurs les plus récents des ouvrages défigurés et entraîner de leur part une méfiance généralisée à l'égard de tous les documents (terme de notre jargon) à leur disposition sur nos rayons et dans nos magasins? Quelle perspective était la pire: que notre public, du coup, renonce à la lecture ou qu'il se figure connaître le véritable Proust, l'authentique Racine, alors qu'ils n'avaient eu en main que des contrefaçons grotesques?

J'en étais là de mes tourments quand je fus convoquée par le directeur. Je n'avais eu d'entretien particulier avec lui qu'à mon arrivée à Keryado, peu de temps auparavant. Je tremblais... on dit comme une feuille, je dirai comme cent pages. C'était un homme à fossettes et risettes, impénétrable. Il me fit signe de m'asseoir, ne me quittait pas des yeux. «Nous nous connaissons à peine, et déjà vous allez devoir nous quitter», dit-il.

Je me liquéfiai... J'entendais déjà faute grave, conseil de discipline, licenciement, radiation non seulement de la lecture publique mais de toute fonction publique... Mais comment pouvait-il... Par quel diabolique instinct... Pourquoi devançait-il la révélation que...

«J'ai vu vos derniers emprunts...»

Il laissait d'insupportables blancs entre des segments de phrases.

«Vous me pardonnerez mon indiscrétion, mais elle m'a permis d'apprendre...» 
Comment ai-je résisté à la tentation de me lever et de m'enfuir?

«... que vous aviez un appétit peu commun en matière de littérature. Un peu tourné vers le passé, certes... - Le passé est l'avenir du livre», dis-je.

Où avais-je été pêcher pareille réplique? Tais-toi, grands dieux, tais-toi!

«Peut-être pas, allons. Mais ce que je voulais dire... Les pâtissiers, paraît-il, mangent peu de gâteaux. Et nous, bibliothécaires, nous le savons bien, consommons en moyenne de moins en moins de livres... Je vous félicite, donc, et je comprends mieux ainsi...»

Il rétrécissait encore ses yeux. S'il est un jeu que je déteste, c'est celui du chat et de la souris.

«... qu'on fasse appel à vous pour la nouvelle bibliothèque centrale.»

Finalement, en haut lieu, on avait décrété l'ancienne trop exiguë, et on avait opté, en vue de l'agrandir, pour des locaux situés dans un ensemble moderne qui, au départ, devait accueillir des sociétés, des bureaux. La bibliothèque centrale n'était plus tout à fait au centre de Lorient et, personnellement, me fit assez penser lors de son inauguration, à un magasin de surgelés. Mais il est vrai qu'en l'occurrence non plus nul ne m'avait demandé mon avis sur le type de bâtiment que devait être une bibliothèque. Je le confesse ici: une bibliothèque doit accueillir le moins de monde possible et n'est jamais assez exiguë. Pour deux raisons au moins, que je tirais de mon expérience et j'ose même écrire: de mon exemple. La première est que les livres ont tendance à abîmer les humains, à les éloigner de leur salutaire animalité. La seconde est que les humains ont tendance à abîmer les livres, je n'en donnerais pour preuves que mes découvertes à Kervénanec puis Keryado.

La nouvelle bibliothèque centrale allait à l'encontre absolument de mes intimes convictions. Elle était lumineuse, 
spacieuse, les sièges y étaient confortables, elle risquait d'attirer jusqu'à des gens que n'aurait jamais effleurés le vertige d'ouvrir un livre et qui s'y prélasseraient de l'ouverture à la fermeture, des CD ou des DVD dans le casque, ou même qui se verraient offrir des formations, en informatique ou en english, je t'en fiche. Quel rapport - la musique! le cinéma! la formation! - avec le rôle, la tradition des bibliothèques? J'avais subi sur le sujet des communications, des stages, des circulaires, sans protester ni contester. On avait pris pour du zèle ce qui n'était chez moi que le mouvement d'approbation exagérée par lequel l'ironie se gausse de son objet. De sorte que j'étais censée avoir appelé de mes vœux le paradis conceptuel que j'étais conviée maintenant à inscrire dans la réalité et autres billevesées.

Parmi ceux qui s’inscrivaient dans la réalité de la médiathèque François-Mitterrand puisque tel est son nom, il y avait, vu la modicité pour eux des tarifs d'abonnement, des clochards, appellation qu'on me pardonnera de persister à trouver moins hypocrite et même plus chaleureuse que l'acronymique SDF. Il en fleurissait de plus en plus dans cette partie de la ville, proche de la gare où ils arrivaient allez savoir d'où, de Bretagne ou d'Afrique, de Pologne ou d'Amérique latine. Avec leurs cartons, leurs bardas et leurs chiens, ils occupaient certains porches et la plupart des abribus, mais lorsque le froid était trop vif ou la pluie trop violente, on en voyait refluer vers notre hall et investir les fauteuils de nos salles de lecture.

Une fois surmonté mon haut-le-cœur à la découverte de ces mœurs, je réfléchis aux opportunités qu'elles m'ouvraient. Je me mis à offrir mon visage le plus avenant à ces miséreux (parmi lesquels quelques jeunes femmes livides et déjà édentées), et plus d'un prit le pli de venir emprunter à mon rayon, de littérature policière. Et le soir, quand je quittais la médiathèque, il n'était pas rare, boulevard Dumanoir ou cours de Chazelles, que je sois hélée depuis un sac de couchage et même invitée à partager une 
canette ou un canon. J'appris les noms ou les surnoms d'une bonne douzaine, leurs parcours parfois. Général par exemple racontait avoir été mercenaire au Congo, Marylin m'affirmait que grâce à la bibliothèque (elle avait la grâce d'user encore de ce terme), elle sentait qu'elle allait reprendre pied et comme je n'avais sans doute pas l'air suffisamment convaincue de la pertinence de son pronostic, elle ajoutait:

«Sans déconner, Marianne.»

(Pas de "Madame» entre nous, je la jouais assistante sociale. Et pour ce public particulier je m'attribuais le prénom que mes parents, s'ils avaient eu des convictions républicaines, auraient tenu à étaler sur la personne de leur fille au lieu, pour exhiber leur nostalgie royaliste, de la baptiser Marie-Antoinette.)

Un soir, on m'en présenta un que je n'avais jamais vu à la médiathèque. Haut-Fourneau, l'appelait-on. On me dit qu'il avait travaillé dans la sidérurgie, dans un lieu au nom d'ange, comme en Lorraine presque tous. Qu'il grêle ou qu'il vente, Haut-Fourneau refusait, appris-je, d'entrer sur notre site, ou même d'en approcher. À cause du nom, finitil par me cracher. Ce type-là le poursuivait. Il aurait oublié tous les noms de la terre, et jusqu'à ceux de ses propres enfants, qu'il se souviendrait encore de ce nom-là. Ce nom-là, il l'avait gueulé sur tous les tons, collé, distribué. Au temps où il allait aux réunions, aux manifs. Où il avait du taf. Où il avait peur de le perdre. Où il avait cru qu'avec ce type il allait le garder. Où il avait compris qu'avec ce type il le perdrait, pareil ou même encore plus vite. Après, s'il s'était mis à boire et à battre sa femme, s'il s'était vautré dans tous les clichés de la déchéance, s'il avait fini par se faire expulser de son toit et enfermer en prison, d'accord c'était sa faute et pas celle du type. Encore que, si tu grattes... Si tu sondes... Si tu pioches...

"Changez de nom, et je viendrai comme tout le monde», conclut Haut-Fourneau. 


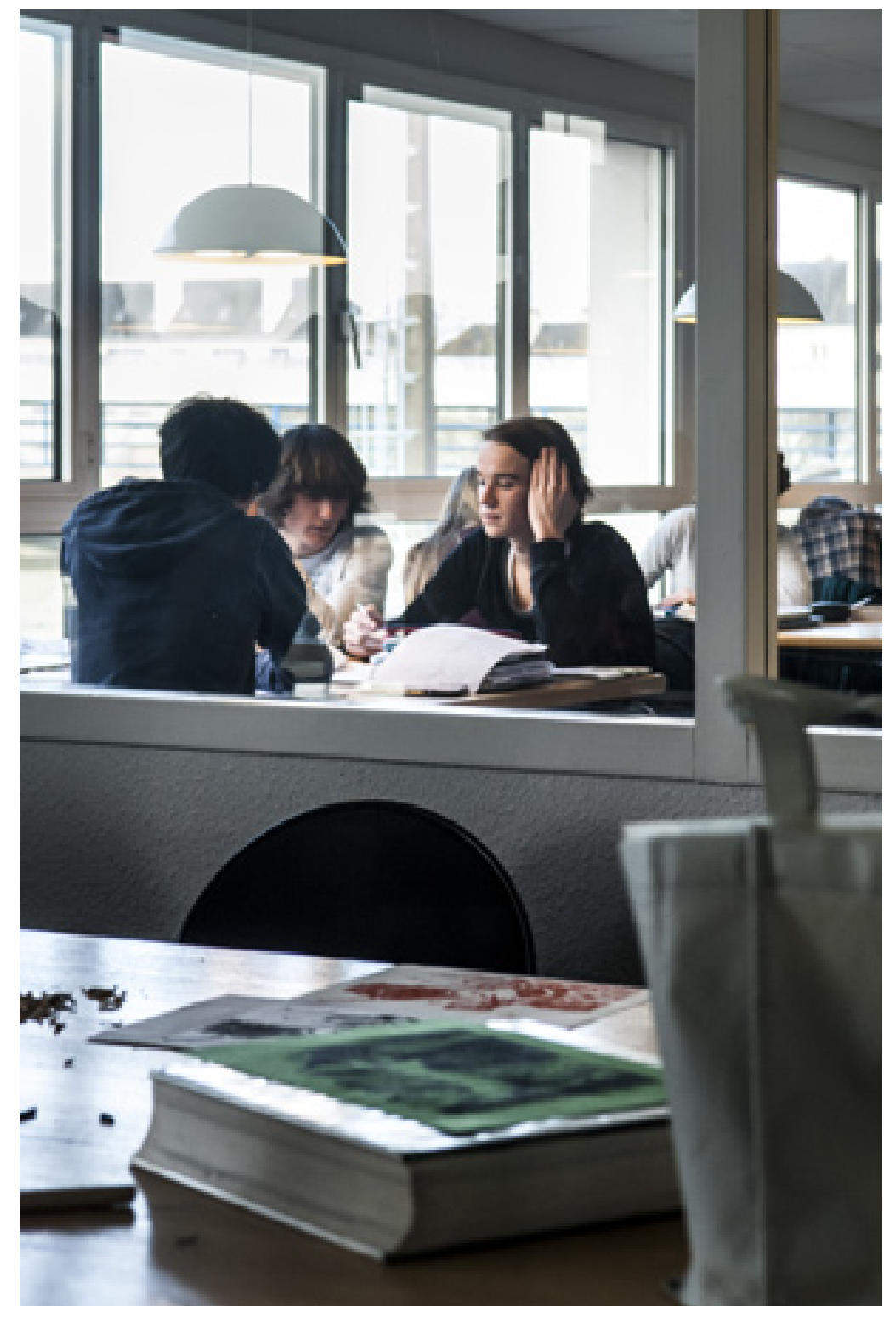


Je lui expliquai que ce n'était pas demain la veille qu'on allait débaptiser notre médiathèque, et en cela je ne mentais pas. J'ajoutai, ce qui en revanche contrevenait à la vérité:

«Et d'autant moins qu'elle regorge de portraits, d'études, de souvenirs, que ce soit sous forme de livres, de disques ou de vidéos consacrés à François Mitterrand. »

J'eus l'impression d'avoir ainsi rajouté un peu de combustible à ce Haut-Fourneau. J'étais bien loin, Maître, de deviner l'usage qu'il en ferait.

Deux mois à peu près après mon arrivée à la Médiathèque François Mitterrand, des gens commencèrent à rapporter, furieux, des romans policiers où dès sa première apparition dans le texte le nom du meurtrier ou de la meurtrière était souligné au feutre, ou surligné. Dans les romans noirs c'était sans importance, mais dans les polars anglais ou scandinaves, avoir dès l'entame l'œil attiré sur un personnage dont l'auteur s'échinait à dissimuler la culpabilité, vous privait de l'essentiel du plaisir. Je me plongeai dans les fiches et découvris, ô stupeur, que ces dégradations, quoique minuscules si grandement dommageables, correspondaient chaque fois non pas à un prêt et à une sortie de la médiathèque, mais à une consultation sur place, et chaque fois par quelqu'un bénéficiant de l'abonnement le plus bas... Autrement dit, un clodo. Je fis part de ce pénible constat à ma supérieure, et je pensai qu'on allait en conclure (enfin!) à la suppression de l'accueil de ces personnes qui déparaient la conception, indestructible en moi, de ce que devait être une bibliothèque.

Hélas c'est l'époque à peu près où, à Keryado, des gens commencèrent à remarquer certaines bizarreries dans L'Étranger, À la Recherche... ou Le Rouge et le Noir. Et c'est l'époque aussi où à Kervénanec, on s'étonna que depuis mon départ plus personne ne rapportât d'ouvrages aux 
pages arrachées. La directrice du réseau des bibliothèques de Lorient (une femme à la redoutable gaieté) passa une fin d'après-midi (grise, tellement grise) la tête par la porte de mon bureau:

«Vous auriez un moment, Marie-Antoinette?»

À cet instant, je compris, Maître, que si je voulais continuer d'exercer la noble profession de bibliothécaire, ce ne pourrait être qu'à la prison de Rennes. À cet instant aussi (dans ma mémoire, au moins, les deux instants se confondent), des cris venus du rez-de-chaussée nous alertèrent: un incendie venait de s'y déclarer. À cette heure-là, la médiathèque était fermée aux lecteurs. Restait le personnel. J'étais incertaine sur ce que je souhaitais: que nous en réchappions, tous, ou que j'y périsse parmi les cendres de tant de pages. Mais j'étais sûre qu'il s'agissait d'un incendie criminel et que, seule, je connaissais l'identité du pyromane. Pensez-vous, Maître, que je pourrais négocier contre la révélation de cette identité mon maintien dans la fonction? 
Jacques Séréna

Bibliothèque de la Roseraie, Angers

\section{Elle est ici chez elle (La bibliothèque de la Roseraie à Angers)}


Tu es quelqu'un qui ne s'attarde jamais, qui reprend toujours le premier train après ta prestation, en principe. Et tu penses que dans cette ville ce sera pareil. Au départ, tout se passe comme d'habitude. Tu débarques, c'est le soir, on te fait souvent arriver la veille. L'avantage, c'est d'être déjà sur place, d'éviter l'angoisse d'arriver trop tard pour ta lecture publique, à cause des sempiternels retards de trains. L'ennui, c'est la soirée à tuer. Du temps de vie pas forcément mortel, si on sait s'y prendre, et tu sais, à force. Tu laisses ton sac à l'hôtel, dans ta chambre toujours trop belle pour y être seul, avec la télé d'aucun secours, plus envie de tenter le coup, gâcher encore une heure précieuse à zapper en vain, mêmes têtes, mêmes mots, formules éculées. Vérifier une fois de plus que toujours, partout, seuls les lourds ignares ne doutent pas une seconde d'eux.

Te reste la balade en ville. Pour la sensation de te sentir étranger, te dire que ceux qui te connaissent ne savent pas que tu es ici, et ceux qui te voient ici ne te connaissent pas. Et rien de spécial à faire, marcher de-ci, de-là, t'en remettre au hasard, te remettre en jeu. Le trip nowhere man in nowhere land for nobody. Tu passes devant des bars, pleins d'alcoolos tristes, tu n'es pas triste, pas alcoolo. Mais tu n'exclus pas, on ne sait jamais, si rien d'autre ne se présente, faute de mieux. En attendant, il n'est pas si tard, tu marches, tu espères. Et tu tombes sur une sorte de vernissage, galerie d'art, cocktail. Tu as ta belle veste, la bonne allure, tu connais la musique, tu y vas franco, salut, ça va. Saumon, champagne. Deux canapés, une coupe. Tu sais que tu ne devrais pas. Boire, tu sais bien qu'avec tes cachets ça se mélange mal, et ne t'arrangera pas la gueule, ni la voix pour demain. Mais les soirs seul en ville inconnue, tu aimes te retrouver au milieu de gens dans un lieu sans trop savoir où, qui. Voilà certainement pourquoi tu acceptes toutes les invitations pour des lectures publiques, oui à tout, partant pour tout, partout, et ça se sait, les bruits courent vite, ce genre de bruits.

Et là, te voilà dans un de ces moments de vie en soirée où tout semble possible, et toi ouvert à tout, belle rencontre, affrontement héroïque, tu navigues à vue dans ces minutes 
pourvoyeuses de doses d'espoir. Tu as bien fait de sortir, de ne pas te contenter dans ta chambre des messages ambigus par SMS avec une ex-future, une future ex, ni de la douce amertume de l'abîmement en toi-même. Rien ne vaut ces minutes où tu es l'inconnu énigmatique que chacun croit être le seul à ne pas encore connaître, en tout cas c'est ce que tu aimes à penser, dans ce lieu où se mêlent ceux qui tiennent à te faire savoir qu'ils ont été quelqu'un, en d'autres temps, ou sous d'autres cieux, et ceux qui seront sous peu quelqu'un, ça ne va pas faire un pli. Et toi en plein milieu de là où tout se joue, te sentant au cœur d'un de ces moments de guerre totale, un contre tous, tous contre tous, à coups d'incroyables craques, de fantasmes éperdus. En fait, tu ne sais pas si ce moment dure dix minutes, une heure, tu sais simplement que c'est du temps vibrant qui broie bien les cœurs, disloque comme il faut les visages et les corps, qui deviennent simples surfaces de circulation pour l'espoir et l'angoisse.

Face à ces êtres, tu laisses croire que tu es quelqu'un au présent, tu en rajoutes peut-être, pour que deux, trois restent face à toi, toute leur vie dans leurs mains, haletantes, terrifiées, féroces, tu entends leurs voix éperdues, tu vois leurs gestes paniqués, tu te souviens de temps à autre que tu ne peux rien pour elles, tu vois des lames surgir dans les regards, des tessons dans les bouches, entre les éclats de rire, tu entends les cris tapis au fond du silence, tu n'arrives pas toujours à peindre de la gloire sur ton visage, tu souris. Tu penses que dans ce genre de lieux, dans ces sortes de villes, à ces heures-là du soir, les gens ne parlent que pour taillader ou mendier.

Tu as beau savoir, au fond, que personne en ces lieux ne peut rien pour personne, tu sens nettement que tu peux en ces moments pourrir ou requinquer ton aura au milieu des grimaces, ricanements et louanges. Traversé d'instants d'hyper solitude où tu sais exactement ce qui en toi résiste à ça, quels livres, quels gestes, quels mots, un de ces moments qui te disent: face à ta propre mort, que vois-tu.

Tu es enfin sorti de ce lieu, tu marches. Vers ton hôtel face à la gare, tu te souviens qu'il y a une place, une fontaine, une 
statue de sirène, te revient que tu es à Angers. Mais tout en marchant, calme, dans la nuit tiède, tu te sens quand même un rien trop calme. Léger, pour ainsi dire flottant. Dans ce coin de ville du soir, ni trop clair ni trop sombre. Traverser en diagonale la place face à la gare, voir des gens immobiles qui se parlent autour, au loin, personne qui comme toi traverse en diagonale, et toi tu commences à te dire qu'il y a une raison, que traverser une large place le soir remue en nous des choses, on ne sait pas trop quoi mais quand même. Et toi, là, spécialement. Comme si, à chaque pas, tu t'allégeais encore. À presque te sentir t'envoler, pour un peu. Mais marchant toujours. Et la légèreté en toi qui va s'accentuant. Avec l'envie de faire quelque chose de définitif, peut-être te jeter dans une gigue. En tout cas te jeter. Mais continuant d'avancer. Sans plus rien savoir. Boussole au pôle Nord. L'image de l'aiguille tournant sur elle-même. Si seulement il y avait une direction. Si seulement.

Tu n'as pas bu, sur ce point tu es formel, une coupe, et encore, tu ne l'as pas finie, tu as dû l'abandonner quelque part à moitié pleine, ce serait bien de toi. Tu n'es pas éméché, tu te sens juste de plus en plus léger mais tu continues de marcher, en attendant que ça se tasse. Ces accès d'apesanteur, ça t'arrive, ces derniers temps, quand c'est chez toi, tu t'adosses au frigo, te laisses couler par terre, mais là, face à la gare, ça ne passe pas, l'air s'est mis à scintiller. Alors tu accélères, droit comme à vol d'oiseau, sur l'entrée de l'hôtel.

Tu n'as pas atteint l'hôtel, quand tu reviens à toi, comme on dit, c'est pour te retrouver assis sur le trottoir. Pas vautré, non, quand on est accoudé on n'est pas vautré, et tu pourrais jurer que tu es accoudé au trottoir quand tu reprends comme on dit conscience.

Tu ne te relèves pas tout de suite, tu attends un peu. Peut-être dix minutes. Tu vois des gens passer. Un peu au large. Qui évitent de te voir. Soit dit en passant, tu aimes autant qu'on regarde ailleurs quand tu es un peu étendu dans la rue, déjà assez gênant comme ça sans avoir en plus à expliquer, remercier. Les gens quand ils s'y mettent. 
Et puis il y a cette fille, soudain. Tout à coup, la tête de cette fille très près de toi. Qui ne te parle pas. Seulement sa tête, et à l'envers. Qu'elle renverse pour la mettre au niveau de la tienne. Ses cheveux cascadant, tandis qu'elle te regarde sans parler. D'un regard, comment dire, attentif, on dirait même curieux. Et puis elle parle, d'une voix étonnamment amicale, pour dire levez-vous. Amicale, comme chaleureuse. D'autant plus qu'elle sourit, on dirait, un sourire où il manque des dents, ce qui lui fait un air, d'une confiance incroyable. Alors toi, à ce sourire, cette voix, ce regard à bout portant, pleins de, qui sait, peut-être de bienveillance, toi tu te sens tout de suite mieux, c'est peu dire. Te sens te dilater, sous ce regard, comme un champignon séché mis dans l'eau tiède. On dirait qu'elle te voit au fond de toi, et n'a rien à y redire. Et toi, son regard, alors, tu en veux, de sa pour ainsi dire bienveillance. En sentant sa main attraper ton bras, pour t'aider à te relever, alors que tu peux tout seul, quand même elle te tient. Et comme ça, sans te lâcher, elle dit: Vite, les policiers vont arriver. Sur le dernier mot, tu entends son accent, sur le $r$. Tu te dis que c'en est une, Roumaine, ou Moldave, et tu remarques alors seulement sa large robe et ses gros souliers sans chaussettes. Et à côté des souliers le livre qu'elle a posé pour t'aider. Samuel Beckett, Watt.

Le livre à côté des gros souliers sans chaussettes, tu en es sûr, vu que c'est à cause de cette proximité qui t'intrigue, dont tu as du mal à détacher tes yeux, que tu ne vois pas les deux policiers arriver. Ils t'attrapent par le dos de ta veste, comme pour une cloche éméchée. Tu leur demandes de te lâcher, mais sur un ton. Qui fait de la peine à entendre, tu t'en rends compte. Ta requête faiblarde t'a placé d'emblée en position de faible à achever, mais difficile d'être à son meilleur alors qu'on est tiré par le dos de sa veste, qu'on ne voit pas le rapport entre soi et une cloche éméchée. Et c'est alors que tu entends la fille crier: laissez-le, il a eu un malaise mais ça va. Eux ne répondent rien, doivent vouloir l'attraper aussi, tu ne vois pas mais tu entends des piétinements, la cavalcade de semelles frappant le bitume, frappements si vifs que ça ne peut être qu'elle, et tu souris, tandis qu'ils se rabattent sur toi. 


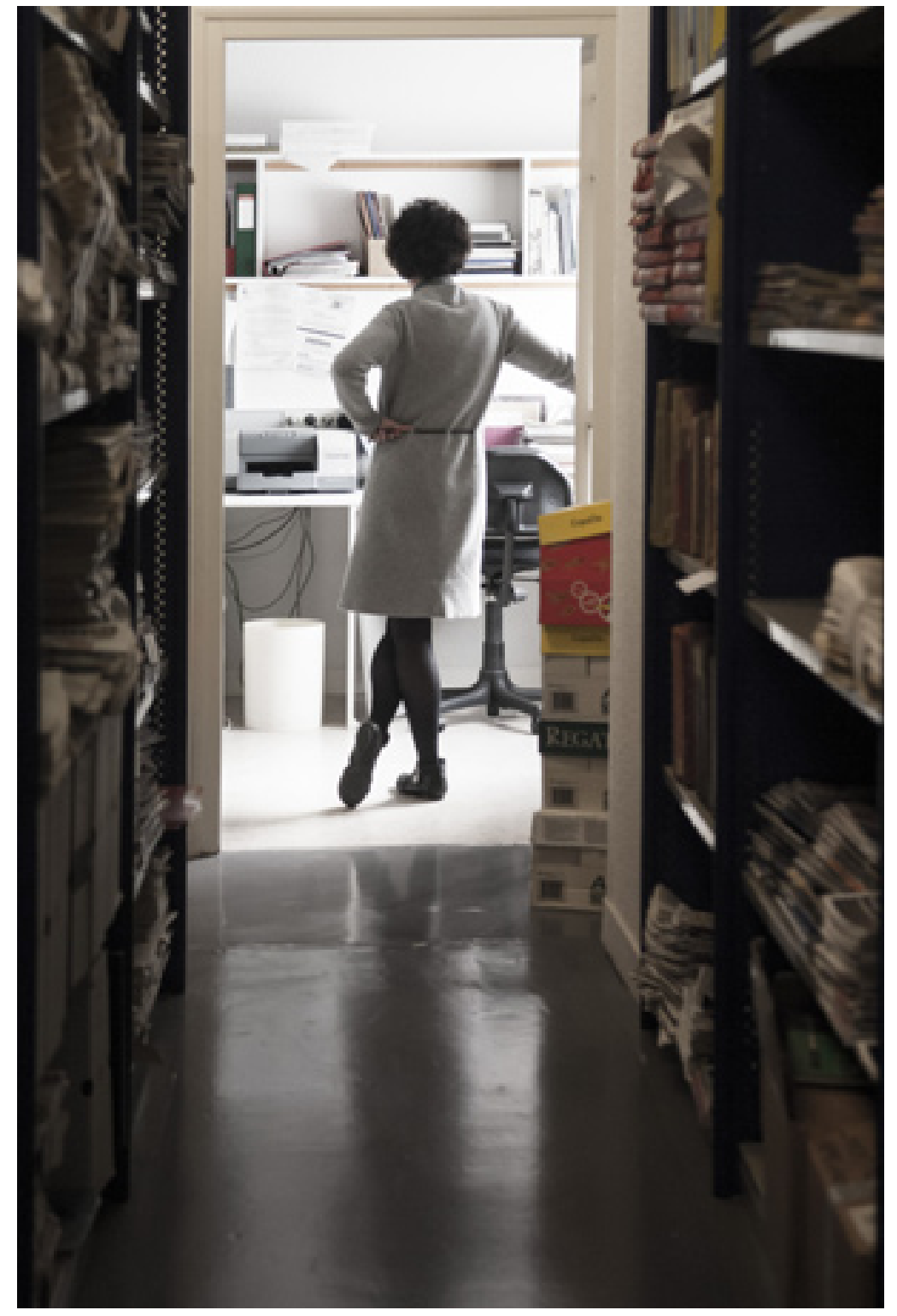




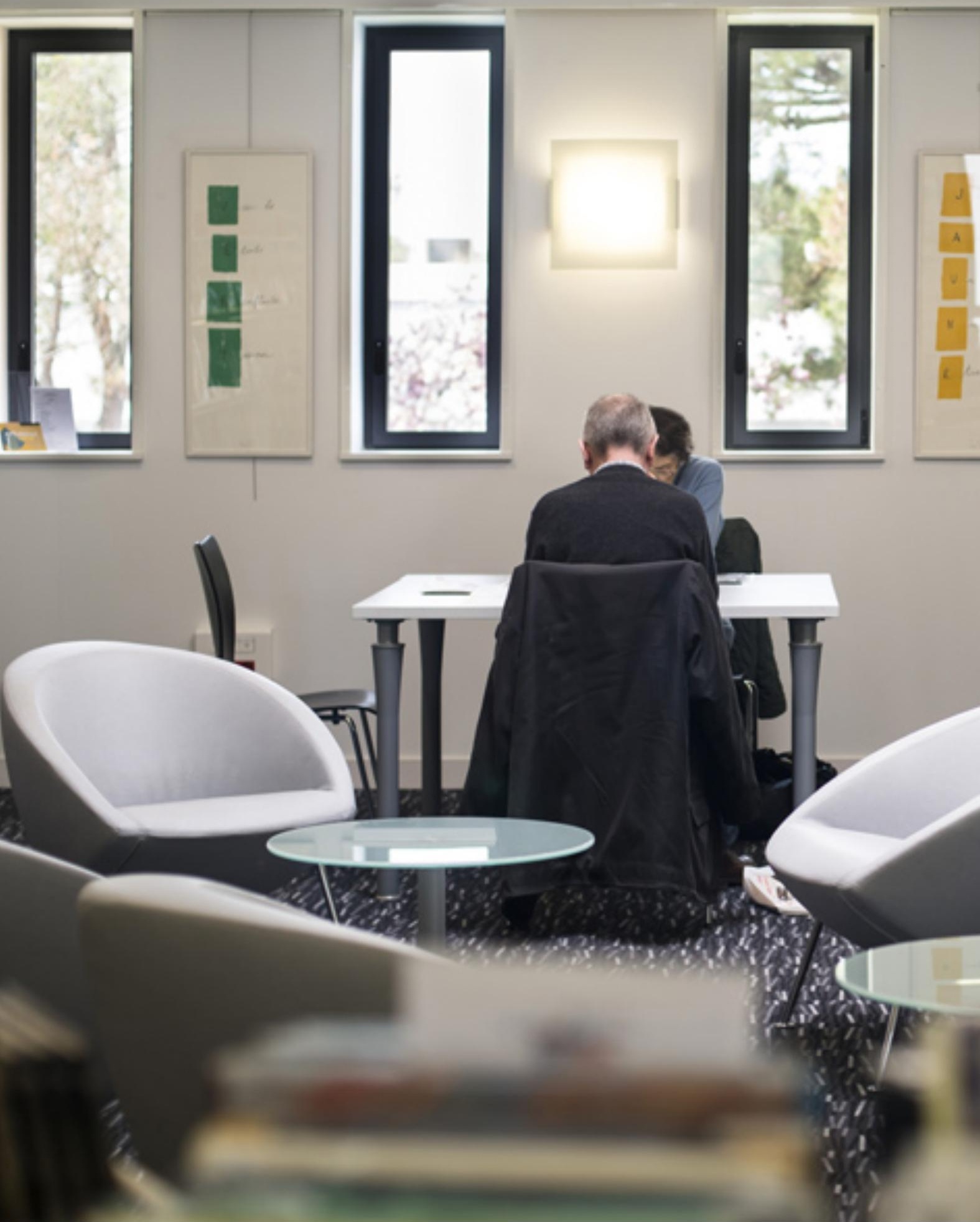



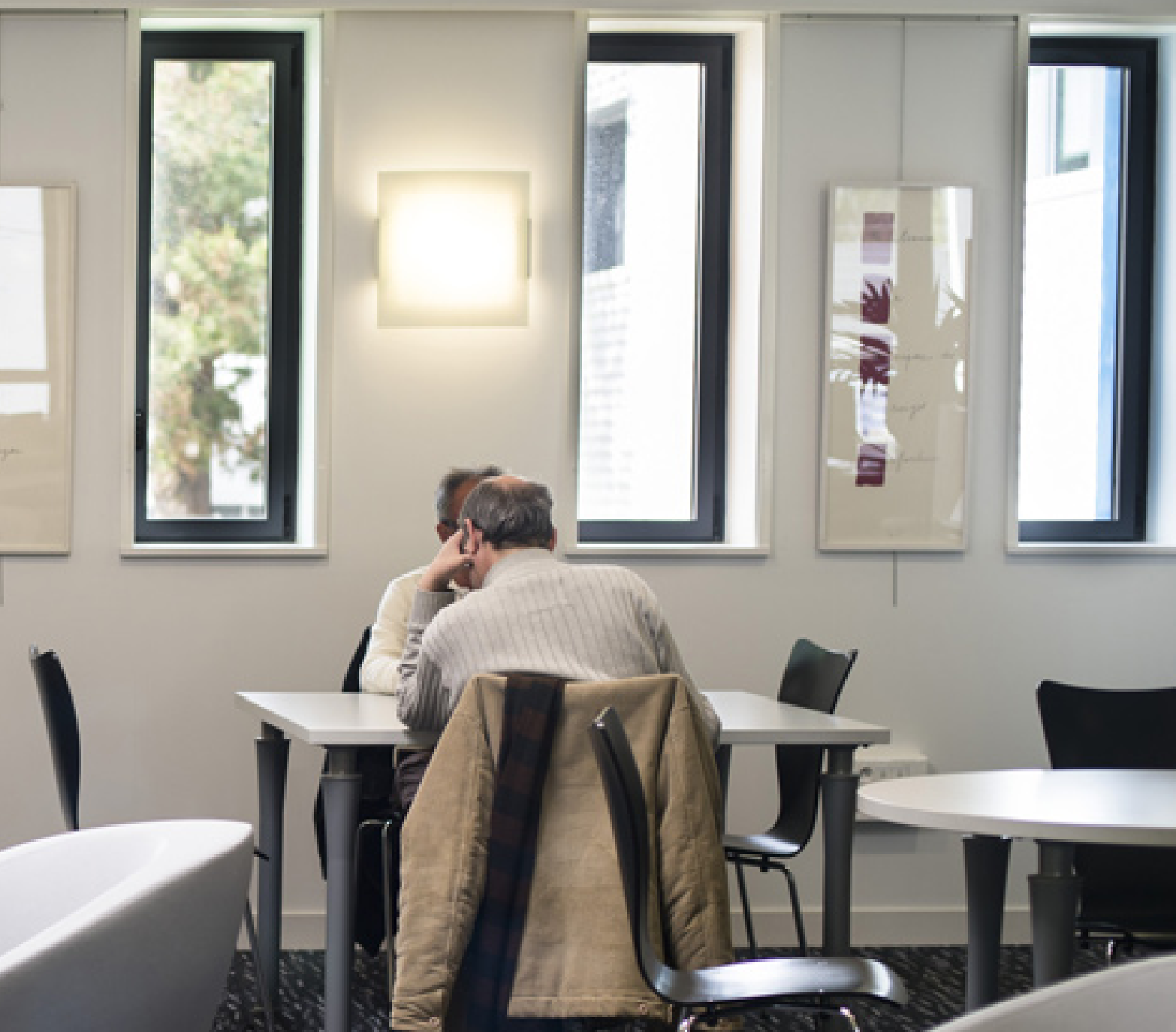

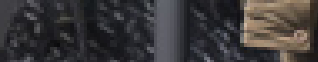

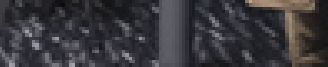
4. $\therefore$ *
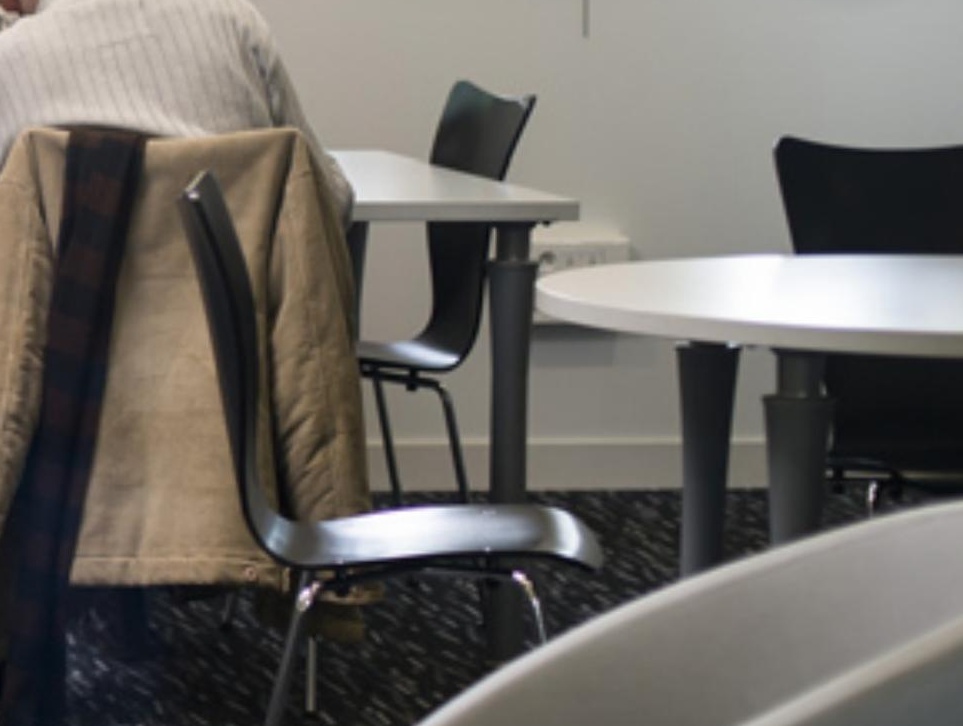
Toi, ce n'est pas grave, l'affaire est vite réglée, tu as sur toi la clé de ta chambre d'hôtel, et même le programme du lendemain, avec ton nom, ta photo. Toujours, tu as dans ta poche le programme du lendemain avec ta photo et ton nom, tu ne saurais pas trop dire pourquoi, tu n'oses peut-être pas t'avouer dans quel but tu te trimbales avec, toujours est-il, tu l'as ce soir-là. Alors, ils te lâchent, te conseillent de vite rentrer à ton hôtel, doivent même rester là jusqu'à ce qu'ils t'aient vu entrer et prendre l'ascenseur.

Le lendemain, la lecture publique. Tu es content, et surpris, ton truc, pour ce qu'il vaut, est de lire et gesticuler jusqu'à ce que tu sentes que les auditeurs décrochent, et cette fois ils ne décrochent pas, au contraire. Ils rient aux bons moments, par exemple au passage des ruses pathétiques du héros rapport à sa peur des factures, et ont le bon goût de ne pas rire quand ce héros erre dans les rues avec sa fausse canne pour assommer son vieux rival. Tu finis quand même par poser ton livre, et un groupe aussitôt vient à toi, ça arrive, mais ceux-là te parlent naturellement, te tutoient, comme s'ils te connaissaient de toujours. Et, au milieu d'eux, ta sauveuse de la veille, enjouée, rieuse. La reconnaissant, tu regardes mieux les autres et remarques que tout ce groupe a comme un air de famille, tous parlent avec chaleur, tous ont cet accent qui les dénonce sur les mots avec des $r$. Des Moldaves, en fait, ils te le disent sans façon, t'apprennent en riant qu'à Angers ils sont beaucoup, s'y sentent bien. Et toi, par eux, tout de suite, sidéré, capté. C'est peu dire, charmé, carrément, toi. Par elle, surtout, autant le dire, charmé surtout, toi, par elle, ta sauveuse. Elle dit s'appeler Mad. Et quand ils veulent se prendre en photo avec toi et que tu dis craindre les photos à cause de tes joues et tes cernes, cette Mad s'insurge et dit qu'elle te trouve «considérablement joli ».

Vous ne décidez rien, tu la suis, jusqu'à tard dans la nuit. Tu pourrais t'attarder sur quand elle regarde l'église à travers son verre de bière et dit avec gravité: C'est comme ça que les Hongrois ont dû voir le château du prince Vlad. Ou quand, au bord du fleuve, sous la pénombre argentée de la lune, elle te dit 
avoir passé son enfance au bord de sa rivière à Iasi à jouer avec les grenouilles. Ou quand il y a de plus en plus d'étoiles chaque fois qu'on regarde le ciel. T'as pas l'impression toi qu'elles finiront par t'avoir, le genre de question qu'elle te sort. Et encore ci ou ça, mais tu préfères te focaliser sur l'impression que ça te fait, de liberté belle et juste, de vérité, d'évidence. Et tenter, autant que faire se peut, de comprendre pourquoi. Peut-être parce qu'elle a grandi loin, n'a pas encore vécu trop longtemps par chez nous. N'a pas encore trop eu à se conformer.

Et là, toi, te revient l'envie de retrouver en toi authenticité et charme, en trouvant un coin où t'isoler. Ce vieux rêve d'être seul, d'avancer dans la direction que l'on veut à son propre rythme. Alors qu'à marcher parmi les usagers, fatalement, soit on passe son temps à bousculer, soit on suit le mouvement, va où ils vont à leur rythme. Et, bon sang, qu'ils sont lourds, les lourds.

Elle, par exemple, quand elle te parle des périodes où elle a été malade. Ces doux échos qu'elle éveille en toi. En disant que son mal et elle s'entendaient. Son mal ne lui arrivait pas n'importe quand ni pour rien, il venait lui faire un moment où s'arrêter et réfléchir, voir les choses autrement. Juste une autre phase dans le cours de sa vie. Malade, elle se fait tranquillement son temps de fièvre. Elle sent, au fond, que son mal s'en ira dès qu'il ne sera plus approprié pour elle. Son mal et elle ont toujours joué ensemble et pas l'un contre l'autre. Son mal n'est pas quelque chose d'étranger qui vient du dehors. Alors que, pour l'usager moyen, ça ne fait pas un pli : être malade est mauvais, et donc, à la moindre alerte, il fonce se décharger de sa maladie sur son médecin, pour au plus vite être rendu compétitif comme devant.

Et toi, donc, en l'écoutant elle, te revient que, jusqu'à tard dans ta vie, avant de trop coudoyer les lourds, tu sentais les choses comme elle. Et tu te demandes pourquoi donc tu t'es renié, as fini par t'aligner sur eux. Le fait que la majorité croit une chose a bien toujours été la preuve que cette chose est crétine. 
Elle te sidère aussi, sans doute surtout, par son érudition. Quand elle te récite par cœur une strophe de Robert Desnos à propos de filles derrière des murs hérissés de tessons de bouteilles. Et quand elle te dit que Freud a raison quand il dit que la vie en ville va avec la névrose, que toute la société repose sur le refoulement, le renoncement, la non-satisfaction. Mais que déjà de son temps Sigmund trouvait que la société était allée trop loin. On ne peut pas demander aux gens de sans arrêt renoncer à tout. On aura beau leur rabâcher rigueur, crise, que force doit rester à la loi et tolérance zéro.

Et toi, tu es là, à écouter cette Moldave d'Angers, qui cette nuit-là te fait comprendre à quel point sans elle on est désormais tous condamnés à perpète à la frustration légale ou aux échappées belles prohibées.

Tu lui demandes comment elle sait tout ça. Tu n'en reviens pas, chez une Moldave, de cette culture, cette imagination, intuition, clairvoyance, poésie, son humour, sans parler de sa connaissance de la langue. Elle ne voit pas pourquoi tu t'étonnes. Elle dit que, bien sûr, elle lit. C'est une évidence. Ce qu'elle a, qu'elle est, c'est ce qu'on apprend en lisant, des histoires, des livres. Elle te dit qu'il n'y a, au fond, que deux sortes de gens: ceux qui lisent des livres et ceux qui n'en lisent pas. Les gens qui ne lisent pas de livres sont dangereux, à fuir absolument. C'est la chose à savoir, quand on connaît quelqu'un de nouveau, s'il lit des livres ou pas.

Mais elle, comment a-t-elle pu avoir tous ces livres?

Elle te dit en riant qu'elle va, qu'ils vont tous, à la bibliothèque de la Roseraie. Elle aimerait beaucoup te la montrer demain. Alors, sur-le-champ, tu décides de rester un jour de plus. Vous vous séparez, tard dans la nuit, devant l'hôtel, tu ne lui proposes pas de monter, ce n'est pas de toi. Du reste, rien ne dit que c'est ce qu'elle voulait de toi, du calme.

Avec elle, comme elle, tu tombes sous le charme de cette bibliothèque de la Roseraie. Vous y arrivez par le tramway. Arrêt Jean-Vilar. Elle connaît le trajet par cœur, les yeux fermés. Le bâtiment se repère de loin. En plein cœur du quartier. Les façades composées d'une succession d'ouvertures aux 
méplats colorés. Elle te dit que leur intensité varie au gré de la journée, ajoute qu'en nocturne les façades font comme une lanterne, à cause des facettes de couleur éclairées par la lumière intérieure. Elle sait tout, un vrai guide, mieux qu'un guide, ses yeux brillent. Elle est fière de ce qu'elle te montre, qui te ravit, elle est fière de ton ravissement. Un bâtiment vivant, dit-elle, qui change selon la lumière et les déplacements.

Vous prenez l'ascenseur. Parce que le lieu magique est situé à l'étage. Elle avance, circule, elle est ici chez elle. Elle t'invite à t'asseoir avec elle, te vante ce qu'elle appelle les espaces conviviaux. Tu peux avoir du thé, du café. Tu peux prendre place sur le grand banc rond et vert qu'elle appelle la soucoupe volante. Tu reconnais là certains de sa tribu, que tu as rencontrés la veille. Bien sûr, tu rêves d'y venir un jour avec elle, lire dans ce lieu imaginé pour. Elle te montre l'espace pour les expos, les conférences. Tu t'amuses à regarder avec elle les gamines se débrouiller seules, sérieuses comme des grandes, avec les automates de prêt. Une façade intérieure vitrée s'ouvre sur le centre Jean-Vilar. Tu lui demandes si par hasard elle sait quel architecte a pu concevoir un lieu de ce genre. Elle sait, bien sûr: Pierre Chudeau. Quand tu dis qu'il faut que tu y ailles, tu espères qu'elle va t'accompagner à la gare. Mais elle te fait une bise joyeuse sur la joue et te dit qu'elle veut rester là. Et tu la comprends. 
Médiathèque François-Mitterrand, Poitiers

De haut en bas 
Il faut commencer hors de la bibliothèque, dans la ville. Elle est finie, la splendeur des préfectures de province. Les enseignes sont les mêmes.

Les rocades et autoroutes contournent sans s'arrêter. Le commerce s'est exilé dans les zones périphériques. Pourtant, sans l'hyper-centre, pas d'identité de la ville: il faut l'irriguer de ce dont il ne dispose plus lui-même.

Il y a quarante ans pile, les Dames de France étaient le commerce essentiel, là où une galerie assez triste semble trois fois trop grande pour la Fnac qu'elle abrite. Nous allions chez libraires et disquaires (il en reste, heureusement), mais le centre-ville doit s'imposer, là où autrefois tout y convergeait.

Ici, à Poitiers, il s'agit d'histoire: en face, le baptistère SainteCroix et son musée. En face, le délicat portail roman de Notre-Dame-La-Grande.

Plus loin, les ponctuations de la splendeur d'avant les hypermétropoles: où Poitiers a mangé Civray, Chauvigny et les autres, Nantes et Bordeaux ont partiellement mangé Poitiers sans compter que Paris n'est qu'à une heure trente, et que les campagnes dépeuplées remplacent les fermes par des résidences secondaires. Pas possible de parler de la médiathèque de Poitiers sans ce grand panneau publicitaire du département de la Vienne, à toutes les haltes d'autoroute: vallée des Singes, parc à crocodiles, rafting et autres serpents, ou le Futuroscope du temps qu'on y croyait, au futur.

Cela veut dire quoi? Que l'implantation même est militante, et le quotidien une lutte. Mais qu'elle ne concerne pas seulement le livre et la culture, et bien la question même du territoire, de la ville, de qui on est et pourquoi on vit là (ou qu'on en est parti, c'est mon cas).

C'est ainsi que j'apprécie le premier geste architectural de Laurent Beaudoin: la médiathèque s'encastre dans la vieille ville sans la rompre, fait partie inclusive du labyrinthe, ne touche pas aux petites rues, vient se loger même dans les toits. Des salles de lecture, à quatre mètres des vitres, la ville 
médiévale recommence. Tout le contraire de ces bâtiments lancés partout sur nos villes comme par hélicoptères, faits pour être vus de loin: ainsi la bibliothèque aura trois façades fractionnées, même si chacune, dans la modestie de cette continuité imposée à même la ville, sera un hommage particulier à la rigueur du vieux maître le Corbusier.

Conséquence de tout cela: nous qui pratiquons ces rues et ces places, on les a dans les pieds. Il y a les cafés, les éventaires de bricole et bouquins en plein vent - où le centre-ville encore est société, s'est implantée, sur ce même chemin des pieds, la double entrée de la médiathèque, presque comme la porte discrète d'un bazar oriental. Ce n'est pas du dehors qu'il faut photographier la médiathèque. Conséquence: voir les arrêts de bus, làhaut à la fac, quand sonne la fin des cours: les étudiants habitent le centre-ville. Ce qui donne aussi une clé de cette présence sociale du bâtiment: être étudiant, on ne cesse de tenter de leur inculquer, c'est profiter de cette tranche particulière de vie pour ne pas s'en tenir à l'apprentissage didactique qu'on leur propose. La ville est ce qui déborde le travail qu'on leur donne, mais aussi le lieu où ils vont aborder ce dont nous avons proposé les pistes, mais pas le matériau - la «B.U.»y pourvoyant parfaitement. Proximité, lieu social de l'activité intellectuelle et, au fondement même, cette curiosité organique au travail intellectuel, qui est de trouver ce qu'on ne cherchait pas.

La médiathèque de Poitiers commence quand on y entre. Volume de cathédrale, mais cassé et structuré: notre activité intérieure aussi est labyrinthe, et pour oser se perdre dans le labyrinthe il faut le sentiment du tout. Frappe l'éclairage zénithal: bascule dans l'architecture, pour s'insérer dans la ville il fallait prendre la lumière ailleurs - au XIXe on n'aurait pas su. Les puits de lumière qui trouent le toit de la médiathèque (je les verrai aussi du dessus, tout à l'heure), ont chacun un de leurs quatre pans peints d'une couleur primaire. Leur recomposition divise et multiplie la lumière, à l'opposé du blafard qu'elle est, si on ne l'organise pas.

La lumière participant ainsi de la division de l'espace dans l'ensemble monobloc (ou l'éclairage électrique à iodure métallique 
pour rester au plus près de cette lumière zénithale: comment justifier de ce surcroît de dépense? - et pourtant...).

Restons à ce lien de la médiathèque à la ville. Ancrage symbolique par le fonds ancien, socle mémoriel de la communauté, et fonction ouverte - numérisation, catalogage, restauration, disponibilité aux chercheurs.

Mais le contraire d'un ancrage quand le personnel tourne pour prendre place aux banques d'accueil, la médiathèque un service et une présence décentralisée, pourtant jamais neutre: chargée de créer une attente ou un écart qui ne préexistent pas dans la demande des visiteurs.

Décentralisée: oui, quand le service inclut le portage à domicile, notamment pour les personnes âgées. On téléphone, on échange sur le livre souhaité, et la médiathèque se charge de la mise à disposition. Où, alors, est le lieu de la bibliothèque? Oui, quand ces cartons qu'on aperçoit doivent rejoindre le centre pénitentiaire tout neuf, à Vivonne: trois grands secteurs de détention, donc trois bibliothécaires détenus recrutés et formés sur place, deux emplois à mi-temps côté médiathèque pour les dépôts, le soutien, la gestion.

Quand on entre à la médiathèque de Poitiers, mot latin et mot grec qui vous accueillent: forum et agora parce qu'on n'a rien trouvé de mieux depuis - fauteuils avec la presse en libre accès, bornes d'ordinateur, livres, films et disques en suggestion. Et ce n'est pas une zone de silence. Niveau rue, aussi, trois marches pour entrer dans l'auditorium souterrain (j'y ai souvent fait des rencontres, des ateliers, mais je n'aime pas trop ce côté linéaire des rangées de fauteuil, le lourd mobilier de l'estrade, et préfère nettement, à trois cents mètres, la coupole de l'ancien planétarium - mais est-ce que ce n'est pas nous qui avons évolué quant à ce que nous demandons à ces espaces?), mis à disposition de la communauté par la médiathèque, encore une flèche exogène dans l'activité. L'autre entrée: la banque de prêt de l'artothèque, 2 œuvres à la fois, parmi 600, pour 8 semaines chez vous. Niveau rue aussi, cette fois zone silence et lourde porte, une autre caractéristique importante de Poitiers: relier la fonction «savante» et patrimoniale de 
l'établissement à sa présence publique: une salle Moyen Âge où la spécialisation de l'établissement est aussi un espace "grand public», et la salle de consultation des livres du fonds ancien et du patrimoine (sa série de lampes alignées, aussi inamovible et aussi immobile qu'un rituel d'abbaye, mais visible de la rue: concentration garantie, mais pas coupée du temps). Ainsi, le travail de conservation se donne littéralement pignon sur rue - il y aurait eu d'autres choix fonctionnels, le choix est bien d'abord symbolique.

Mais la médiathèque commence pour moi par l'usage que j'en ai, les tables de la salle de lecture, lumière et diversité des silhouettes, chacun dans son monde, et quand presque un tiers des usagers sont les étudiants de la ville c'est contagieux: on se retrouve avec un peu de leur âge et nos propres souvenirs, dans le coin où l'on s'installe.

J'aime ce mot, s'installer, pour la pause même brève dans une bibliothèque.

J'aime considérer qu'une place soit mienne. J'aime à y apporter telle et telle ressource en affinité avec mon travail du moment, ou ma distraction du moment, quitte à ne pas les parcourir toutes. La quantité de ce que propose une bibliothèque, vous la refaites à votre échelle individuelle, puisque c'est permis, et qu'on n'a même pas à ranger soi-même.

Désormais, Internet est pour moi ce lieu de ressources, je le demande moins aux livres. Dans ma récente année à Québec, où nous n'avions emporté qu'une malle de livres, j'étais souvent à la bibliothèque Gabrielle-Roy, et c'était souvent aussi dans les heures vides du dimanche (elle bruissait, le dimanche) ou dans ces heures du soir où on va à la rencontre de la ville, où on fuit la table de travail : làbas cela fermait à $21 \mathrm{~h} 30$ tous les jours, et une fois par semaine on y faisait atelier d'écriture.

Non pour dévier, mais parce que les questions sont les mêmes. Ainsi, j'ai plus que rarement emprunté un livre, même dans ce voisinage immédiat d'une médiathèque de taille sensiblement équivalente à celle de Poitiers. La médiathèque pour y être, et non comme banque de prêt. 
Dans la médiathèque de Poitiers, quand on s'acclimate, c'est ce fractionnement de l'espace sous puits de lumière qui est le premier signe. Passé le forum agora de l'entrée, il n'y a plus une bibliothèque, mais un jeu complexe d'espaces. On peut s'y perdre, peu importe, la rampe en trois longs pans triangulaires qui structure l'espace vous ramènera toujours au point central.

Tout en haut, comme pendu sous le toit, en suspens sur les deux étages du hall, un espace avec une table triangulaire tout aussi inamovible, l'espace Gilles-Deleuze (qui mourut en se jetant de sa fenêtre, difficile de n'y pas penser dans cette salle sans cloison, suspendue). On y ferait bien des rencontres ou lectures, à une trentaine de personnes, si l'acoustique s'y prêtait. J'y ai rarement vu du monde, sinon de la façon dont enfant on se plaçait dans la toupie au centre du manège, pour être vraiment seul jusqu'au vertige. Voilà le type même de bonne idée apparente qui n'engendre pas d'usage, mais ce n'est pas prédictible.

Alors qu'on redescend, et qu'on longe la salle de littérature (désolé, j'ai peu regardé les livres, mais à la banque retour j'ai aperçu des Jaccottet et des Jabès, et du coup j'aurais tellement voulu voir qui venait de les rapporter), voilà le «salon de lecture» - mot bien bourgeois pour un lieu aussi social. Éclairage zénithal: un large pan oblique de verre découpe les nuages, lumière blanche et solaire. Pourtant, nous sommes dans un cube avec galerie. Je retrouve le même mobilier d'étagères, rampes et balustrades que je connais à la bibliothèque de l'école des Beaux-Arts, à Paris, une de celles où j'aime à me glisser une paire d'heures, même si depuis longtemps je n'interviens plus dans l'école. Explication suit: mobilier qui vient de l'ancienne bibliothèque de la ville, et qu'on a voulu garder comme continuité, signe et transmission. Sous la galerie, des découpures blanches comme les murs et la lumière: un carton avec le mot "poésie» et deux étagères et demie d'une sélection qui est loin de remplir les vides.

Alors, oui, la suggestion d'en prendre un et de s'asseoir ici (pas de table, juste des canapés et fauteuils) fonctionne comme incitation. 



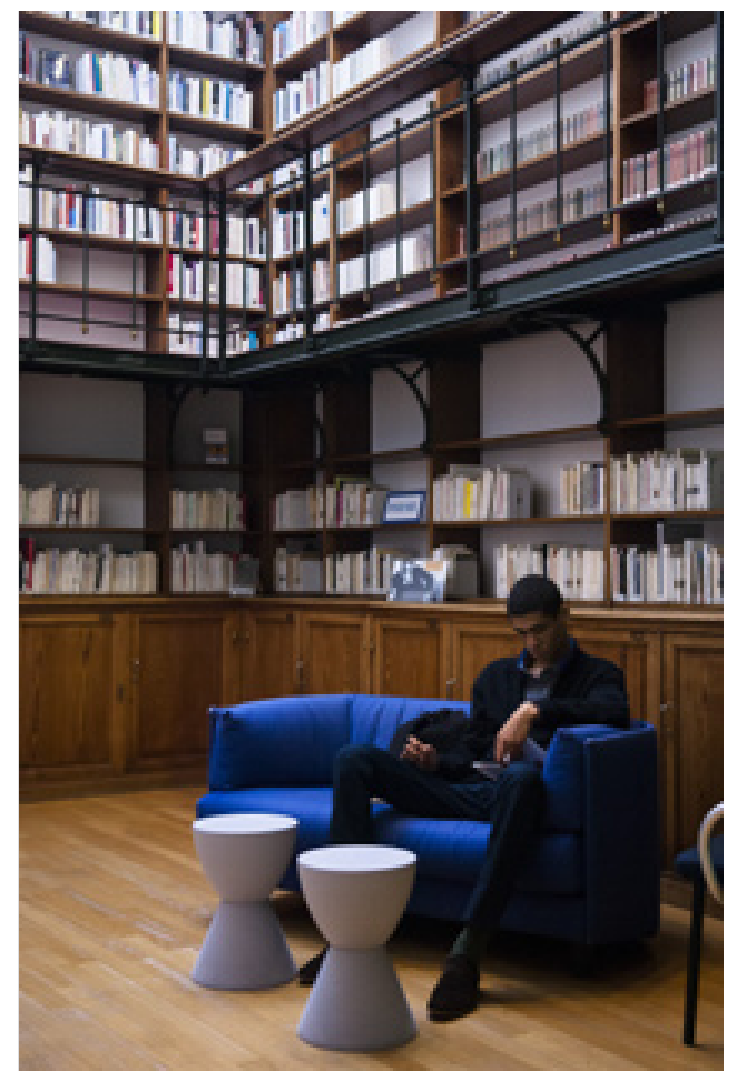




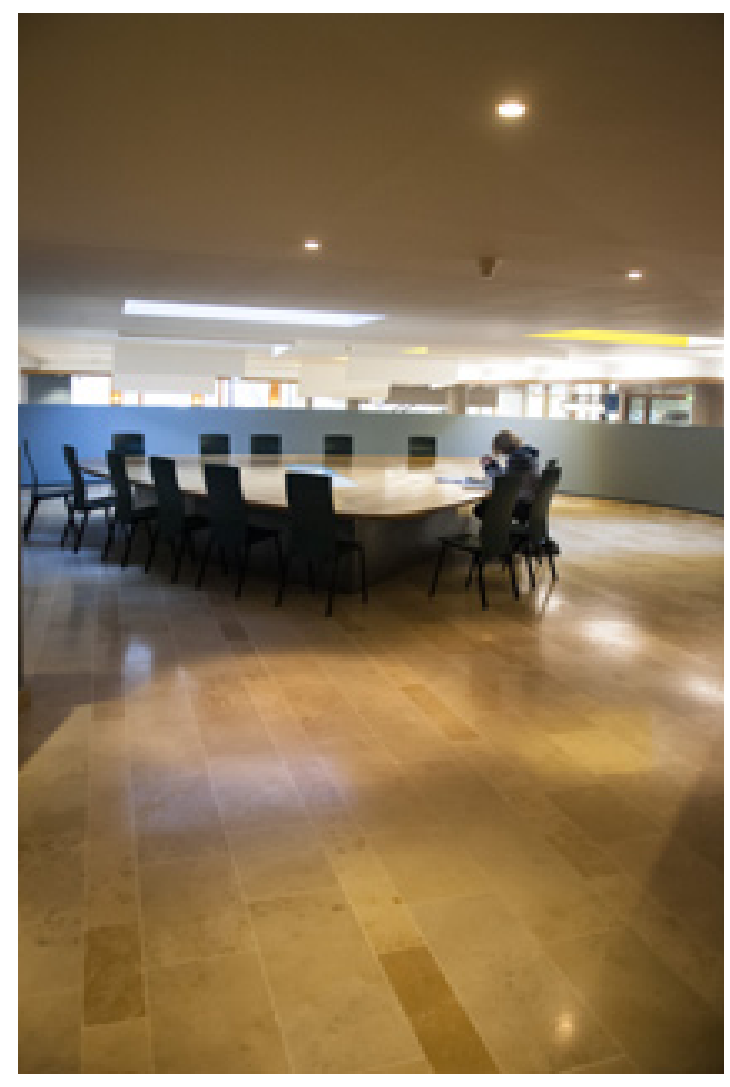




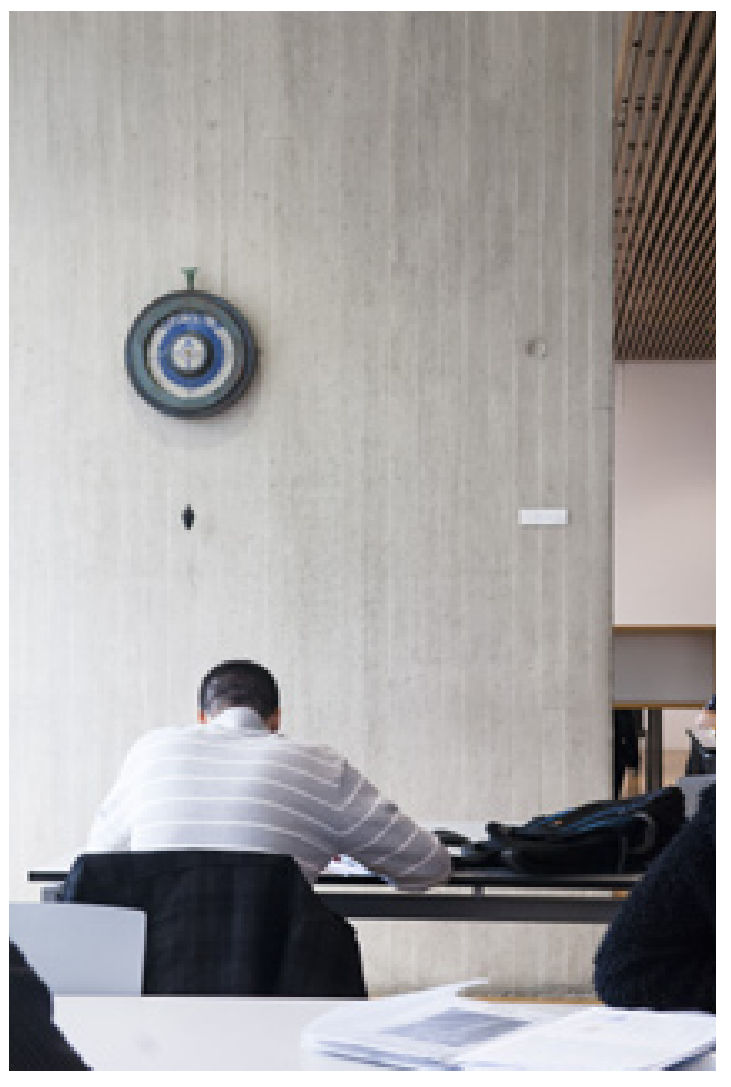


La bibliothèque, pour lire assis à une table? Tant d'écrivains ont écrit debout à leur lutrin, comme Rilke et Victor Hugo, ou Baudelaire qui se refusait à avoir une table chez lui. Souvenir du texte de 1927 de Walter Benjamin, dans Sens unique, où il parle de ces variations dans le temps: l'oblique du Moyen Âge, l'horizontale de l'imprimerie, la verticale du journal. Tout au long des livres, en surplomb du hall d'entrée (l'importance de ce lien direct au ventre de circulation et répartition des espaces), une planche oblique et ses tabourets de bar. Je me suis souvent perché sur des tabourets de mange-vite, avec vitrine sur rue, pour une heure d'écriture dense avec café en gobelet. Peut-être un jour devra-t-on remplacer la longue rampe-lutrin par une planche de bar à l'horizontale qui permettra, sur les mêmes tabourets, dans le même voisinage des livres, de s'y poser avec son ordinateur.

Parce qu'ils sont là, les ordinateurs. Dans ce nœud vital du premier étage, à l'intersection de trois espaces majeurs : les livres de fiction, le recoin fanzine et bande-dessinée, les livres non-fiction. Notez que je n'emploie pas littérature pour la seule fiction et essais et documents pour la seule non-fiction. Les bibliothèques savent envoyer valser les catégories, malgré leurs découpages Dewey et autres joyeusetés. Je dirais même qu'elles prennent souvent les devants pour éclater les catégories convenues, à la société de suivre. Ici, ne cherchez pas de lecture «ado»: ne pas isoler collections «adultes» des collections «ado » c'est faire honneur à leur curiosité. Et cela n'empêche pas, par contre, qu'ils aient des espaces privilégiés, dont la décoration tranche avec l'espace commun.

De même, quand on y descend, comment qualifier l'espace enfants?

Vaste espace sans rupture, avec des coins et recoins ras du sol tant qu'il en faut. Là aussi, l'important, c'est le lien avec le volume pris globalement: la bibliothèque des grands est au-dessus de vous, mais vous n'en êtes pas séparé. Autre signe: les colonnes et vestiges de la Poitiers antique, exhumés lors de la construction, induisent une continuité du temps, le bâtiment neuf intégrant en lui-même, à l'âge de la lecture 
maternelle, le témoignage ancien. Ainsi, en Mésopotamie, les particuliers installaient un clou de fer dans le socle de leur maison d'argile, pour signifier leur droit et leur accroche à la terre - et dans le palais du roi, c'est une maquette en argile de la ville qu'on installait pour cette même fonction. Ce n'est pas dans toutes les villes qu'une médiathèque neuve peut se le permettre, ni dans les annexes de quartier de la médiathèque. Et donc, les ados ne sont pas chez les enfants, et ne forment pas une catégorie qui les séparerait de la littérature adulte. Allez dans les livres, c'est à eux d'avoir votre âge. Ce signe de confiance est un régal en soi.

Ma propension personnelle, dans les bibliothèques, est de m'installer dans les territoires du savoir et de la non-fiction. Et quand je vais côté récits, poésie et roman c'est plutôt pour les essais et biographies. Cela correspond à mon itinéraire de lecture, et au besoin, s'il s'agit de fiction, que le livre soit une possession personnelle, au moins le temps de la lecture.

Et puis l'âge (retour à la question ado): la curiosité vers les savoirs est un travail permanent, et pour la fiction on a tendance à relire les mêmes livres. Toujours accepter, d'une bibliothèque, qu'elle se compose depuis la somme de demandes divergentes et chacune légitime.

Leur métier ne doit pas être facile (mais si l'exercice en est collectif, accompagner cette divergence devient aussi possible), s'il faut respecter cette demande hétérogène, et la bousculer en même temps - comme en annulant l'existence d'un territoire ado spécifique.

À Québec, où c'est entré dans les mœurs, je me demandais à quoi pouvait penser l'agent d'accueil, avec devant lui les huit écrans avec gens lisant, l'image basculant d'une caméra l'autre. Ici à Poitiers il y a aussi ces caméras dans les salles. Peuton lire les lignes des livres que lisent les usagers? Bien sûr que non, mais moi quand je lis j'aime bien que ce soit un rapport secret, je n'aime pas être observé: j'aime les bibliothèques pour le droit qu'elles vous accordent d'être seul - mais cette question des caméras dépasse l’horizon Poitiers. 
De même, en bibliothèque que les gens sur les ordinateurs tournent le dos à qui surveille la salle, et eux-mêmes par le fait: pourtant l'écran aussi est d'une intimité. Je préfère venir avec mon portable. Et comment, me connectant depuis ma place choisie dans ces espaces fractionnés au long des trois façades, j'ignorerais les propositions et suggestions du lieu qui m’accueille? La possibilité de médiation numérique, dans un établissement comme celui-ci, est liée à l'offre qui vous est faite d'accéder à toutes les ressources que vous souhaitez. Ici, de plus, l'accès aux ordinateurs (74 pour l'ensemble du réseau des médiathèques: l'impression qu'ici, dans la médiathèque principale, on doublerait le nombre de postes qu'ils seraient occupés pareillement) ne suppose même pas d'inscription préliminaire à la bibliothèque: geste pareillement lié à intimité et liberté.

Comment échapper à la fascination d'un fonds ancien? La langue poitevine est de formation plus ancienne que la française. C'est à Fontenay-le-Comte que fut inventée l'algèbre, et on sait le rayonnement pris au temps de Rabelais, ou comment Agrippa d'Aubigné fut le premier à installer près d'ici, en son bastion huguenot, une presse à imprimer. Mais ce qui m'émerveille, c'est peut-être moins les livres en eux-mêmes que le fait, maintenant que nous avons à nouveau à les interroger dans leur fondation même, de leur propre invention.

Ces livres d'Heures sont des mondes. Et dans cette Vie de Sainte-Radegonde du XII siècle on voit encore les traits à la pointe sèche par lesquels le copiste a réglé sa page, rien n'a affaibli l'éclat rouge minium des encres. Et cet herbier sur parchemin, ou cette cosmographie animée du XvII siècle. En prenant la charge de ces trésors qui sont comme le socle de l'ensemble (tout le deuxième sous-sol), c'est de la continuité du présent qu'on témoigne. Banalité de le dire: moins banal le fait que les peintures qui donnent une telle intensité très douce aux lumières intérieures, en jouant sans 
cesse de leur complémentarité, soient précisément celles des enluminures du vieux et précieux livre d'Heures. Et Richard Texier, à qui on a donné carte blanche pour dessiner sur les murs, a joué en grand peintre de cet écart et de sa signification. Peu de médiathèques récentes ont osé ainsi s'écarter de la fonctionnalité neutre du moderne, on se plante ou on réussit, avec Texier et Beaudouin ça a marché. Et moi combien de fois je suis venu ici m'asseoir sans savoir que ces jeux de couleurs venaient de l'an 1100, et du copiste anonyme illustrant comment sainte Radegonde délivre du démon la possédée Faifrède (elle sauve aussi le pêcheur Floreius, guérit l'aveugle Bella et ressuscite quelques morts)?

Je découvre, dans l'hygrométrie et l'éclairage contrôlés de la «salle précieuse", où on prend les livres en gants blancs, comment aujourd'hui on les enferme plutôt dans un étui de carton - à la façon autrefois des Romains (mais du carton «neutre»). Et comme tous les fonds, l'histoire de celui-ci est à l'image des secousses de l'histoire, des abbayes détruites, ou de ce conservateur indélicat, qui au xix siècle a vendu le fonds à tour de bras, livres ensuite rachetés quand on les a retrouvés. Mais quelle belle pesanteur ces cinq cent mille titres, et comme vous glissez tout naturellement vers ce magnifique Buffon. Il y a des tenseurs, fonds La Mauvinière, fonds Jean-Richard Bloch, mais aussi ces allées sombres, qui terminent par des dépôts encore à inventorier, dans de beaux cartons tout simples des vins d'ici. La bibliothèque s'est aussi chargée des "éphémères", ces myriades de publication qui ne cherchaient la pérennité qu'on leur offre (mais amorcent une question qui revient au premier plan pour les archives numériques de nos blogs). Elle est en charge aussi du dépôt légal régional, et quand je descends vers Charroux et Civray ce sont toutes nos chroniques de village qui s'empilent, avec leurs sorciers et leurs mystères criminels. Fonds vivant, avec acquisitions et numérisation: que s'y joue-t-il de nous-mêmes? On rêve d'une vie où on pourrait explorer à sa guise, on sait qu'on n'en aura pas le loisir et pourtant. 
Je n'avais pas idée de la machine qu'est une médiathèque. On s'en doute pour un hôpital, pour les conditions de sécurité dans un lycée. Mais ici que transitent deux cent mille personnes chaque année (autant que de visiteurs à l'abbaye de Fontevraud, où j'interviens en ce moment), il y a les mêmes coulisses que dans un théâtre? Sans ce texte je n'aurais pas eu droit d'entrée dans cette salle sans fenêtre, près du grand rideau de fer qui permet l'accès rue aux camions (comme dans un théâtre, ou dans cette étrange rue qui troue par-dessous la BnF), où une équipe de jeunes gars décontractés, environnés d'ordinateurs et d'écran, règle les températures, les éclairages, les accès et éventuelles intrusions. Ça vous intéresse? Eh bien on vous y emmène. Centrale d'air, $11000 \mathrm{~m}^{3}$ par heure: et ça vous emporte combien de lettres parmi celles que vous avez lues, combien de rêves pendant que vous aviez les yeux au-dessus de votre livre? Posé sur le toit, un générateur de secours, à même cette "terrasse technique» qui est comme la respiration du bâtiment, avec ses invisibles chaudières à gaz (deux, de 450 kilowatts chacune), son système de réfrigération et son réservoir de $20 \mathrm{~m}^{3}$ d'eau. Mais, dans les souterrains qui prolongent le fonds ancien, une série de portes bien protégées: l'EDF a ici le transformateur de sa «boucle de quartier » - n'en encombrons pas ce texte, mais combien, ô combien, nous souhaiterions pour nos fictions et récits cette vieille imbrication de la littérature aux rouages du monde, du temps d'avant qu'on la relègue au «culturel», et tout simplement oui, après cette visite j'ai perçu autrement ces heures en suspension qu'on a ici, dans les dix ou douze bulles aux tables claires, séparées par des rayons de livres ou documents, où on choisit de s'asseoir pour le rendez-vous avec soi-même.

Est-ce que c'est le moment alors, pour rester sur cette notion d'espace, d'interroger la bibliothèque comme espace vide? Ne pas venir ici pour l'encombrement mais, au contraire, parce que dans la ville on nous propose un volume, avec du silence, de la distance ou de la lumière, qui permet l'échange (à plusieurs, on a le droit de parler, les lieux silencieux sont désignés) ou l'écart? Que, dans cet écart, la présence de la 

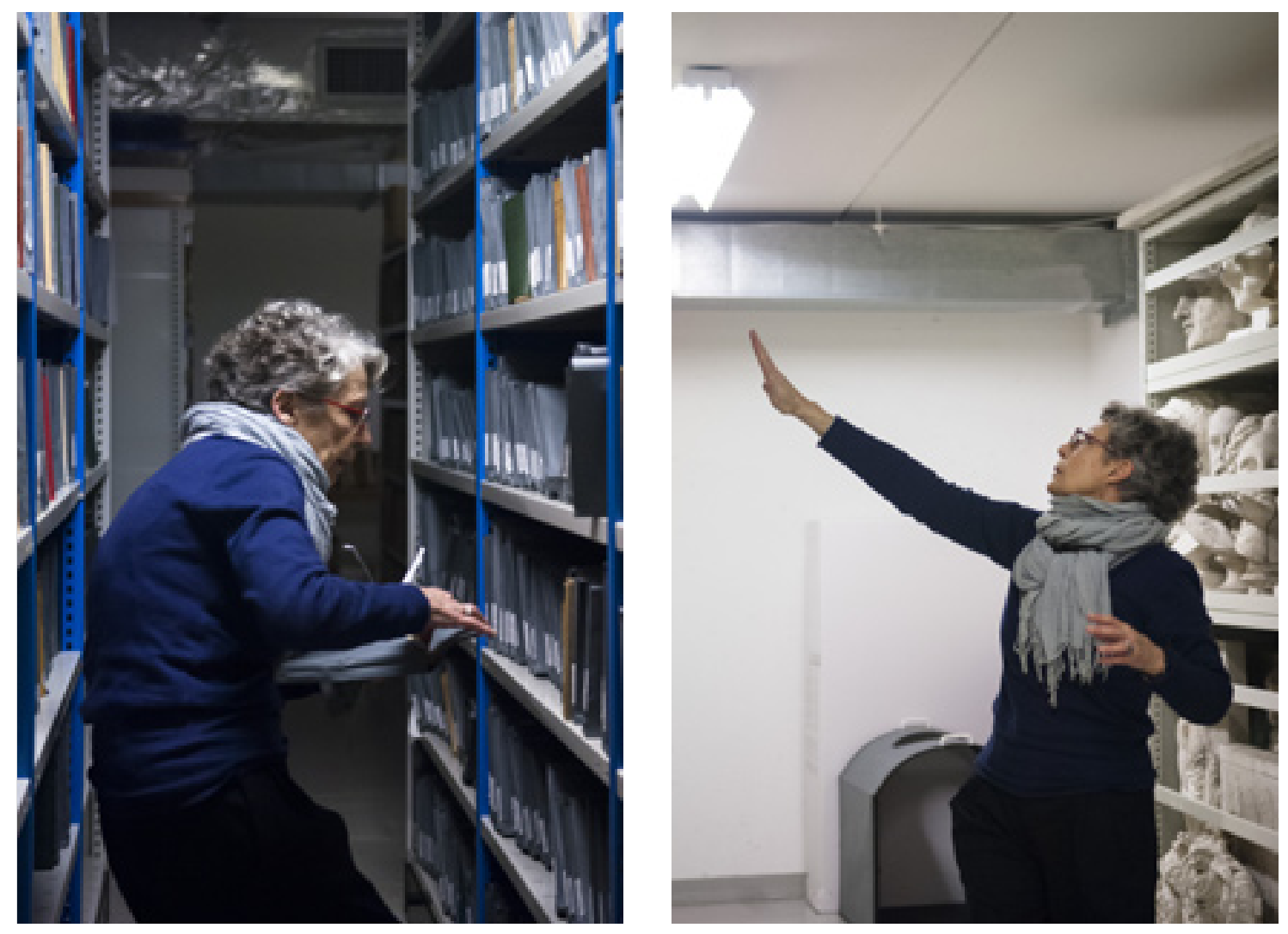


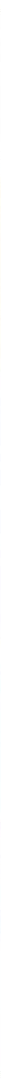


ville, ses toits, ses volumes imbriqués, sa présence, reste aussi décisive que le sont, sous nos pieds ou dans les rayons, les livres et documents qui témoignent que notre travail peut lui aussi être destiné à circulation et partage, y compris lorsque c'est par l'ordinateur que s'établit la lecture?

Alors compte, dans la politique d'achat, disponibilité et présence, qu'on ne propose pas un espace saturé, mais que la médiation du bibliothécaire soit dans ce choix même, de l'immédiatement présent.

Ils sont 130 dans le réseau des médiathèques Poitiers, dont 94 ici même (dont 21 pour la technique et l'administratif). Combien en aurez-vous aperçu, dans les deux heures que vous serez venu y passer? On vous laisse faire, quand bien même vous savez qu'en cas de besoin il y a toujours du monde aux banques d'accueil. Et pas pour passer devant le scanner le code-barres de ce que vous empruntez, ça on s'en débrouille tout seul. Poitiers n'est pas une "grande» ville comme Nantes, Nice, ou Bordeaux: seulement ce tissu vivant qui fait notre pays, précisément parce qu'on peut y rester et y travailler. On a parlé d'un lieu "suréquipé», parce que ce niveau d'établissement coïncide avec celui des villes de taille supérieure. Mais les 14000 inscrits, ils en pensent quoi, du «suréquipé»? En sport, ou dans le domaine du spectacle, ce serait parfaitement respecté, qu'une ville joue en division 1 . Je dis simplement ceci, et gravement: un lieu réussi, et qui en fait la preuve à quinze ans de son ouverture, aide à poser les questions qui comptent, qui nous sont vitales, et débordent la seule question du livre pour poser le statut collectif du travail intellectuel, toutes disciplines confondues, les fait respirer avec le culturel, et en permet à la fois l'exercice le plus singulier, et la transmission la plus large, la plus humble. Je suis reconnaissant à cette médiathèque de ce qu'on s'y sente bien. C'est très simple, c'est beaucoup.

Avril-mai 2012

Ci-contre Annales d'Aquitaine de Jean Bouchet Les Annalles d'Acquitaine faictz et gestes en sommaire des roys de France et d'Angleterre et des pays de Naples et de Milan. Nouvelleme[n]t corrigées avec aucunes addicions de la duche de Bourgongne et comte de Flandres/[Jehan Bouchet]. - Et sont a ve[n]dre a Paris [...] et a Poictiers: par Enguilbert de Marnef; Et a l'imprimerie a la Celle et devant les Cordeliers: par Jacques Bouchet, [1525]. Cote: BM 73 


\section{Nettoyer une phrase de Marguerite Duras}




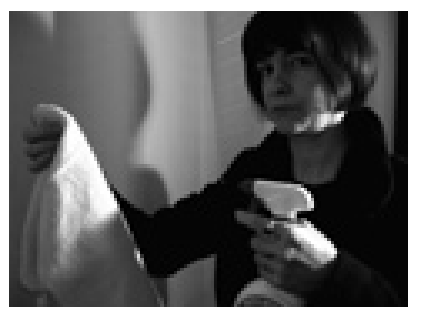

1 - Nous sommes en avril 2012, les feuillages persistants se relèvent d'un pénible hiver à contretemps, notre république reprend son souffle pour changer de président, et les bibliothèques demeurent nos lieux magiques, lieux pascaliens de l'humanité apaisée et du savoir classé. Pascal préconisait que nous restions assis à la maison, dans un fauteuil proche de la fenêtre, un gros volume ouvert sur les genoux; mais il n'aurait pas vu d'inconvénient, j'en suis sûre, à ce que nous sortions une fois par semaine pour nous réapprovisionner à la bibliothèque.

2 - En avril 2007, il y a cinq ans presque jour pour jour, tandis que j'arrivais à Lyon et emménageais dans le sud-est de la ville, ouvrait dans le même quartier, une médiathèque nommée Marguerite Duras. Le quartier où nous vivons, la médiathèque Marguerite Duras et moi depuis cinq ans, est un quartier en cours de requalification, ancien quartier d'ateliers et de petites entreprises, nouveau quartier d'habitation. J'habite dans un ancien bâtiment de bureaux transformé en habitation; la médiathèque est un bâtiment neuf et lumineux, construit après démolition d'une barre.

3 - Marguerite Duras, nom simple, lyrique, souhaitable, me disais-je, un nom qui choisit de conserver le livre et la littérature en tête de proue même si on aura à l'intérieur du bâtiment du son, de l'image et des ordinateurs. Je repensais par contraste aux noms de rues et lieux culturels donnant l'impression que nous nous cognons à chaque pas à un plafond trop bas, ou qu'au contraire on nous appuie dessus pour tenter de nous noyer dans un liquide quelconque.

4 - Les médiathèques sont de l'ordre du clinamen: au départ, avant le début du monde, tous les atomes tombent dans le même sens, 
parallèlement; mais, à un moment donné, expliquait Epicure, un atome se met à dévier de sa trajectoire, percute ses semblables, s'accroche à quelques-uns, en agglutine d'autres au passage, et si tout va bien, il crée un monde. Un monde apparaît, là où on n'avait jusqu'alors qu'une pluie monotone de particules.

5 -Au départ, tous les atomes de l'économie mondialisée tombent dans le même sens, et la population mondiale est unanime: la séduction maximale va aux centres commerciaux, au shopping. L'architecte Rem Koolhaas explique l'épanouissement dans le monde entier des malls, les vastes centres commerciaux, par les innovations techniques: escalator, air conditionné, lumière artificielle. Tous les malls tombent dans le même sens, dans le monde entier, les gens en raffolent. Or, à un moment donné, il y a vingt ans: clinamen, le fameux clinamen de 1992. En 1992, le prestige souhaité par nos autorités se mit à coïncider avec le savoir et sa démocratisation encore mieux qu'avec les centres commerciaux. Les pouvoirs publics eurent subitement envie de ranger les livres, les films, la musique, dans de vastes bâtiments ouverts sur la ville, éclairés non par des ampoules mais par la lumière du jour, bâtiments dont on ressent l'ampleur en 3D traversée de passerelles et d'ascenseurs. En comparaison, ce n'est pas pour critiquer, mais autant dire que les centres commerciaux perdirent de leur attractivité, et devinrent désagréables et datés avec leur pauvre lumière électrique, avec leur vacarme, leurs produits, leurs marques.

6 - Ainsi est notre médiathèque Marguerite Duras du $8^{e}$ arrondissement de Lyon: née en 2007 des suites du clinamen 1992 toujours vivace quinze ans plus tard. Spacieuse, ouverte sur l'extérieur, précise à l'intérieur, vitrée de bas en haut. À gauche de la porte d'entrée, en façade, dans l'immense vitrine de verre, on peut lire une phrase de Marguerite Duras:

«Écrire, c'était la seule chose qui peuplait ma vie et qui l'enchantait. Je l'ai fait. L'écriture ne m'a jamais quittée.»

7 - J'aime la présence dans le quartier de cette phrase écrite sur une seule ligne de dix mètres de long, en lettres blanches très visibles 
de la rue, sur fond de bois blond. Lorsque j'ai emménagé dans le quartier, j'aimais la voir ainsi, lisible depuis le tramway. Ne connaissant pas la ville, j'aimais que notre quartier en rénovation porte cette devise inattendue, comme une indication de direction à suivre. Et j'aime cette phrase pour elle-même, ces trois phrases qui n'en forment qu'une et résument une vie où ce qui tient du rêve, de l'enchantement, a tout simplement été réalisé.

«Écrire, c'était la seule chose qui peuplait ma vie et qui l'enchantait. Je l'ai fait. L'écriture ne m'a jamais quittée.»

C'est le résumé d'un monde où les conseillers d'orientation ont un emploi du temps réduit. Pas de longs tests de QI, pas d'étude de marché. Une question unique posée aux collégiens: "Qu'estce qui enchante votre vie? » Une réponse unique à leur réponse: «Ok, eh bien alors faites-le.»

8 - Je me souviens des premières phrases de Marguerite Duras que j'ai lues. J'avais quinze ans, c'était un samedi en fin de matinée; je rentrais du lycée. L'Amant venait d'obtenir le prix Goncourt. Marguerite Duras y parlait de son visage, dévasté, vieilli prématurément. Elle parlait aussi, dans une interview peut-être, des paroles déterminantes de Queneau, lorsqu'il lui avait conseillé de toujours écrire, de ne plus rien faire d'autre que ça, le reste de sa vie, de ne se laisser intimider par rien. J'étais en classe de seconde. L'Amant était arrivé dans le salon de mes parents par abonnement: le livre du mois était le prix Goncourt, L'Amant de Marguerite Duras. Et c'est ainsi par le truchement imprévisible du prix Goncourt et de l'abonnement France Loisirs que, confrontée à cette étrangeté d'être au monde et au magnétisme du livre, j'ai ressenti une intense secousse esthétique, un enchantement.

9 - Dès lors, en quête du même enchantement, j'ai lu tous les autres livres de Marguerite Duras, les livres écrits avant celui-ci, entre le moment où elle avait décidé de consacrer sa vie à l'écriture et le moment où elle avait rédigé L'Amant d'une seule coulée, très vite. Tous ses opus étaient au cdi de mon lycée; je les ai dévorés, réservant quand même la palme du magnétisme à L’Amant. Marguerite Duras 
l'expliquait en 1984, plusieurs années d'écriture lui avaient été utiles pour mettre au point le style à l'œuvre dans L'Amant: à force d'écrire, à force de travail dans les années passées, elle avait atteint un stade où l'écriture, rapide, fluide, ne lui demandait plus d'efforts et coulait d'elle avec facilité, si bien que L'Amant avait été écrit en trois petits mois. À force d'écrire, Marguerite Duras avait transformé son existence, sa parole, sa personne: tout était devenu écriture. Dans les années qui suivirent, cette parole très particulière émanait d'elle et transformait les choses du monde; le monde passait à travers elle, à travers sa machine, et ressortait à chaque fois enchanté.

10 - Et cet enchantement est devenu notre devise de quartier. Ainsi sommes-nous dans le sud-est lyonnais, dit la devise, il y a cette sorte d'exemplarité qui nous caractérise: nous voulons que soient mis à disposition de tous les meilleurs livres, films, disques. Nous localisons ce qui enchante notre vie, et nous le réalisons. Quand nos kids shootent dans leur ballon de foot sur la placette devant la médiathèque, ils ont toujours à l'horizon de leur champ de vision la phrase de Marguerite Duras, et leurs passes, leurs buts, sont imprégnés de cette vérité.

11 - Simplement une chose me tracassait depuis quelques mois. En l'espace des cinq ans écoulés depuis l'ouverture de la médiathèque, la poussière a pénétré dans la vitrine à gauche de la porte d'entrée: la phrase s'est ternie. Des toiles d'araignées pendent ici et là de notre devise. Je m'inquiétais qu'en cinq ans, la phrase de Marguerite Duras se soit altérée, laissant à craindre que dans dix ans, certaines lettres de notre devise pendront tête en bas, que dans vingt ans des gravats envahiront la vitrine, que nos rêves et nos idées seront bafoués. Étrange d'ailleurs, me disais-je, que la phrase de Marguerite Duras s'abîme quand le reste du bâtiment reste impeccable. L'imprévoyance que cela suppose m'inquiétait et me rappelait vaguement une bureaucratie années 70 quelque chose de sourd et inattentif. La même incompréhension qu'on ressent quand les horloges des bâtiments institutionnels, les horloges des stations de tramway, s'arrêtent et sont abandonnées à un horaire faux parce que semble-t-il on n'a pas prévu de budget pour les piles; une légèreté dans l'organisation du collectif qui, déjà en soi, nous 
rend nerveux, et nous inquiète d'autant plus un an après Fukushima, et nous évoque les réacteurs, les milliers de vannes et robinetteries, les centaines de milliers de petits joints, enfin bref.

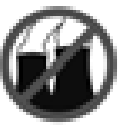

12 - Pour toutes ces raisons, j'ai acheté une peau de chamois et un cif javelisé. Et, comme on me proposait d'écrire un texte sur une médiathèque, j'ai bien sûr choisi la médiathèque Marguerite Duras, et profité de l'occasion pour tenter de me faufiler jusqu'à la phrase. J'ai acheté cette peau de chamois et ce cif et le 10 janvier, je me suis présentée à la médiathèque et j'ai proposé à la direction mes services de ménagère en vue de nettoyer la phrase de Marguerite Duras. Une ménagère peut-être pas excellente, mais que j'espérais suffisamment compétente pour une tâche limitée, pour un nettoyage de phrase.

13 - Le 10 janvier 2012, j'ai compris que j'aurais du mal à me faufiler. Depuis une passerelle traversant et surplombant le bâtiment, Anne-Marie Rouge, la responsable de la médiathèque, m'a montré le problème: la vitrine dans laquelle est enfermée la phrase de Marguerite Duras est inaccessible; les vitres intérieures de la double-peau, qui s'ouvrent partout ailleurs, sont à cet endroitlà inamovibles. L'architecte n'a pas prévu d'ouverture vers cette vitrine comme il l'a fait pour les autres, m'a-t-elle expliqué. Un oubli, semble-t-il, ou une mesure d'économie. Lorsqu'a lieu une fois par an à la rentrée le nettoyage général des vitres de la médiathèques, bien qu'Anne-Marie Rouge tienne à la beauté et à la conservation de son bâtiment, à ses collections à la fois larges et pointues, à ses animations bien pensées, bien qu'elle tienne à son public à l'heure, et aussi à son public en retard, bien qu'elle tienne à tout, elle ne peut faire nettoyer cet espace.

14 - Cependant, ce même 10 janvier, tandis qu'Anne-Marie Rouge et moi, accoudées à la rambarde de la passerelle, nous surplombions la bibliothèque et regardions la vitrine inaccessible, elle m'a indiqué 
la faille: le chemin qu'il serait malgré tout possible d'emprunter pour se rendre jusqu'à la phrase de Marguerite Duras. La vitrine n'est pas hermétiquement close: si on ne peut y pénétrer directement, on peut en revanche passer par la vitrine à droite de la porte d'entrée, puis poser une échelle, grimper au-dessus de la porte d'entrée de la médiathèque, hisser l'échelle et la faire passer de l'autre côté en marchant sur l'étroit plan horizontal au-dessus de la porte, puis redescendre dans la vitrine de gauche.

15 - «Il faudrait passer par là, si vous vouliez nettoyer, me disait Anne-Marie Rouge. Mais bien sûr, pour des raisons évidentes de sécurité, on ne vous laissera pas faire. Il faudrait mettre une échelle, qui risquerait de glisser, je vous la tiendrais, vous monteriez, vous pourriez d'ailleurs en profiter pour nettoyer le dessus de la porte qui est fort sale, me disait-elle plaisamment. - Pas de problème, lui ai-je dit, je nettoierai aussi le dessus de la porte de la médiathèque. Vous imaginez comme ce serait bien, lui disaisje, on pourrait filmer depuis l'extérieur ce parcours vertical et horizontal dans la vitrine de la bibliothèque, ce serait vraiment beau. - Ce serait vraiment très beau, a-t-elle dit. Le seul problème, c'est que je ne pense pas qu'on vous laisse faire.»

$16-$

Il

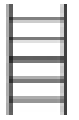

y a un problème, en effet, avec les

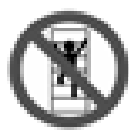

échelles:

17 - Bilan : j'avais un cif, une peau de chamois, une échelle, des jambes pour grimper, des bras pour frotter, et une conservatrice diplômée disposée à me tenir l'échelle.

Simplement les assurances préfèrent en général que je ne monte pas sur une échelle pour ensuite aller tomber et en cas de pépin faire supporter aux autres les conséquences de mon imprudence. Les assurances ont ce pouvoir de s'entreposer entre nous-mêmes et nos gestes. Couvrant les risques, elles exigent qu'il n'y en ait au- 
cun, qu'on s'engage à ne monter sur aucune chaise pour changer l'ampoule, sur aucune échelle, surtout pas un cif dans la main. Les assurances placent notre argent, médiatisent nos gestes et les éteignent. Mobilité de l'argent, extinction des gestes. Et qu'importent la beauté et la subtilité des rêves de nos kids.

18 - Ne baissant pas les bras, tant l'acte me paraissait simple à réaliser, et parce que je ne comprenais pas exactement qui s'y opposerait ni comment, j'ai rédigé une demande d'autorisation de nettoyage de phrase. Mais en même temps, dans les soubassements de mon cerveau se mettaient en place, je dois l'avouer, mes réflexes mentaux paranoïaques de collectionneuse.

Je collectionne en effet les amputations de liberté au nom de gains plus qu'hypothétiques, ce qui nous sépare de notre réel, ce qui tend à nous affaiblir, à nous rendre piètres et sans envergure, incapables d'accomplir les actes les plus simples, d'avancer la main et de toucher les objets. Je collectionne les tuyaux, les autoroutes, où les événements circulent selon un sens préétabli, de telle sorte que nous perdons prise, les injonctions contreproductives, les arguments sécuritaires nous mettant en danger, lois anti-terroristes, campagnes de vaccinations meurtrières, abattages de montagnes de bêtes.

\section{Fumer}

Enfant, lisant des livres de science-fiction, je me demandais comment les gens du futur en étaient arrivés là, comment ils avaient été conduits à admettre des situations inadmissibles. Les transformations s'étaient-elles passées par degrés continus et imperceptibles? Ou les choses avaient-elles été bouleversées à la faveur d'un accident, dans le tumulte d'une catastrophe?

Oui, je sais, j'y allais fort, je réagissais comme quelqu'un qui a vécu dans un pays en guerre et dont les mécanismes de méfiance, les stratégies de survie, sont profondément ancrés, comme quelqu'un qui a de tout temps vécu dans une période de crise. 
19 - Un lundi de février, j'ai montré la phrase de Marguerite Duras à Aurélie Pétrel. J'ai pris mon vélo, mon cif et ma peau de chamois, j'avais une petite grippe, mais je ne voulais pas rater le rendezvous. Aurélie a photographié la phrase et mes accessoires de ménage; des garçons assis sur un banc nous ont dit que si nous avions besoin de beaux gars sur les photos, ils étaient là. L'idée du nettoyage de phrase plaisait à Aurélie, et aussi qu'on puisse le filmer à travers la vitre: "A $200 \%$ », a-t-elle dit. Plusieurs personnes de mon entourage s'étaient d'ailleurs proposées les jours précédents pour venir m'aider à briquer les lettres blanches au cas où cela deviendrait possible. Puis Aurélie et moi, avons pris le temps de faire connaissance; devant la médiathèque fermée ce jour-là, nous avons dressé la liste de nos relations communes; j'ai appris à Aurélie la mort d'une jeune femme qu'elle avait connue; Aurélie a reçu un choc à l'annonce de cette nouvelle, et moi-même j'ai vacillé à cause de mon virus et de la mort présente entre nous. Nous nous sommes assises sur le trottoir et nous avons continué de parler un moment sous la phrase de Marguerite Duras.

$20-$

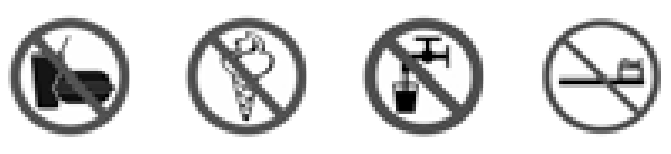

Ce n'est pas possible, me disais-je, dans les semaines qui ont suivi.

21 - Et puis l'horizon de cette petite action s'est dégagé. AnneMarie Rouge m'a annoncé qu'elle avait trouvé une solution pour que nous puissions régler le problème correctement et nettoyer enfin cette vitrine à l'abandon depuis trop longtemps. Le clinamen des médiathèques avait opéré et des échelles ont été fixées sur les côtés de la porte d'entrée. J'ai pu grimper sur une échelle. J'ai pu grimper sur l'autre échelle. Je suis montée à droite de la porte. J'ai marché au-dessus de la porte, j'en ai profité pour arranger un peu ce dessus de porte qui laissait à désirer. Je suis redescendue à gauche. Et j'ai nettoyé la phrase de Marguerite Duras. 
22 - Et à présent que, grâce à ce texte, une impossibilité a pu être réduite, j'aimerais beaucoup poursuivre dans cette voie et écrire d'autres textes afin de contrer de nombreux interdits. J'aimerais écrire des textes afin que nous puissions entrer à cheval, rester en compagnie de nos amis à quatre pattes, afin que nous refassions le monde comme Sartre une clope au bec, afin que nous fassions cours comme Gilles Deleuze dans un nuage de fumée où on distingue à peine les étudiants, afin que nous puissions plonger là où l'eau est peu profonde ou alors trop profonde, afin que nous portions des gants mais pas de chaussures, afin que nous puissions courir très près du bord, passer en dessous d'une charge, boire enceinte, parler fort dans nos mobiles, dévaler la pente en luge, sonner le clairon, pénétrer dans ces lieux avec nos stimulateurs cardiaques, survoler les continents avec nos poitrines siliconées, stationner les motos, passer par cette petite porte au volant de notre Fenwick, afin que nous puissions simplement entreposer ici nos skis, bâtons et chaussures de ski, puis entrer à pieds, avancer la main et toucher les objets.
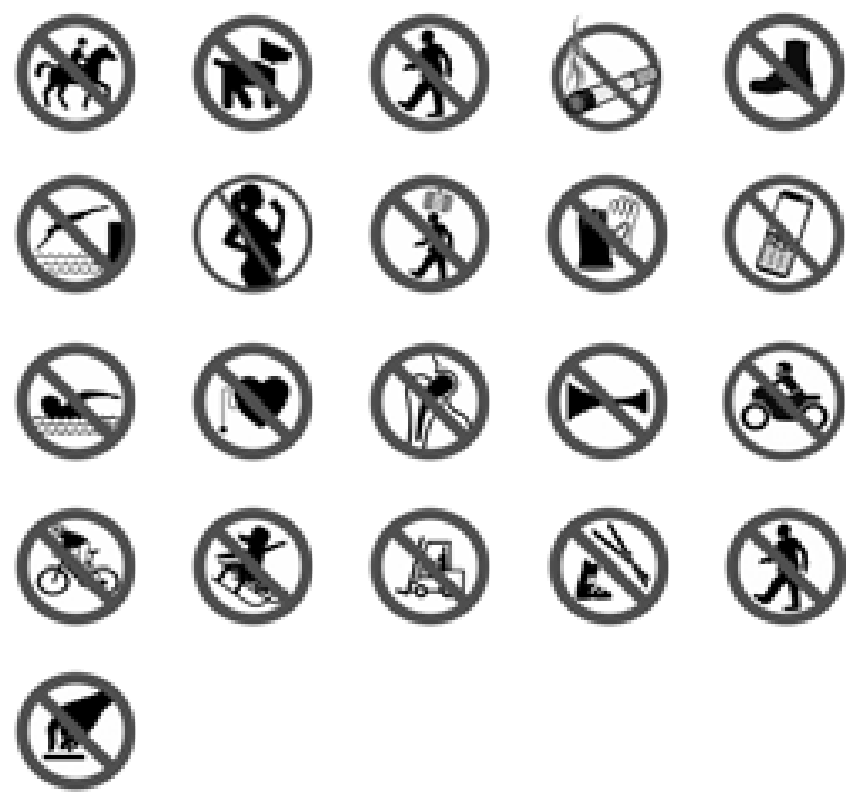


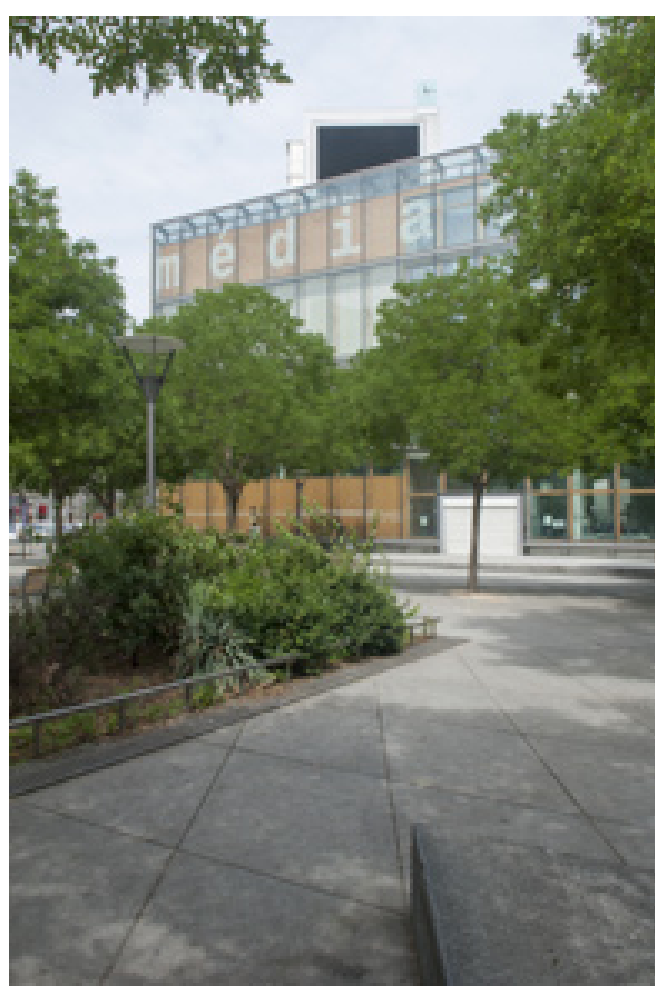




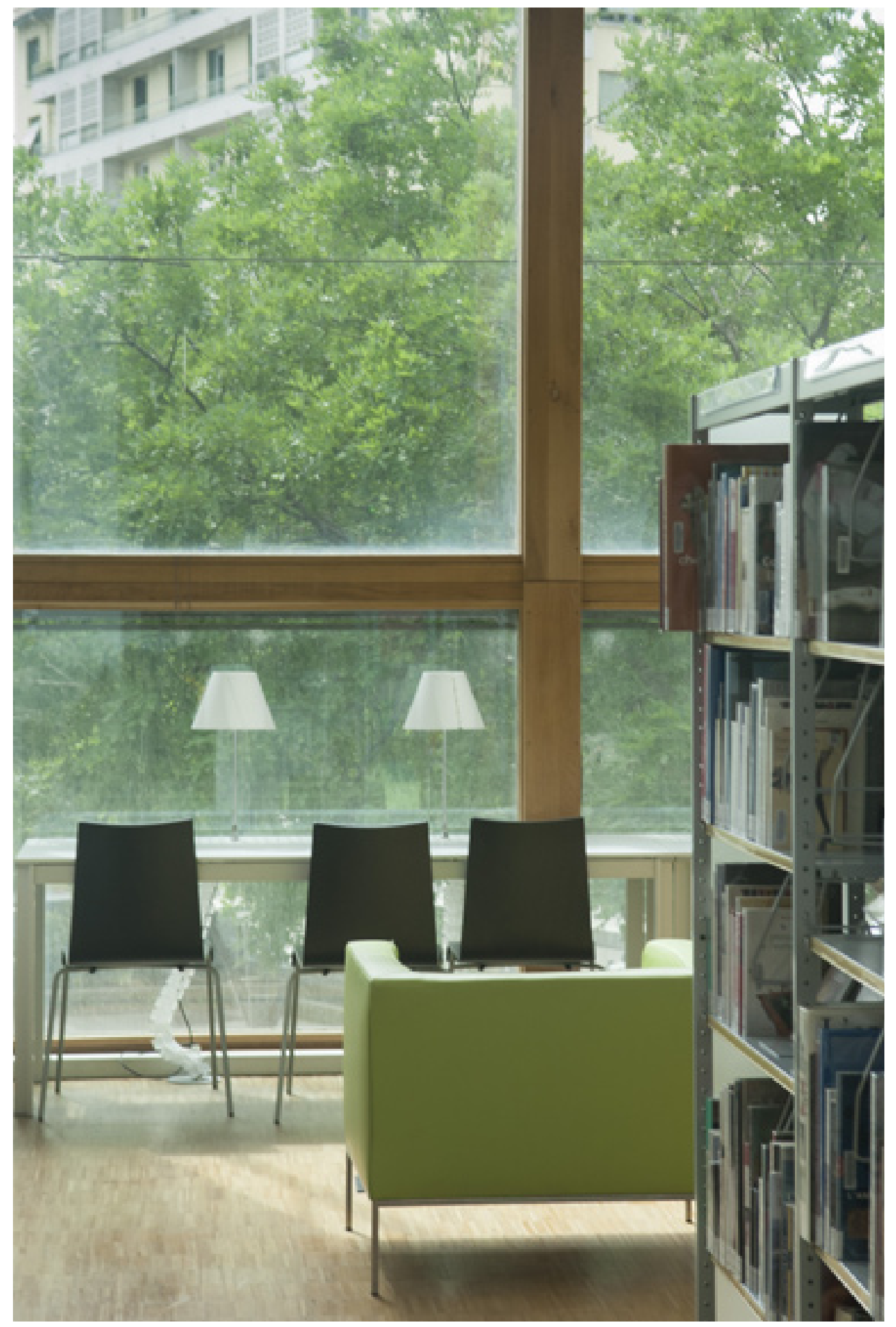




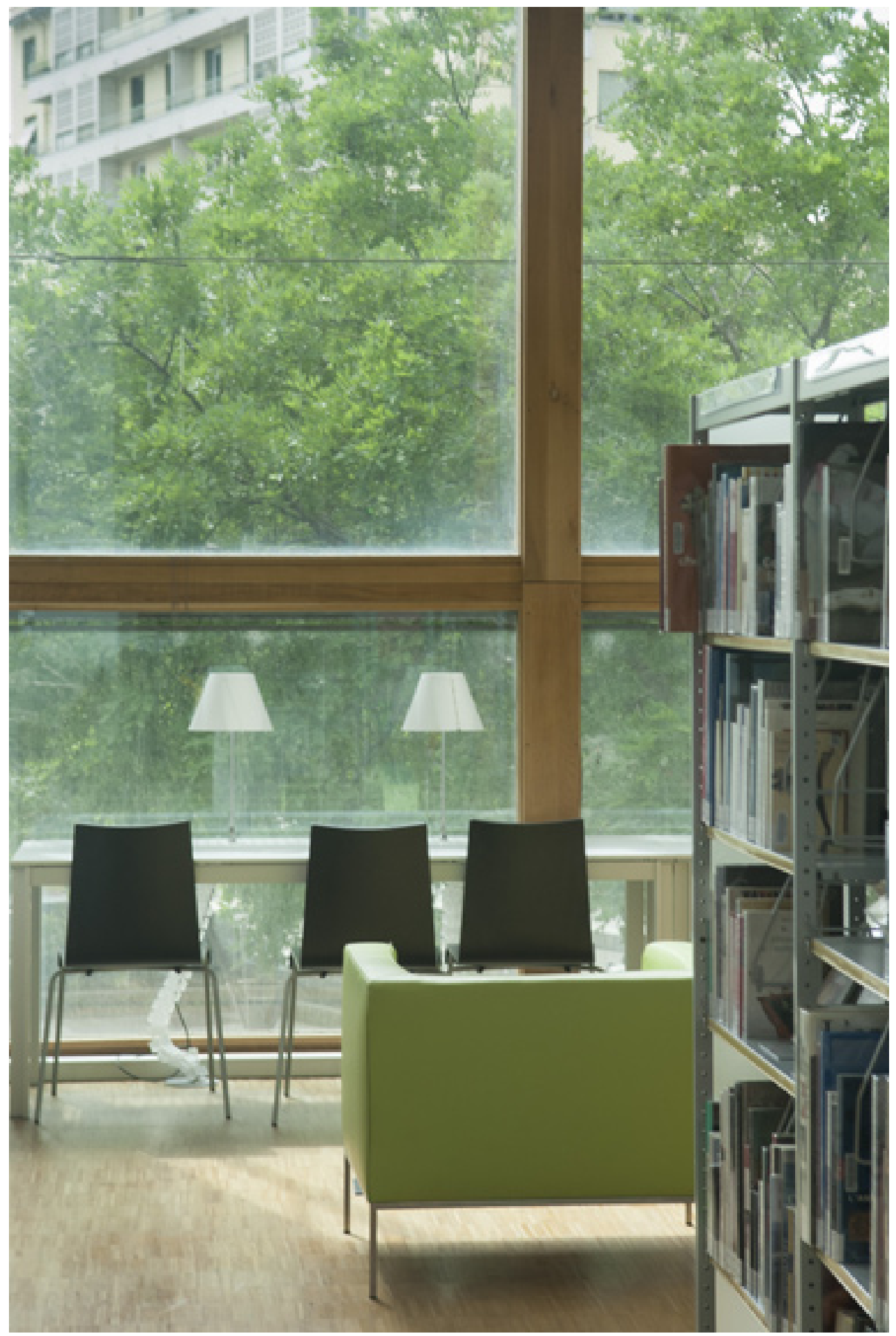




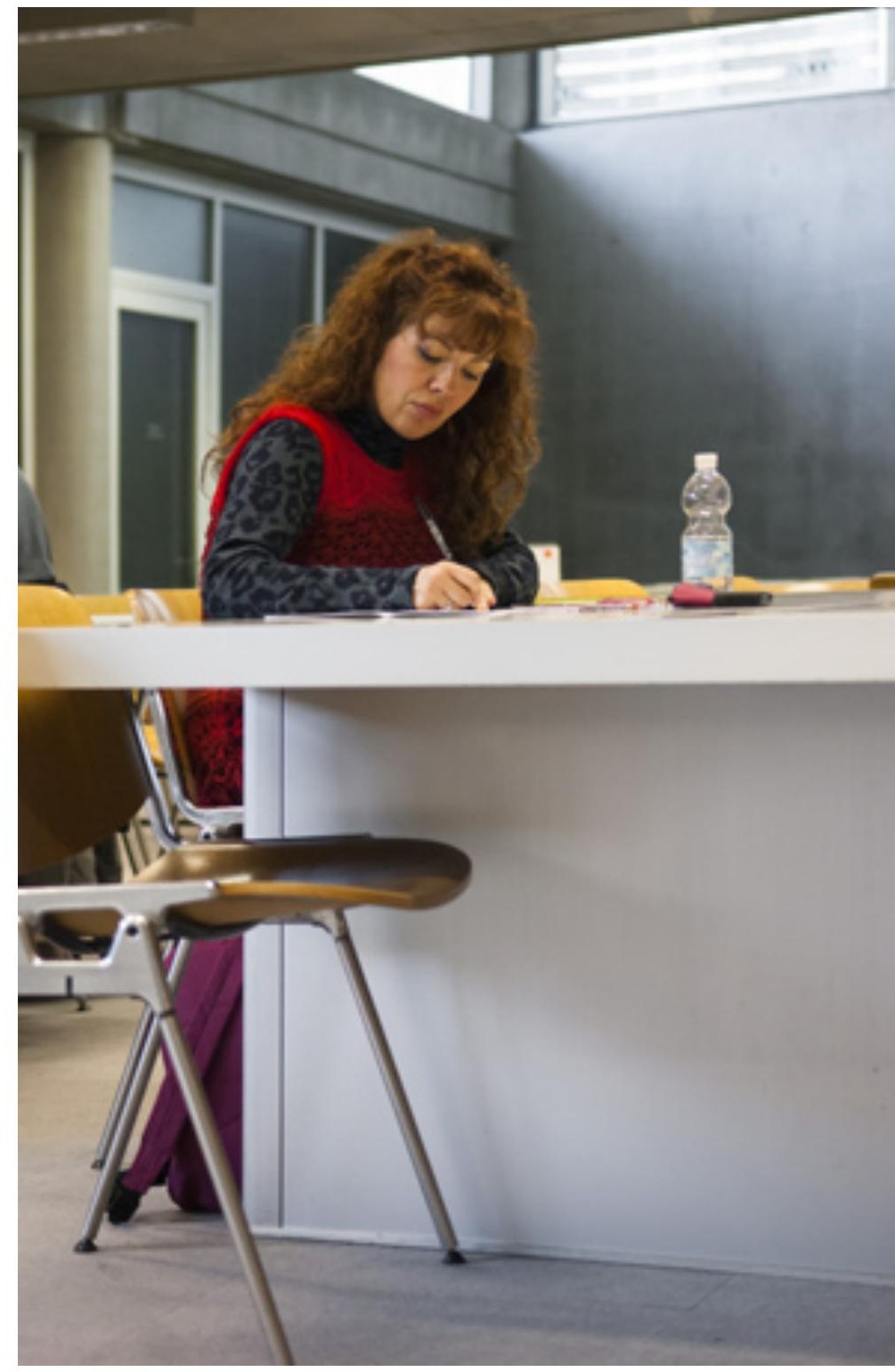


à ma mère

I/ Préambule

comme une biographie de lire

1- Cela a commencé ainsi

On m'a donné la chambre des Grands

Il y est sur l'étagère de livre «une vie de Proust», par un auteur anglais, George D. Painter ${ }^{1}$,

Une lecture de ma mère

en prêt de bibliothèque

Et, après qu'on eut sonné à la porte de l'appartement, la chambre tout près, mon père vint me chercher et me demanda d'assumer

la commande que j'avais faite:

Dans ces années 1950 - j'ai sept ans, puis bientôt quatorze - les éditions Jean de Bonnot et les éditions suisses Rencontre, proposent dans la presse quotidienne, l'achat de livres - avec belle reliure - payable à tempérament, je leur avais écrit, j'avais commandé les œuvres complètes de Tolstoï, Chekhov, Rousseau... Rouge de confusion, je remerciai le facteur, et mon père qui paya le premier tempérament.

Et je lus.

Arrivé à l'âge de deux ans à Lyon,

Ce sera à la bibliothèque de Saint-Jean, alors bibliothèque municipale principale,

sous la cathédrale,

que je fais les premières incursions de travail:

Dois-je lire les ouvrages sur, ou les textes de,

telle fut ma première grande question avec le livre,

1. George D. Painter, Marcel Proust: Les Années de la jeunesse (1871-1903), Les Années de maturité (1904-1922), 2 volumes, Mercure de France, 1966.
Quant à ma première déconvenue, mais édifiante, je jubilais, au collège de Bonneville (Savoie), interne, pour ma seconde, ma première avec mon premier 
baccalauréat, menace de renvoi: je lis en étude Steinbeck, Les raisins de la colère, En un combat douteux, Louis-Ferdinand Céline... Les livres sont enfouis dans le tiroir de mon bureau.

2- Bibliothèques

a-d'étudiants:

Bibliothèque de Lyon Saint-Jean

De l'École de médecine, à Grange-Blanche, Lyon,

De la faculté de droit, rue d'Assas, à Paris

Du conservatoire des Arts et Métiers, porte Saint-Martin, Paris

$\mathrm{b}$ - en visites

Seulement visites, avec les camarades architectes, autour de Desssau, Leipzig, Weimar, Berlin, Est, Ouest - J'écris, à La voix du Lyonnais, chaque semaine, et à L'Humanité. La Grande Bibliothèque de Berlin.

Nous sommes en 1983, accompagnés du grand architecte Gagès.

2005, dans la nuit de l'au-delà, à trois cents kilomètres au-delà du cercle polaire, en hiver, la bibliothèque d'Ivalo où mon épouse et moi-même demeurons tout un mois. Les poètes, Edith Södergran, Bo Carpelan, Pentti Holappa, la musique, Sibelius, Bj rk, la langue finnoise, et saami. Et suédoise. Nous avons notre propre carte d'usagers. Le bibliobus passe une fois par semaine au village de Kopello.

2009, L'installation d'Alain Fleisher à la Bibliothèque nationale rue de Richelieu. Et pourquoi le livre n'arriverait-il pas sous les yeux des chercheurs sur les tables, en écran? J'y lis dans Satori à Paris, que Jack Kerouac, lui, chercha sans succès des documents sur sa famille bretonne...

1999-2011, bibliothèque de la Durance, à Cavaillon. Je l'ai manqué. J'y suis allé. Mais tout n'est pas perdu. Et puis nous y avons retrouvé Bernard Noël autour de cinq jeunes écrivains.

2005, désuète, mais très belle, romantique bibliothèque de l'Alliance française de Buenos Aires. 
2011, Dans la province de Québec, à l'automne 2011, alors que je sais avec bonheur devoir me rendre à Nîmes en janvier 2012: Chicoutimi, bibliothèque publique, le 29 septembre 2011 Montréal, bibliothèque et Archives nationales du Québec, automne 2011

Trois-Rivières, bibliothèque Gatien-Lapointe, les 7 et 8 octobre 2011, Festival international de poésie...

Montréal, bibliothèque d'Ahuntsic - j'aime la consonance amérindienne

Montréal, bibliothèque du Plateau-Mont-Royal - exposition soirée pour les quarante ans des éditions du Noroît, de Trois-Rivières, poésie. Paul Bélanger. Dessins de Valère (Novarina). Guy Cloutier, qui frissonne à ces nom et prénom... Dans les Laurentides, la bibliothèque de Val-David. Dans les Cantons de l'Est, à Magog, impossible de ne pas penser à Samuel Becket...

Mots de communication envers les humains pour les encourager à fréquenter la bibliothèque, c'est-à-dire le savoir:

Emprunt, Renouvellement, Distance, Résident, Abonnement, Identité, Ressources, Gratuit, En ligne, Services, Archives, Liures, Responsabilité, Accès, Carte d'abonnement, Conseils, Collection...

c- engagé

Lire et lire, et passer

Années

1970,

À la bibliothèque de Villeurbanne, table ronde avec Patrick Laupin, Mathieu Bénézet, Michel Pouille. [Je suis l'éditeur de la revue Actuels (Comité de rédaction Henri Poncet, Patrick Laupin, Michel Pouille...)]

2. Jean-Louis Schefer et Jacqueline Salmon, 8 rue Juiverie: la lumière élargie. Architecture de Philibert de I'Orme, Lyon, Comp'act, 1989.
1990,

À la bibliothèque Lyon Saint-Jean: Nous invitons (C. G. et moi) Jean-Louis Schefer et Jacqueline Salmon à l'occasion de la parution de leur livre rue Juiverie ${ }^{2}$. 
1993,

Warszawa. Musée d'art contemporain, Zamek-Ujazdowski.

Je montre Lire, une installation faite d'une table, un manuscrit et sa traduction en polonais, un carnet, un stylo, une photographie, une chaise.

Les Archives de vingt ans du travail réalisé avec d'autres par la Galerie-Librairie l'Ollave à Lyon sont présentées à la bibliothèque du musée d'art contemporain de Varsovie. Là, je lis Un épisode en bibliothèque, du grand poète polonais Zbiegniew Herbert - maintenant traduit ${ }^{3}$ : «La jeune fille blonde est penchée sur le poème. D'un crayon aiguisé comme un bistouri, elle reporte des mots sur la page blanche et les transforme en traits, accents et césures. La lamentation du poète tombé a maintenant l'air d'une salamandre dévorée par les fourmis.

Quand nous l'avons emportée sous la mitraille, je croyais que son corps encore tiède allait ressusciter dans le mot. Maintenant, en voyant la mort des mots, je sais qu'il n'y a pas de limite à la dissolution. Il restera de nous dans la terre noire des lettres éparpillées. Accents au-dessus du néant et de la poussière. »

1998 ,

à la bibliothèque de Lyon, Part Dieu.

Mercredi 7 janvier 1998: Pourquoi? (Parcourir ce chemin comme un rite.) Aller à la bibliothèque, chercher et lire, dans le brouillard, des textes qui nourriraient une question que je me pose? Combler le vide de ce qu'est la vie? La vie, cette longue et courte étendue dans le temps. Nourrir! De la chasse au liure! Qu'est ce corps placé entre deux autres lecteurs?

Jeudi 8 janvier 1998: À travers la vitre du bâtiment, il me regarde. D'autant plus que je lui ai souri, perplexe et soupirant de me voir ouvrir mon cartable et en sortir cahiers et liures. Cette fois-ci c'est moi qui le vois, il me tourne le dos et lève sa bouteille et boit au goulot et plonge ses doigts des mains dans l'oreille et les cheveux.

Lundi 19 janvier 1998: J'ouvre les livres et sais bien que ce qu'ils abordent est loin - à la périphérie quand même! - de l'objet de mes 
recherches, comme approche avant d'entrer dans le sujet, avec un temps imparti, une donnée précise, une attente d'un commanditaire, et le savoir, soit de mon incompétence, soit de ma critique du sujet.

2002,

Bibliothèque de l'Institut français de New York, là je lis ma poésie dans la bibliothèque, j'expose des photographies de la Ligurie et de Dublin.

Bibliothèque Lyon Part-Dieu. Vingt-six ans de travail sur le livre et lectures publiques réalisés par le même groupe d'amis cités pour Varsovie. Création d'un Fonds, Fonds Galerie-Librairie l'Ollave ${ }^{4}$, comportant également l'action autour du livre et sa lecture publique, et le restant de sa bibliothèque.

Lectures, avec C. J., avec Isabelle Baladine Howald. J'invite Patrick Rousseau, Siegfried Plümper-Hüttenbrink.

Médiathèque de la Halle aux Grains, à Apt. Les deux soirées annuelles des Cris poétiques depuis sept ans avec le Vélo Théâtre, abondent le fonds Poésie par don des ouvrages des auteurs rencontrés et sollicités à lire.

Aussi, j'y lis.

II/Lire.

Ah! J'achète les livres que je lis

L'automne 2011 est québécois

Le 19 septembre 2011

Un hiver au p’tit Hippolyte, de Paul Grégoire

21 septembre 2011, Nelly Arcan

Burqa de chair, avec une préface de Nancy Huston

3. Zbigniew Herbert, Corde de lumière, EEuvres poétiques complètes I, Le bruit du temps, 2011 , traduction Brigitte Gautier. 4. Inventaire d'archives, bibliothèque municipale de Lyon: $<$ http://www.bmlyon.fr/trouver/pleade/ archives.htm >
22 septembre 2011, La Presse, quotidien de Montréal, titre Inventer sa vie pour La petite cousine de Freud, de Ann Charney ... et Ann Charney émigrait de Pologne. "Dans ce Nouveau Monde on peut s'inventer comme on le veut. 
C’est ça l'expérience immigrante.»

$1^{\text {er }}$ octobre 2011. Je trouve le livre de Denise Boucher, qui vient de paraître, chez Leméac, et que Patrick Dubost me demande d'acquérir et de lui rapporter.

Le livre, là, de Jean-Luc Nancy chez Galilée me fait penser à Philippe Lacoue-Labarthe, et à son texte que je souhaite trouver qui concerne la phrase. Y a-t-il un livre de Philippe L.-L. ayant pour titre Phrase? Le bibliothécaire cherche et trouve, chez Bourgois La poésie comme expérience. Il va me le préparer. Là, Philippe Lacoue-Labarthe travaille autour de deux poèmes de Paul Celan.

Le plus possible qu'il m'est, j'achète les livres de mes amis.

Il faut participer à la chaîne du livre - ici, en l'occurrence les librairies.

III / Nîmes

Je lis en bibliothèque.

En 2012, les 19 et 20 janvier, Le Carré d'art, bibliothèque de Nîmes

$1-$

Avant cela:

Première pluie de feuilles des arbres

Dans les rues arborées d'érables

Et fouler dans la marche la douceur

Des jaunes et des rouges

J'avais vu Jan Fabre au Carré d'art. Oh! Et Paul Klee? Il y a si longtemps, et c'était magnifique! J'ai fêté, aussi, avec tous les autres, Patrice Pouperon et ses éditions de la Garonne, Patrice disparu cette année 2011, Éléonore peu avant Patrice.

Cette nouvelle année me conduit à nouveau au Carré d'art, et pour y lire.

Ce sont bien des saisons, qui mènent, nous et le faire. Et le temps. 
J'ai l'automne et l'hiver pour me rendre au Carré d'art.

Le 20 janvier 2012, lire.

Je foulerai - monterai, descendrai - ses marches - il y en a tant

- même dès le 19 janvier. Je prendrai une chambre en ville, accompagné de Martina.

2 - Préparation (Montréal, automne 2012)

On se prépare toujours. Je.

Dans le voyage, l'ailleurs

Avec le livre

Dans l'écrit

Cet après-midi, j'ai trouvé que

La rame du métro montréalais

se fait entendre, avant l'arrivée aux quais,

comme la mer son immense vague

avant de s'échouer sur la grève.

Accompagnement 1

Ailleurs n'est pas pareil: ici, il y a érable

À heures fixes et toute la journée

Les avions sont déjà bas à atterrir

À l'aéroport, à l'ouest, à Montréal

Au-dessus de la rue Drolet 8384,

À Dublin, à mon aube, c'étaient les trains du DART à la North Train Station

À Zagreb, à Trnsko, Nouveau Zagreb, c'est le train de marchandise Le transport.

La ruelle montréalaise est le rear dublinois

Accompagnement 2

Le déplacement de l'objet de sa phrase

Et l'érable, nombreux, bordant la rue,

Je viderais bien ainsi la maison de ses objets,

Et vide, commencerais à la dire. 
Les adresses sont multiples.

Pas tant à moi que les miennes.

Nous avons fait de la place

la plupart du temps,

Le plus difficile c'est dans la phrase,

Les envois.

Accompagnement 3

Il a la sienne lorsqu'il tape la brique

Juste posée sur le ciment après l'avoir

raclée de son trop, et les autres rient,

là-haut au faîte du mur brun de l'échafaudage.

Il n'est pas que l'entente, encore que

les langues sont à écouter bien, aussi

la vision, des gestes que nous ne savons

et que leurs phrases n'empêchent pas. Autant d'adresses d'envois

qui lient trois hommes qui construisent.

La bicyclette est au haut, contre la rambarde

de l'escalier vers le deuxième, il est

difficile de savoir quelle langue ils parlent

qu'on entend des cuisines et par le jardin

dans la ruelle, et quand l'avion vers l'aéroport

s'y met à les couvrir, bien sûr on ne saura pas.

Seul l'éternuement, ou la phrase de l'enfant

qui s'exclame en découvrant la feuille rouge

au retour de l'école, c'est l'heure, avec le père.

Oh! Une feuille rouge! C'est bien là une exclamation, la petite fille a mis un point tout de suite à sa phrase, je l'entends au haut de la page, tout autre bruit, la vaisselle essuyée de l'évier, qu'on range, un rire trop fréquent pour être déliuré, le silence même d'une personne assise sur sa terrasse et qui demeure un mystère, et ce qui lie le tout qui sont mille films entre les mains tout au long de la ruelle, la suite de la phrase de l'enfant est en elle, comme ce qui l'inspirait déjà captivée pour ensuite l'exclamer. 


\section{Accompagnement 4}

Ce qui est fini s'annonçait ce qui commence s'annonçait, cela même qui s'oublie est concret dans le chaud et le froid, l'immobilité et le vent, la nudité et la couverture, le feuillage et la branche, la parole et le silence, le sec et la buée au-delà des lèures, concret et du fleuve, et de l'homme, objets de l'univers.

C'est à la jonction qu'est la chance de percevoir

C'est à une phrase seule

et ce qu'elle laisse entendre

Une phrase définitive permet de rouvrir, qui cachait le merveilleux - à la relire

La saison serait-elle alors une phrase?

Et l'intersaison la fin d'une phrase, le commencement de l'autre?

Car il n'est pas fini de parler

L'autre phrase était annoncée

De l'écrit qu'on lit.

Nîmes. La bibliothèque du Carré d'art

1. La bibliothèque, entité nationale ou municipale est Institution, pilier essentiel de la société du savoir. Elle offre elle a cette mission - un accès démocratique à la culture et à la connaissance. À la culture: pratiquer la lecture. Une pratique. Mallarmé: "Lire, cette pratique». Lire, écouter, voir ce qui est dit, ce que ça dit, et comment c'est dit. Et les sons, et les couleurs.

Et modifier le cours des existences.

Dans le monde actuel, commencé, la bibliothèque, et sa pratique, deviennent un lieu et acte de résistance. Puisque la marchandisation du savoir arrive aussi, et notamment à l'école et à l'université. Au moment où les scientifiques de diverses pratiques de recherche disent et démontrent le rôle délétère, et participatif de la barbarie déjà présente dans nos sociétés occidentales, de la télévision, la Bibliothèque - 
portons-lui une majuscule - est le lieu emblématique de l'éducation, de l'ouverture, de la possibilité du vivre.

Elle reste également, la bibliothèque, le lieu de la conservation, et inaliénable, des essais et des œuvres.

2. Je dois dire ma propension à regarder avec plaisir le construit. À le photographier, même. Le terme construit vient du constructivisme, avant-garde de la peinture du début du xx siècle, qui nous vient de l'Est de l'Europe - cardinal à égale propension de mon attention - en Pologne. En France, Cercle et Carré. Nous nous trouvons, l'humain, à nos justes places: pour moi, Nîmes, au Carré d'art de Norman Foster qui répond à la Maison Carrée, comme à l'Arène. L'homme fait sa forme, une forme, dans sa geste. Me voilà à Nîmes.

3. Je ne suis pas si sensible à ce que la bibliothèque, son bâtiment, soit d'une architecture. Le livre avant tout, et un fouillis ne m'exaspère pas. Et un désuet. Je remarque le bâtiment, en accédant à la bibliothèque, et il est possible de remarquer que le livre est sanctuarisé: c'est bien. Dedans, par exemple à Montréal cet automne 2011, à Berlin (Ouest à l'époque, en 1983) - où, je l'admets, j'étais avec des architectes! À Nîmes où ce n'est pas la première fois que j'y travaille, j'ai bien pensé qu'il fallait que le "service» soit pensé, et qu'au moins les espaces intérieurs, de diverses occupations, soient pensés. Il demeure bien que nos siècles doivent construire, au moins l'institution républicaine, et que ce ne soit pas seulement les Empires, les Monarchies et les Églises qui bâtissent de la beauté, celle qui demeure, et nous ravit, la bourgeoisie devenue frileuse, qui nous laisse tant ignares - nous qui élisons. Que la république au moins nous construise, et sans pouvoir! Bibliothèque, musées, maisons de Région, mairie, etc. Elle l'a fait ici, face à la Maison Carrée romaine, le Carré d'art!

4. Est-on assez honnête avec l'usager de la bibliothèque? Ne devrait-on pas le prévenir que «Dans une phrase prononcée, écrite, quelque chose vient à trébucher»?

5. «Puis je traversais la rue de Richelieu 
Pour rejoindre ma place, lecteur euphorique, Jouir en souverain d'un républicain lieu. » Jacques Roubaud. (Que les sachants, les bibliothécaires dirigent les bibliothèques! Vigilance aujourd'hui: pas les gestionnaires ou les amis politiques, pas l'entreprise, mais le Service Public!)

Accompagnement 5

Et la pluie, immédiatement la phrase dite, très vite vient le crépuscule, le jour non fini. C'est suivant la saison car, la phrase dite

le vent chasse les nuages pour un ciel bleu tout au long et tard dans le jour infini.

La nuit est la phrase du rêve, la syntaxe du poème La saison est la voix des chapitres, et la phrase comporte d'autres mots, ses mots.

D'autres sons, ses sons.

La phrase sonore.

Le rêve a la chance d'être l'expiration, l'exclamation en développement.

6. Je ne prends pas au sérieux, mais énormément à la tendresse le construit et l'institution que parce qu'ils sont parties prenantes de la vie. Et telle, pour moi, la commande de l'anniversaire: J'ai dit déjà mes allers à la bibliothèque de Nîmes. Bientôt, et ça y est, c'est fait alors qu'on me lit là, j'y retrouverais le jeune ami - de la génération d'un de mes fils, écrivain et traducteur qui m'y a invité à lire, j'y retrouverais la jeune amie poète qui m'invitait à la bibliothèque de l'Institut français de New York - elle avait dix-huit ans juste quand je la connus, je me souviens bien nous fûmes à une table réunis, à mon côté elle me dit, moi déjà séduit, «'écris de la poésie». Nous lirons - nous avons lu - le même soir. Ne soyons pas sérieux: Que croyons-nous, des jeunes ou vieux barbons, et des filles, qui viennent dans le silence, aux tables et aux 
lampes de travail des bibliothèques, sinon vivre l'imprévu recherché ou non que nous trouvons dans les livres?! Ainsi je souligne la transparence de la Maison Carrée, la traversée du regard possible, la sensualité d'êtres à sourire - la réflexion, dont les jeux dans les reflets. Comme Philippe LacoueLabarthe "je rêvais de contribuer à cette production de phrases qui nous font être ce que nous sommes, qui nous trame dans ce langage que personne - nul humain en tout cas - n'a jamais inventé, et qui nous rythment selon une scansion dont nous ignorons la loi, sachant seulement qu'il y a loi ${ }^{5}$.»

IV/Nîmes,

19 janvier 2012.

5 h 45.

Le ciel de janvier va s'éteindre sur/la Maison Carrée et le Carré d'art/La majesté de siècles/s'empourpre de brume /mais c'est encore l'heure/des palabres et des jeux/ sur l'agora l'heure encore/de studieuses têtes penchées / auprès des vitrages dans les arbres/sur les pages des livres des cahiers/et des ordinateurs/Mais/où sont les lieux silencieux/et les lumières qui cernent les livres? / On s'en occupe/Justement on s'en occupe. / Présence des jours: Ce jourlà je retiens: Claude Simon, Ah! L'Acacia!/Claude Simon grand comme le croate Krlza et Mars /...

Et la nuit est tombée/Les phrases s'écrivent dans les têtes / Celles jamais énoncées / Parce que nous avons peur

- ça chahute fort en cette fin de journée,

les adolescents courent dans les allées

s'appellent dans les escaliers, se perdent dans les ascenseurs

un carré d'ados

dans les fauteuils de Norman Forster

sont heureux,

ils se photographient

- Que cela leur soit souvenir!

5. Philippe Lacoue-Labarthe,

Phrase, Paris, Christian

Bourgois, 2000.

6. Robert Darnton,

Apologie du livre,

Gallimard

(Nrf Essai), 2009

7. Ibid.

8. Ibid.

9. Ibid. 
20 janvier 2012

$10 \mathrm{~h} 30$

Je demande à la bibliothèque Apologie du livre, de Robert Darnton ${ }^{6}$. Je suis de la génération qui ne lira pas sur tablette. Norman Forster a fait une œuvre, à Nîmes. Pour un centre d'art, rappelons-le. Mais il fallait Un centre du savoir ${ }^{7}$. Et c'est ce qu'est une bibliothèque, un centre du savoir et non pas un entrepôt du liure ${ }^{8}$. L'entrepôt disparaîtra, la bibliothèque demeurera.

Je n'ai aucun doute que mon excessif aller au livre tient de ma mère. Aller à la lecture, cela m'a dangereusement amené ailleurs, là où se trouve tout le monde.

Un Noël, je lui offrais un livre de Pablo Neruda, Une vie à changer. La lecture et ses mystères ${ }^{9} . .$. Le dedans et le dehors. Quelle chance!

Montréal - Nîmes 2011-2012 


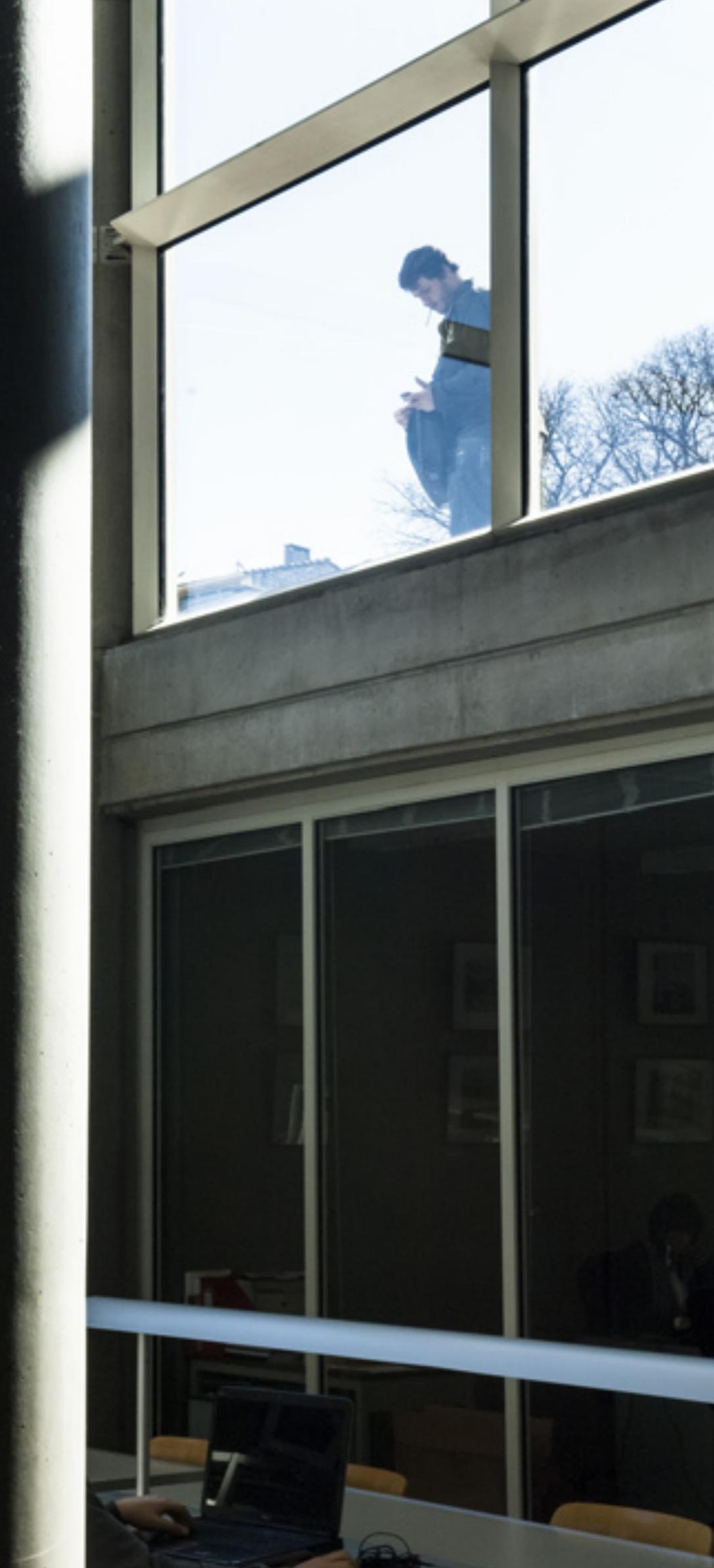




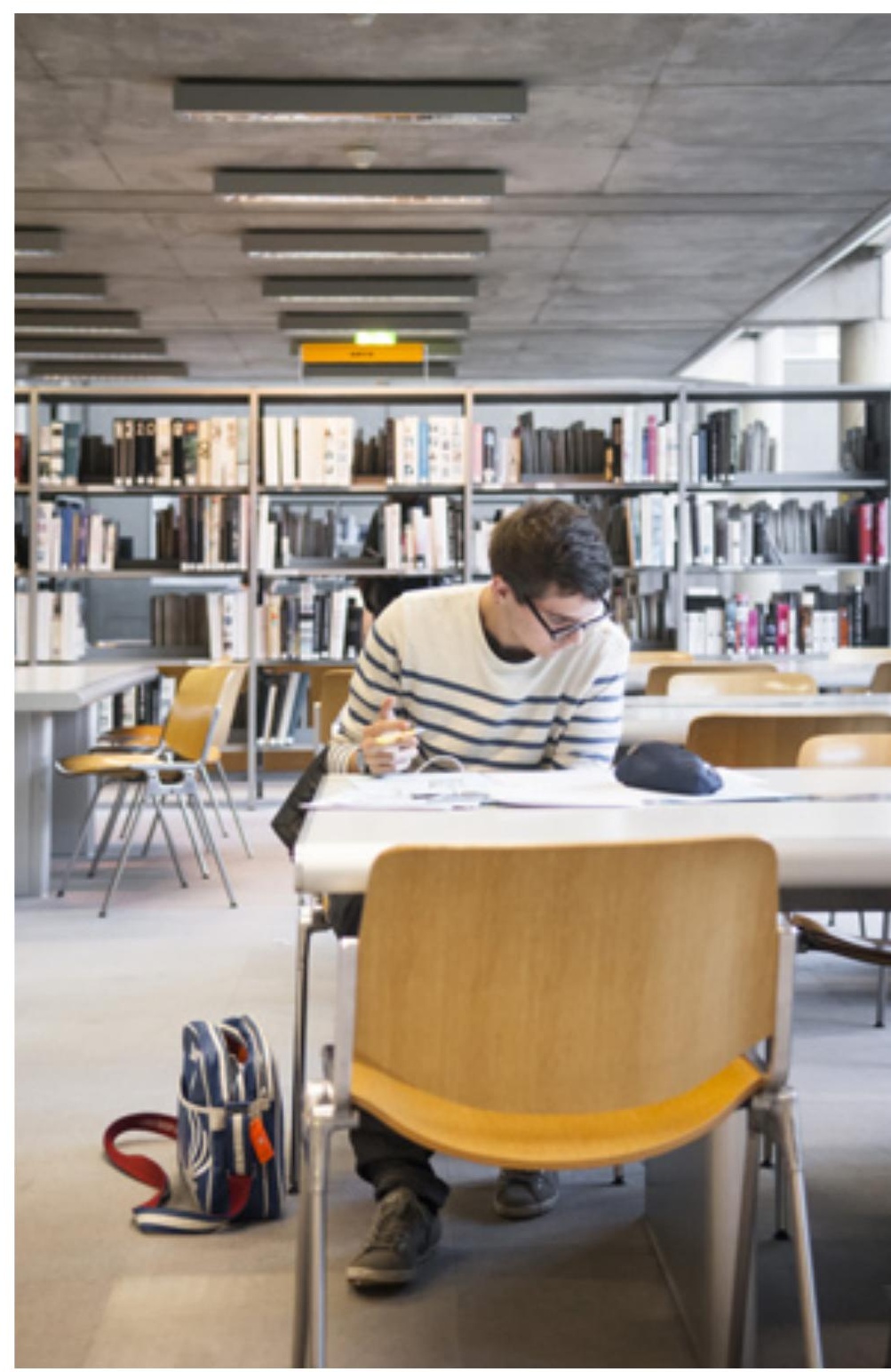




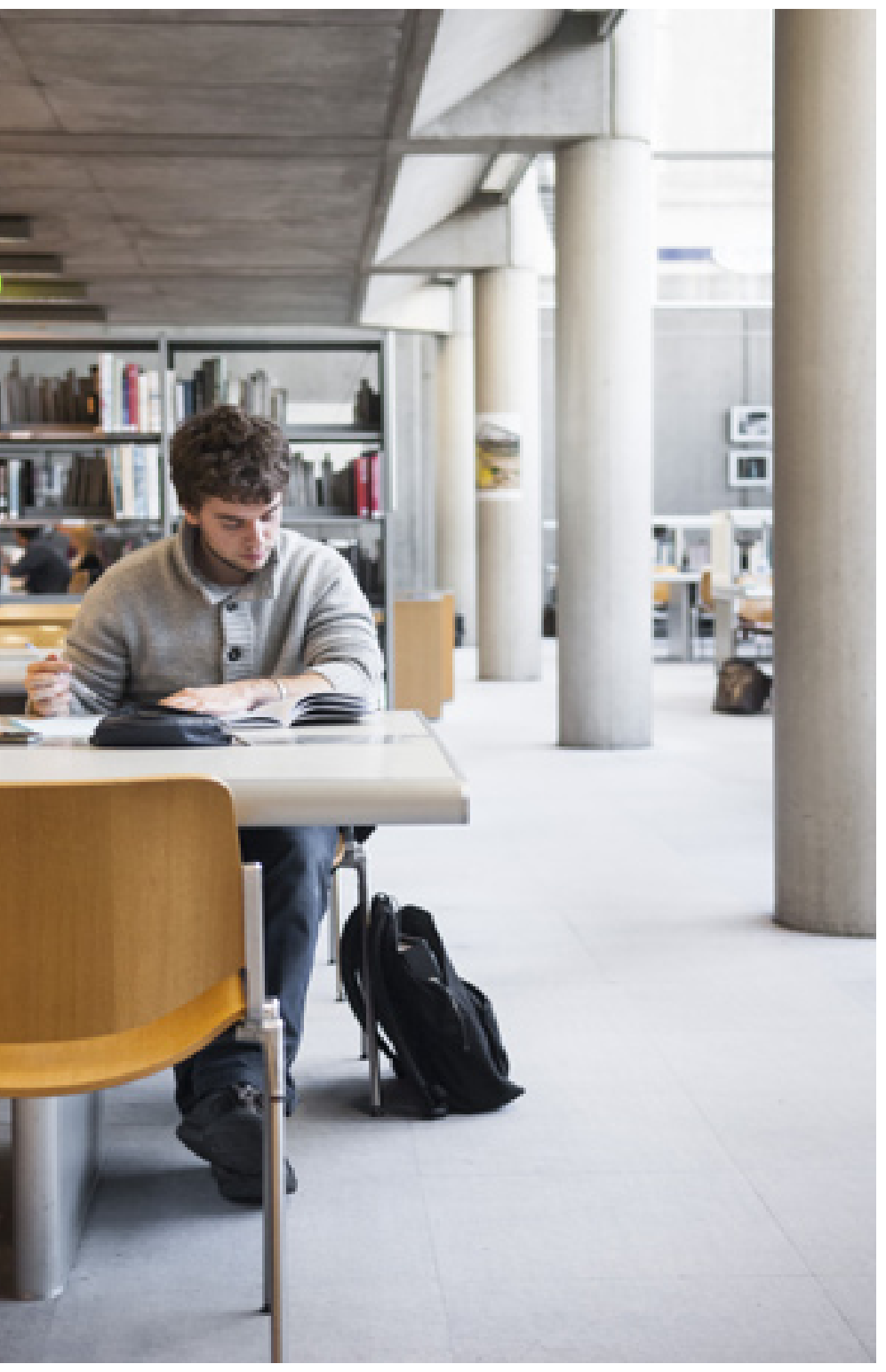




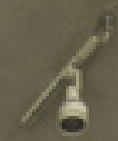

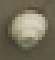

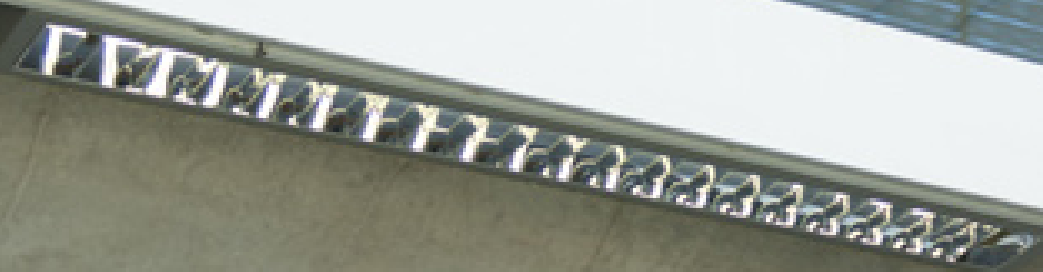

82

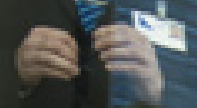

1
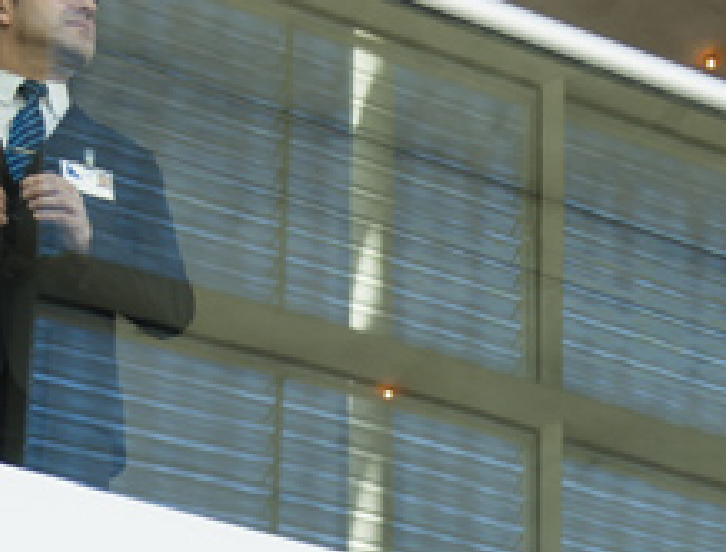

1
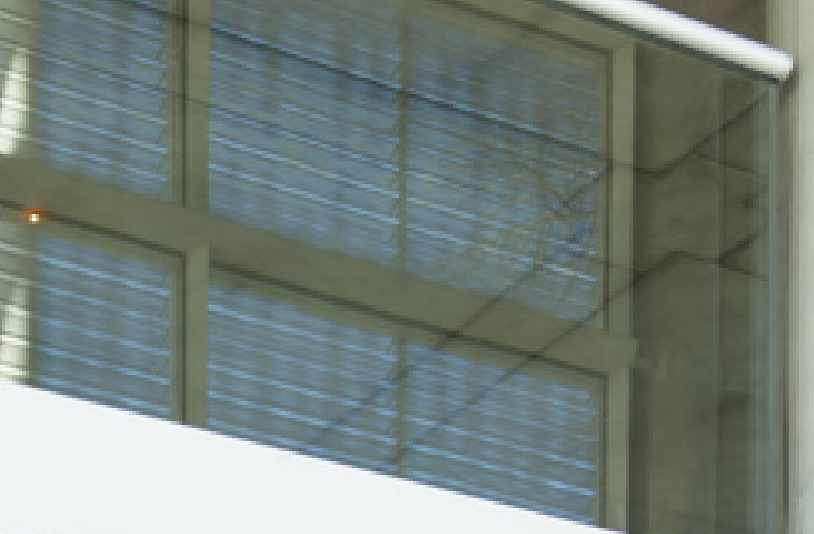


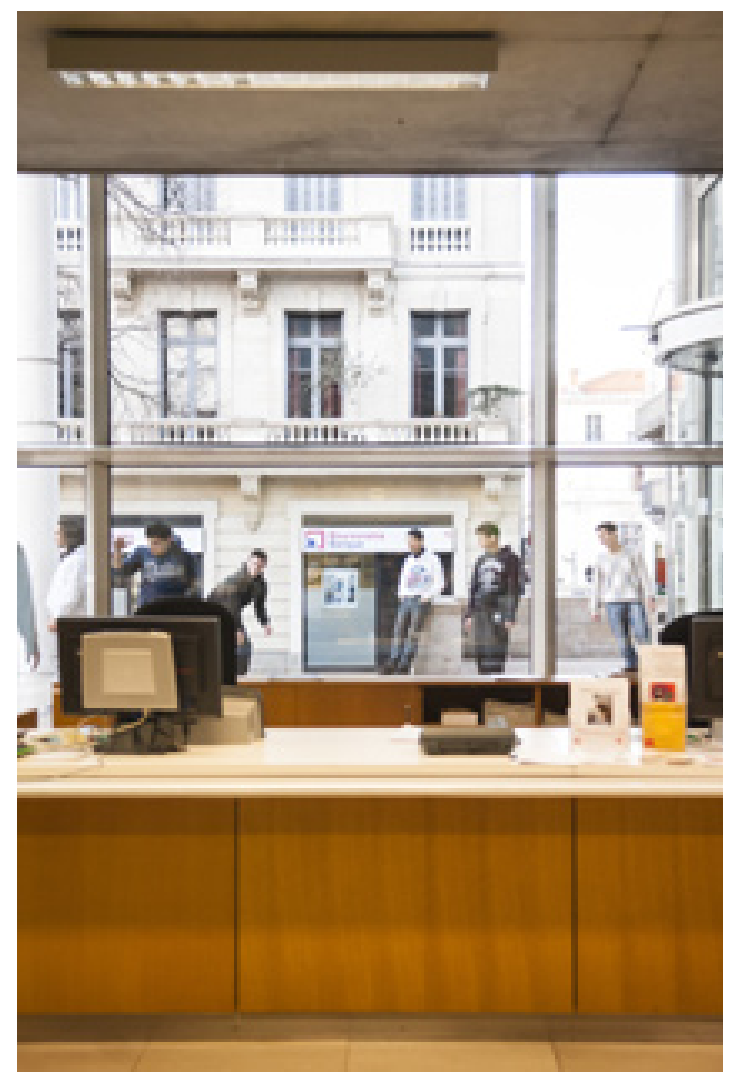



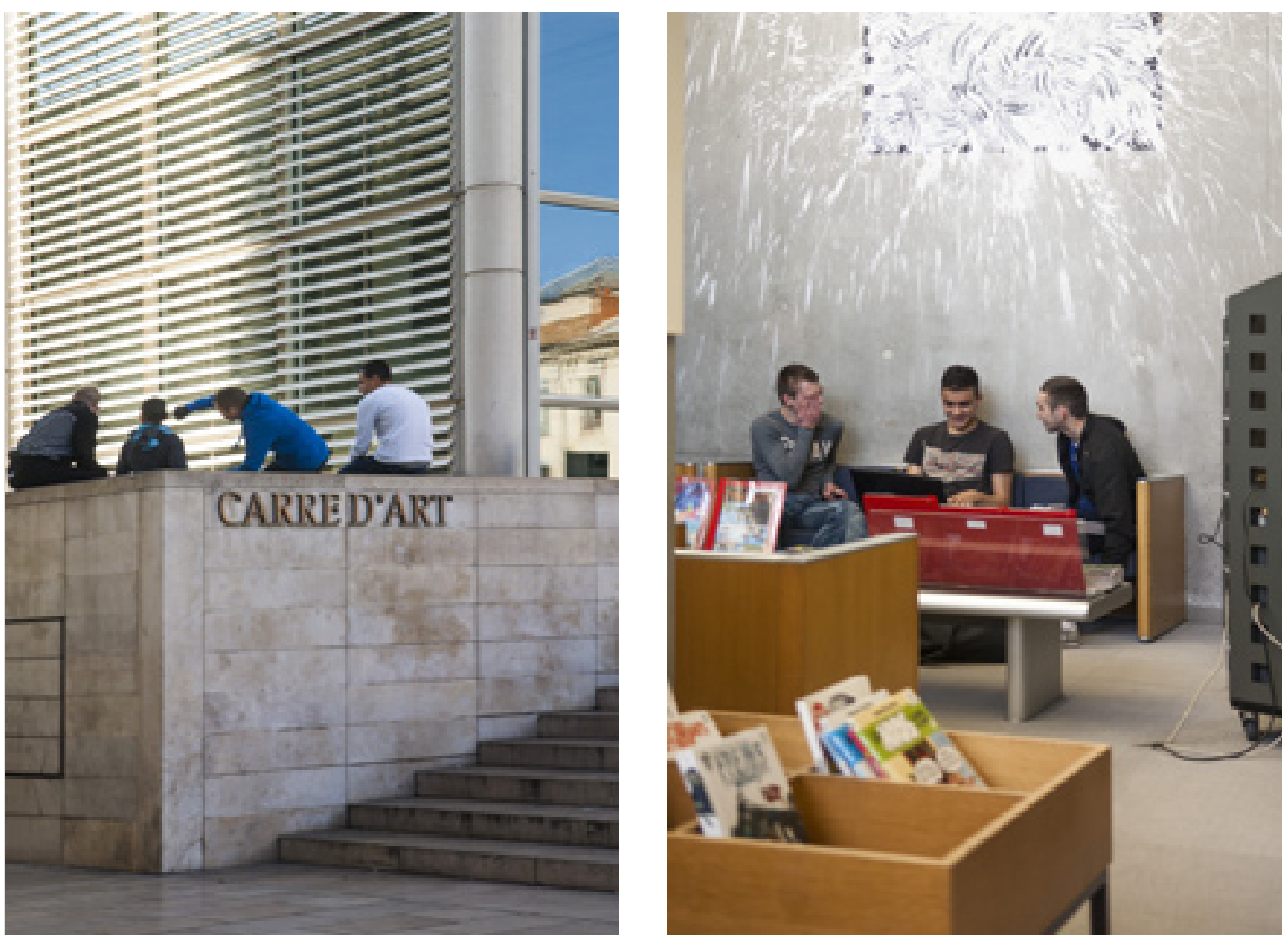
Sylvie Gracia

L'Alcazar - Bibliothèque de Marseille à vocation régionale

Au hasard l'Alcazar 
Je suis tombée dessus par hasard. Depuis le haut de la Canebière, j'ai pris en biais vers la mer, en laissant le Vieux-Port à gauche. Je savais qu'elle se tenait là, pour y être tombée de la même manière par hasard il y a quelques années, un jour d'hiver où le mistral soufflait des lames. Je connais peu Marseille, j'aime Marseille. Je cherchais Saint-Charles, un train m'y attendait quelques heures plus tard et, remontant le long de la ligne de tram, j'avais découvert à la pointe d'un alignement de petites boutiques populaires - vêtements-chaussures-valises-vaisselle - une façade monumentale de verre et de marbre, tranchant sur les immeubles décatis. L'Alcazar, était-il inscrit en lettres d'or sur le fronton en bois d'une ancienne marquise en fer forgé, qui détonnait. L'entrée donnait de plain-pied sur la rue, alors, moitié par curiosité moitié parce que j'étais frigorifiée, je m’étais enfoncée dans une sorte de grande rue intérieure, étonnée de découvrir des salles de bibliothèque sur les côtés et en hauteur. Je m'étais laissée tomber dans le confort d'un fauteuil en cuir, durant une heure pleine m'y étais réchauffée, et mes voisins, en majorité retraités, maghrébins pour la plupart, semblaient apprécier eux aussi l'abri, journaux, chaleur, luxe et beauté...

Au hasard Balthazar, c'est toujours comme cela qu'il faudrait procéder, dans les villes inconnues comme dans les livres, à lire ou à écrire. J'allais bien la retrouver, la médiathèque, maintenant que je la cherchais? Alors, au croisement des larges allées Léon Gambetta et du boulevard d'Athènes - avec sa perspective magnifique sur l'escalier de la gare - j'ai vite quitté les grandes avenues, toujours bruyantes, toujours embouteillées, pour me laisser porter dans la descente, c'était des petites rues maintenant, rues étroites, populeuses, cliché éternel d'une Marseille méditerranéenne et immigrée. Les boutiques de textiles en gros, tissus chamarrés, pailletés. Les valises et les malles métalliques sur le trottoir, en attente d'un départ, les odeurs de cuisine. Les hommes qui traînent, qui font des affaires. Et c'est comme ça que je suis tombée dessus, débarquant brutalement de la rue des Convalescents sur le cours Belsunce, soudain éblouie par la perspective, les larges trottoirs, la foule nonchalante, la façade blanche de l'Alcazar 
et ce mouvement perpétuel de passants sous sa marquise, entrant et sortant. Deux jours plus tard, à la documentation régionale, troisième étage, je retrouverais une atmosphère quasi semblable, pourtant datant du siècle précédent, quand une bibliothécaire me tendrait Marseille transit: les passagers de Belsunce', et que la page de garde s'ouvrirait sur une photo sépia titrée "Hommes à la valise dans la rue Belsunce au début du xxe siècle».

Superposition des époques. À plusieurs reprises, à l'Alcazar, j'aurai cette même sensation des temps fondus l'un dans l'autre, sans doute parce que la médiathèque a été bâtie dans le cœur historique de la ville - à l'instar de ce chemin d'inox que l'artiste Bernard Pagès a dessiné sur le sol, mémoire du ruisseau fondateur de la calanque du Lacydon. Ici même, deux mille ans plus tôt. Ici même, prestige des temps classiques qui se marque encore sur certaines façades, enceinte colbertiste, promenade aristocratique, négociants cosmopolites - symboliquement les architectes ont conservé, en superposition sur le verre et le marbre, un pan de façade xvII et ses fenêtres carrées. D'ici même, en 1792, le premier bataillon montait vers Paris - ah, la Marseillaise! Jusqu'au nom de l'Alcazar, celui de l'ancien music-hall, qui revendique l'héritage d'une culture populaire et locale, frondeuse et exigeante, celle qui fit ou défit les réputations des plus grands - la liste serait longue, Joséphine Baker et Fernandel, Tino Rossi et Yves Montand, Vincent Scotto, Tino Rossi. L'Alcazar du temps d'avant, quand on venait pour l'opérette, le café-concert, la galéjade et les claquettes. La grande culture populaire, oui. Dialogue et mélange des genres, sur scène et dans la salle. Et si c'était cela aussi, la réussite d'une médiathèque, d'être populaire dans tous les sens du terme?

Le jour de mon arrivée, je suis estomaquée par la très longue file d'attente devant les bornes d'enregistrement: gens de tous les âges, de toutes les conditions. Samedi dernier, me dit-on, un record a été battu: 7000 entrées enregistrées. Ici, on vient avec des cabas à provision, des sacs plastique de supermarché et on les remplit de livres, de CD, de DVD. Des personnes âgées, des

1. Émile Témine, Marseille

Transit, les passagers de Belsunce, Autrement, Collection Monde/Français d'ailleurs, peuple d'ici, 1995. 


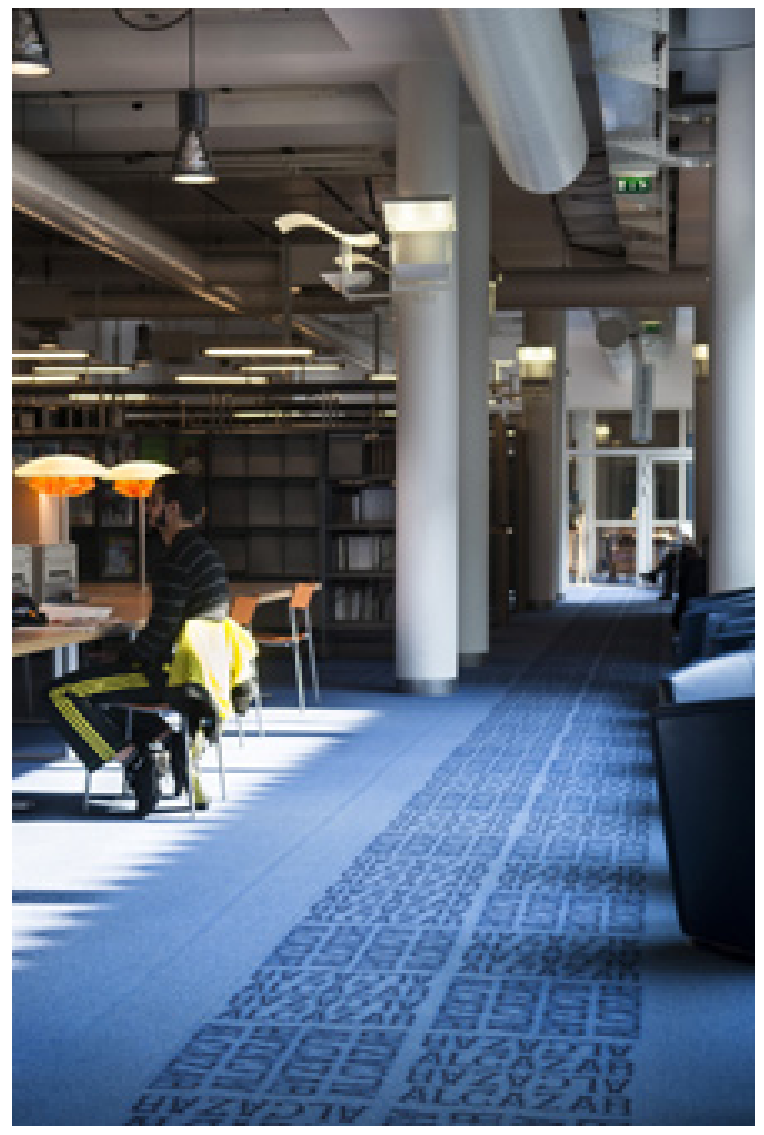




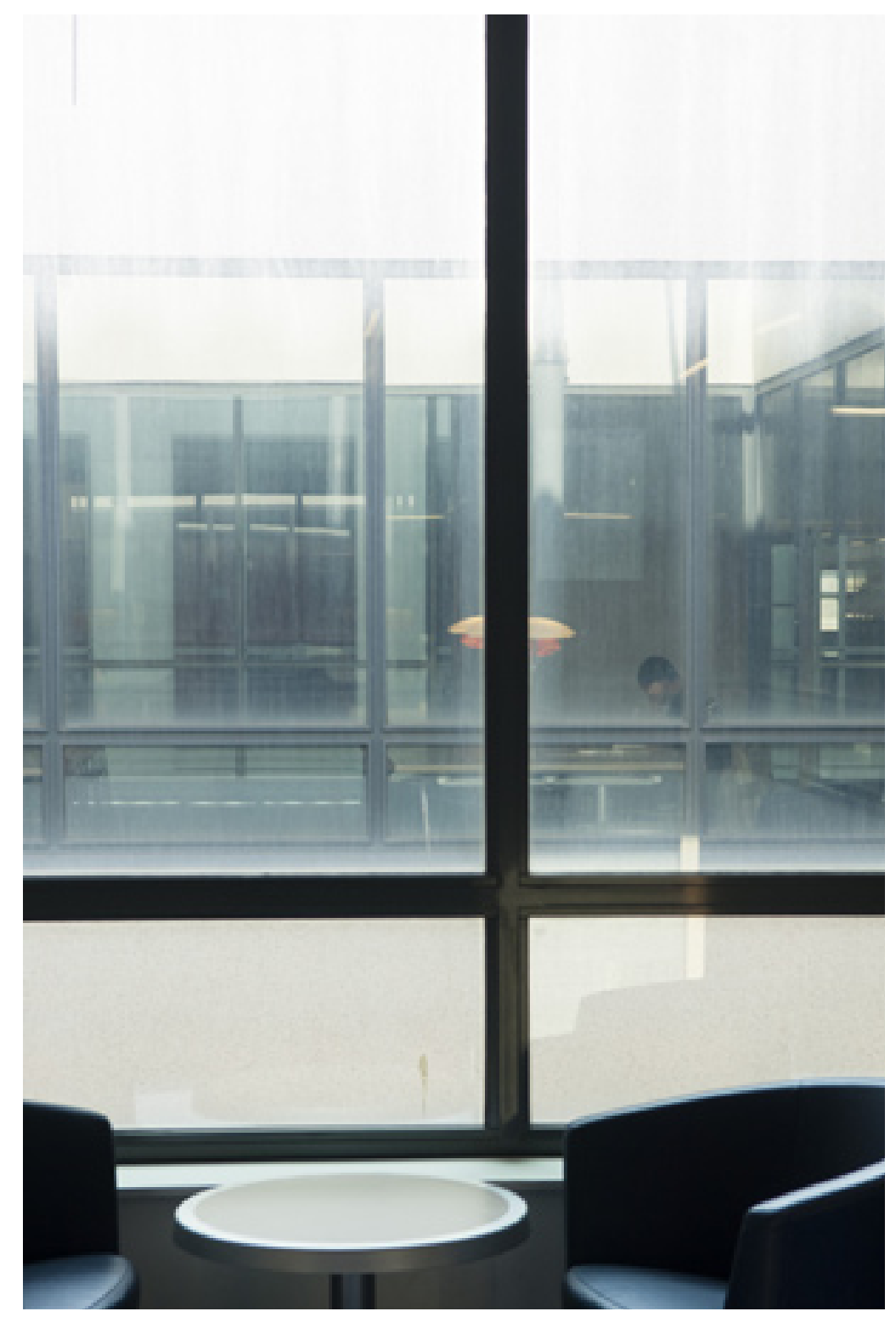




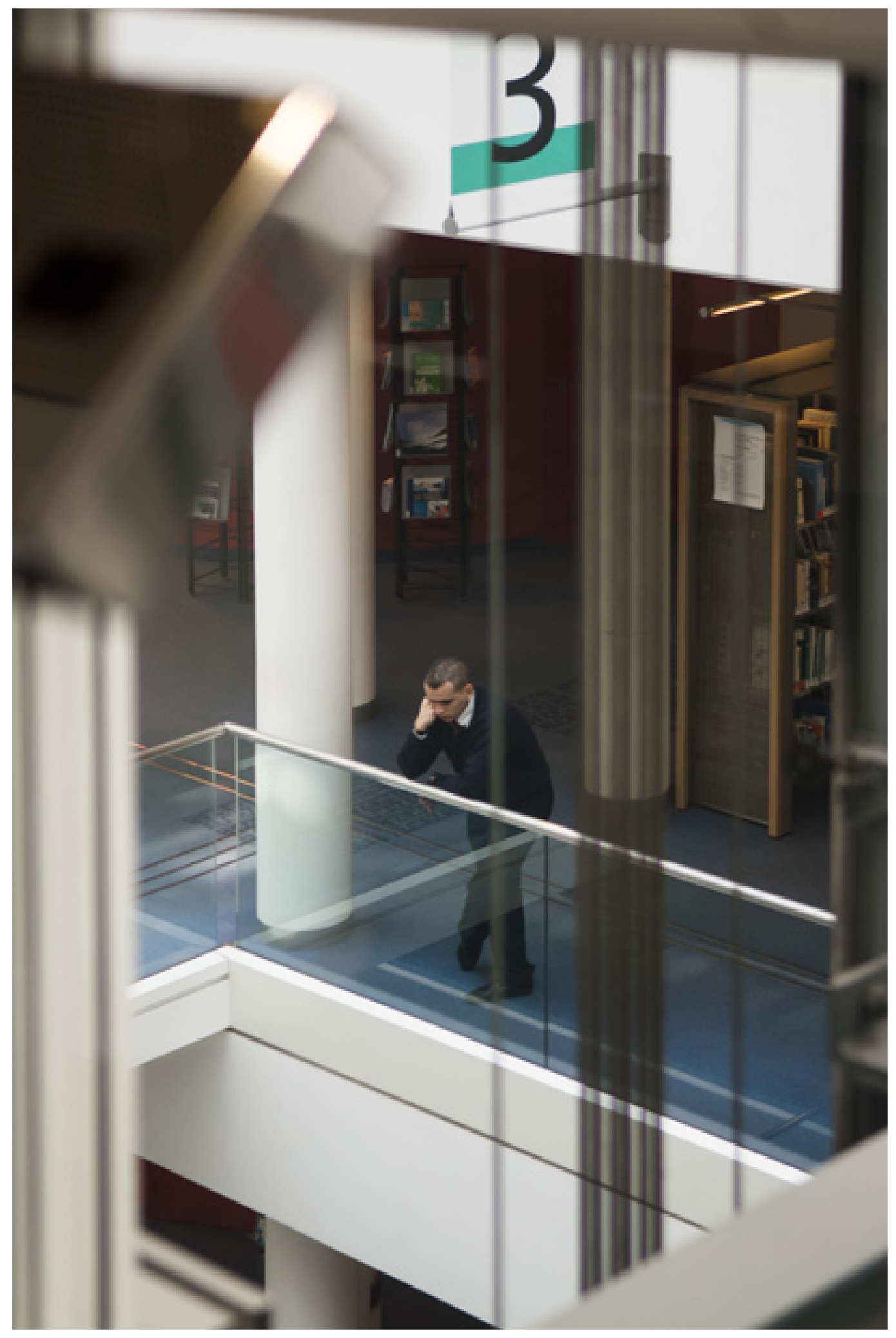


étudiants, des mères, beaucoup de mères d'origine arabe, puisqu'être du quartier c'est être d'origine arabe. Et des enfants, des enfants partout. Lieu de vie que l'Alcazar, me dit-on et me répète-t-on. À l'étage de la jeunesse, le samedi après-midi, des enfants font leurs devoirs sur les tables, certains aidés par des adultes, des gamines jouent sur les ordinateurs à habiller Dora, le petit mannequin de Dressup, de jolis habits... Les plus jeunes attendent avec papamaman l'heure habituelle du conte comme eux je pleurerais presque en écoutant l'histoire de Mimi la souris qui se cherche un mari. On me dit que certains parents déposent leurs enfants le matin et repassent les chercher le soir, ils savent qu'ils sont ici en sécurité, et il y a tant de choses à faire, alors les bibliothécaires font avec. On me dit que l'été ceux qui ne partent pas en vacances viennent faire leurs courses ou remplir les heures de canicule devant un film, dans les salles climatisées. Et tous ces étudiants installés sur les tables en étage, qui se précipitent dès l'ouverture à 11 heures. J'en observe deux, assis côte à côte, cours à bûcher, boules Quiès dans les oreilles, mais ils ne peuvent pas, oh non, se retenir de se pencher sans cesse l'un vers l'autre, se parlent avec les mains, inventant leur propre langage des signes. Combien de romans d'amour à l'Alcazar, dans les rayons et les allées? Démocratisation culturelle et intégration des populations du quartier, c'est comme ça qu'on dit en langue officielle, non?

À écouter mes amis marseillais, il semble en tout cas que le nouvel Alcazar ne démérite pas: comme au music-hall dans son temps, tout le monde y va, tout le monde en parle, tout le monde a une opinion, applaudit ou lance des tomates. Les trois vigiles devant lesquels on ouvre son sac à l'entrée et ceux qui arpentent la bibliothèque, on n'a jamais vu ça ailleurs! On me raconte qu'il a fallu qu'ils apprennent qu'une bibliothèque, ce n'était pas un supermarché, on n'y affiche pas ses muscles, on discute avant d'empoigner. On me dit aussi que, sans doute, on ne pourrait faire sans eux, parce que l'Alcazar est un lieu ouvert, vraiment ouvert. On hausse la voix pour me parler de la démission du précédent directeur et du manque d'encadrement, on me rapporte des choses sur la gestion locale, à l'Alcazar comme ailleurs sur la ville. Un ami écrivain, 


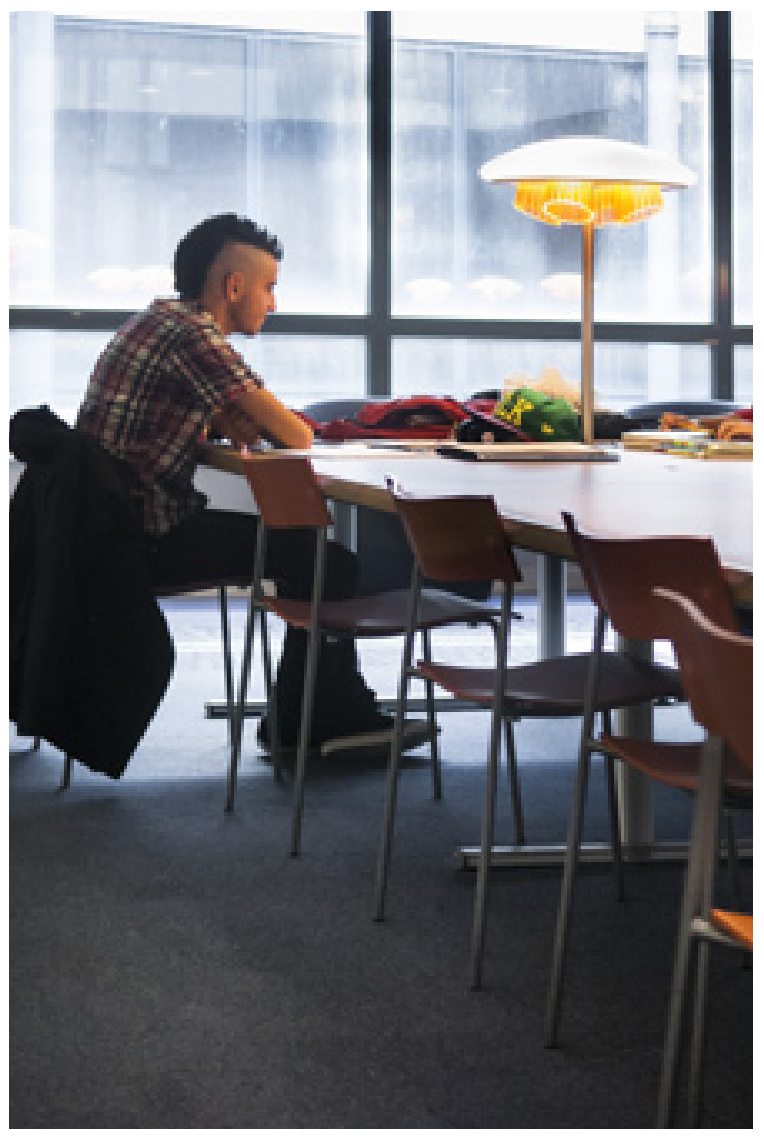


marseillais de toujours, veut me faire croire, bonne blague du Vieux-Port, qu'avant de venir (souvent), il téléphone pour savoir si tel service est ouvert. Et justement, l'après-midi où il me fait visiter son Alcazar, un des départements est fermé. Grève nationale, et pas assez de personnel pour les ouvrir tous. Lui et moi passons quand même l'entrée de la salle, faisant fi du panneau de fermeture, il m'entraîne vers la cote 901 -les cotes, il a l'air de connaître ça par cœur-, mais au moment de mettre la main sur le livre espéré, un vigile nous tombe dessus, Dehors, m'sieur-dame, c'est fermé, vous voyez bien! Et mon ami écrivain volontairement outré, qui hausse la voix, faut ce qu'il faut, il serait presque chez lui ici, oui chez lui parmi les livres! C'est si excitant, les bibliothèques, me dit-il. Je viens prendre des livres qui me donnent envie d'écrire, mais s'ils me donnent envie d'écrire, je ne les lis plus! Et nous rions. Et le vigile à cravate noire s'est éloigné... Histoires, histoires. "Pourquoi es-tu venu à Marseille? -À cause beaucoup belles histoires sur le Marseille. Beaucoup magnifiques, beaucoup mensonges. » C'est du Albert Londres ${ }^{2}$, quand le grand reporter peignait Marseille, avec cette poésie raciste pur jus années 1920, "Voilà les fourbis, les bicots et les mouquères... » Tant d'histoires qu'on pourrait entendrait, à l'Alcazar, si on se posait longtemps sur une chaise. Tant de héros de fiction et de la réalité. Au hasard, l'Alcazar. Dans les toilettes, dont les usagers se plaignent - unique emplacement pour ce bâtiment immense et véritables toilettes publiques, puisque accessibles depuis la rue - je surprends une scène délicieuse, le manège bizarre d'une gamine d'une dizaine d'années. Elle porte un pull rouille large et flasque, un grand tissu bleu noué sous le menton, elle est face au grand miroir comme moi qui me lave les mains et semble impatiente de mon départ. Alors, quand je passe la cloison menant à la sortie, vivement je me retourne pour la surprendre: elle a dénoué son voile et une masse de cheveux longs et épais tombe dans son dos, qu'elle secoue d'un mouvement déjà séducteur, en s'admirant dans le miroir. Lieu de liberté, la bibliothèque, lieu d'invention de soi?

À flâner dans la grande rue intérieure, on est déjà dans l'imaginaire d'une ville du Sud, avec ces coursives qui courent à 
chaque étage, la lumière zénithale qui tombe d'en haut par la grande verrière et ses pare-soleils, j'entendrais presque une mama, penchée de tous ses seins à la rambarde vitrée, interpeller vivement son gamin: Alors, tu montes manger ou quoi, faut te le redire combien de fois? Et pendant que je me crois dans un film néo-réaliste italien, au microphone on annonce la conférence du soir sur Simone de Beauvoir, Je veux tout de la vie. Il paraît que des bibliothécaires, en ouverture, liront ses lettres d'amour à Nelson Algren, et en musique s'il vous plaît. La veille, dans la même salle de conférence, c'était un film sur l'humoriste Fellag... Ouverture et mélange des genres, je vous disais. Bibliothèque publique et conservation. Rayons mangas et portulans. Livres en braille et rap. Ici, on pourrait passer la journée et vivre plusieurs vies, être un de ces «aristos du troisième étage ", comme on dit, et travailler dans la salle du Patrimoine sur l'histoire coloniale, à partir du Fonds de la Société de géographie, ou fouiller les archives des Cahiers du Sud, cette grande revue littéraire fondée à Marseille et qui accueillit les plus novateurs du xx siècle, d'Antonin Artaud à Henri Michaux. On peut être enseignant et vouloir sortir d'une vision lénifiante de la littérature jeunesse en prenant ses quartiers à l'île aux livres, un bulle vitrée et magique, au premier étage, un centre de ressources qui possède une documentation et un patrimoine rares en France - non, La petite fille aux allumettes n'est pas morte ${ }^{3}$, bien vivante dans sa boîte... Dans les réserves du soussol qu'on m'emmène visiter, on me présente avec passion les trésors de l'île, dessins originaux, valises-jeux, livres-objets, mais c'est sur la série Fantômette de la mythique Bibliothèque rose que je m'attarde, premières lectures, nostalgie de l'enfance... Est-ce qu'on se souvient tous de la première bibliothèque qu'on a fréquentée, comme on se souvient du premier livre décisif? Un ami retraité, génois d'ascendance qui a grandi dans les quartiers Nord, vrai marseillais donc, me fait visiter l'Alcazar par l'extérieur, tout en faisant remonter les souvenirs de la bibliothèque de sa jeunesse, qui se tenait derrière le lycée Thiers. Boiseries sombres - aujourd'hui, tout est lumière et transparence. Entrée interdite avant la classe de troisième-aujourd'hui on y accueille les enfants 
de crèche. Avec deux doigts, il dessine une patte-d'oie, celle dans laquelle l'Alcazar s'est insérée, comme la dernière pièce dans un puzzle serré, celui de Belsunce. Il me fait découvrir l'arrière du décor: le bâtiment administratif séparé du corps de la bibliothèque par la rue du Baignoir et, par-dessus, les deux passerelles aériennes les reliant. Il me dit l'arrivée récente des Asiatiques, dernière vague d'immigration, des gamines jouent dans la rue du Petit-Saint-Jean, pendant que leurs parlent les surveillent, sur le pas des boutiques de textiles made in China. Ce même pâté d'immeubles qui fut décrit par Anna Seghers, dans Transit ${ }^{4}$ : durant la Seconde Guerre mondiale, les réfugiés de l'Est, juifs, communistes, s'entassaient dans les taudis du coin en espérant le bateau vers l'Amérique. Porosité de la vie et des livres. Porosité de l'Alcazar. Porosité de Belsunce. Le quartier est entré dans la médiathèque, s'est-on félicité devant moi plusieurs fois. C'est ça, Marseille, l'intégration immédiate des corps étrangers. 



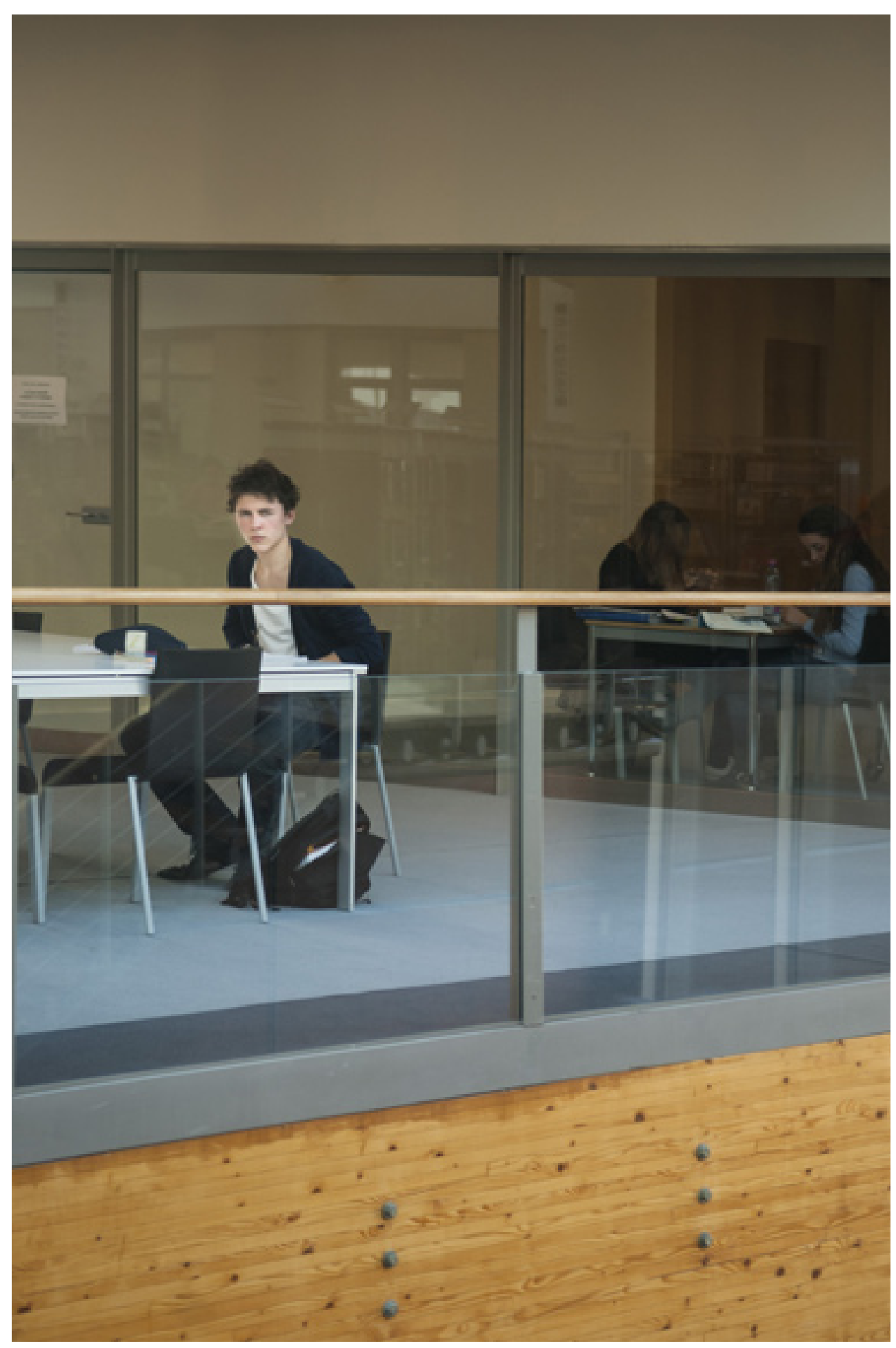




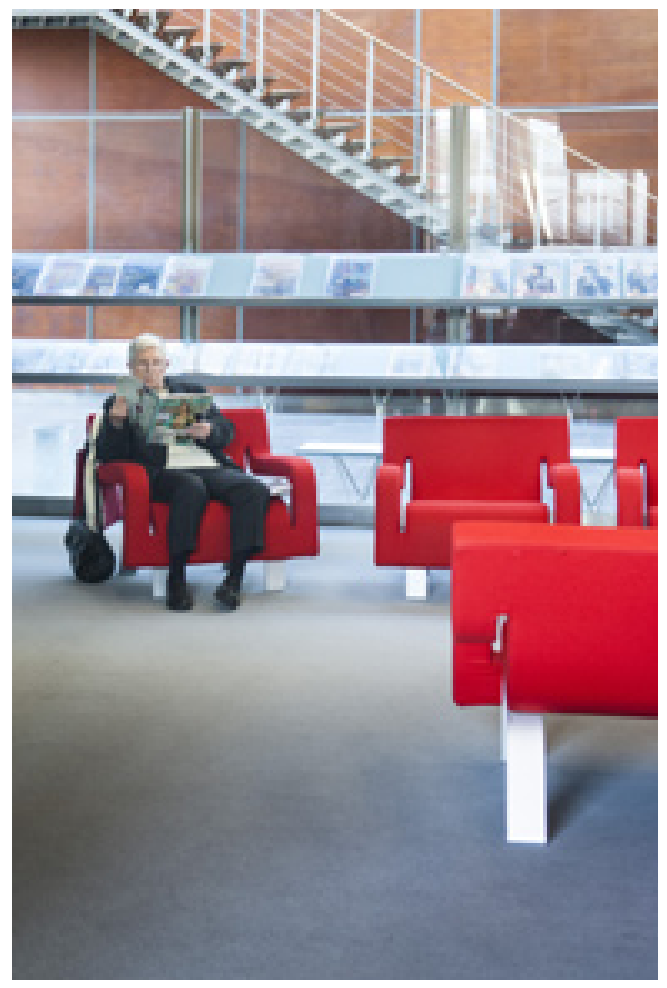


À la mémoire de Franck Henry

Sur le quai,

Tête penchée, elle est immobile devant la vitre. Ses yeux semblent suivre les mouvements sur la mezzanine. Elle s'éloigne. À peine quelques minutes. Elle reprend son poste d'observation. Comment aurait réagi François Lombard, architecte concepteur de la médiathèque de Biarritz, à la vue de cette mouette curieuse? Ravi de sa présence ou agacé par ce genre de volatile accusé de détériorer les édifices? Peut-être ému par cet hommage ailé pour le vaisseau qu'il imagina et réalisa? Maître d'œuvre d'un navire ultra-moderne au cœur d'une cité balnéaire, un vaisseau battant pavillon du livre et de l'image.

Mort peu de temps avant l'ouverture, l'architecte ne fut d'aucun voyage; excepté celui qu'il effectua durant des années, seul ou avec ses collaborateurs, pour arrimer son rêve, son projet, sur le plancher urbain. Pas un "pari architectural» gagné d'avance, surtout auprès des riverains et du reste des administrés de Biarritz. Comme beaucoup de bâtisses publiques aux lignes audacieuses, cet édifice a irrité certains contribuables et alimenté moult polémiques dans les chaumières biarrotes et ailleurs. "T'as vu le pognon qu'ils ont claqué pour c'truc là! Ce quartier était vachement mieux avant. "sûr que le chantier d'un hôpital, un palais des congrès, un centre commercial ou un terrain de rugby aurait plus facilement obtenu l'assentiment des habitants. Un élu dépensant les deniers publics dans la construction d'une bibliothèque risque de le payer dans les urnes. L'électeur est-il encore un lecteur? Malgré les prévisions pessimistes ici ou là, des signes indiquent que, notamment avec Internet, la lecture reprend du poil de la bête dans notre société balisée d'écrans plats. Certes peut-être une lecture kleenex, trop de livres dont des pas mauvais mais inutiles comme l'affirme un critique à la dent dure. Depuis la lecture de son article, je gamberge sur l'utilité de mes bouquins. Une question que tout auteur devrait se poser... Au risque de heurter et apparaître élitiste, je pense que ce critique a raison d'établir un distinguo entre "produire» et «écrire»; à part quelques exceptions comme l'immense Simenon. Ce qui ne 
m’empêche pas de dévorer thrillers et best-sellers bien rédigés, une littérature populaire de qualité souvent plus intéressante que des livres estampillés littéraires. Quoi qu'il en soit, l'écrit et sa compagne la lecture sont toujours vivants au xxi siècle. Et à nous tous, professionnels du livre ou pas, d'entretenir cette flamme. Concernant la lecture publique, les nombreuses personnes sortant de la médiathèque ou s'y dirigeant sont un bon baromètre matinal. Aujourd'hui à Biarritz, beaucoup de passagers, sûrement aussi des grincheux de la première heure, grimpent à bord du «navire médiathèque». Seuls ou en famille, ils gravissent les marches de l'escalier monumental; appareiller un instant ou une journée entière. À chacun sa traversée, son horizon d'encre et d'images.

À bord,

J'embarque à mon tour. Avec les squares et les chiottes de certaines villes, la bibliothèque municipale est l'un des derniers lieux publics sans besoin de carte bleue ou monnaie. Combien de temps encore? L'escalier donne sur un hall entièrement vitré. Lumière naturelle et artificielle se partagent l'espace comme dans nombre de sièges de grandes entreprises, conseils généraux, hôtels de ville, commissariat, Macdos, usines réhabilitées en Loft dans les zones boboïsées... La vitre devenue un matériau incontournable? Une quête de transparence? J'ai l'impression d'être déjà venu dans cet endroit. Ma première sensation à bord est plutôt décevante.

Mon voyage-repérage pour la rédaction d'un texte commandé dans le cadre du vingtième anniversaire de l'enssib débute mal. Pas journaliste, incapable de synthétiser une doc à la sauce Sciences Po, et peu habitué à un déplacement pour écrire-décrire un lieu, je ne me sens quelque peu à l'étroit dans ce rôle; plus à l'aise dans un bar à observer les clients et les passants. Comment pondre minimum 10000 signes sans emmerder le lecteur? «Si vous acceptez cette mission... ». L'émergence du générique de Mission Impossible me fait marrer. À vrai dire, je n'en mène pas large. Quel mode opératoire? Se la jouer incognito tels les critiques gastronomiques du Gault et Millau ou me présenter? 
Le fait de décliner le but de ma mission risque-t-il de changer ma perception de l'espace, des usagers et employés? Pas le temps de tergiverser.

Assis derrière des banques de prêt, plusieurs bibliothécaires (plus simple de les nommer ainsi, même si tous n'ont pas ce statut), une majorité de femmes, enregistrent les emprunts du samedi; journée avec le mercredi généralement la plus chargée. À qui m'adresser? Après un rapide coup d'œil, je gagne un comptoir et fais la queue. Devant moi, un homme flanqué de deux gosses, se renseigne pour une inscription. Je bafouille les raisons de ma présence matinale. Visiblement au courant de l'opération de l'enssib, la bibliothécaire m'explique que la directrice est en réunion et me propose de prendre un rendez-vous. Puis, très professionnelle, elle me soumet quelques pistes intéressantes sur l'historique de la médiathèque. Pourquoi pas revenir et visiter les lieux en compagnie d'un membre de l'équipe? Sans aucun doute le meilleur moyen d'obtenir de «la matière » pour rédiger un texte le plus proche de la réalité. Mais, très vite, je balaye cette idée de visite guidée. Par habitude - trouille du caractère formel d'une telle démarche? - d'éviter les sentiers battus, j'opte pour un cheminement guidé par le hasard. Sans filtre officiel. Bien sûr, il y a le risque de passer à côté de données essentielles pour nourrir cette mission "dire/raconter les bibliothèques ", perdre en cours de route une partie des éléments collectés par le regard et, a posteriori, confondre la réalité des lieux avec la projection d'auteur-visiteur. Tant pis pour le réalisme. De plus, je suis incapable de rédiger un guide touristique ou un essai sociologique sur le fonctionnement d'une Bib. Des spécialistes le font déjà avec brio. Ça y est: ma trouille récurrente de ne pas être à la hauteur intellectuelle vient de tomber. Enfin me lâcher vraiment et explorer. "Certains pensent qu'ils font un voyage, en fait, c'est le voyage qui vous fait ou vous défait. » écrivait si justement Nicolas Bouvier. Je vais me glisser dans la peau d'un nouvel usager de la médiathèque. Découvrir seul.

La fin des usines à prêt?,

Pour être franc, il ne s'agit pas d'une totale découverte. Avant de prendre le train pour Biarritz, j'ai épluché le site de la médiathèque. 
Que me reste-t-il de cette visite virtuelle? Je me gratte la mémoire encore à marée basse à cause de la soirée arrosée (bon pinard mais fruits de mer sans goût) de la veille au Port-Vieux.

Espace de $4000 \mathrm{~m}^{2}, 40000$ liures, 5000 DVD, des

départements America, Basque, Image, une expo Ciné

Latino, une navette gratuite pour venir à la

médiathèque, atelier de pop Philosophie...

Que des informations "classiques» liées aux activités d'une médiathèque. Rien de décalé ou d'insolite. Sauf la vidéo d'animation ponctuée d'esquisses de Bernard Fric: ami et collaborateur de François Lombard. Quelques minutes d'un film signé par Caroline de Otero où océan, lignes architecturales, mots, sons, s'entremêlent et donnent une vision - en accéléré - de la conception du projet. Une sorte de poème visuel qui éclaire les fondations invisibles. Le cœur de toute œuvre.

Après un rapide tour des espaces de lecture, je m'arrête et jette un regard circulaire. Que dire d'original? Rien de nouveau sous le plafond d'une bibliothèque: des rayons balisés par genre et des livres rangés par ordre alphabétique. Décidément: encore du déjà vu? Souvent, la fonctionnalité prime sur l'esthétique dans les espaces dédiés au public. Un peu mauvaise langue? Oui. L'aménagement intérieur, proche de celui d'un paquebot, n'est pas banal. J'ai l'impression que les corps se meuvent différemment, plus souples et légers, que dans les allées moquette grisâtre ou parquet vieillot des «usines à prêt de livres, DVD et CD » quasiment toutes sur le même modèle. Un modèle pas très joyeux. Cela dit, on peut constater de plus en plus d'efforts architecturaux pour la réhabilitation des médiathèques et les nouvelles constructions. Une bonne stratégie pour attirer de nouveaux lecteurs. Culture même pointue et intérieur agréable pas incompatibles. Au contraire.

Individualivre,

Pourquoi la vue de toutes ces jaquettes me fait penser à l'éclosion du numérique? À peine immergé dans une bibliothèque que je mets à gloser sur la fin de l'ère Gutenberg. Déjà hors sujet. Je cherche une accroche plus facilement «exploitable». En vain. Autant se laisser aller et tirer ce premier fil in situ. Bien que 
conscient de la dématérialisation inéluctable - un retour de la primauté du texte sur l'auteur? - de la plupart des livres, je reste attaché à cet objet; depuis l'enfance, il me donne la température du monde, et la mienne. Ces milliers de bouquins, à portée de main, possèdent une caractéristique qu'ils perdront immanquablement avec une liseuse ou un I-Pad: l'individualité. Debout dans des rayonnages, posé sur le comptoir d'une brasserie, abandonné sur un banc de square ou siège d'un train, un livre - par sa présence physique - ressemble à celle d'un individu. Objet indépendant de ses «semblables » issus des mêmes imprimeries. Pareil à un fauteuil conçu en série qui, au fil du temps, se modifiera en fonction du dos et des postures de son utilisateur. Le support numérique, quelle que soit la qualité de l'écran et de la «vilisibilité» - néologisme de Jacques Anis -, lui ôtera la possibilité de naître, voyager de lieu en lieu, vieillir, finir chez un soldeur, dans un salon ou noyé de poussière dans un grenier... Contrairement à nous, un texte imprimé ou pas peut renaître à tout moment grâce à la magie d'un simple regard. Même un très mauvais bouquin accède à l'immortalité tandis que, avec ou sans épée, jamais un auteur n'échappe à sa nécro. Alphonse Allais, prévoyant, anticipa avec ses Euvres anthumes. Dernier mot au lecteur. Peu importe le support pour le talent. Une question se pose tout de même en termes d'espace: le numérique va-t-il tuer les vendeurs de bibliothèques et étagères?

Je m'amuse à lire des quatrièmes et picorer des premières lignes. Certains incipits seront à jamais des claques: «Ses amis l'appelaient Harry. Mais Harry n'enculait pas n'importe qui. Uniquement des femmes... Des femmes mariées. ». Le Démon, roman de Selby, n'est pas uniquement une fiction provocatrice et dénuée de sens; un très beau livre sur une plongée dans la folie. «Ça a débuté comme ça. Moi, j'avais jamais rien dit. Rien. » "Aujourd'hui maman est morte. Ou peut-être hier, je ne sais pas. " "Je sortis de la marquise à 5 h00." Que de claques en suspens dans un rayon littérature! Des phrases qui bousculent, un style, un travail sur la forme et le fond... Que demander de plus? Ce zapping de bouquin en bouquin me permet de me sentir bien, comme chez moi. Les autres lecteurs semblent aussi chez eux. Tous sous le même toit. Intimité aux côtés d'inconnus. Pas la promiscuité des transports en commun ou de 
celles d'ados confondant parfois l'espace public avec leur piaule. Ici, chacun est embarqué dans une aventure générée par une poignée de signes derrière une couverture reliée. Quelque chose de l'ordre du magique en direct. Alchimie inexplicable.

Silence habité,

Outre l'accès au savoir et à la culture, les bibliothèques recréent une forme de solitude. Rares les lieux fréquentés par du public qui donnent cette possibilité. Sortir du groupe à l'instar de ce gosse happé par une BD et, assis plus loin, un étudiant, front plissé, décortiquant la prose technique d'un historien, ou cette vieille femme presque allongée sur un roman... En plus de la solitude du lecteur, de l'auditeur de musique et du spectateur devant son écran, règne un silence particulier, semblable à celui de certaines librairies. Un silence habité par des milliers de personnages de romans, nouvelles, BD et films. Il y a aussi les acteurs de l'Histoire lointaine ou contemporaine. Sans oublier le destin d'hommes et femmes, connus dans leur quartier ou sur la planète, imprimée dans les quotidiens régionaux ou nationaux. Une foule d'individus de chair ou fiction grouillent entre les lignes et sur les écrans. Parfois, ce silence presque religieux m’emmerde. Après, Hôpital: Silence, Médiathèque: Silence. «On dirait qu'ils enterrent un mort! » avait lâché un copain de classe si intimidé qu'il ne remit plus les pieds dans une bibliothèque. Pourtant ces îlots de silence et de solitude sont nécessaires. Je regarde par la fenêtre. Le film de la ville continue, sa bande-son muette derrière la vitre. À l'intérieur, 40000 livres; plus d'habitants que la commune de Biarritz. Surpopulation souhaitée à toutes les villes et villages.

Ce paquebot, entouré d'une barrière végétale, ne navigue pas en pilotage automatique. De la proue à la poupe, sur les ponts et en soute, une vingtaine de personnes se chargent de la navigation. Par tous les temps, même en période de gel des subventions. N'ayant pas pris l'option visite guidée, je ne peux fouiner dans les bureaux: salle des machines où se concocte achat, animations, expositions. Certainement qu'un passage dans les coulisses aurait évité erreurs, oublis et approximations dans ce récit. Un récit tissé de sensations et de mémoire. 
Dinosaure de papier?,

Me rendre au département Images? Après une hésitation, je le traverse au pas de charge. À quoi est dû mon manque d'intérêt? Peut-être mon côté dinosaure de papier qui privilégie le livre à l'image - surtout dans une bibliothèque? Média et biblio sont dans un bateau: qui tombe à l'eau. Tu peux partir maintenant, me dis-je, persuadé d'avoir accompli une partie de ma mission. Et pressé de boire un demi en terrasse face à la grande plage, jeter quelques notes à chaud. Pourtant je reste dans le hall et continue d'observer. Qui sont réellement ces passagers? Difficile de le savoir sans leur adresser la parole ou les côtoyer. Pourquoi choisissent-ils la médiathèque alors qu'un ciel lumineux s'étale sur les toitures et descend jusqu'aux plages? Des étudiants, retraités, chômeurs, SDF, ados, enfants... Toutes sortes d'êtres réunis ici, sûrement un des seuls endroits des villes et campagnes où classes sociales, us et coutume, ethnie, se dissolvent... momentanément. Un homme sans âge, le cou tanné par une existence de banc en banc, avait le regard rivé sur une page de journal. Lit-il ou simplement un geste pour se fondre parmi les autres? Personne pour demander de renouveler sa consommation ou quitter la station de métro ou le quai de la gare. Je promène mon regard de l'un à l'autre comme pour tenter de saisir l'essentiel de chacun, transformer les expressions des visages en mots. Faire revivre ces quelques instants d'un voyage hors du temps. Je souris en les voyant: lui assis devant une encyclopédie, elle, debout un livre à la main. Ils se dévorent des yeux. Leur lecture suspendue. Un futur rendez-vous sous d'autres couvertures?

Retour à terre,

En descendant l'escalier, je lève la tête. Toujours la même mouette près de la façade? Encore une question sans réponse. Elle se détache de la baie vitrée, rase le toit de l'hôtel Oxo et s'éloigne au-dessus des immeubles.

Se posera-t-elle sur le Casino réaménagé par François Lombard? Bâtisse blanche face aux flots. Pas la même motivation pour pousser la porte de la médiathèque et celle de la salle de jeux. Usagers d'un côté, clients de l'autre.

Et porteurs d'un même désir: s'enrichir. 


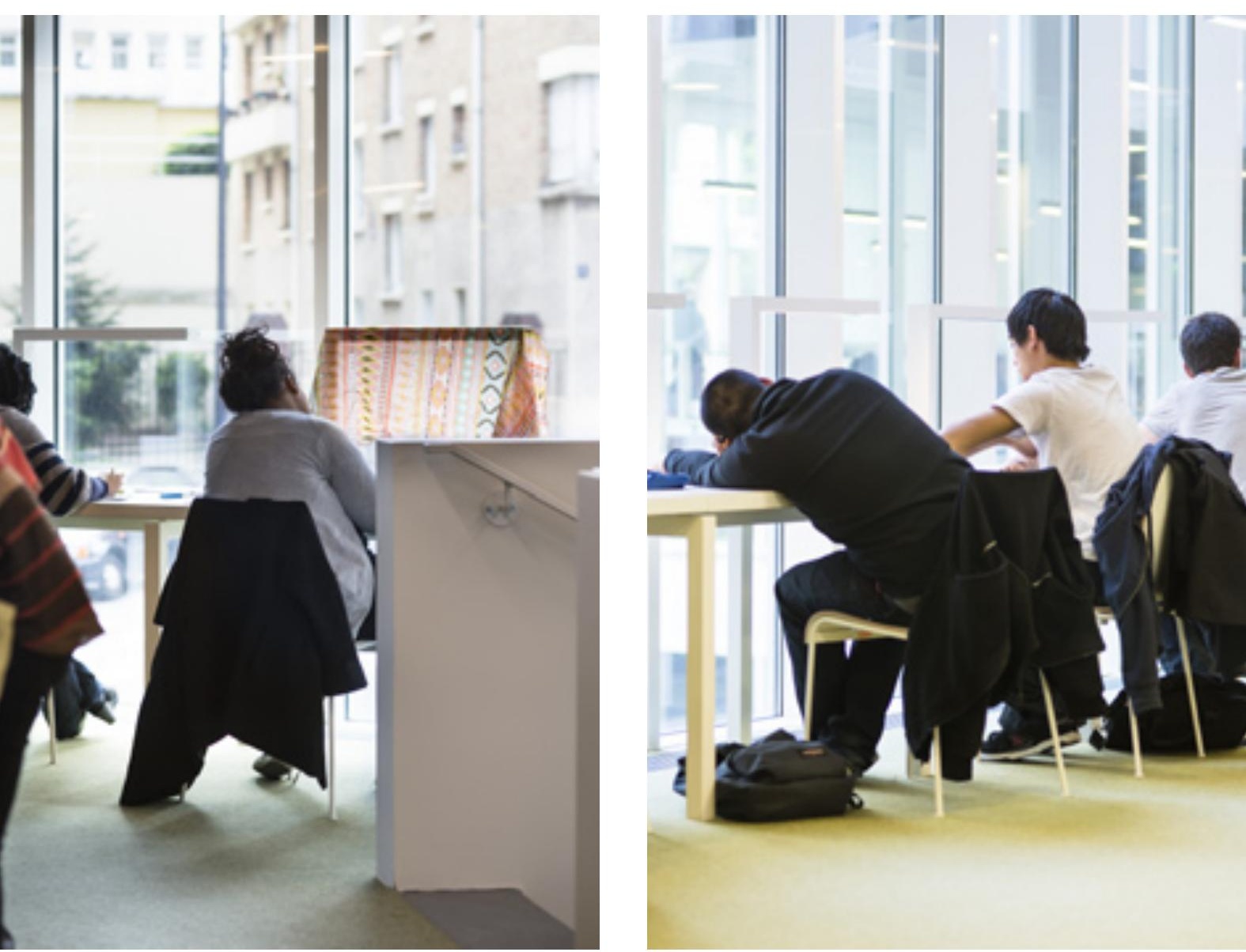


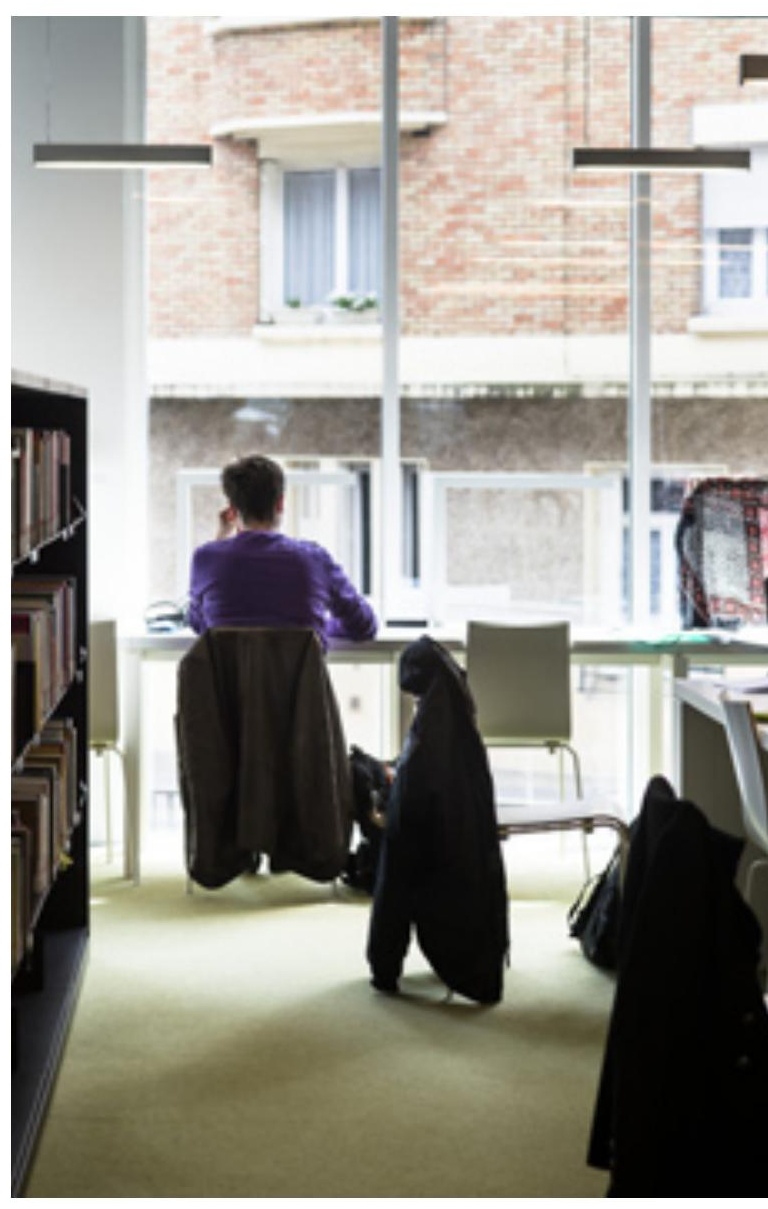




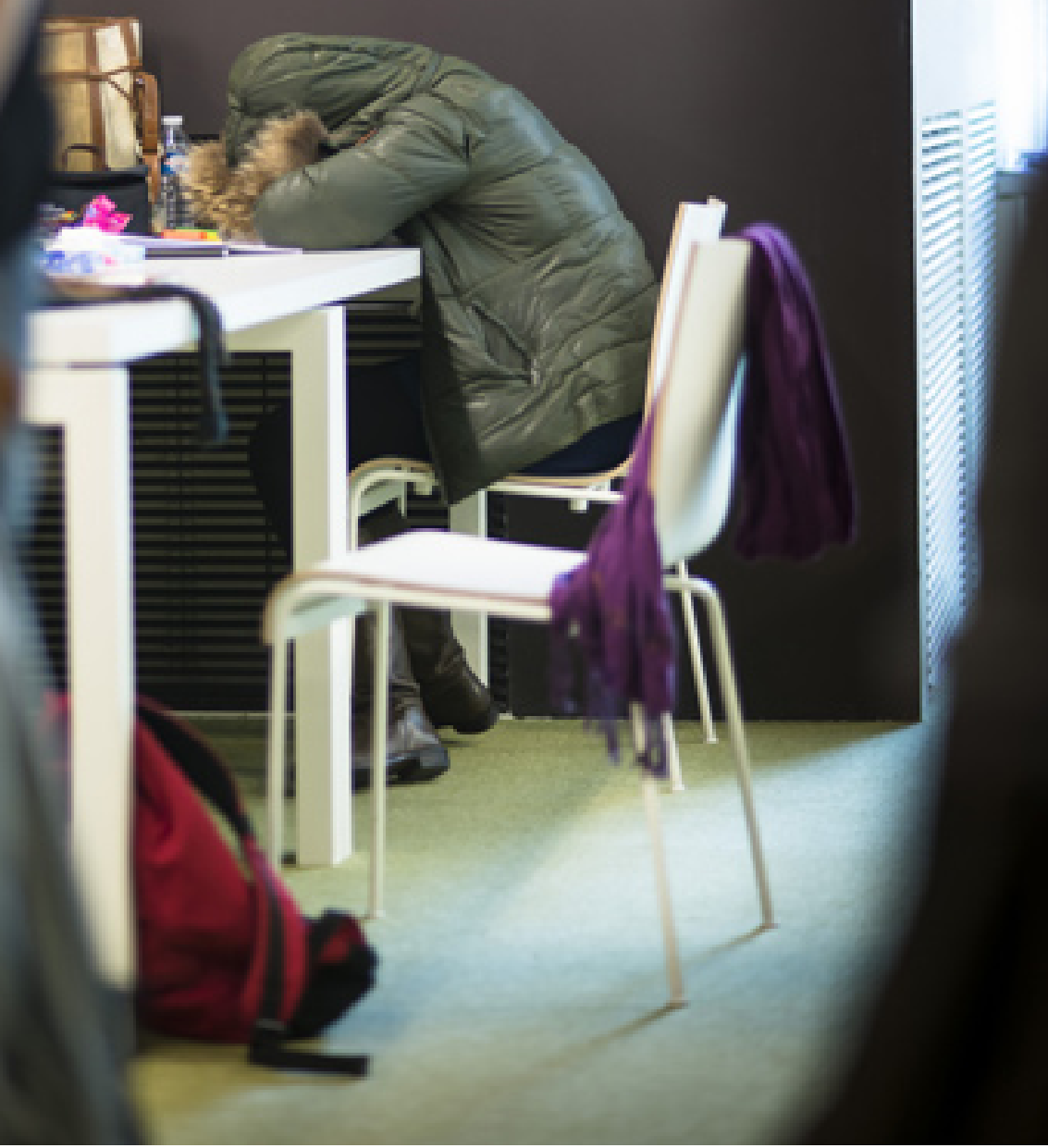




\section{1}

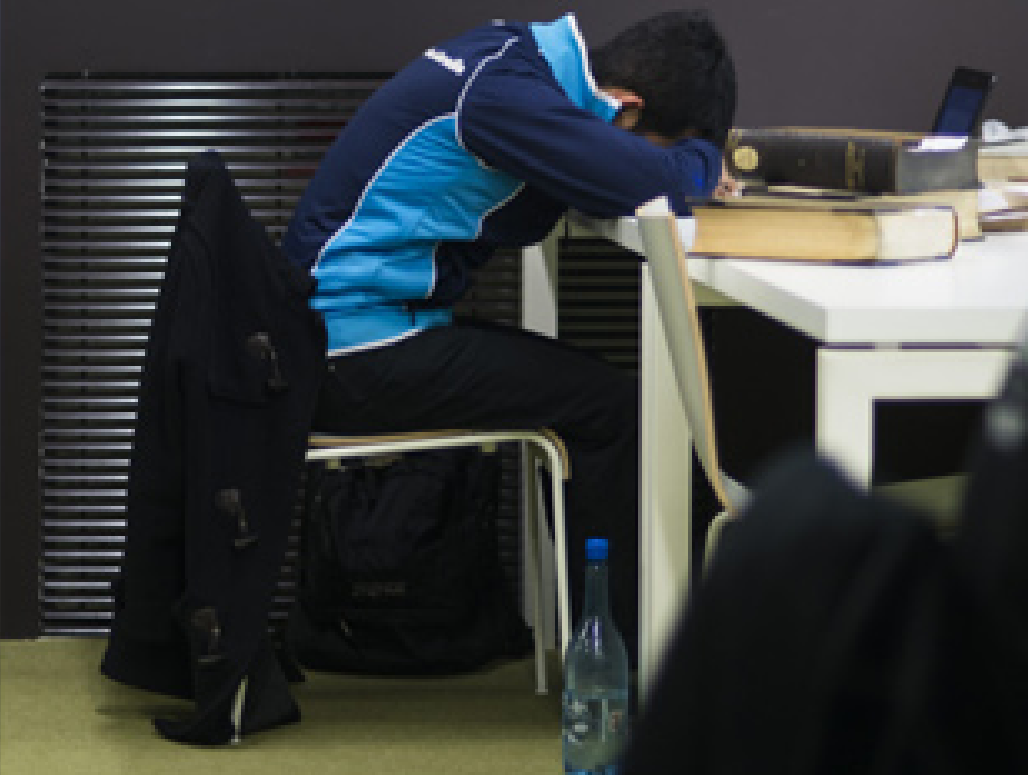



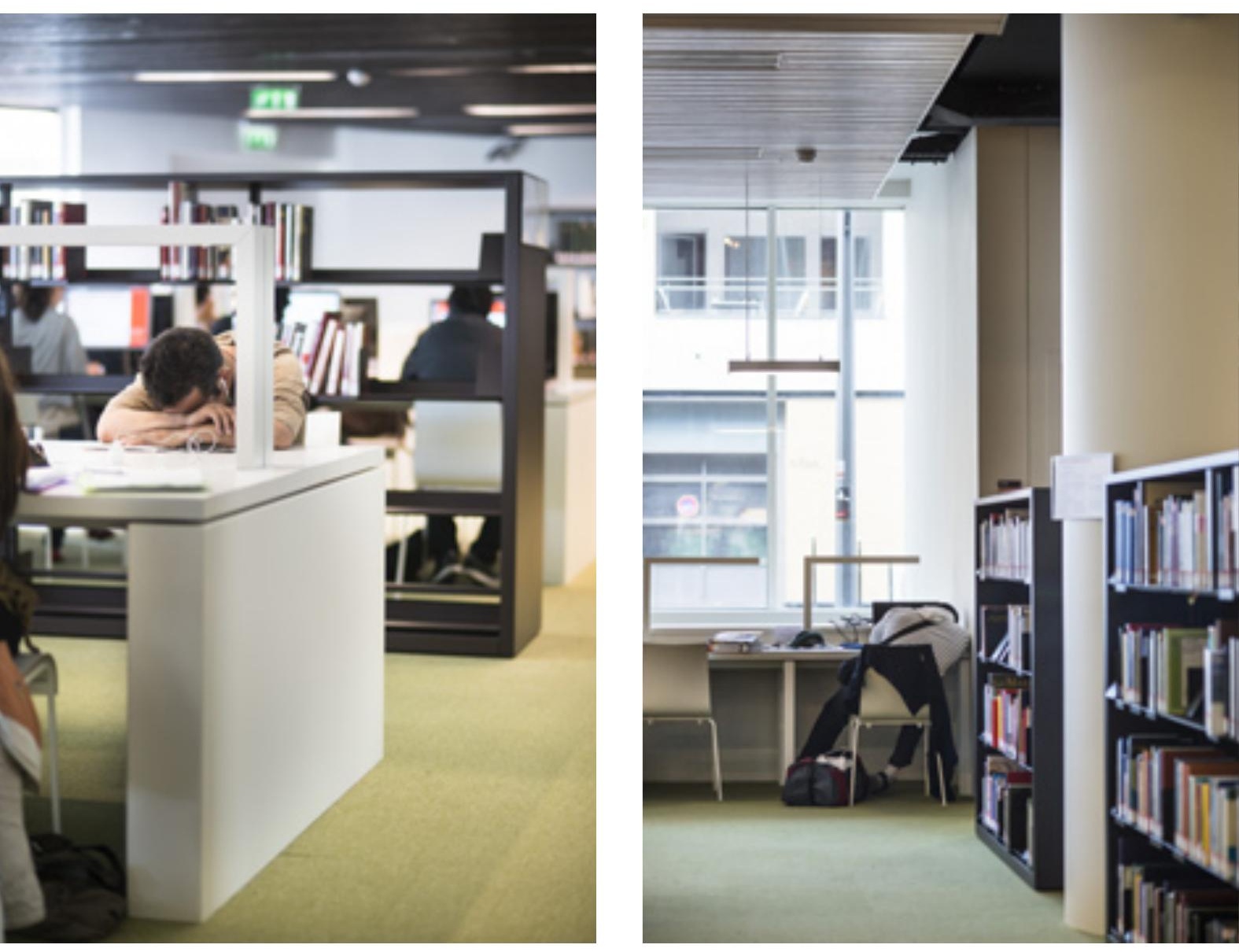


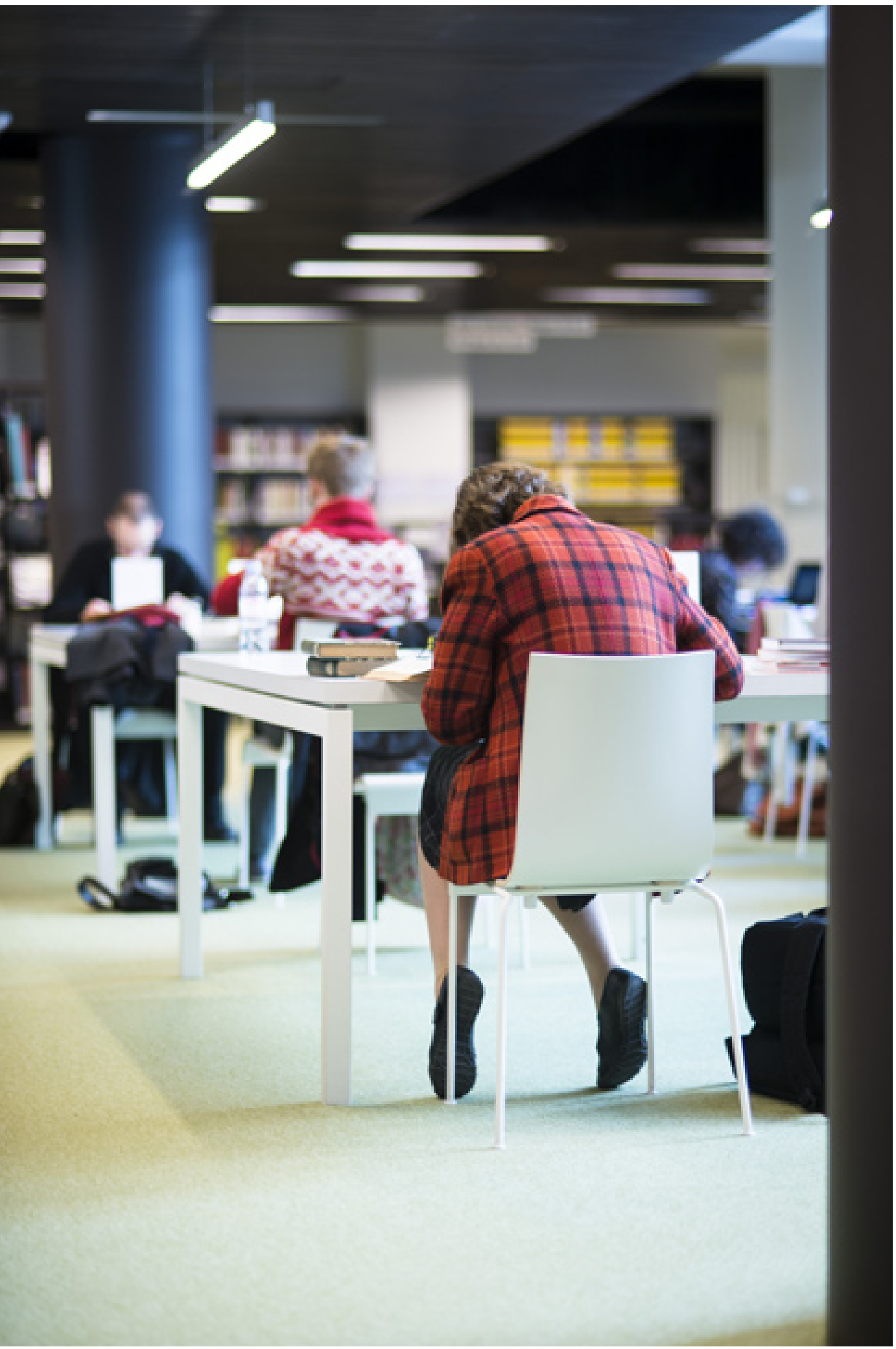




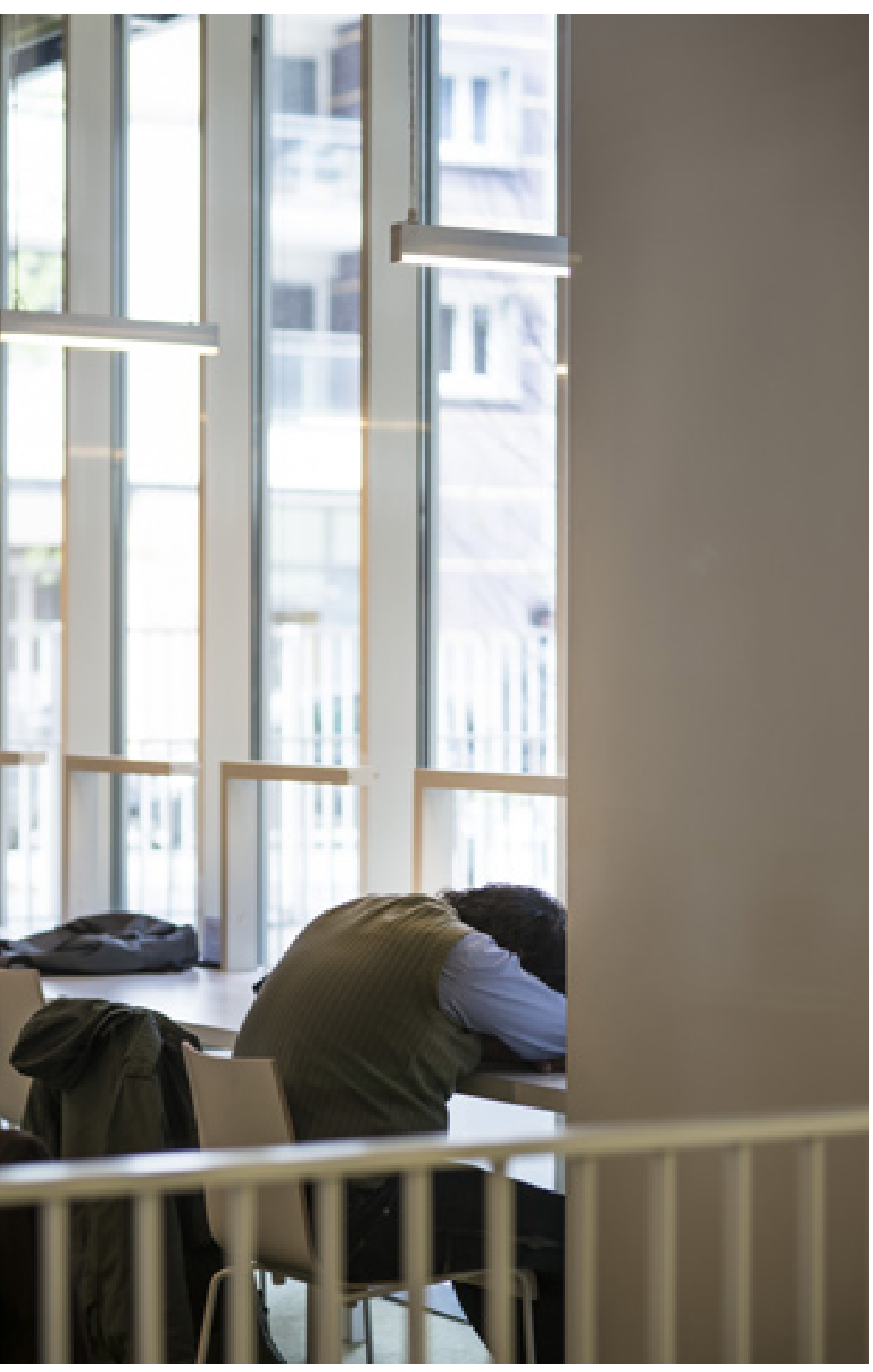




\section{Trafalgar à Austerlitz}


J'ai une tendance exagérée à la sévérité vis-à-vis de la France et des Français, et tout particulièrement vis-à-vis de Paris et des Parisiens. Je voudrais notre capitale moins sale, plus aérée, mieux disciplinée, plus moderne et d'un cosmopolitisme plus homogène. Et les Parisiens plus élégants et moins enclins à rouscailler. Bref, je voudrais que Paris soit Londres et les Parisiens londoniens. Et je ne trouve jamais la ville si digne de sa réputation internationale que lorsque, à la faveur de travaux d'embellissement à l'angle d'un boulevard ou de l'initiative d'une poignée de riverains humanistes soucieux d'espace public et d'intérêt général, je tâche de me convaincre avec un orgueil hargneux que les Britanniques, mes parangons incontestables d'audace, d'ouverture d'esprit et de civisme, ne feraient pas mieux.

À ce titre, j'aime assez l'ensemble formé par les rues PrimoLévi, Marie-Andrée Lagroua Weil-Hallée et Alice-Domon et Léonie-Duquet, au cœur de ce qu'il est convenu d'intituler, avec le conservatisme et l'étonnement provincial qui nous caractérisent, Le Nouveau Quartier latin, ou encore Le Nouveau Treizième. Comme à Southbank, Elephant \& Castle et d'autres secteurs outre-Manche promis à ce que les Anglais appellent parfois eux aussi The New London (mais sans que ma mauvaise foi y trouve quoi que ce soit à redire), comme là-bas on y rencontre désormais d'hardis îlots ouverts de logements neufs aux pignons de béton lasuré, ainsi que des façades en cours d'achèvement capitonnées de grands panneaux isolants en laine de roche de couleur jaune soufre attendant d'être couverts de matériaux de parement aussi exotiques que des bardeaux de terre cuite ou des plaques d'aluminium anodisé. Au sein de ce bref périmètre répondant aux normes environnementales européennes les plus récentes, on circule dans un silence affairé. Les pelouses des squares y sont jusque-là épargnées par les mégots et les papiers gras, le mobilier urbain vierge de graffitis et les trottoirs pas encore constellés d'empreintes de chewing-gums ou d'odorantes déjections canines. Un vrai mirage de netteté et d'harmonie pour le Latin refoulé que je suis. 
L'illusion est complète un peu plus à l'ouest, au 65, rue des Grands Moulins. Là, dans l'élan d'une perspective subtilement coudée, faisant écran à la Cité-refuge de l'Armée du Salut dessinée par Le Corbusier, un édifice tout neuf d'un million de briques grenat percé à intervalles irréguliers de hautes fenêtres néo-élisabéthaines contournées de blanc vous téléporte sans sommation quelque part entre les stations Tottenham Court Road et Euston Square: le Pôle des Langues et Civilisations. Dans cet espace de 32000 mètres carrés qui, depuis décembre 2011, regroupe opportunément l'Institut National des Langues et Civilisations Orientales (INALCO, ou «Langues O'») et la Bibliothèque Universitaire des Langues et Civilisations (BULAC), évolue du matin au soir un public multiculturel serein et studieux que l'on ne croyait réservé, mettons, qu'aux amphithéâtres de la School of Oriental and African Studies (SOAS), dans le quartier de Bloomsbury. Saris brodés, sarouels de soie, cols Mao, coupes afro soignées, pakols afghans, bérets chéguévariens, sandales bouddhiques, tatouages araméens et déclinaisons fort travaillées du désormais traditionnel ensemble hijab-jean-baskets: nulle part ailleurs en France la jeunesse n'a la mondialisation aussi coquette et la conversation aussi chic: "Ah bon, il parle thaï aussi, Mathias? " Tu peux me passer ton dico de guarani, steup? J'ai cours dans cinq minutes. " «Alors, c'était bien votre semaine à Gasa Dzong? » C'est le paradoxe des deux plus grandes puissances coloniales des temps modernes que d'avoir assujetti les peuples, les idiomes et les cultures de la planète tout entière au fil des siècles pour finir, dès la fin de la Première Guerre mondiale, par chercher passionnément à en restituer les nuances et les spécificités (voire à les ressusciter), notamment au sein de ces deux institutions universitaires d'enseignement et de recherche uniques au monde. "Être français, résumait dans ce sens l'écrivain polonais Witold Gombrowicz, c'est s'intéresser à autre chose qu'à la France. » Si nos réticences de tout poil tendraient aujourd'hui à démentir cette observation généreuse jusque dans les orientations trop souvent ambiguës de nos politiques extérieures, le Pôle des Langues et Civilisations des Grands-Moulins fait, lui, 
figure d'imprenable et constante forteresse d'optimisme et de générosité.

L'INALCO contre la SOAS (puisque c'est obstinément en termes d'affrontement que j'entends envisager les choses ici), c'est d'abord une surenchère comparative de chiffres, un peu comme celle des dépenses monétaires et des pertes d'effectifs militaires au sein de la Marine impériale et de la British Royal Navy sous Napoléon. Avec l'École des Jeunes de Langues fondée dès 1669 par Colbert, Langues O'présente un considérable privilège d'antériorité par rapport à la SOAS, créée en 1917. Quatre-vingt-treize langues y sont enseignées (dont l'inuktikut, le nahuatl, le sorabe et tant d'autres vulnérables merveilles) contre trente-quatre à Londres. 4500 apprenants à la SOAS, le double à Paris. Mais avec leurs 153 societies (dont un club d'amateurs de cigare et un cercle des metteurs en scène radicaux), ainsi que la distribution gratuite de dhal épicé organisée quotidiennement par une association Hare Krishna devant la Brunei Gallery, les Anglais l'emportent poing levé question fantaisie et convivialité. Ajoutons la détermination, si l'on mentionne que, fin 2011, la police municipale de Londres n'a pas hésité à détacher sur le campus un agent undercover plusieurs jours durant afin de procéder à l'arrestation d'un abusif voleur de bicyclettes.

Trêve de trivialités: la différence réellement significative entre l'INALCO et la SOAS, ce sont leurs bibliothèques. Tout commence par les aimables et discrets pictogrammes apposés sur les portes vitrées de l'entrée de la BULAC signifiant aux visiteurs qu'il est préférable, à l'intérieur de l'établissement, de désactiver les alertes sonores de leur téléphone portable et de ne consommer que de l'eau. Rien de commun avec le martial et péremptoire Food \& drink are NOT ALLOWED in the Library imprimé en caractères XXL sur une affichette de carton jetable à la SOAS, assorti un peu plus bas de la réfrigérante mention: Les contrevenants à cette règle se verront retirer leur accès à la bibliothèque.

J'insisterai également sur les vertus de sobriété et d'œcuménisme de la carte magnétique blanche d'adhérent, personnalisée et frappée du logo de la bibliothèque dans quatre écritures 
bien distinctes (coréen, hindi, birman et amharique), qui vous sera remise par les Français. Elle est gratuite sans contrepartie insidieuse et vous est délivrée, photo numérique comprise, en moins d'une minute à l'accueil sur présentation d'un justificatif de domicile et d'une pièce d'identité. À la SOAS, vous débourserez sur-le-champ 100 livres sterling (124,32 euros) pour un abonnement d'un an, payables uniquement en espèces ou par chèque, mais sous réserve d'une présentation de carte de garantie de validité dudit chèque. Je m'abstiendrai ici de tout commentaire désobligeant sur le pragmatisme marchand des Anglo-Saxons comparé aux bienfaits bien connus de notre État-providence.

Ce n'est pas tout. Exception faite de sa discutable moquette vert absinthe, il faut également reconnaître à la BULAC une immédiate précellence de confort. Entrez les mots «SOAS library » sur votre moteur de recherche Internet et sélectionnez l'option Images: vous y découvrirez une sorte de patio besogneux de néons et de formica que surplombent lourdement trois niveaux très exagérément fournis en rayonnages, eux-mêmes bondés de volumes. Certains clichés montrent même des lecteurs appréhendés en flagrant délit de consultation malcommode, racrapotés entre les quelques dizaines de centimètres à peine d'espace séparant entre elles ces intimidantes et sinistres étagères. C'est à ce prix, voyez-vous, que les Anglais peuvent ainsi se flatter de laisser au public leurs 2 millions de volumes en accès libre.

225000 ouvrages «seulement» en consultation directe à la BULAC, 1,25 million accessibles sur demande. Mais quelle paix visuelle que celle procurée par ces spacieuses et claires allées desservant 910 postes de lecture en hêtre véritable et bénéficiaires, dans leur grande majorité, d'une non moins authentique lumière du jour!

Je n'entrerai pas dans une étude concurrentielle des trophées de rareté conservés dans les réserves spéciales de chacune des deux bibliothèques, car il semblerait bien chicaneur d'aller mettre en balance un livre d'Heures imprimé en arabe à Fano (Italie) en 1541 (BULAC) et un recueil de fables du poète persan Hussein Wa'iz Kachifi édité en 1504 (SOAS). Non. Je ne ferai 
pas non plus aux Anglais l'affront de leur demander s'il existe quelque part dans le béton de leur édifice un clou de fondation élaboré, comme au Pôle des Cultures et Civilisations, selon les vénérables rites des architectes mésopotamiens d'antan. Que le Dieu Nabû te bénisse et te garde en bonne santé et heureux éternellement: c'est l'antique formule que les Parisiens ont eu le bon goût de faire graver en alphabet cunéiforme sur le talisman susmentionné au moment des travaux sur le site des Grands-Moulins, en 2008.

Maintenant, écoutez cette phrase: "Nous avons des syllabaires, comme les hiragana et katakana japonais, des alphasyllabaires ou abugidas (qui mélangent les caractéristiques de l'alphabet et du syllabaire) comme le devanagari servant à écrire l'hindi et d'autres langues indiennes et, bien sûr, les sinogrammes de l'écriture han pour le chinois. La bi-écriture implique une équivalence avec l'alphabet latin, donc plus on s'éloigne du système alphabétique, plus il est difficile d'automatiser le processus de saisie. Mais au-delà de cela, d'autres spécificités inhérentes à chacun de ces fonds rendent leur catalogage quelquefois peu évident. »

Voilà comment on sait parler, chez les conservateurs de la BULAC. J'ai cru comprendre que les dites difficultés de translittération relatives au catalogage des ouvrages en alphabets non latins (à moins qu'il ne s'agisse de rétroconversion?) avaient donné lieu, à la BULAC et encore une fois nulle part ailleurs, à la création d'une norme particulière. Vive le Service Public.

Bref, la BULAC, j'aimerais bien en dire un peu de mal, mais je ne vois pas. Pas encore. Ah, si: au 15 mai 2012, soit cinq mois après l'inauguration officielle des locaux, la grande horloge du niveau supérieur, tout comme au matin du premier jour, marquait invariablement midi. 
J'aime/J'aime pas: Carnet de route vers la médiathèque d'Alfortville 
J'aime rouler dans des paysages qui défilent et me parlent audedans, et déplacent mes pensées comme les éclats de verre multicolores à l'intérieur du kaléidoscope. J'entame la traversée de Paris d'Ouest en Est jusqu'à Alfortville où je rejoindrai le Pôle culturel, 26 rue Joseph-Franceschi. J'aime l'idée de ce trajet. Il faut prendre les quais et longer la Seine sur sa rive droite jusqu'au pont qui enjambe le fleuve vers MaisonsAlfort. Ma vieille voiture, qui ne roule quasiment plus, se mêle à la transhumance quotidienne des citadins. Le trajet est beau comme la grande ville couchée, le Trocadéro majestueux, la tour Eiffel qui me rappelle le début des Voyageurs de l'impériale, l'Alma grouillante d'une foule industrieuse, la Concorde sublime comme l'a dit Nina Berberova. Je m'engage dans le tunnel qui me séparera des Tuileries, du Louvre, des bazars de livres et d'animaux avant le Châtelet, mais je profite d'Orsay et de la Conciergerie. Sur la grande façade du Palais de Justice une affiche: Devenez magistrat. J'avance à travers les lieux connus vers un lieu inconnu. Parce que je sais que j'écrirai un récit, je regarde avec plus d'attention. Écrire est un redoublement de la vie, comme lire l'est également. Écrire est une manière de retenir en soi ce qu'on pourrait ignorer. Je ne sais pas si j'aime écrire, mais je n'aime pas vivre sans écrire. L'écriture est une obligation vitale, j'aime donc avoir écrit: l'obligation intérieure remplie ouvre la porte au plaisir. J'aime lire, qui est aller chez les autres, partir ailleurs, se quitter soi-même et se redécouvrir ensuite. J'aime lire qui est bien plus facile qu'écrire. J'aime lire pour apprendre comment s'y prennent les autres. Est-ce que je roule en pensant à tout cela? Je ne sais pas. L'esprit est un jaillissement qui s'oublie. Voilà une raison de plus pour écrire. Consigner. Ne pas laisser passer ce qui fut.

Je viens de dépasser le pont Henri-IV.

L'acier, le verre, qui abritent les livres invisibles: les quatre tours de la Grande Bibliothèque se dressent à ma droite, arides, excessives, sans charme. Je n'arrive pas à les aimer. Je fais attention aux panneaux, j'attends de voir écrit Alfortville. Je m'inquiète de ne pas bifurquer et d'avancer si vite vers 
l'autoroute de Lille sur laquelle je crains de me trouver embarquée sans voie de retour. Je n'aime pas les voies rapides, les sens uniques, l'enfermement des routes qui au contraire devraient figurer la liberté. Je me décide à tapoter la destination sur un GPS dont je ne me suis jamais servie. Et tout à coup miracle, ça parle dans l'habitacle: «Tournez à gauche à 250 mètres!» Une voix de femme, qui a un accent. Je vois le drapeau rouge planté sur le point de la carte qui figure la médiathèque. Je n'ai fait aucune erreur. Il me suffit maintenant de suivre les indications. J'approche. Je réalise que j'avais peur de me perdre. Et pourtant, quel danger, quelle importance, de se perdre? Pour moi, le danger est de perdre du temps. Je suis capable de le penser clairement chaque fois que je fais quelque chose. Le temps est compté, rare, source de toute œuvre: je n'aime pas le laisser s'engloutir dans l'erreur inutile.

C'est un quartier de petites maisons de briques entourées de jardinets mitoyens, séparés par des murets. Les arbres sont en fleurs. J'ai toujours aimé ces halos de blancheur légère, parfumée et éphémère. Non loin, de hautes tours modernes surplombent ce décor de banlieue ancienne au charme suranné. "Vous êtes arrivé à destination », dit le GPS. Je dépasse en effet sur la droite un bâtiment gigantesque, un gros parallélépipède rectangle de vitres fumées à travers lesquelles j'aperçois des tables et des chaises. La médiathèque. L'énormité me sidère. Je me gare non loin de ce Parvis des Arts vers lequel je reviens en levant haut les yeux. Assis à une table, un vieux monsieur penché est occupé à lire, tout seul au premier étage. Je m’imagine qu'il travaille. Pôle culturel. En lettres orange sur le béton. Un jeune homme sort en sautillant dans les escaliers et saute sur son vélo appuyé contre la rampe. C'est le Vendredi saint. Tout est calme. Je sais que la médiathèque est ouverte.

À l'entrée: les annonces des prochaines manifestations culturelles. On peut écouter Mendelssohn, Schumann, le 7 avril. Une salle de spectacle et un cinéma adjacents proposent des projections de films, un spectacle de cirque, un tournoi de danse. Il existe des ateliers multimédias. J'admire ce 
dynamisme éclectique. Une exposition photographique est en cours, du 6 avril au 2 mai. Titre: Les indécis. Par Valentin Dupitier. Trois histoires retracent les aventures de trois personnages confrontés à l'indécision. Rita qui voit des fantômes. Rembrandt qui entend une musique. Rolland qui s'ennuie avec ses parents. Les photographies sont accrochées dans le hall d'accueil, encadrées, disposées. Je m'approche. J'aime qu'un cliché me montre ce que je ne sais pas voir. J'aime l'écart de perception et de création, entre mon œil humain et l'œil d'un objectif talentueux. Photographie et littérature vont bien ensemble, qui partagent l'art de regarder avec attention: comme un art du gros plan. Et de la composition à partir du réel. J'aime voir ce qu'élabore le regard d'un autre.

Deux dames bavardent derrière un bureau. Peut-on me renseigner? demande l'une d'elles en me voyant apparaître dans l'immense hall désert. "Je suis là pour le projet Carnet de route», dis-je. Et j'annonce: "Je vais me promener dans la médiathèque. » Les deux dames ne savent rien. Personne ici n'est au courant de ce projet. Je suis un peu désolée de ne pas le partager, mais le suis-je vraiment? J'aime assez qu'on me laisse tranquille! Quand on veut écrire, il n'y a rien à dire, il faut s'y mettre, seul avec soi-même. Je lève les yeux: ici aussi des panneaux indiquent les différents rayons. Code couleur: Orange. Jeunes. Adultes. Actualités. Poésie. Art. Musique. Cinéma. Albums. Romans. Rien ne manque. C'est une caverne d'Ali Baba, ouverte à tous, sans mot de passe. Et si l'on y restait enfermé, ce ne serait pas la mort mais la meilleure des vies: se gaver de livres, d'images, de musique. Les caisses destinées aux enfants sont pleines de livres de tous les formats. Partout sont disposées des tables individuelles surplombées d'une lampe. Le lieu est dédié à l'étude silencieuse. La presse est au rez-de-chaussée. Un grand escalier mène aux documentaires et romans pour adultes, au premier étage. Dispersés dans l'espace immense, des bureaux, des ordinateurs, derrière lesquels sont assis les responsables de chaque domaine. Image d'une modernité que je n'aime pas: chacun face à son écran. Occupé. Captivé. Séparé. 
Je n'ai cependant besoin de personne pour circuler avec plaisir entre les étagères du rayon littérature. Pour lire, je n'ai jamais eu peur de m'égarer. Je lis rarement les livres que me conseillent les amis ou les gens que je rencontre. J'aime choisir seule, dans la logique de mon avancée personnelle. Mon appétit me vient du dedans. Pas de GPS! Personne ne me dit: «Prenez ce livre! » «Tournez la page! » «Allez à la ligne! » «ous êtes arrivée à destination! » Je peux même ne pas lire la quatrième de couverture, qui m'enfermerait peut-être dans une interprétation. Je peux négliger tout le paratexte, comme l'appelait Hubert Nyssen dans son beau livre sur l'édition Du texte au livre. Les avatars du sens. Je peux choisir sur la foi d'un auteur, le charme d'un titre. Je peux être fidèle les yeux fermés à ceux dont je lis tous les livres et qui sont encore assez vivants pour en écrire de nouveaux: Sylvie Germain, Pierre Bergounioux, Richard Millet, Jean-Philippe Toussaint, Pierre Michon, François Bon, Annie Ernaux, Patrick Grainville. Je peux lire la dernière page avant la première. Je peux relire le début quand j'ai terminé la fin. Je peux relire tout ce que j'ai souligné. La solitude, la liberté, le temps et les mots, cocktail détonnant qui ouvre des fenêtres qu'on n'avait pas vues, qui m'emporte loin, dans la vie universelle, devant des questions que je ne me posais pas, à la place des autres: où je veux.

Un fond de jazz vient me toucher. Domine pourtant une impression de silence: personne n'est venu à la bibliothèque en ce vendredi. Je trouve l'espace si grand qu'il en est froid. Le décor moderne n'arrange rien à mes yeux. Tout est neuf. Il manque encore la patine. Le pôle culturel a été inauguré le 17 mars 2007: il y a tout juste cinq ans. Qu'y avait-il auparavant? Maintenant il y a cet espace géant, posé au milieu de la ville, ouvert à tous. Il y a des canapés couleur prune, à dossiers perforés, et des poufs en cuir orange. J'essaie d'imaginer le lieu quand il est intensément fréquenté. Les familles assises qui chuchotent. Les enfants, assis en tailleur. Des lecteurs solitaires. Je me réchauffe aux livres. Daudet. Djian. Don Delillo. Druon. Durrell. C'est merveilleux comme l'ordre alphabétique 
fait cohabiter tant de diversités. Jim Fergus. Annie Ernaux. Echenoz. J'ai lu tous ces gens. Maintenant je peux voir de près le vieux monsieur qui lit. Il n'est pas si vieux! Et pas si studieux que je me plaisais à l'imaginer. Il ne lit que des magazines. Il a l'air de s'ennuyer, lève les yeux, n'est pas concentré. Comment se concentrer sur des magazines! J'entends derrière moi les murmures de deux lycéens, cette façon particulière de se parler dans le calme obligatoire d'une salle de travail. Les bibliothécaires sont silencieux derrière leurs écrans.

Puis-je avouer que je n'emprunte jamais les livres? Je n'aime pas emprunter ce que je vais lire avec attention. Étudiante désargentée, j'achetais les livres de poche: centaines d'heures de lecture pour quelques francs. L'histoire du livre est celle de la baisse de son coût. Jamais je ne trouve cher un livre que j'ai prévu de lire. J'aime posséder les textes auxquels j'ai donné mon temps. J'aime les garder, pouvoir y revenir, connaître la place de chacun, tendre le bras, les attraper pour en parler, savoir où et quand je l'ai lu, pouvoir le vérifier sur la dernière page. J'achète les livres que je lis. J'écris dans leurs marges. Ils traversent les années dans ma maison. J'aime avoir une bibliothèque. Aucune propriété ne m'est plus chère. J'espère qu'un de mes enfants désirera la garder, intacte, comme celle de mon grand-père aujourd'hui dans ma chambre.

Je n'aime pas prêter mes livres et j'aime offrir des livres. Je peux acheter un titre pour ne pas avoir à prêter l'exemplaire que j'ai lu. Je fais partie de cette sorte de personne qui se fâche avec un ami pour un livre pas rendu. Je ne prête plus mes livres parce qu'ils ont pour moi une valeur que personne n'enregistre: ils ont pour moi une valeur qu'ils n'ont pas pour ceux qui me les empruntent et jugeront sans gravité de les égarer. Je ne prête qu'à mes amis écrivains. Mais je peux de ma bibliothèque donner n'importe quel livre que je n'ai pas encore lu. C'est le temps que j'ai passé avec un livre, les émotions qu'il m'a values, ce que j'ai appris en le lisant, qui, restant consigné dans le livre, doit aussi rester à mes côtés. Le temps que j'ai passé à lire des pages me les rend précieuses. Les livres lus 
sont le support de mon travail, de ma recherche personnelle ou littéraire. Ils sont pleins de mes secrets et de ma passion pour le talent.

J'achète les livres des autres et pourtant j'ai peine à penser que les miens se vendent. Je n'aime pas l'idée que les gens doivent payer pour lire un de mes livres. Je ne suis pas favorable au prêt payant. J'aime que les livres vivent. Je regarde les livres alignés sur les étagères, recouverts d'une couverture plastifiée, marqués selon l'organisation des bibliothécaires. Dans ma bibliothèque, il n'y a pas d'étiquettes. Les exemplaires des livres peuvent vivre des vies différentes. Certains sont personnels, privés, intérieurs, ils ne sortent pas d'une maison où ils vivent. Les mêmes mains toujours les tiennent et les ouvrent. D'autres sont au lieu du passage, du partage et de l'emprunt, ils circulent, ils ne sont pas toujours choisis, ils pénètrent dans des maisons inconnues, on les rapporte. Des petites mains les serrent qui voudraient ne pas les rendre. Parfois ils sont volés. Je comprends un enfant qui veut garder Moby Dick ou Les Trois Mousquetaires! Il ne veut pas rendre son bonheur.

J'aime ces gens qui laissent un livre sur un banc, le quai d'un métro, un siège d'autobus. J'aime aussi les vieilles bibliothèques, personnelles ou nationales, là où un bibliophile vous trouve une édition ancienne d'un titre épuisé. J'aime les librairies. J'y passe chaque jour un moment. Voir les livres nouvellement nés.

Tout peut finir dans un livre. Tant commence avec un livre. Il faut de tout pour faire un monde de lecteurs.

Je dis au revoir aux deux femmes qui bavardent derrière le bureau à l'entrée.

Je n'ai pas eu envie de parler avec elles. Ai-je refusé de jouer le jeu d'une rencontre? C'est ainsi: avec les livres j'aime être seule à seuls. 


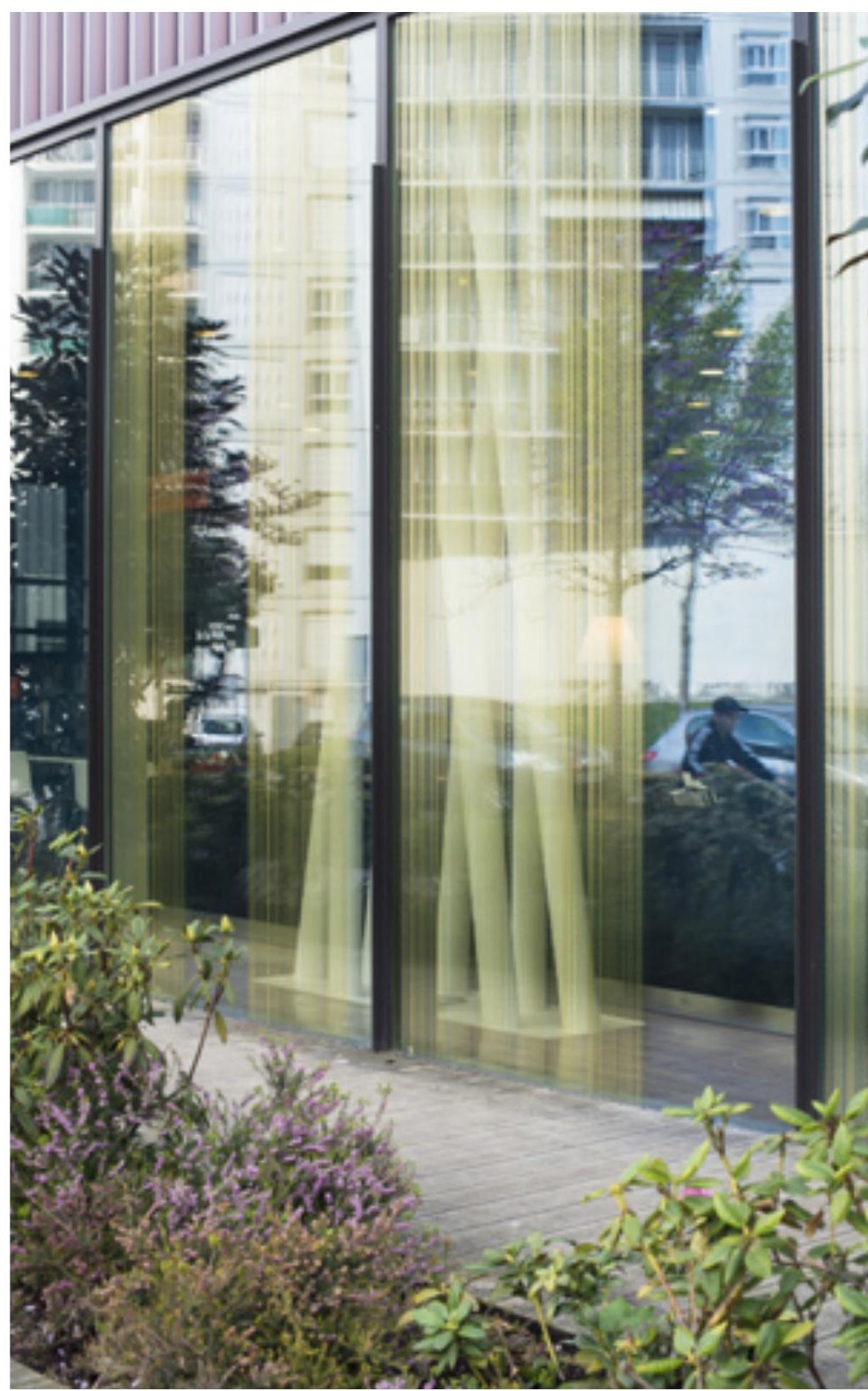



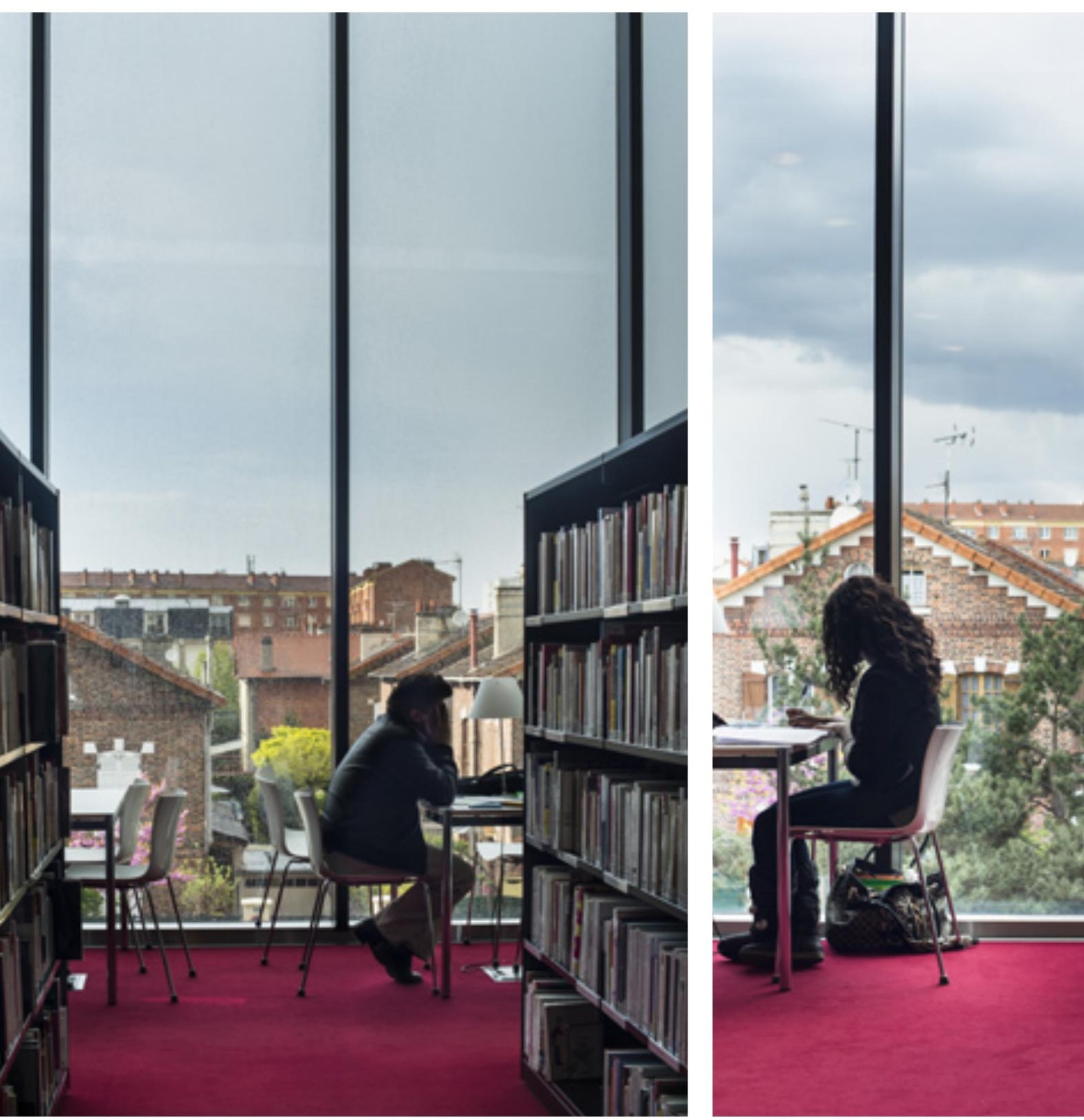

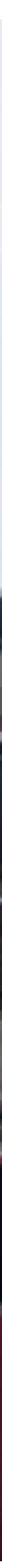


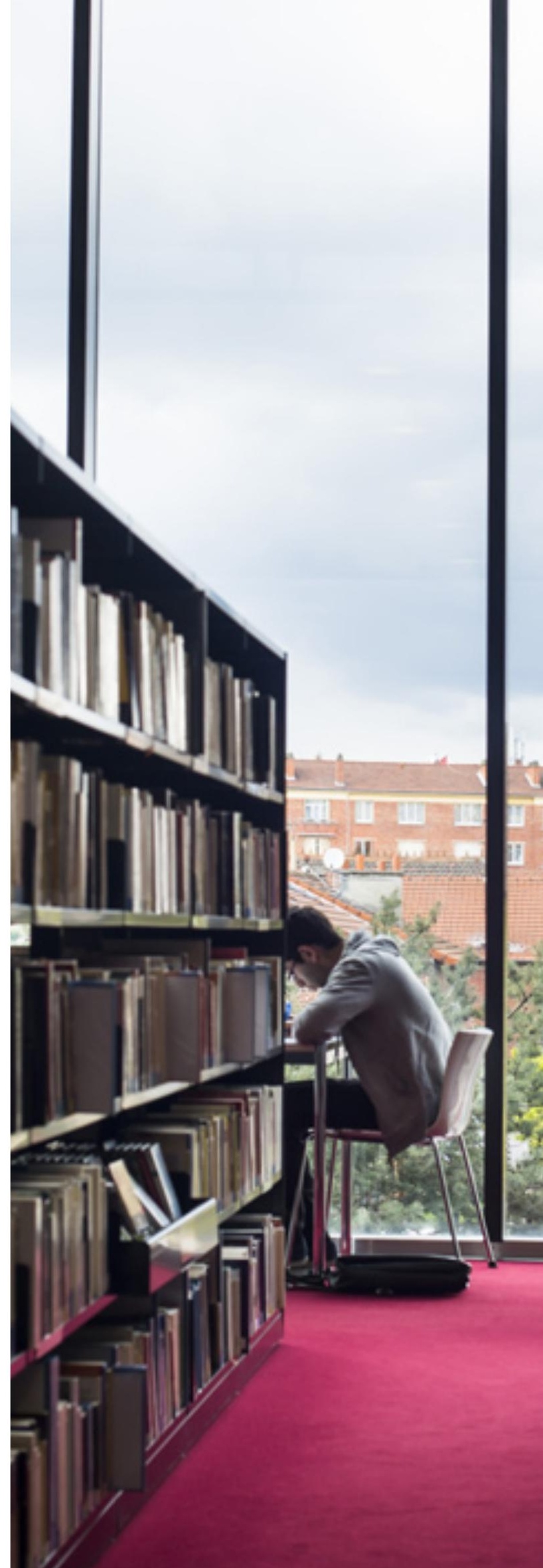




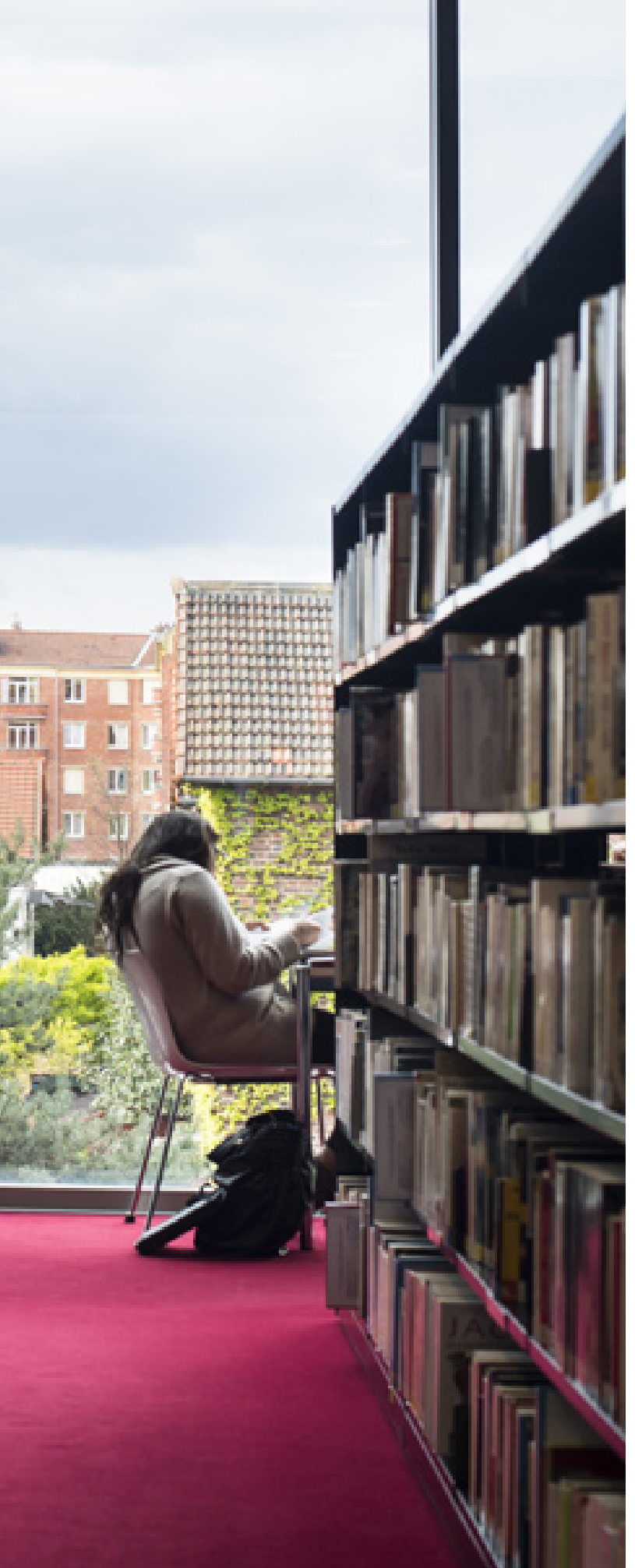


À portée de main 


\section{Un empêchement}

Répondre à une commande. Écrire à partir de, autour d'une bibliothèque, médiathèque - j'hésite souvent sur l'intitulé quoi de plus simple me suis-je dit, et pourtant découvrir qu'il y a de la crainte. Qu'il y a un empêchement.

Bibliothèque universitaire Lumière Lyon 2 de la rue Chevreul. Je visualise bien le bâtiment érigé vers les quais du Rhône où le fleuve poursuit son chemin d'indifférence malgré les promeneurs sur la rive.

Le bâtiment, je le connais de l'extérieur. Je n'y suis jamais entrée. Depuis la commande faite du texte, je l'évite.

Je voulais pourtant le photographier cet hiver. Saisir l'ambiance particulière lorsqu'il fait nuit pendant le jour. Les lumières de l'intérieur qui invitent à entrer. À venir se mettre au chaud.

Je ne me suis pas rendue sur place, je n'ai pas pris de photos. J'ai comme oublié. Fêtes de Noël où de toute façon s'absente de moi toute forme de désir.

Pourtant j'avais sciemment choisi cette bibliothèque universitaire, la BU comme je ne parviens pas à dire. Le lieu des étudiants.

Je n'ai jamais étudié. J'ai quitté l'école en terminale pour m’inventer une vie ailleurs. Le mot «étudier » qui ne s'applique pas aux lycéens. Les lycéens apprennent.

Et moi, j'ai appris quoi?

J'ai choisi la bibliothèque qui m'était la plus étrangère parmi toutes celles de la liste. La plus lointaine, pas en kilomètres puisqu'elle est située dans la ville où j'ai vécu pendant vingtcinq ans.

Pendant tout l'hiver, je n'ai pas réussi à m’y rendre.

\section{Le pas-de-porte}

Me reviennent les propos d'un lycéen en bac pro industriel qui, lors d'un atelier d'écriture, racontait comment, petit, il se sentait idiot à la bibliothèque avec sa carte à la main sans savoir quoi prendre. Un monde impénétrable et depuis il ne s'intéressait qu'au foot. Il avait conclu en disant: la culture ce n'est pas pour moi et j'avais tenté de lui expliquer que la culture n'est pas un but mais un moyen. Qu'il existait des auteurs 
amateurs de foot et que le sport était le thème de certains livres. Je n'ai pas su le convaincre.

Depuis que j'ai accepté d'écrire ce texte, je me sens comme lui. Un peu idiote avec ma commande à la main devant ce lieu que je ne parviens pas à pénétrer.

J'ai perdu mes moyens.

\section{La honte}

La honte. Il y a de la honte pour moi à questionner un tel lieu. Il y a de la honte pour moi à m'épancher sur mon empêchement. Je relis Annie Ernaux:

"J'ai mené une réflexion difficile, qui a duré six mois environ, sur ma situation de narratrice issue du monde populaire, et qui écrit, comme disait Genet, dans «la langue de l'ennemi», qui utilise le savoir-écrire volé aux dominants. ${ }^{1}$ »

Dans mes rencontres avec les lecteurs, parfois à la médiathèque, j'explique que je suis issue d'une famille sans intérêt pour la culture, où les livres servaient à dissimuler une porte condamnée (ce n'est pas une métaphore). Bibliothèque décorative.

Sur quelle frontière inconfortable, ai-je situé cette commande?

J'aurais dû choisir un endroit tout public et m'embarquer dans un joyeux descriptif. Cerner le lieu plutôt que m'enfermer dans la plainte. J'aurais dû contraindre Perec à quitter l'étagère et m'obliger à une belle liste avec des etc. et des et puis voilà.

Choisir l'épuisement du lieu.

J'ai voulu faire la maligne et me voilà avec un bel empêchement d'écrire. Pas de quoi être fière.

\section{Énumération}

En attendant que la date butoir me contraigne à l'écriture et il faudra bien que quelque chose s'écrive, j'ai 
listé sur mon carnet, tout ce qui me relie à une bibliothèque. L'école primaire protestante de mon enfance à Amnéville devenue la médiathèque Jean-Morette. La bibliothèque du Centre Georges-Pompidou où je traînais à dix-neuf ans parce qu'au chômage, sans le sou et que je ne connaissais personne à Paris. Bibliothèque municipale de la Part-Dieu où j'emmenais mes filles et leur lisais des histoires, souvent d'autres enfants se rapprochaient. J'y ai découvert mon goût pour la lecture à voix haute. Médiathèque du Bachut où je repartais le sac gavé de livres et de cédéroms. Oubliant vite ce que j'avais choisi et comme une surprise en rentrant. Médiathèque de Bédarieux où j'animais des ateliers d'écriture le dimanche, on me laissait la clé et le code pour désactiver l'alarme. La petite bibliothèque de la Duchère aujourd'hui disparue où je faisais écrire des enfants surexcités sur le thème du sport, moi qui n'y connais rien et l'un deux obtiendra un prix pour sa nouvelle. Mediathek de l'Institut français à Berlin pour lire les journaux dans la langue maternelle. Médiathèque Jean-Falala de Reims où bientôt je vais lire avec la cathédrale en arrière-plan.

Lieux connus.

Lieux communs et pourtant l'appréhension.

\section{Une étape}

J'écris une lettre à mon amie K. qui s'intéresse à ce travail où je dis entre autres:

"Ce matin, j'ai allumé l'ordinateur et j'ai ouvert le dossier "J'amasse», textes que je dois lire bientôt, mais que je trouve mous. Sans jus. À la ramasse. Alors j'ai fermé le dossier et j'ai ouvert celui d' "Annette» et j'ai passé une heure à corriger les fautes, à changer l'ordre des mots dans certaines phrases. Je n'ai pas ouvert le dossier "enssib», je ne sais toujours pas quoi écrire. J'ai commencé plusieurs textes et je ne sais plus ce qui m'est demandé. Je ne sais plus quoi dire. Je reste à la porte... un titre possible pour le texte?

J'aimerais sentir la nécessité m'imposer un rythme et prendre le dessus. Je veux éviter l'alignement de mots. La logorrhée. L'autosatisfaction. Il ne s'écrit rien. Je suis devenue bête.

Je quitte l'écran. 
Dehors, la neige s'accroche aux cimes pendant que l'herbe s'extrait de la terre. Des chats prennent le soleil ou chassent le mulot. J'aime les chats, ils n'aboient pas. »

Dans toutes les villes où je me rends, je visite le cimetière pas forcément la bibliothèque.

\section{Un questionnement}

Que s'agit-il d'écrire? Un éloge du lieu? Un commentaire du présent? Que vont écrire les autres? De quoi suis-je redevable et qui me paye exactement? Qu'est-ce qui est important dans une bibliothèque?

Rendre compte.

J'ai du yaourt dans la tête.

Je saute à la ligne.

\section{Une deuxième étape}

J'envoie un courriel à la directrice de la bibliothèque universitaire et à ses collègues. J'y annonce que je passerai à la bibliothèque les 23 et 24 avril; que je ne souhaite pas une visite particulière mais que je tiens à signaler ma présence. Je contrains l'agenda.

\section{Pas de porte}

Lendemain du premier tour des élections. Il fait froid et gris. J'ai oublié mon appareil photo à 150 kilomètres de là. Rues embouteillées, j'arrive avec une heure de retard sur l'horaire prévu, mais je suis la seule à le savoir. Je me gare rue Chevreul, quelques euros dans l'horodateur. Tension intérieure qui s'impose en migraine. C'est idiot de craindre ainsi un lieu public. Un espace public. Tout le monde peut entrer, pourquoi pas moi? Qui va me démasquer?

Je me laisse happer par le flot d'étudiants.

J'y suis.

Au rez-de-chaussée, dans la lumière nette et le vif des meubles colorés, je prends une inspiration forte. Peur que l'on me demande le pourquoi de ma présence alors je m'assois à une 
table. Je me mets à l'abri des regards et j'ouvre mon carnet. Je me donne une contenance. Venir aujourd'hui et demain. Quelques heures de présence. Immersion.

\section{Rez-de-chaussée - salle de presse}

Des ordinateurs ouverts sur les tables alignées face aux fenêtres, déballage de feuilles, doubles pages, carnets, cahiers, blocs-notes, fiches, photocopies et des surligneurs. J'en compterai jusqu'à quinze différents pour une jeune fille dont le fluo va recouvrir presque entièrement la page. Je doute de l'efficacité du système mais peut-être est-elle atteinte de synesthésie. Je découvre la quantité de nuances possibles dans la famille des surligneurs.

Je suis la seule à écrire sans avoir de livres ou documents ouverts devant moi. Je lève les yeux, j'observe, je note et je m'amuse à compter le nombre de filles et garçons présents.

Dans les présentoirs, à portée de main, de nombreux journaux: The Times, Süddeutsche Zeitung, Corriere della Sera commentent les élections de la veille, j'hésite à déplier l'un d'entre eux. Lire les commentaires des pays étrangers sur les élections et sortir enfin de l'étroit regard national, c'est bien tentant ce matin, mais je ne suis pas là pour bouquiner. Rester concentrée.

Ce sera pour un autre jour.

Quelque chose s'apprivoise puisque j'évoque une autre fois. Je quitte la salle de lecture, je change de niveau.

Escalier hélicoïdal qui invite à la photographie. L'appareil resté sur mon bureau dans son étui avec le chargeur de batterie à côté. Et puis zut.

\section{Premier étage - pôle droit}

Quarante-deux filles, onze garçons. Concentration palpable, une absence de bruit plutôt que du silence. Sur les tables, les trousses entrouvertes comme des bouches colorées. Un reste d'enfance. Pas un seul portable ne sonnera. Rien de perceptible quant à leurs questionnements intérieurs. 

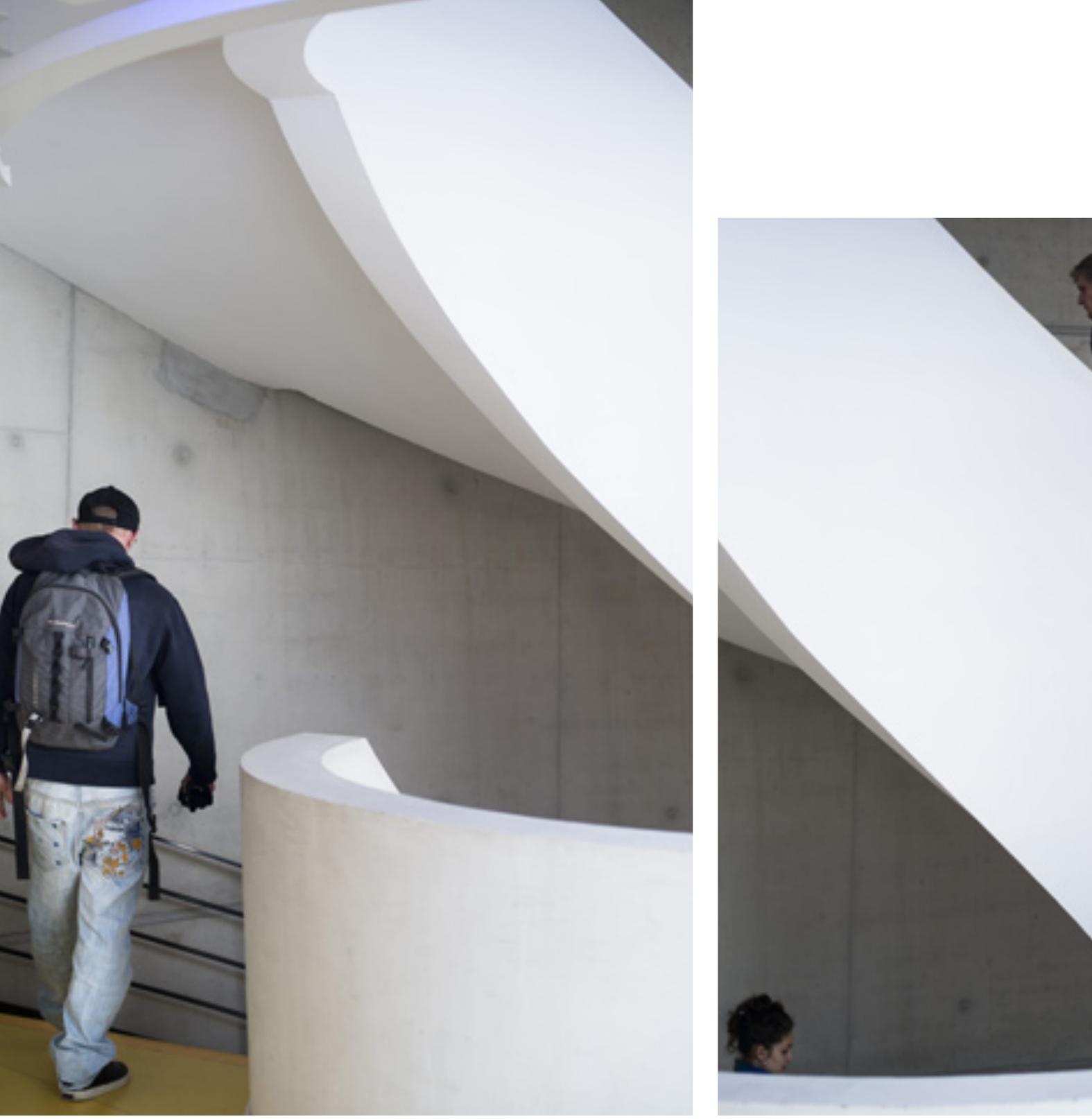

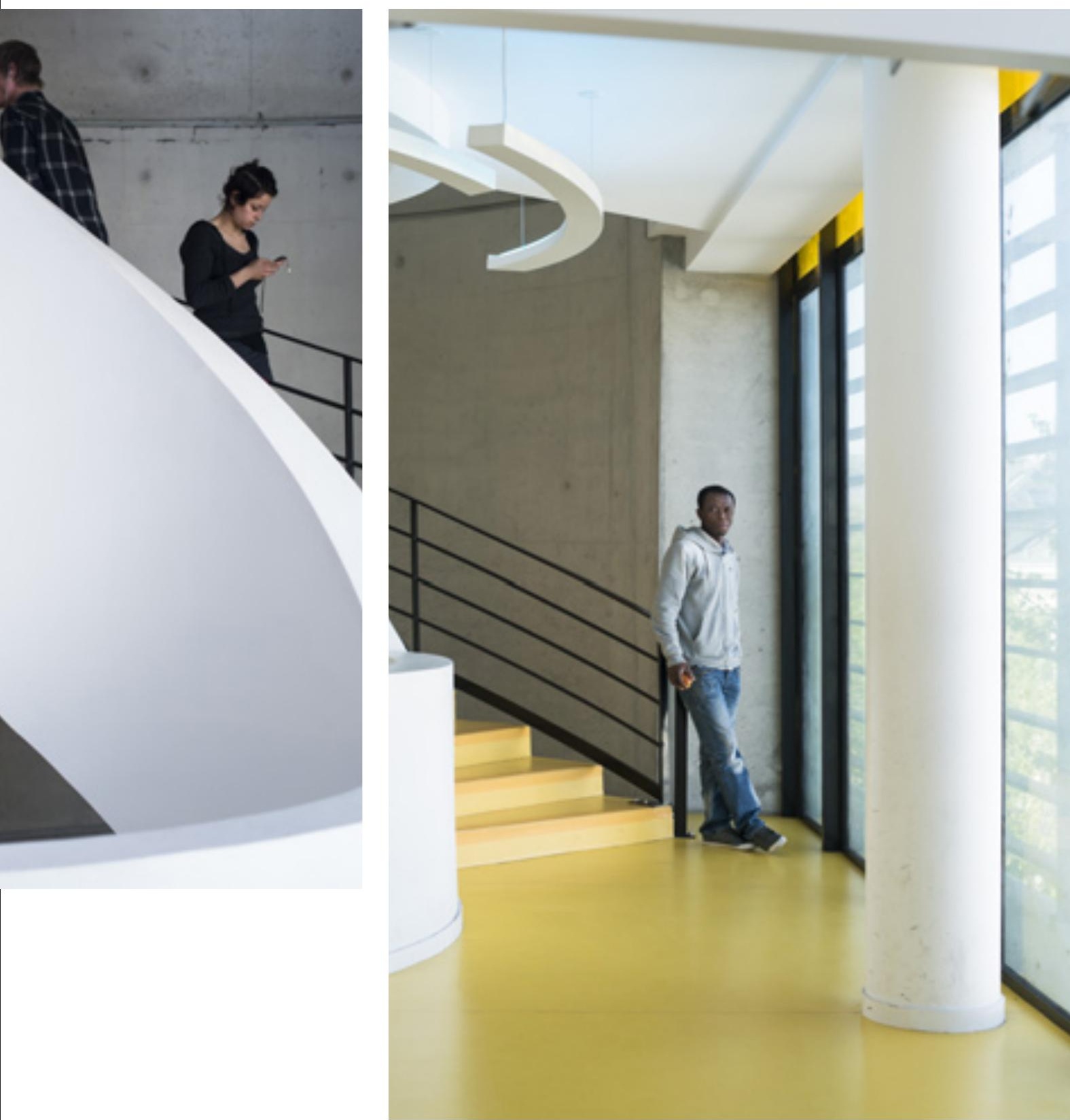
Des doutes, de l'ennui, des craintes, de l'excitation intellectuelle... que se passe-t-il pour eux en ce moment? Il serait intéressant d'en questionner quelques-uns au hasard. Pourquoi le droit? Comment imaginent-ils leur avenir? Aiment-ils apprendre où s'agit-il seulement de réussir des examens? De quelles volontés sommes-nous captifs?

À la fin du collège, j'ai voulu m'engager dans une voie littéraire. Il aurait fallu redoubler, mais les parents n'ont pas voulu puisque j'étais acceptée dans une section commerciale. Seraisje devenue professeure de français? Mes lecteurs me disent souvent qu'il valait mieux que je ne suive pas une voie littéraire. Et je ne sais pas comment interpréter cette réflexion. Quel lien y a-t-il entre des études littéraires et la littérature?

Le titre des livres proposés dans les rayons ne m'attire guère sauf l'alignement rouge des ouvrages Dalloz. Je passe mon doigt sur le dos, comme un signe amical: je suis passée par là.

\section{Deuxième étage - pôle économie-gestion}

Vingt et une filles et onze garçons. Moins d'ordinateurs ouverts qu'à l'étage précédent. Je n'en déduis rien, je constate. Une jeune fille bâille longuement au-dessus de son livre puis reprend soigneusement sa prise de notes, écriture régulière sans aucune rature.

Étage qui ressemble à celui du dessous. J'écris: économie nombril du monde.

Je regarde autour de moi, note peu. Pas envie de m'attarder. Trop de réel dans tous ces livres. Un a priori, mais l'époque nous sature les oreilles et la pensée avec l'économie. Je m’échappe déjà vers l'étage du dessus, envie de dépenser du rêve.

Me revient une lecture donnée à la Duchère, j'avais lu des extraits sur le désherbage, terme technique bien connu des bibliothécaires. Extraire des livres pour que respire la bibliothèque. Exercice de nettoyage très compliqué.

Préserver l'exception ou entretenir le tout-venant?

\section{Troisième étage - pôle sciences sociales}

À l'entrée, des nouveautés s'offrent sur le présentoir, j'entrouvre Heurs et malheurs scolaires en milieux populaires de Bernard Lahire. ${ }^{2}$ 
Je lis debout et m'interroge sur l'habitude prise de lire ou écrire assis. Pourtant le savoir devrait nous mettre sur pieds.

Je note quelques phrases du livre et retrouve, telle une compagne de voyage, des extraits du livre Les Armoires vides d'Annie Ernaux ${ }^{3}$.

Dans les différentes salles de l'étage, je compte vingt-trois filles, huit garçons. Les livres proposés ici m’intéressent déjà plus. Territoire du social.

En farfouillant, je trouverais certainement des réponses à mes questionnements quant à ma place dans le monde intellectuel. Mais il me faut être prudente, depuis deux ans j'ai développé une allergie au papier et mes doigts s'irritent vite au contact des documents imprimés surtout s'ils sont anciens. Un comble. Il m'arrive de saigner sur les pages.

J'envoie un texto à $\mathrm{K}$. pour lui dire combien les lieux sont agréables et que je me sens mieux. Je m'imagine volontiers venir y écrire. Elle me propose de m'accompagner pour la visite du lendemain. J'ai couvert de notes mon carnet et je suis traversée par une belle faim. Je redescends l'escalier avec énergie.

Je reviendrai donc demain.

$\mathrm{K}$. me rejoint à la bibliothèque. Je lui fais visiter, elle ne connaissait pas les lieux. Je l'emmène dans les étages comme si c'était chez moi. Puis je l'invite à nous séparer car je dois poursuivre ma visite. C'est un travail sérieux.

\section{Troisième étage - Pôle langues - LEA}

Trente-huit filles, seize garçons. Nombreuses fiches de couleur, classeurs et cahiers éparpillés sur la table. Univers papier, à quoi servent les ordinateurs?

Un jeune garçon tente de résister à la fatigue puis s'endort franchement sur son livre, sa joue gauche froisse

2. Bernard Lahire, Tableaux de famille: heurts et malheurs scolaires en milieux populaires, Points, 2012. 3. Annie Ernaux, Les Armoires vides, Gallimard, 1984. la page. Je m'installe face à la baie vitrée, toits gris qui s'ajoutent aux nombreuses nuances de gris du ciel. Il fait bon dedans.

Près de moi le rayon littérature arabe, calligraphies dorées des couvertures. Je me dis que je ne sais 
rien ou si peu sur la culture arabe. Un monde rétréci par le fait divers et la peur des autres. J'ouvre un livre pour élargir l'horizon. L'ignorance est une arme délicieuse pour les dominants.

Pour ceux qui ont appris

À lire dans les ténèbres,

Et qui les yeux fermés

N'ont pas cessé d'écrire

Mourir ainsi c'est viure.

\section{Kateb Yacine $e^{4}$}

Aujourd'hui j'ai amené une trousse avec des crayons de papier, un taille-crayon, une gomme et un surligneur jaune. Je n'ai pas amené comme beaucoup, la petite bouteille d'eau qui vient rafraîchir.

Je regarde. Je note.

L'avenir a un visage studieux en ce lieu. Apprendre est-ce savoir?

Je me remets en mouvement, il me reste un dernier étage à visiter.

\section{Quatrième étage - Pôle Arts}

Comme une récompense de gravir les quatre étages, territoire des arts où je me sens plus à l'aise. La ville s'agrandit derrière les fenêtres.

Je compte trente-huit filles, dix-huit garçons.

Je note sur mon carnet une pensée qui m'étonne: la bibliothèque comme la piscine est un lieu où le désir sexuel ne me traverse pas. Corps occupé?

Les jeunes qui étudient ici sont-ils les mêmes que je croise sur les quais près des péniches bars? Mouvement, ivresse et fous rires.

Ici le corps est presque immobile et ne révèle quasi rien des pensées intimes. Les postures souvent avachies au bout d'un moment ou si rigides que l'on imagine les tensions le soir dans la nuque ou le bas du dos.

J'ouvre de nombreux livres. Peintures, sculptures, 
biographies d'artistes, photos, architecture. J'envoie un texto à K. : décidément c'est trésor un tel lieu.

Je m'attarde sur un livre de Lucian Freud. Corps déformés, encombrés qui m'entraînent vers d'autres territoires de la création. Prendre en photo les corps apprenants, oui ce pourrait être un projet.

J'oublie les appréhensions du début. Je suis entrée dans la bibliothèque universitaire qui ne sera jamais une BU pour moi, mais peut-être un nouvel espace de travail.

Je referme le livre et me revient que la bibliothèque du Centre Pompidou m'a permis de voir ma première exposition d'art contemporain. Une rétrospective de Niki de Saint Phalle aménagée dans une salle attenante. Un cheminement à travers ses peurs (lorsqu'elle tirait avec un fusil sur ses œuvres) jusqu'à l'éblouissement de ses géantes rondes et colorées. J'avais acheté le livre de l'expo que je possède encore. Ce jourlà j'ai su que je ne deviendrais pas folle comme ma mère. Des mains invisibles mais décidées m'avaient dirigée jusqu'à là. La bibliothèque m'avait ouvert une sacrée porte.

J'y suis entrée. 
Lucien Suel

Médiathèque L'Albatros, Armentières

\section{Trois petits tours avec L'Albatros}


Les livres et les lieux où je peux en choisir sont à mes yeux, aussi nécessaires à la vie, que frites et bière, friteries et brasseries, air et eau, mer et ciel, jardin et maison, amour, chaleur, travail et connaissance. Une consommation sans modération. Albatros. Oiseau de la famille des diomédéidés. Il est, dans «Spleen et idéal 》, la triste métaphore du poète, au début du recueil Les fleurs du mal de Charles Baudelaire. L'Albatros est aussi le nom de la médiathèque d'Armentières. Est-ce à cause de la forme architecturale du bâtiment ou pour saluer le poème, le poète, la poésie que ce nom fut choisi ? J'étais venu ici, incognito, visite clandestine en 2008 pendant ma résidence d'auteur au G18, secteur de psychiatrie générale, à 1'EPSM Lille Métropole. Un personnage de mon roman en cours fréquentait la médiathèque d'Armentières. Repérages. Impressionné par volume des lieux et silence «cathédralesque 》 ambiant. La sortie du roman donna l'occasion d'une entente entre 1'hôpital, l'éditeur, le libraire et

\section{2}

la médiathèque. Guillaume Coustenoble, responsable du secteur adultes était venu m'interviewer. Vidéo diffusée à L'Albatros en septembre 2009. Guillaume et son adjointe Keara Berger, du rayon fiction, se joignirent à moi pour lire quelques extraits de La Patience de Mauricette lors de la fête organisée à l'hôpital pour la présentation du livre au public. Exactement deux ans après, me voici de retour pour un nouveau motif, travail sur la médiathèque même. lère visite à L'Albatros, 30/11/2011. Je rencontre sur rendez-vous, Sandrine Vansteelant, directrice, Tatiana Dumont, coordinatrice des actions Culture. Devant un café, je leur parle du projet «Tours et et détours en bibliothèque ». Je viendrai observer le lieu, voir ce qui s'y vit, ce qui s'y passe, en 
février. Et je propose aussi de m'intégrer à titre gracieux dans la programmation des rencontres avec les auteurs à 1 'occasion de la sortie de mon roman Blanche étincelle. Nous fixons la date du 7 avril. L'Albatros et sa couverture d'inox comme un papier

3

précieux. Je la regarde, saveur chocolatée dans la bouche. Livres protégés par une pellicule argentée comme ce Dali édité par Draeger au Soleil Noir qui ressemble à une bô̂te de chocolats fins. Ici, près de la Belgique, vue de 1 'extérieur, la médiathèque pourrait m'évoquer une bô̂te de Léonidas, mais les parois en verre transparent me rappellent au réel. Loin de ressembler à 1'oiseau entier, cet albatros se résume à une vaste aile protectrice étendue audessus des richesses de la médiathèque et des gens qui s'y rassemblent, abonnés, employés et invités. Le bord de 1'aile, surplombant 1'entrée, abrite de la pluie les usagers qui attendent 1 'ouverture des portes coulissantes. Médiathèque = Service public. La file d'attente se mire dans les parois. Reflets de reflets. Images de 1 'extérieur en surimposition parmi les rayons de livres, caressant les dos, les tranches. Ce n'est pas un film protecteur virtuel. On a réellement l'impression que la cité se trouve à 1 'intérieur de la bibliothèque. Du côté opposé à

4

1'agora, sur le trottoir en face, les silhouettes, ombres issues de la caverne, se réfléchissent dans la façade (mélange d'eau et de sable) : Cinéma REX (latin retrouvé) désaffecté-abandonné-tagué. Grand espace vacant. Une camionnette Emmaüs garée devant 1'auto-école. Tabac À la Civette. Banque Crédit du Nord. Boulangerie fermée. Agence immobilière vide. Un quartier en rénovation, des friches artisanales et industrielles, des terrains vagues, témoignages 
du passé. Espace dégagé devant le bâtiment. Ici ou là, des bancs fixés au sol. Chat perché sur un des blocs de pierre qui barre l'accès aux voitures. Le regard plonge à l'intérieur de la médiathèque sans entrave, à livre ouvert. Chassé-croisé de lumière. La façade-image de la médiathèque montre à la fois stabilité (clôtures, maisons, magasins, trottoirs) et mouvement (autos, piétons, cyclistes, oiseaux), comme si un film (décors et actions) était projeté sur le bâtiment. La poétique du monde traverse les parois. Les lecteurs-habitants franchiront bientôt

5

le passage, arpenteront un monde de papier, vivant de chaque côté des allées de livres, entassés dans des immeubles d'étagères, des casiers studios, des bacs et des rayons peuplés d'ouvrages, des rangées et des piles. Savoirs, rêves et délices accumulés. NB. Écrivant lecteur, je pense lectrice. Elles ont le nombre pour elles à défaut du genre grammatical qui impose toujours ses règles chauvinistes. Sic ! Le contraste est manifeste entre l'architecture de la médiathèque et celle des anciennes bâtisses qui 1 'entourent (briques, ardoises, fenêtres étroites, grilles). Jeune homme accroupi près des palissades du chantier voisin. Panneau du lotissement à venir 《 25 maisons 》. Arbres dénudés. Livraison d'arbres de Noël par la municipalité. Bacs à fleurs en bois colorés de blanc, terre de Sienne, vert printemps, bleu clair. Terre vierge, prête à accueillir semis ou plantations. Ouverture de la médiathèque par le jeune bibliothécaire. Il tient le battant de porte pour la dame à la poussette. Service qui commence.

6

$2^{e}$ visite le 18/02/2012. 11 heures, j'arrive. Suis accueilli au comptoir de 1 'entrée par Keara qui me guide à travers la médiathèque, du rayon adulte au 
rayon jeunesse, des BD aux CD et autres DVD, de la salle de presse à celle d'Internet, de la salle du conte à 1 'auditorium... Je m'assieds sur un canapé dans un endroit stratégique au rez-de-chaussée, au pied d'une paroi avec vue sur l'entrée, le secteur enfants, les rayons de BD, 1 'accès à 1 'étage. Muni d'un bloc-note, j'utilise la contrainte oulipienne de l'inventaire-description-épuisement de ce lieu. Affiche Éloge de nos terres. Actualités. Panneaux. Exposition de planches originales. Les auteurs des BD seront reçus ici dans 1 'après-midi. Trois dames assises lisant. J'apprends qu'il y a deux nouveaux genres littéraires dans la bande dessinée : mangas et romans graphiques. On cherche dans les étagères en se penchant, en s'accroupissant ou à 1 'inverse, en se hissant sur la pointe des pieds. Certains se laissent choir, s'assoient sur la moquette, jambes

7

croisées. D'autres, plus jeunes, se glissent entre les poussettes à quatre pattes. Homme courant pour récupérer un petit qui tente d'escalader un casier à livres. Une mère et sa petite fille, «Maman, tu vas acheter des livres ? 》 Père voiturant un jeune handicapé (dans cette médiathèque, forte attention portée au handicap, dans la tradition de la ville, sans doute [Maison des Bons Fieux créée en 1615]). Homme qui marche en lisant quatrième de couverture comme s'il épluchait une liste d'ingrédients, à la recherche d'OGM ou d'aspartame. Enfant qui pleure. À chaque question, sa réponse : la jeune fille qui faisait de la gymnastique dans le rayon mangas est allée chercher une bibliothécaire qui lui sort Les Voyages de Shira (?). BD rangées par titre d'après le nom du héros, détail à savoir. À l'entrée, à ma gauche, de nouveaux arrivants posent des questions sur le règlement. Homme avec Boule et Bill. Quatre enfants explorent un bac à livres (bac à sable ?). Monsieur en bluejeans, la soixantaine, casquette à 
8

la main (s'est-il décoiffé par politesse, comme en entrant dans une église ?), gabardine sur le bras, sachet plastique tenu du bout des doigts. La porte automatique grince (importance de ce bruit ?). Pas de sonnerie comme dans les magasins, mais quelques ressemblances avec le supermarché. Des «clients 》 de tous âges et de toutes conditions, circulant de secteur en secteur, sac à la main. La promotion en tête de gondole des nouvelles acquisitions. Codesbarres. Portiques de détection. Mais la différence qui saute aux oreilles, c'est le silence, le calme des lectrices et des lecteurs, des familles. Nulle musique d'ameublement, nulle annonce doucereuse ou agressive. Respect du silence intérieur nécessaire à la lecture ou au simple choix dans les ouvrages. Jeune en jeans qui dit : "Tchoupi, c'est pour les tout petits. 》Couple papotant à voix basse debout près de 1'entrée. Bips d'enregistrement des codes. «Maman t'es où ? - Ch'suis 1à. 》Petite cherchant sa mère occupée à choisir un roman graphique. Dame

9

tirant un sac à roulettes, CD et DVD à la main. I1 est 11 h 50 ; annonce par haut-parleur : Mesdames, messieurs... Les enfants sont à 1 'aise, mais leurs parents (surtout les mamans) ont les bras couverts de vêtements. Voici encore des jeunes qui entrent, pressant le pas. Bruit des livres sur le comptoir. Les portails de sécurité sonnent quelquefois, mais on sait pourquoi. C'est une erreur, jamais un vol. 11 h 51. La queue se forme. Mère avec deux petits, homme seul, père avec un enfant qui a oublié on ne sait quoi (tant pis), gens de tous âges, vêtements de toutes sortes, du blouson nylon à la parka, des foulards aux casquettes. Enfant qui se déplace, la pile de livres sur la tête. "Ce livre-là, je sais qu'on 1'a déjà pris. Il y a beaucoup à lire ! (pas grave) 》 On remet les cache-nez. «Les deux cartes 
sont arrivées à échéance. Il faudra les renouveler la prochaine fois. Venez avec une facture récente, une carte d'identité et le livret de famille. 》Il est 11 h 56. Des jeunes filles ensemble. « Oh ! Il

10

en manque un. On peut vous le prolonger. 》L'heure de la fermeture, les lumières se coupent une à une (ne m’étais pas aperçu qu'elles étaient allumées). D'ici ou de là-bas, à tout moment, on peut visiter virtuellement le lieu : armentieres.fr/mediatheque Vu de 1 'extérieur : Trois personnages qui sortent, blousons marron et orange, grands sacs plastique à la main (dedans, des livres, peut-être des CD, des DVD) suivis par une adolescente en jeans et boots, trois-quarts à capuche, qui examine son téléphone. Ensuite un jeune garçon ébouriffé, cheveux sombres et lunettes à monture rouge, entre, suivi par deux 1ycéens munis de sacs en bandoulière. À travers le vitrage, des reflets cubistes à la Georges Braque. 1726 AV 59, une 4CV Renault devenue pièce de musée est installée dans un reposoir de verre au sein de la médiathèque. Une œuvre d'art ? Ready-made placé sur un caillebotis entouré de galets au milieu des livres ? Sont-ce des élèves du lycée professionnel d'Armentières qui ont rénové la machine ? Pourquoi

11

pas ? Fête des Nieulles, jour de 1'inauguration de L'Albatros, les Armentiérois défilent à travers la ville derrière le véhicule de collection. À la fin du parcours, la voiture soulevée par une grue, est installée au centre de la médiathèque ( 1 \% pour la culture) sur une idée du plasticien Samuel Beckman qui voyait 1 'auto bleue comme 1'hérö̈ne d'une BD ! Derrière les parois vitrées, la 4CV témoignera des jours anciens, fossile industriel de la période de l'énergie fossile. Tout autour d'elle, des livres. 
Placé en hauteur dans le prolongement du comptoir, un crocodile bleu en papier mâché ouvre sa gueule. L'animal a été façonné par la classe de CM2 de Mme Deprey, école Anatole-France, année 2010-2011. Son corps est marqueté de pustules colorées. Rubéole? Près du crocodile, les affichettes de concerts, la tarification et le règlement de la médiathèque, la pile de flyers. Tout noter voir entendre recevoir. À 1 'entrée du rayon enfants : affiche La Marque du Chat pastichant La Marque Jaune. Au sol, casier de

12

livres, chaise orange. Une maman porte sur le bras droit un enfant endormi encapuchonné. Devant elle, la poussette vide. Albums présentés de biais et de face dans une étagère métallique sur 2 niveaux. Le mobilier est adapté comme à l'école maternelle. Un petit devant le mur composé d'une dizaine de baies vitrées rectangulaires. Livres posés dans des bacs carrés divisés en quatre compartiments. Au centre, les plus bas pour les tout-petits avec des albums. Une table blanche, des chaises en plastique blanc, orange ou vert. Le sol est moquetté. D'autres bacs plus élevés. Recherche du confort. Albums d'éveil. Au milieu des casiers verts, jaunes, orange, jeune femme à grosses lunettes, debout, qui téléphone en souriant, la main gauche sur le guide d'une grande poussette monospace télescopique en aluminium avec un capuchon toilé, marque Bébé-Confort. On voit le peton du petit passager, la jambe de pantalon vert pomme. Un sac en vannerie est suspendu au bras qui retient la poussette. Autre sac à 1'épaule du bras

13

qui porte le téléphone. On voit la pelouse, un pan de mur, le début d'une inscription N'ATTENDS RIEN.

Comme auteur, n'ai pas pu résister, suis allé voir lettre $\mathrm{S}$ dans les rayons, trouvé mon best-seller: 
Mort d'un jardinier serré par un clip de métal, vu les noms de mes voisins, Eugène Sue (Le Commandeur de Malte), Michel Subiela (Les jardins de Palerme, Le Royaume sur la mer et Les Chevaliers de proie). Une dame en manteau, sac à main aux pieds, assise, genoux joints, sur un canapé design, arrondi, vert et blanc (charte de couleurs), lisant un magazine, ou plutôt une BD, empruntée au rayonnage derrière. Amours fragiles/Blondes/Bob et Bobettel rangés par ordre alphabétique (Dewey). Absorbée par le livre. Soigner mon enfant/Bien se moucherl une série pour la vie quotidienne. Des livres entrouverts, debout sur la planche supérieure des rayonnages. Une dame en blouson de lainage bleu, sac plastique plein de livres pendant à la main gauche, s'est penchée sur le côté, observant le bas d'un poster style Bogart

14

Baca11, Construction d'un mythe, le rêve américain en 6 tomes. Mémoires de cendres. Au mur, à gauche, extincteur rouge évoquant 1 'incendie d'Alexandrie. Devant les rayons, un jeune couple debout bavarde. Elle, jeans, manteau, sac à dos, cheveux longs, et lui, jeans, blouson noir, cheveux courts, radieux. Escalier blanc, rampe transparente. Une salle avec des sièges orange devant des écrans d'ordinateurs. Lecteur à lunettes, au fond d'un fauteuil, absorbé par son livre autant que par son siège. Plus loin, un écran allumé, comme une lampe d'ambiance. Néons aussi comme des lignes de tirets au plafond. Rails de soutènements. Vue sur 1'extérieur : poutrelles, trottoirs en planches de bois exotique brut, herbe rase, immeuble d'appartements en voie de finition. À 1'intérieur, un siège en plastique jaune près de 1 'exposition de livres jeunesse. Hauts panneaux de bois debout par paire avec affiches BD sous verre. Un chevalet de peintre présente une autre affiche. D'autres sur le sol, appuyées au dos des étagères. 
15

Sous 1'escalier partant de 1'entrée, un alignement décroissant de fenêtres étroites devant la pelouse tondue. Affiche jaune, bleue, orange : un clown au visage troué. Des enfants y passent la tête. Rires étouffés. Inscription en haut «L'ALBATROS CIRCUS». À gauche, une sorcière géante avec son balai et un chapeau pointu noir, une espèce de poussin dans un petit sac sur son ventre. Près d'elle, un chaudron noir dans lequel mijotent des livres. Une soupe de lettres ? Un bouillon de culture ? Balai et brouet d'albatros. Sur une cloison de l'espace petits, un ensemble de planches, la suite de l'expo BD, qu'un homme parcourt en canadienne marron et béret vissé sur le crâne, s'arrêtant devant chaque affiche, en méditation, tête levée, mains jointes dans le dos. Pièce du conte. Guéridon polyester blanc, coussins circulaires bleus, jaunes, rouges, sur les gradins comme des smarties géants. Le fauteuil prestigieux de la conteuse, très confortable, formes arrondies asymétriques, un patchwork jaune-bleu-rouge-orange

16

majestueux. Le trône de la reine face aux smarties de son peuple d'enfants. La chambre du conte offre une vue sur l'extérieur, dallage, marches de bois, plantations dans la cour intérieure du «palais», gradins de béton laissant supposer une utilisation par beau temps. La statue d'un personnage de conte de fées avec une couronne, perchée au sommet de la baie dans 1 'encoignure. Frise ornementale au fâte de 1 'encadrement, toute une rangée de bébés assis, album ouvert entre les mains, sous cette formule : «Moi ce que j'aime le plus, c'est quand on se met tous ensemble pour lire des contes dans les livres de la bibliothèque. 》La lecture n'est plus intime mais devient une affaire collective. Est-ce bien ? Les livres en braille, présentation sobre, reliure 
uniformément blanche (comme les cannes d'aveugle). Ce sont des dossiers reliés, perforés, plastifiés, avec une étiquette au dos (pour le personnel, pour le stockage). Quelques titres : Les vilains petits canards, Il n'y a que braille qui m'aille, Comment

17

voient les aveugles, Cuisinez entre copains, Guide des aides pour malvoyants et aveugles, ler volume, transcription intégrale de 1 'édition originale par le Centre de Transcription et d’Édition en Braille 3bis rue du général Hoche, 31200 Toulouse. Le CTEB remercie cet éditeur. Lire sur le bout des doigts. Je pose la question du livre numérique. On y pense mais pour l'instant, il n'existe pas de demande du public. Mais je sais que L'Albatros est très actif sur le web, qu'il existe en lien avec le site, des blogs en partie animés par des abonnés. ZigZag, le blog ado et Armentières en bulles, le blog BD. Yo. 3 ème visite le 7/04/2012. Invitation à L'Albatros, samedi, veille de Pâques. Comme d'habitude, laissé ma voiture sur le parking de la gare à deux pas de la médiathèque. La rencontre est prévue à $14 \mathrm{~h} 30$. Frédéric Cretel et Simon Kerfyser enregistrent les retours. Keara occupée ailleurs, Frédéric m’emmène à 1 'auditorium où aura lieu la rencontre. Salle de spectacle, rangs de fauteuils disposés en gradins.

18

C'est ici qu'ont lieu représentations et concerts, organisés par la médiathèque. Arrivée de Keara qui m'annonce 1'absence de Guillaume parti en tournage sur une rencontre sportive adaptée au handicap, un des axes forts du projet de L'Albatros : important travail pour les malvoyants, embauche de personnes handicapées travaillant au contact du public... Je suis Keara à 1'étage de 1'administration, la salle de détente du personnel, accepte un café, l'écoute 
parler de Blanche étincelle, du comité de lecture, du vote « coup de cœur 》attribué à La Patience de Mauricette. $14 \mathrm{~h} 20$, on se déplace vers le secteur adultes. Je prends la pose devant les étagères, le linéaire de romans, en face du mur des «people», les auteurs invités par la médiathèque. Keara fait deux photos de moi. On rejoint 1 'auditorium. Petit nombre de personnes dispersées sur les gradins. La porte est laissée ouverte. Quelques lectrices nous rejoignent, puis un lecteur. Je reconnais une dame rencontrée au salon du livre de Bondues la semaine

19

dernière. Tatiana Dumont est présente ainsi que la libraire de Majuscule où en février, j'ai signé le roman. Keara et moi, sommes assis en bas dans deux fauteuils, une petite table entre nous. J'ai amené ma poésie, mais on va parler des deux romans ayant un rapport avec Armentières (une rime avec «Éloge de nos terres 》du 3 au 22 avril à L'Albatros). Je me présente et d'emblée, suis amené à expliquer la création du personnage, Mauricette Beaussart, dans le cadre de ma résidence d'auteur de 1'année 2009 , à 1 'EPSM. Réel intérêt de la part des spectateurs, de 1 'animatrice. Plusieurs ont 1u, au moins un des romans, certain(e)s les deux. Assez naturellement, la rencontre devient conversation commune à propos de 1 'écriture, du bonheur, de 1 'effet de réel dans la fiction, du régionalisme (je ne suis pas auteur régionaliste). Ambiance agréable, chaleur humaine, humour et spontanéité. Je finis en lisant le début de Blanche étincelle. Une table est installée dans le hall d'entrée pour les dédicaces. La libraire a

20

annoncé la rencontre toute la semaine en proposant mes livres dans son magasin. Prolongations tout en dédicaçant des exemplaires. La discussion continue 
devant les livres. Style, démarche, lecture à voix haute... surtout avec celles et ceux qui n'avaient jamais approché mon écriture. Tout ceci au cœur de 1 'activité persistante de la médiathèque : enfants fouillant dans les caisses, personnes allant faire enregistrer leurs livres, d'autres lisant... Petit à petit, les participants à la rencontre s'en vont et je continue à bavarder avec Keara. Je lui signe son exemplaire, ainsi que celui de la médiathèque. J'écris une phrase sur 1 'affiche où sera collée ma photo avant de trouver place dans le Hall of Fame. Il faudra donner mes amitiés à Grégoire Delacourt, mon successeur samedi prochain, et à Guillaume que je regrette de ne pas avoir vu. Je fais mes adieux à Keara, qui manifeste encore sa joie d'exercer ce métier, le bonheur de faire ce qui lui plâ̂t. Elle dit : «J'aime les livres. 》Je quitte L'Albatros.

Ce texte est écrit en suivant une contrainte d'ordre numérique. Chaque ligne comprend le même nombre de signes typographiques. Le texte est constitué de 20 blocs contenant chacun 1000 signes. 


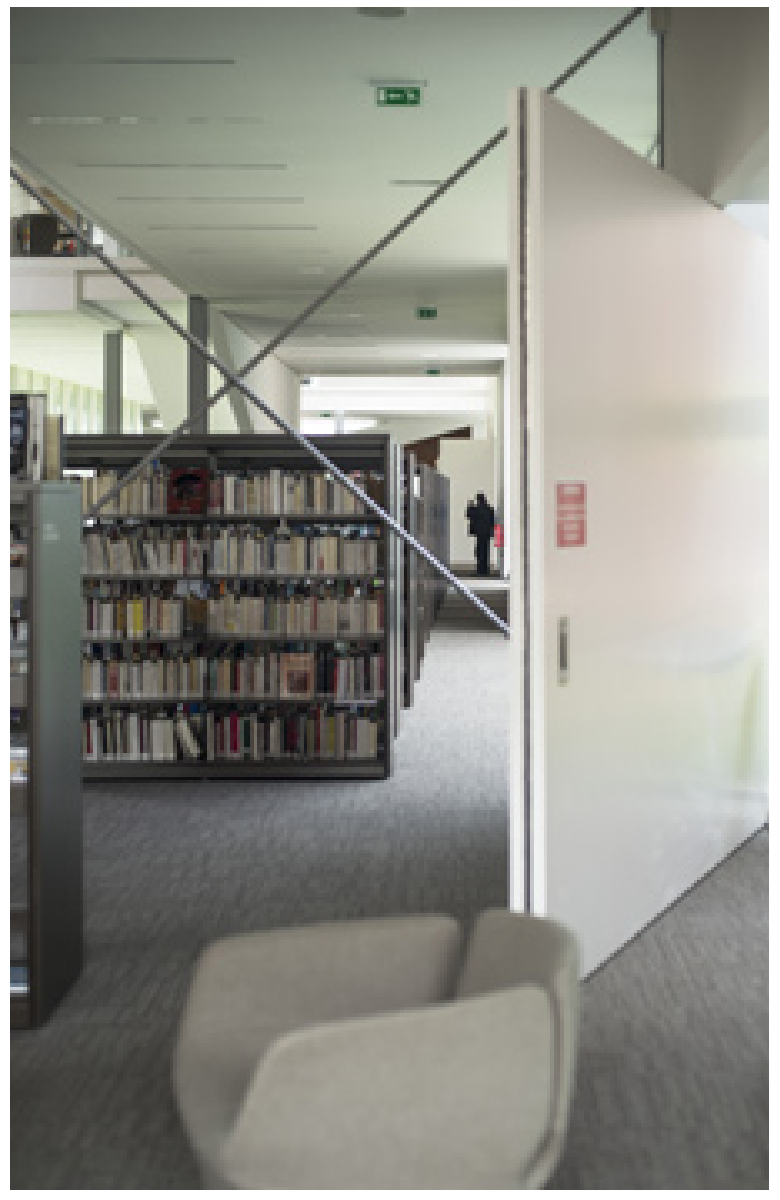




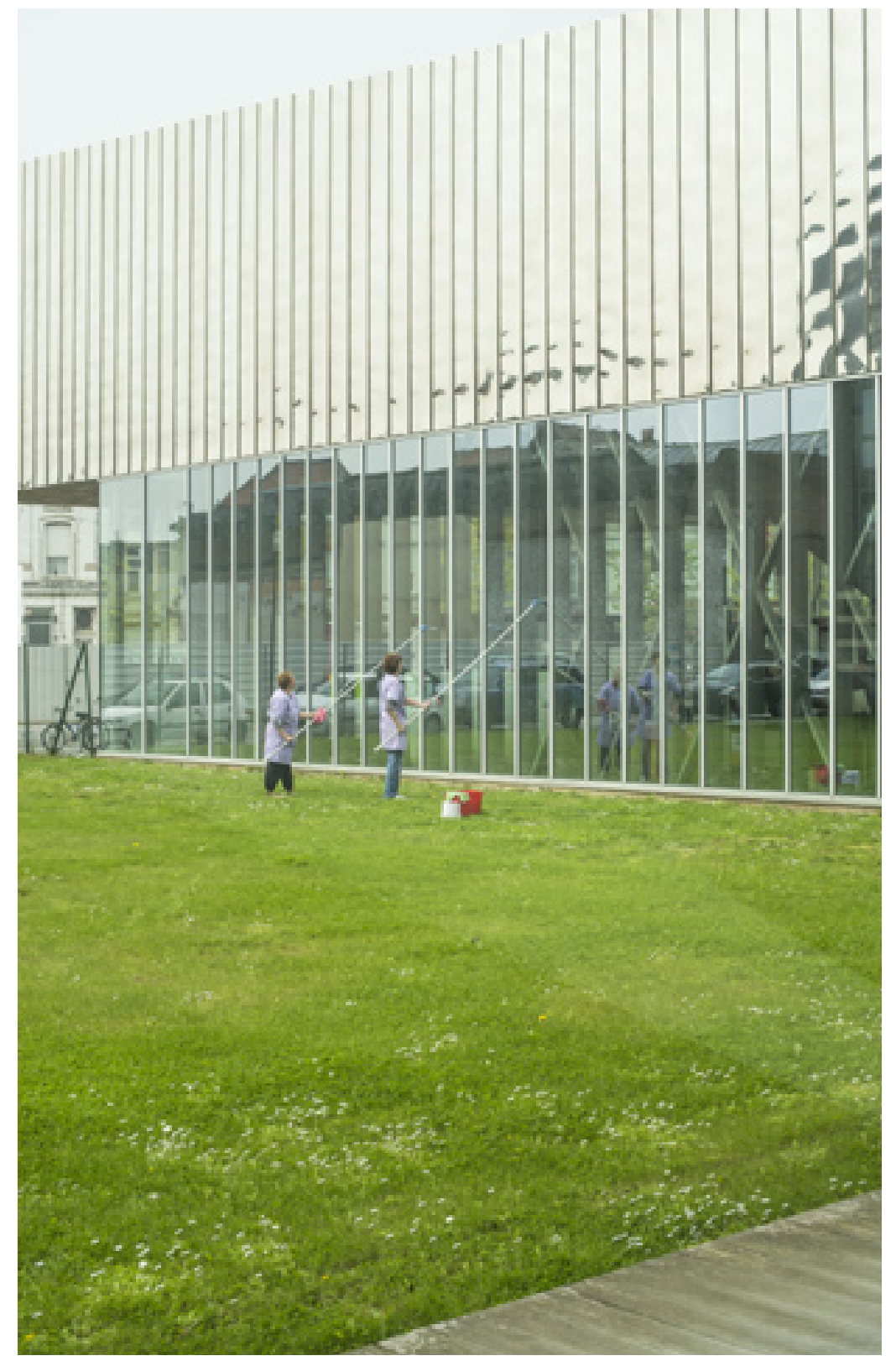




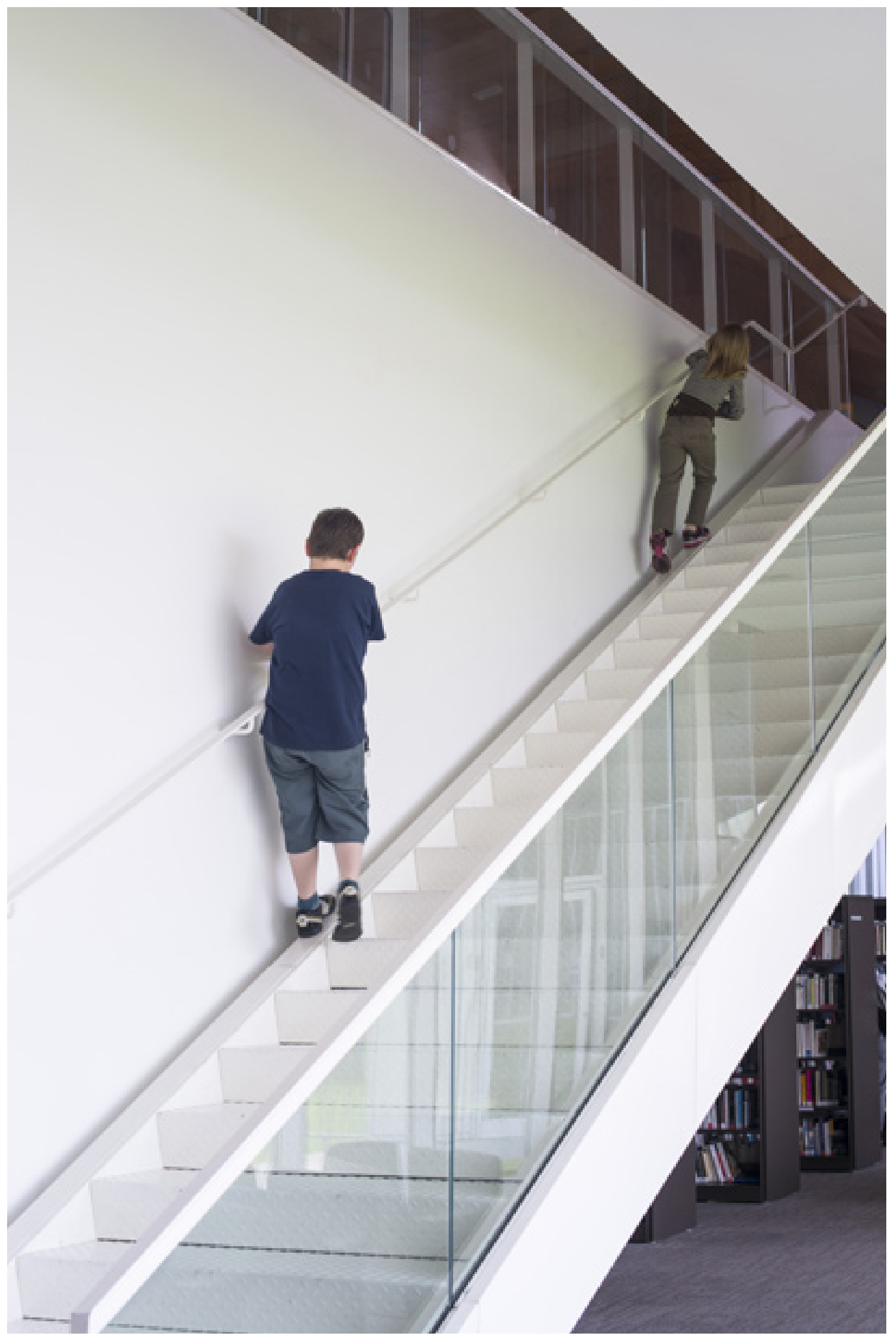



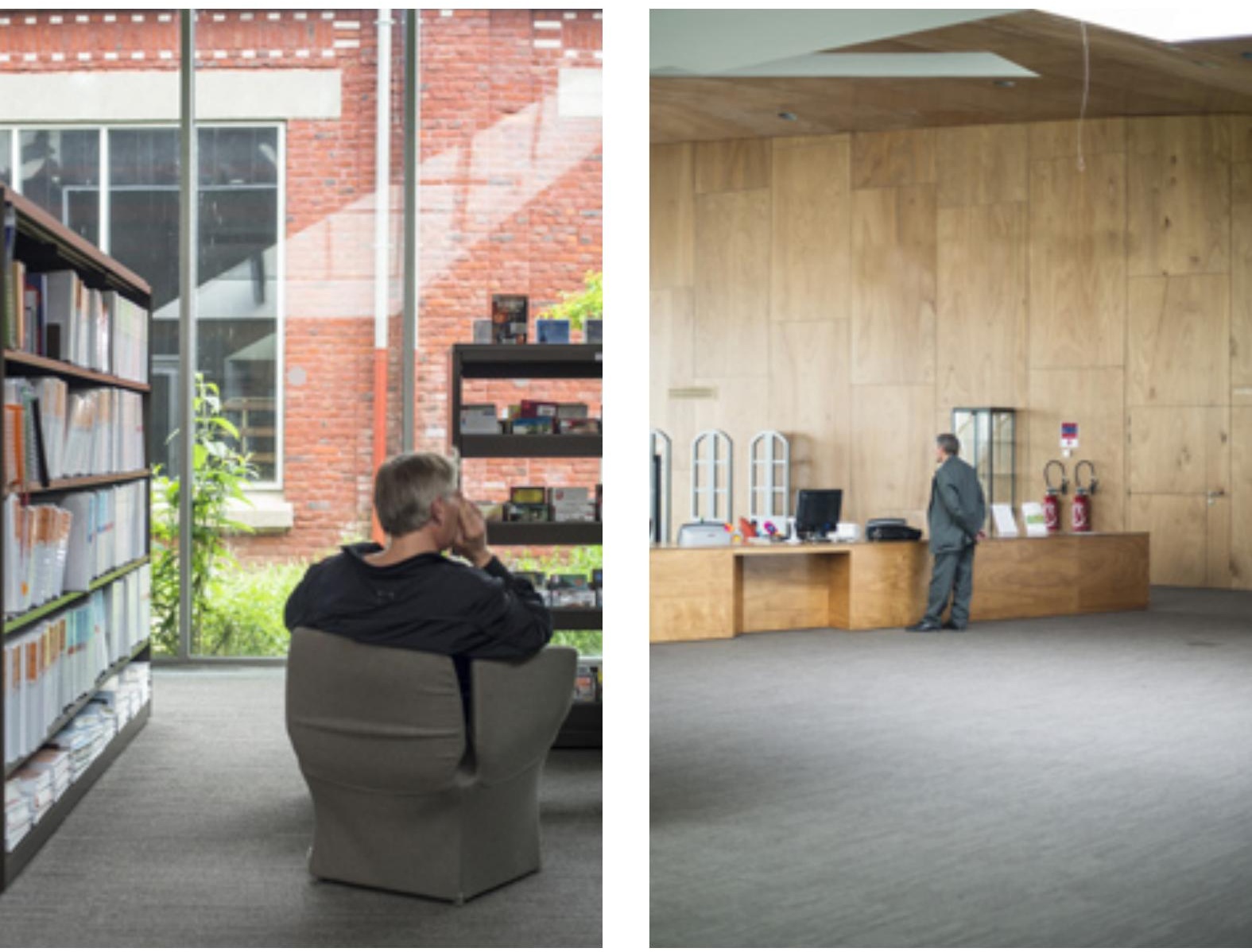


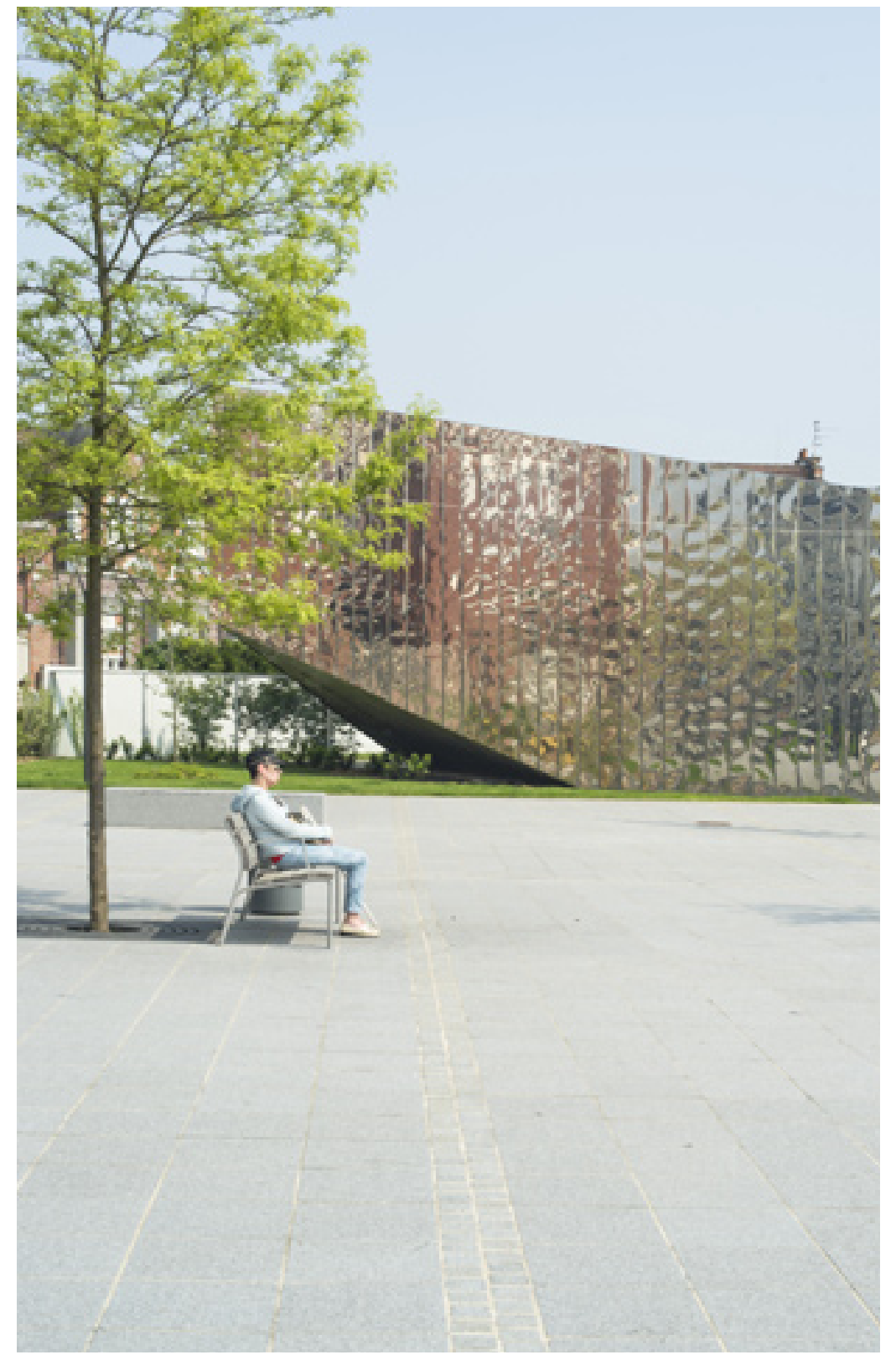




\section{De fil en aiguille}


Dans la liste des bibliothèques à choisir, des noms de villes, empilés les uns sous les autres, dans les cases grisâtres du tableau. Dans cette liste, la bibliothèque de Valenciennes, entre celle de Tulle et celle de Vénissieux. Vénissieux, à 20 kilomètres de chez moi, ça aurait été pratique. Le choix ne manquait pas : également celle de Lyon, Villeurbanne, Caluire et Cuire, Grenoble... De quoi occuper un après-midi, une heure entre le retour du travail et la sortie d'école, une balade entre la montagne et le musée. Non, j'ai pris Valenciennes, à trois heures de TGV, à 695 kilomètres de chez moi.

Il faudrait vérifier, planter des aiguilles, entre cet endroit où j'habite, cette table, cet ordinateur et chacune de ces villes, tirer des fils, ça ferait un magnifique soleil, comme ces trucs qu'on faisait autrefois, dégradés de jaune, de rouge et d'orange, et les fils aux murs s'empoussiéraient et perdaient leurs couleurs. De toutes celles qui étaient proposées, c'est je pense la bibliothèque la plus éloignée de mon domicile. Suivre le rayon le plus long de ce soleil de fils, et tout ça pour se retrouver dans le Nord, c'était bien la peine, ah ah, la bonne blague, c'est facile. Et en même temps, il faut bien reconnaître que ce n'est pas faux. Du Nord, qu'ai-je retenu, si ce n'est des cieux gris très gris, ou alors étaient-ce mon enfance et mon adolescence qui étaient ainsi grises, lourdes et pesantes? Car du Nord, enkystés dans ma mémoire, les soirs de dimanche pluvieux, les briques sombres, la terre poisseuse des champs de betteraves collant aux roues de vélo, les pages et les pages de journal intime, inquiètes et tourmentées. À se demander, si, comme la misère, l'adolescence est moins terrible au soleil... Ce fil tendu entre Valenciennes et moi, c'est aussi la pelote que je dévide, pour ne pas perdre mon chemin dans mes labyrinthes, et revenir, une fois par an, voir la famille, à Noël. Puisque c'est comme ça, une pierre deux coups, le sapin, les cadeaux, et la bibliothèque en prime, joindre l'utile à l'agréable, c'est joli les villes du Nord à Noël, plein de lumières et de décorations, même dans les jardins, des kilomètres de guirlandes électriques, des pères Noël clignotants sur leur traîneau, avec des rennes grandeur nature. Ces mêmes jardins où dans mon enfance, les voitures sur des parpaings, parce que l'assurance est trop chère, quand se sont fermées les usines, abattus les chevalets, arrêtés 
les métiers à dentelle. Et puis, y emmener la fillette, un peu de culture dans la semaine de la consommation effrénée, ça ne fera pas de mal, et la socialisation à la lecture, ça passe par là aussi, une visite à la bibliothèque pour Noël, déjà que je ne lui lis jamais d'histoires le soir, oui, c'est pour le travail de Maman, oui, promis, après, on achète une gaufre au Nutella.

Sous le porche, d'emblée, le sentiment que là, ça y est, je ne peux plus reculer. J'ai bien essayé, pourtant, comme d'habitude, de multiplier les actes manqués, de repousser, procrastiner, on ira demain, il est trop tard, le temps d'y arriver, il faudra repartir, il fait trop froid pour sortir, il fait trop bon, autant aller courir, puisque demain, la météo prévoit de la pluie. J'ai rêvé de pneu crevé, d'accident, pas trop grave quand même, ça serait dommage de gâcher le réveillon, surtout avant d'avoir reçu les cadeaux, j'ai espéré une gastro subite de la fillette sur le trottoir, tu es sûre que tu n'as pas mal au ventre? Par peur de n'avoir rien à dire, rien à écrire, de ne pas savoir par quel fil attraper ce texte, tissu aux mailles béantes, troué de souvenirs. Les bibliothèques, ça fait bien longtemps que je ne les aime plus, depuis la bibliothèque du village, on y descendait après le cours de danse, c'était pratique, dans le même bâtiment. En briques rouges, évidemment. Mais depuis, les bibliothèques, ce sont les endroits où mes talons claquent trop fort sur le plancher, faisant lever toutes les têtes, où je me perds dans les cotes comme des hiéroglyphes, ou prestement, je rends les livres avec trop, toujours trop de retard, interdite de prêt, comme les mauvais élèves, comme les enfants au piquet. Valenciennes, pour moi, ça n'a jamais été la ville d'une bibliothèque. Non. C'était la ville où, dans la classe, la fille du médecin allait faire du shopping. C'était la ville où l'on allait en bus, avec les copines et le prétexte d'acheter un cadeau pour la fête des mères. C'était la ville à quelques kilomètres de notre village, et c'était si loin, et c'était l'aventure, et c'était la vie.

Devant la façade, je ne peux plus reculer, ça ne sert à rien, les enseignes des magasins de toutes façons ont changé, jamais je n'aurais cette paire de chaussures à la mode l'année de la troisième, et je ne sais pas du tout où ces bottes ont mené Karine, la fille du médecin. Moi, ce ne sont pas les bottes, même faites pour marcher comme celles du chat Botté ou de Nancy Sinatra qui m'ont emmenée loin d'ici, mais les livres justement, et les études, encore, encore et toujours. 

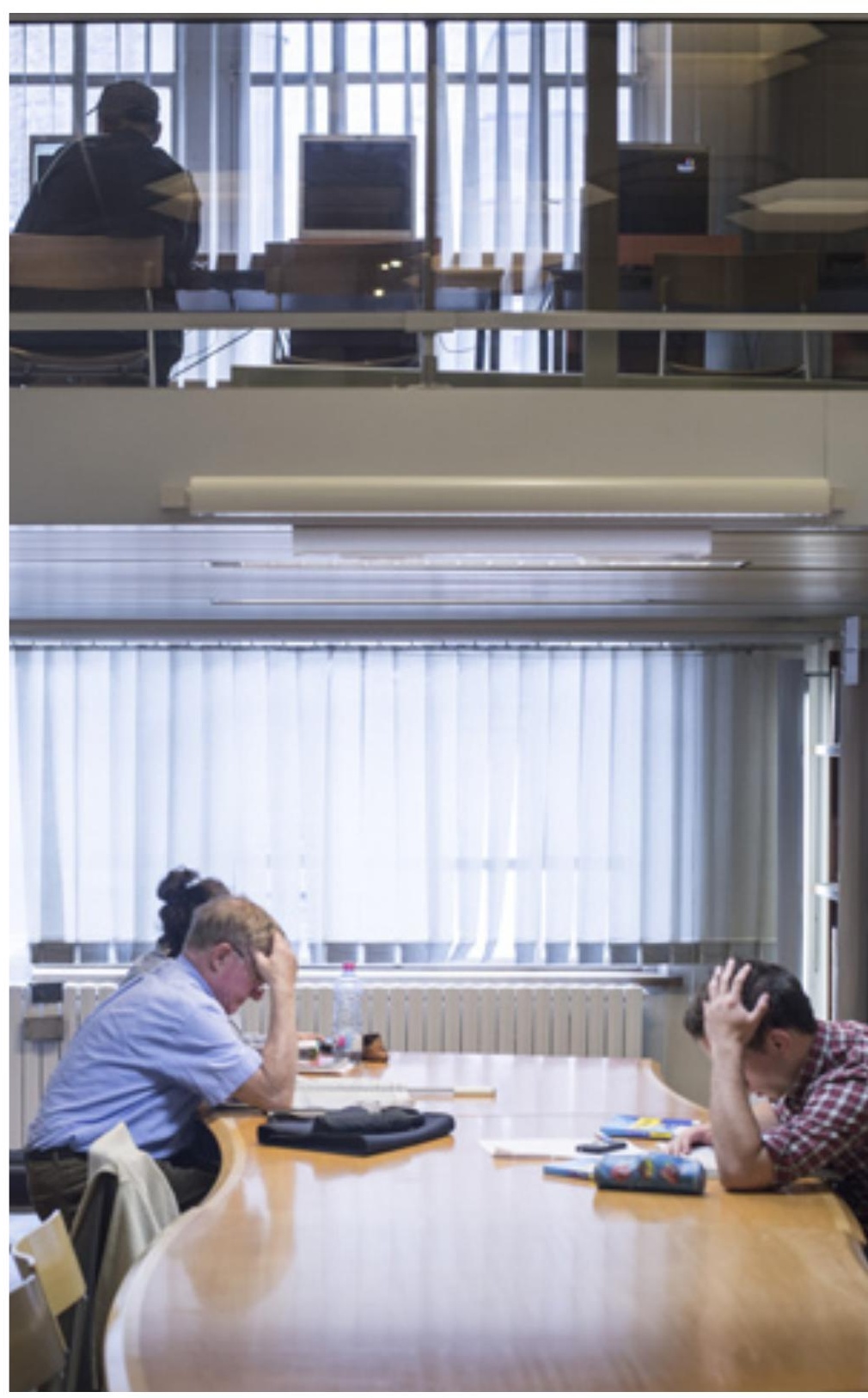
C'est joli finalement les briques, rouges serties de blanc, pourquoi dans mon souvenir les briques sont-elles toutes sombres, comme noircies de mousse et de poussière de charbon, et pourquoi les briques ne seraient-elles belles qu'à Toulouse, Claude Nougaro contre Pierre Bachelet le combat n'est pas équitable, paix à leur âme. Les fenêtres rondes comme des hublots du bâtiment, un ancien collège jésuite. «Je ne rappellerai point ici les institutions bizarres qui fatiguaient et dépravaient l'enfance, usaient la première jeunesse dans un pénible apprentissage de mots: vain simulacre d'éducation, où la mémoire seule était exercée, où une année faisait à peine connaître un livre de plus, où la raison était insultée avec les formes du raisonnement; où enfin, rien n'était destiné à développer l'homme, ni même à le commencer ", disait Daunou des collèges jésuites, en bon révolutionnaire. Celui-ci n’a pas dérogé à la règle, et fondé en 1591, a été confisqué à la Révolution, et ouvert au public en 1801. Sacrée revanche, et quel meilleur lieu que ce bateau ancré dans le passé, ce bateau aux parois de briques poreuses, pour en faire une bibliothèque, royaume des livres d'où larguer les amarres? Sous le porche monumental, donc, avec bloc-note et appareil photo, comme en expédition, et le refrain du Nord et des corons dans la tête, c'est malin. Ça pourrait être pire, cela dit, Enrico Macias, par exemple. Et c'est ainsi chantonnante que j'entrai, enfin, dans la bibliothèque.

Des briques et du verre, des briques et des arbres de métal, des briques et de la lumière, en flot, en cascade. Des arbres en parapluies, tenant le ciel, dans ce qui auparavant, était la cour. Des arbres jetant leurs poutrelles vers le ciel, et les racines prises dans cette histoire sédimentée. Au centre, un escalier de bois, tournicotant vers les nuages. Sous le ventre des oiseaux, ricochant contre la verrière, le bruissement de toutes ces pages tournées depuis des siècles, les chuchotements des élèves, les ânonnements des récitations et les rires des enfants, mais aussi l'écho lointain des bombardements, et de l'enflement des eaux de l'Escaut, mais aussi le crissement des plumes et des stylos, mais aussi le cliquetis des doigts pianotant sur les claviers d'ordinateur, et les pensées qui s'entrechoquent.

Des briques et du verre, du bois et du métal. Du vieux et du neuf, de l'ancien et du moderne. Des manuscrits médiévaux et des 
ressources électroniques, des enluminures et des albums jeunesse, des incunables et des livres de poche, des spots et l'opaline verte des lampes, des enfants et des Jésuites, des poufs dans l'ancienne salle de rhétorique, des cartes du Xvie siècle et les encyclopédies en ligne, les couleurs vives et les teintes passées des fresques, des dentelles et de l'art contemporain, des partitions et des CD... et tout ça raconte à travers les siècles la même histoire, les cervicales qui craquent de trop se pencher sur les pupitres, sur les aiguilles et les pinceaux, tandis que les rêves et l'imagination s'envolent, pour se poser, invisibles, sur les épaules des visiteurs, de génération en génération. Les doigts des femmes sur les aiguilles, nuque douloureuse, les fils comme des lettres, à tresser, entrelacer et ravauder, les mots à ciseler à petits points, le tissu et le texte, et ma grandmère qui était couturière, le dé toujours au bout du doigt, au poignet la pelote d'épingles, étudie ma fille, étudie... Les petites filles penchées sur leurs ouvrages, et moi je coupais le tricot avec des ciseaux tandis que la grand-tante tentait de me dresser aux travaux d'aiguilles, dans la maison qui sentait la soupe aux poireaux et l'humidité, mauvaise fille, c'était trop serré, faire exprès pour retourner lire, refuser le fuseau pour ne pas dormir toute sa vie. Pas beaucoup de petites filles dans le collège jésuite, et le seul frottement des robes devait être celui des femmes de ménage, frottant, cirant, lavant les sols et les pupitres, avaient-elles le droit de toucher les livres, ne serait-ce que pour les épousseter? Qu'en auraient-elles fait, elles qui ne savaient pas lire... Deux petites filles se bousculaient justement dans l'escalier, des livres à la main, dans l'escalier qui montait, montait comme dans un album de Claude Ponti. Une porte fermée à clef, et tout le mystère dans les quelques secondes nécessaires à en ouvrir la serrure, à en pousser les battants. Le cœur de la bibliothèque, noyau de silence, de bois sombre et de reliures, et comme par réflexe, la voix qui se fait chuchotement, et la fillette à ma main qui soudain se serre contre moi, sans doute impressionnée par les craquements du bois sous ses pas pourtant si légers, comme les maisons soudain vivantes dans le silence de la nuit. Sous le regard peint des trente-six pères jésuites, groupés trois par trois, selon leur discipline, sous les toges et manteaux brodés des peintures de Wamps se faisant face, La Cantilène de sainte Eulalie. Regarde, petite fille, c'est le 
premier poème de la littérature française, écrit il y a très très longtemps, au Ixe siècle. On l'a trouvé dans l'abbaye de SaintAmand-les-Eaux et dans la bouche, ce nom imprégné du goût amer de l'eau que j'étais obligée de boire, en visite à mes grandsparents, pour leur cure annuelle, et c'est près de cette fontaine que j'avais appris le mot «marcassin ». Il y avait des sangliers, paraît-il dans la forêt de Saint-Amand. Et longtemps j'ai cru que c'était ce petit bois que chantait Barbara.

Buona pulcella fut Eulalia.

Bel auret corps, bellezour anima.

Voldrent la veintre li Deo inimi,

Voldrent la faire diaule servir.

Elle no'nt eskoltet les mals conselliers

Qu'elle Deo raneiet, chi maent sus en

[ciel,

Il y avait la traduction, mais je ne lui ai pas raconté la suite, histoire de ne pas associer à jamais dans son esprit bibliothèque et traumatisme psychologique. Eulalie, vouée à Dieu, préféra mourir que de perdre sa virginité. Comme la Blandine de Lyon, elle a mis du temps à mourir. Le feu refusant de la consumer, on dut lui couper la tête. Et elle se changea en colombe. Sans doute volet-elle, le soir, au-dessus de l'arbre de métal. Y'a un arbre, pigeon vole et s'envole, dans le petit bois de Saint-Amand.

Et regardant ma fillette, la poche pleine de toutes ces plumes qu'elle ramasse sur les trottoirs et qu'elle m'offre en trophée d'adoration, plumes de pigeons, de moineaux, plumes de toutes ces vierges décapitées à tremper dans l'encre, plumes avec lesquels construire des attrape-rêves, la regardant passer, l'air de rien, la main sur les moulures et le cuir, comme attirée, aimantée, m'est revenue la sensation tellement forte, tellement physique, tellement charnelle, éprouvée depuis l'enfance dans chaque site historique, que le pied sur la dalle, là, alors effleure le souvenir de ceux qui, des siècles auparavant, y ont vécu. Que la main sur ce bois, là, alors caresse une main depuis longtemps tombée en poussière. Et ainsi lui guidant la main, les jésuites, pour que demain ce soit elle qui lise, et elle qui écrive. 


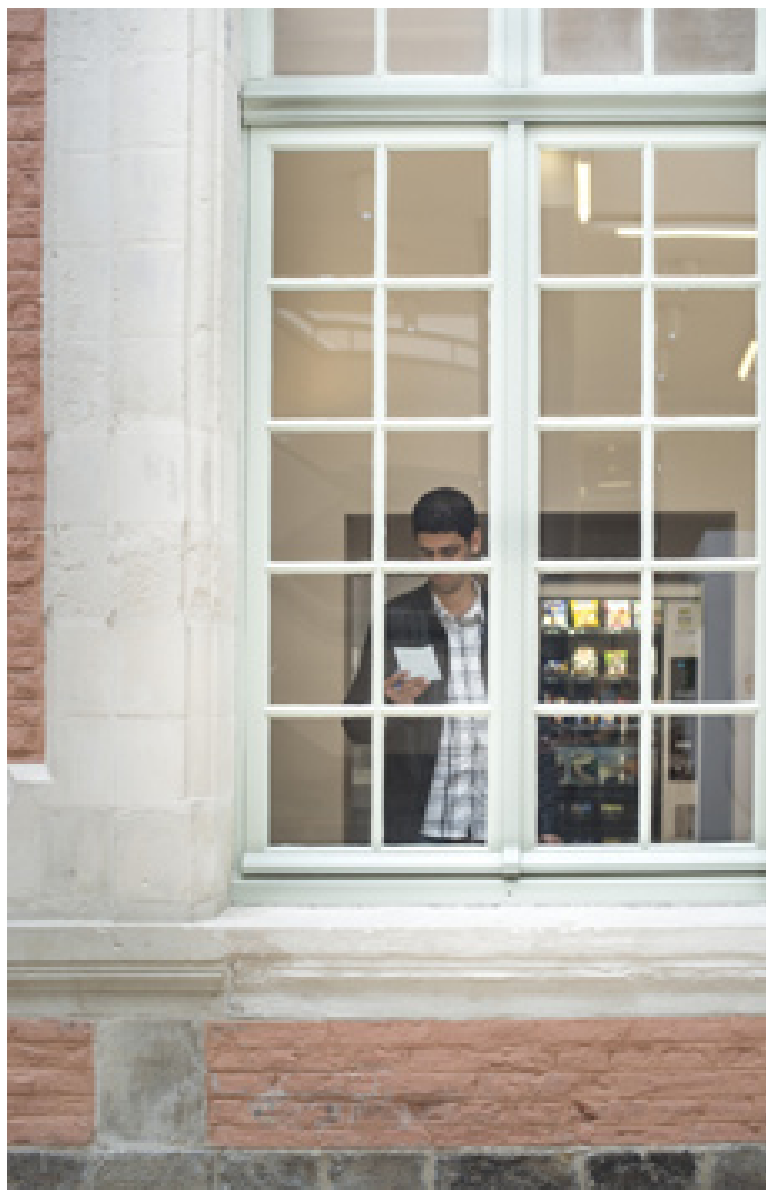



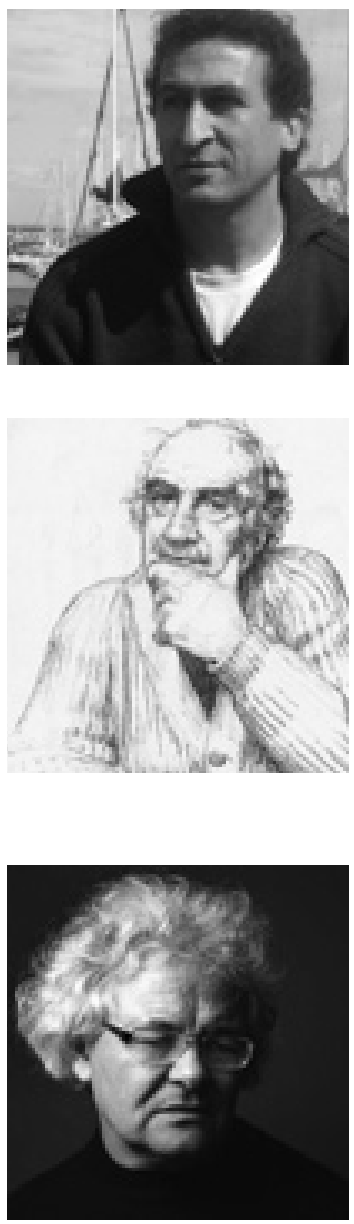

Parmi les publications de François Bon:

\section{Autobiographie}

des objets, Seuil, 2012

Après le livre, Seuil, 2011

Rock'n roll: portrait

de Led Zeppelin,

Albin Michel, 2008

Bob Dylan: une biographie,

Albin Michel, 2007,

le Livre de poche, 2009

Daewoo, Fayard, 2004,

(le Livre de poche, 2006)

Rolling Stones:

une biographie, Fayard, 2002,

(le Livre de poche, 2011)
Sur la route de Bauliac,

Baleine (coll. Série grise), 1999

Les Ardoises de la mémoire,

Gallimard (coll. Série Noire), 1999

Avis déchéance, Gallimard

(coll. Série Noire), 1998

Causse-toujours!, Baleine

(coll. le Poulpe), 1997

Nombreuses publications

en revue, et pièces

radiophoniques.

Le montreur de marionnettes,

Fayard, 2001

Eloge des bibliothèques,

\section{CFD, 2000}

Evangile selon Tommaso,

Desclée de Brower, 1999

Les papiers de Walter Jonas,

Actes Sud, 1995

Eloge de la libraire avant

qu'elle ne meure,

Le Temps qu'il fait, 1991

Esquisse d'un discours sur le livre, Le Temps qu'il fait, 1986

Mécanique, Verdier, 2001

Sortie d'usine, Minuit, 1982

De nombreuses publications en ligne, essentiellement disponibles sur: publie. net.

François Bon a fondé successivement le site de création littéraire et critique remue. net, et publie. net, coopérative d'auteurs pour l'édition et la diffusion numériques de littérature contemporaine.

Son blog: www.tierslivre.net 

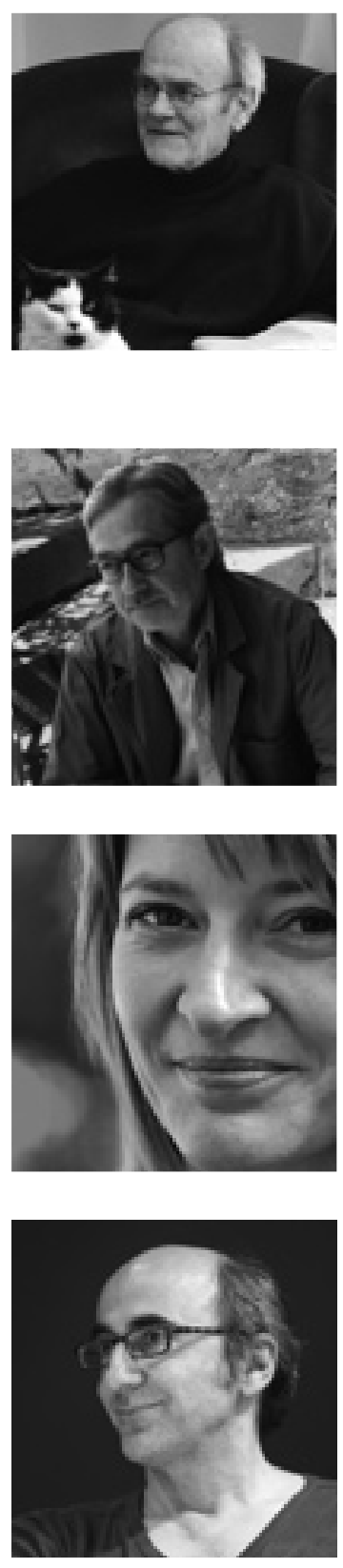

Parmi les publications

de Jean de Breyne - poésie:

Figure, Propos2éditeur, 2011

C'est quand l'homme parle,

Propos2éditeur, 2007

Triages, anthologie, Tarabuste, 2005

Le poème de Dublin, poème

irlandais (gravures de Paul

Hickin), Jean-Pierre Huguet

éd., 2001

Aires, ailes et lignes, Lieux dits

Parmi les publications

de Pascal Commère - poésie:

Les laines qui éclairent,

le Temps qu'il fait, 2012

Mémoire, ce qui demeure,

Tarabuste, 2012

Tashuur: un anneau de poussière, Obsidiane, 2012

Les larmes de Spinoza:

histoires, le Temps

qu'il fait, 2009

Parmi les publications

de Christine Détrez - poésie:

De deux choses l'une, Chèvre feuille étoilée, roman, 2010

Rien sur ma mère, Chèvre

feuille étoilée, roman, 2008

La construction sociale du

corps, Seuil (coll. Points), 2002

Parmi les publications

de Dominique Fabre-romans:

J'aimerais revoir Callaghan,

Fayard, 2010, (le Livre

de poche 2011)

II faudrait s'arracher

le cœur, I'Olivier, 2012

Avant les monstres, Cadex, 2009 (coll. Contres Vers), 1998

Retenues, poèmes, Ecbolade, 1997

Langue, La Sétérée, 1993

Là, ailleurs, URDLA, 1990

La Disparition et ensuite,

Colorature, 1984

À paraître:

Les poèmes de Koppelo, suivi de photographies.

Propos2éditeur

Directeur de la publication

Les commis, le Temps

qu'il fait, 2007

Prévisions d'un passage d'un dix cors au lieu-dit Goulet du maquis, Obsidiane, 2006

Le vélo de Saint Paul,

le Temps qu'il fait, 2005

La grand soif d'André Frénaud, le Temps qu'il fait, 2001

Vessies, lanternes

et autres bêtes à cornes,

Obsidiane, 2000

La serveuse était nouvelle, Fayard, 2005, (Pocket 2007) Moi aussi, un jour,

j'irai loin, Maurice Nadeau, 1995, (Points Seuil 2006)

Mon quartier,

Fayard, 2002

Ma vie d'Edgar,

le Serpent à Plumes, 1998 


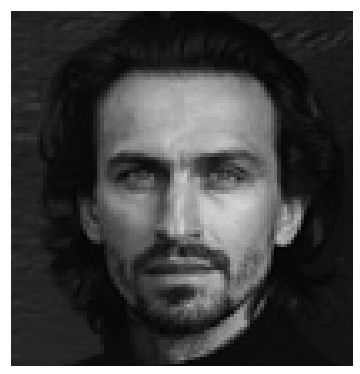

Parmi les publications

de Nicolas Fargues - romans:

La ligne de courtoisie,

P.O.L., 2012

Tu verras, P.O.L., 2011, prix

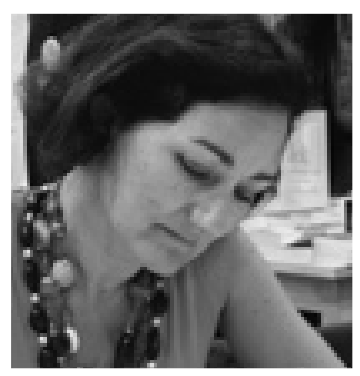

Parmi les publications

de Alice Ferney - romans:

Passé sous silence: roman,

Actes Sud, 2010

Paradis conjugal: roman, Albin

Michel, 2008

Les autres: roman,

Actes Sud, 2006

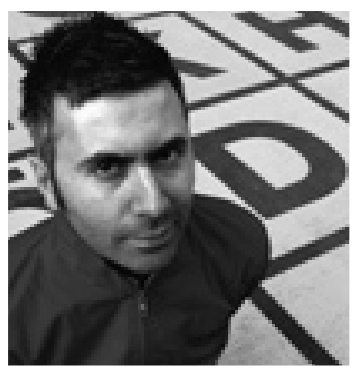

Parmi les publications de Philippe Fusaro:

L'Italie si j'y suis, la Fosse aux ours, 2010

Palermo solo,

la Fosse aux ours, 2006

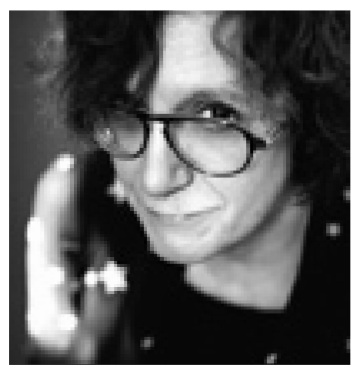

Parmi les publications de Sylvie Gracia - romans :

Le livre des visages,

Jacqueline Chambon, 2012

Une parenthèse espagnole,

Verticales, 2009

Regarde-moi,

Verticales, 2005

L'Ongle rose, Verdier, 2002
France Culture-Télérama

Le roman de l'été, P.O.L., 2009

Beau rôle, P.O.L., 2007

J'étais derrière toi,

P.O.L., 2006

One man show, P.O.L., 2002
Dans la guerre: roman,

Actes Sud, 2003

La conversation

amoureuse: roman,

Actes Sud, 2000

Grâce et dénuement:

roman, Actes Sud, 1997

L'élégance des veuves:

roman, Actes Sud, 1995

Le colosse d'argile,

la Fosse aux ours, 2004

(Folio, 2006)

Capri et moi, la Fosse

aux ours, 2003

Les Nuits d'Hitachi,

l'Arpenteur/Gallimard, 1999

L'été du chien,

l'Arpenteur/Gallimard, 1996

Sylvie Gracia est éditrice au Rouergue, où elle dirige la collection La brune ainsi que les collections de romans pour la jeunesse. 


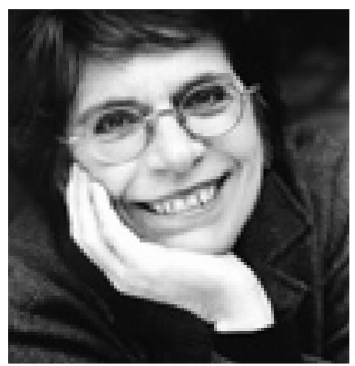

Parmi les publications de Leslie Kaplan - récits, romans, théâtre, essais:

Millefeuille (roman),

P.O.L., 2012

Louise, elle est folle, P.O.L., 2011

Toute ma vie j'ai été une

femme, P.O.L, 2008

Fever, P.O.L., 2005;

puis Gallimard Folio 2007

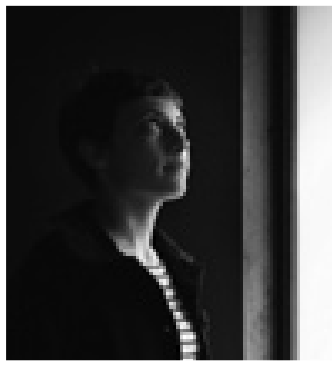

Artiste née en 1980

à Vénissieux (69)

Vit et travaille entre Lyon,

Paris et Genève.

Représentée par Super

Window Project, Kyoto /

Olivier Houg Galerie, Lyon /

Gowen Contemporary,

Genève / Bloo Gallery, Rome.

Chargée de cours et responsable du pôle photographique, Haute École d'art et de design (HEAD), Genève.

Expositions individuelles (sélection)

Round The Corner Gallery,

Lisbonne, Portugal, 2012

Absolut, Pilotenkueche, Leipzig,

Allemagne, 2011

Partition, Musée des

Beaux-Arts,

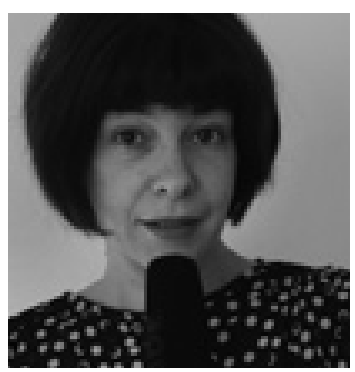

Parmi les publications

d'Emmanuelle Pireyre:

Foire internationale,

les Petits matins, 2012

Féérie générale, I'Olivier, 2012

Comment faire disparaître

la terre?, Seuil, 2006
Les Outils, P.O.L, 2003

Les Amants de Marie,

P.O.L, 2002

Le Psychanalyste, P.O.L, 1999

L'Épreuve du passeur,

P.O.L, 1988

L'Excès-l'usine, P.O.L., 1982

Nombreuses publications en revue, et sur Publie.net éditeur

Shanghai, Chine, 2011

Polygone, Olivier Houg

Galerie, Lyon, 2011

Répétition, Super Window

Project / Muzz Program

Space, Kyoto, Japon

Ricochets, ENS-Science et

ENS-LSH, en Résonance avec

la Biennale d'art contemporain, Lyon, 2009

Tombé du ciel, 3bisF,

Aix en Provence

Garden party, Hôpital

St Joseph - St Luc,

en résonance avec la biennale

d'art contemporain, Lyon, 2007

Aurélie Pétrel favorise

le travail en résidence,

et participe également

à de nombreuses

expositions collectives.

$<$ http://www.dda-

ra.org/fr/oeuvres/

PETREL_aurelie>

Mes vêtements ne sont

pas des draps de lit,

Maurice Nadeau, 2000

Congélations et décongélations, et autres

traitements appliqués

aux circonstances,

Maurice Nadeau, 2000 


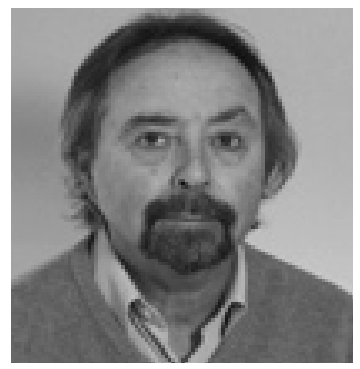

Parmi les publications de Henri Raczymow - récits, romans, essais et biographies:

Points de chute, Gallimard, coll. Haute-Enfance, 2012

Ruse et déni: cinq essais de littérature, P.U.F., 2011

Heinz: récit, Gallimard, 2011

Eretz: récit, Notes par Anne

Amzallag, Gallimard, 2010

Avant le déluge: Belleville années 1950, Phileas Fogg, coll. Flâneries, 2005

Pauvre Bouilhet, essai, Gallimard, coll. L'un et l'autre, 1998 Quartier libre, Gallimard,

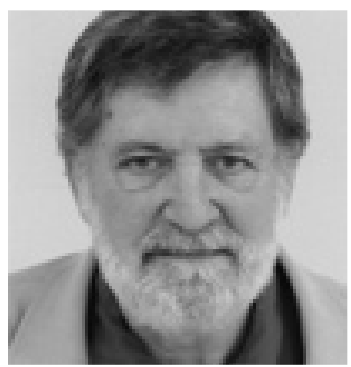

Parmi les publications de François Salvaing:

Un amour au pied du mur, Écriture, 2012

De purs désastres, édition aggravée, Cadex, 2010

Maud et Matilda, Fayard, 2008

La phrase, Mille

et une nuits, 2006 coll. Haute-Enfance, 1995

La mort du grand écrivain: essai sur la fin de la littérature, Stock, 1994 Bloom \& Bloch, Gallimard, coll. Blanche, 1993 Le Cygne de Proust, essai, Gallimard, coll. L'un et l'autre, 1989 Maurice Sachs ou les Travaux forcés de la frivolité, biographie, Gallimard, 1988 Un cri sans voix, Gallimard, coll. Blanche, 1985

À paraître: Les derniers jours de Marcel Proust, roman, Denoël, 2013

Le cœur trouble,

Fayard, 2005

Casa, Stock, 2003

(le Livre de poche, 2005

Raoul, Stock, 2004

Parti, Stock, 2000,

le Livre de poche, 2002)

La boite, Fayard,

1998, (le Livre

de poche, 2000)

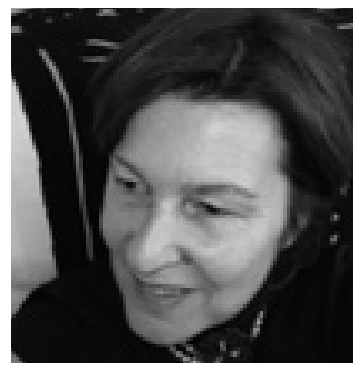

Parmi les publications

de Jane Sautière:

Nullipare, Verticales, 2008

Fragmentation d'un lieu commun, Verticales, 2003

À paraître: Dressing (Verticales) 

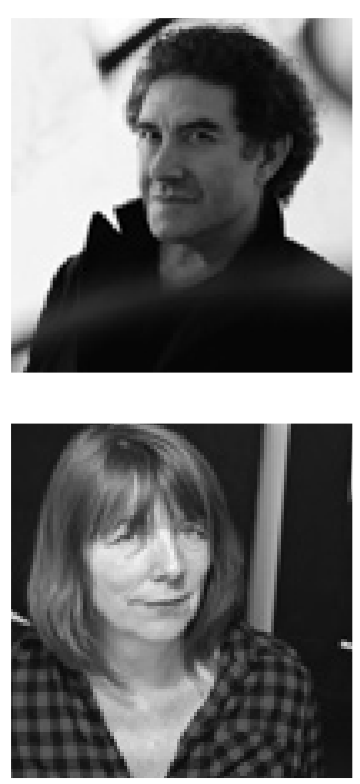

Parmi les publications de Jacques Séréna - romans, théâtre:

Sous le néflier, Minuit, 2007 Les fiévreuses, Argol, 2005 L'acrobate, Minuit, 2004

Parmi les publications de Fabienne Swiatly - poésie, récits, romans, théâtre:

Unité de vie, éd. La Fosse aux ours, 2011

Ligne de partage des eaux, éd. La Passe du vent, 2011 Une femme allemande, éd. La Fosse aux ours, 2008 Jusqu'où cette ville, éd. Publie. net, 2008 Stimmlos - Sans voix (bilingue), éd. En Forêt, 2006

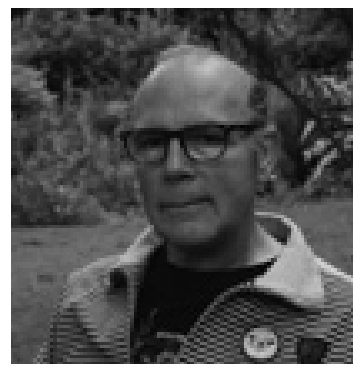

Parmi les publications de Lucien Suel - poésie:

Blanche étincelle,

La Table ronde, 2012

La patience de Mauricette,

La Table ronde, 2019

Mort d'un jardinier, La Table ronde, 2008 (Folio

Galllimard $\left.n^{\circ} 5105,2010\right)$

D'azur et d'acier,

La Contre allée, 2010

Poèmes vi (suel) s. Éditions de la Vachette alternative, collection 8pA6,

Suisse, 2009

La patience de Mauricette,

La Table Ronde, 2009. Folio

Gallimard n5273, 2011

Les versets de la bière

(journal 1986-2006), Dernier

Télégramme, Limoges, 2010
Plus rien dire sans toi,

Minuit, 2002

Quart d'heure, les Solitaires intempestifs, 2000

Lendemain de fête,

Minuit, 1993

Isabelle de dos, Minuit, 1989

Gagner sa vie, éd. La Fosse aux ours, 2006

À paraître:

Annette (théâtre)

Rédactrice en chef de la nouvelle revue de poésie VA! (Maison de la poésie / Centre de poésie pour l'enfance-

Tinqueux), elle anime également le blog

La Trace bleue

(http://www.latracebleue.net/)

La Justification de l'abbé Lemire, Mihàly, 1998

Sombre Ducasse,.

Station Underground

d'Emerveillement Littéraire,

Berguette, 1988

Guess who? Devinez qui?,

Michel Champendal

éd. (coll. Dix de Der), 1984

À paraître:

Petite Ourse de la Pauvreté, aux éditions du Dernier Télégramme.

Les blogs de Lucien Suel: SILO: $<$ http://academie23.blogspot.fr/> - Lucien Suel's Desk:

$<$ http://luciensuel.blogspot.fr/> - A NOIR E BLANC:

$<$ http://anoir-eblanc.blogspot.fr/> 


\section{Aurélie Pétrel}

Les photographies retenues ici, pour ce livre, représentent un petit quart [à vérifier] du corpus rassemblé par Aurélie Pétrel au cours de son voyage en bibliothèque.

D'octobre 2011 à juin 2012 la photographe est allée sur les sites des 19 bibliothèques choisies par les écrivains pour leur microrésidence ${ }^{1}$.

Au fil des mois et des bibliothèques visitées elle a construit son projet, des lignes de force se sont dégagées. Elle a commencé par capter des éléments architecturaux, les baies vitrées par exemples, éléments récurrents des constructions des années 1990. Ainsi la dominante du format vertical s'est imposée². Puis elle a commencé d'isoler des visiteurs, elle parle parfois de "personnages », en favorisant les structures créées entre les mobiliers et les corps, ou l'inverse, comme les personnes endormies sur les tables. Progressivement l'idée de constituer des duos de photos a fait sens, lui permettant aussi de se «libérer du format du livre» pendant cette période du travail.

Certains motifs inattendus, comme les rayures des vêtements, qu'elle a choisi de privilégier inscrivent discrètement l'ouvrage dans son époque.

C'est seulement le parcours bien entamé que les vues de «l'extérieur» sont arrivées.

De Valenciennes, Armentières, Paris à Nîmes, Marseille, Biarritz, en passant par Gérardmer, Lorient, Poitiers, Epinal et encore Alfortville, Villejuif, Lyon elle s'est familiarisée avec tout un écosystème,

1. Leslie Kaplan (BU

Sainte-Barbe, Paris), Jane Sautière (BM Marguerite Yourcenar, Paris), Henri Raczymow (BU Paris Diderot), Philippe Fusaro (BM de Gérardmer), Pascal Commère (BM d'Epinal), Baptiste-Marrey (BM Elsa Triolet de Villejuif), Dominique Fabre (BU de Paris 8), François Salvaing (BM de Lorient), Jacques Séréna (Médiathèque de la Roseraie, Angers), François Bon BM de Poitiers), Emmanuelle Pireyre (BM du Bachut, Lyon), Jean de Breyne (BM de Nîmes), Sylvie Gracia (BM Alcazar, Marseille), Mouloud Akkouche (BM de Biarritz), Nicolas Fargues (la BULAC, Paris), Alice Ferney (BM Alfortville), Fabienne Swiatly (BU Chevreul, Lyon 2), Lucien Suel (BM d'Armentières), Christine Détrez (BM de Valenciennes) 2. Ce qui a largement contribué au redressement vertical du format du livre, initialement imaginé à l'italienne. 3. Le blog du chantier de la BU : <http://www.bib-versailles.uvsq.fr> Ouverture prévue en octobre 2012. 
appréhendant la bibliothèque comme lieu générique tout en captant chacun des établissent dans sa spécificité.

Comme pour les écrivains, elle restait parfois incognito lors de ses visites aux bibliothèques et parfois, quand les circonstances le permettaient elle était accueillie par un bibliothécaire, bénéficiant alors d'une rencontre toute singulière.

\section{Le livre}

Des chaises, des fenêtres, des dos, du mobilier, des dormeurs, des lignes, des couleurs et des lecteurs. Nous retrouvons dans les photographies d'Aurélie Pétrel une dimension qui est au cœur de ses recherches plastiques: interroger le passage de la lumière. Et nous ressentons surtout la vibration particulière qui anime ses images, faite du mélange de la tension que suppose la vitesse de la captation et de la délicatesse discrète avec laquelle les figures sont représentées.

C'est un vrai plaisir d'amener ainsi à la lumière nos chères bibliothèques.

\section{Trombe*}

Aurélie Pétrel a choisi de faire le portrait de la nouvelle BU des sciences ${ }^{3}$ de l'université de Saint-Quentin en Yvelines - ce qui arrondit à 20 le nombre des carnets de voyages de l'ouvrage et l'habite d'emblée, à l'intérieur des rabats des couvertures.

* Le mur Trombe ou mur Trombe-Michel, qui a été conçu par le professeur Félix Trombe et l'architecte Jacques Michel, est un mur capteur. II est composé d'un bloc de matière à forte inertie (béton, pierre, etc.) qui accumule le rayonnement solaire du jour et le restitue pendant la nuit. Devant cette paroi, on place une vitre pour créer un effet de serre pour chauffer l'air."

Wikipedia, <http://fr.wikipedia.org/wiki/Mur_Trombe> (consulté le 28 août 2012). 
Dépôt légal: 


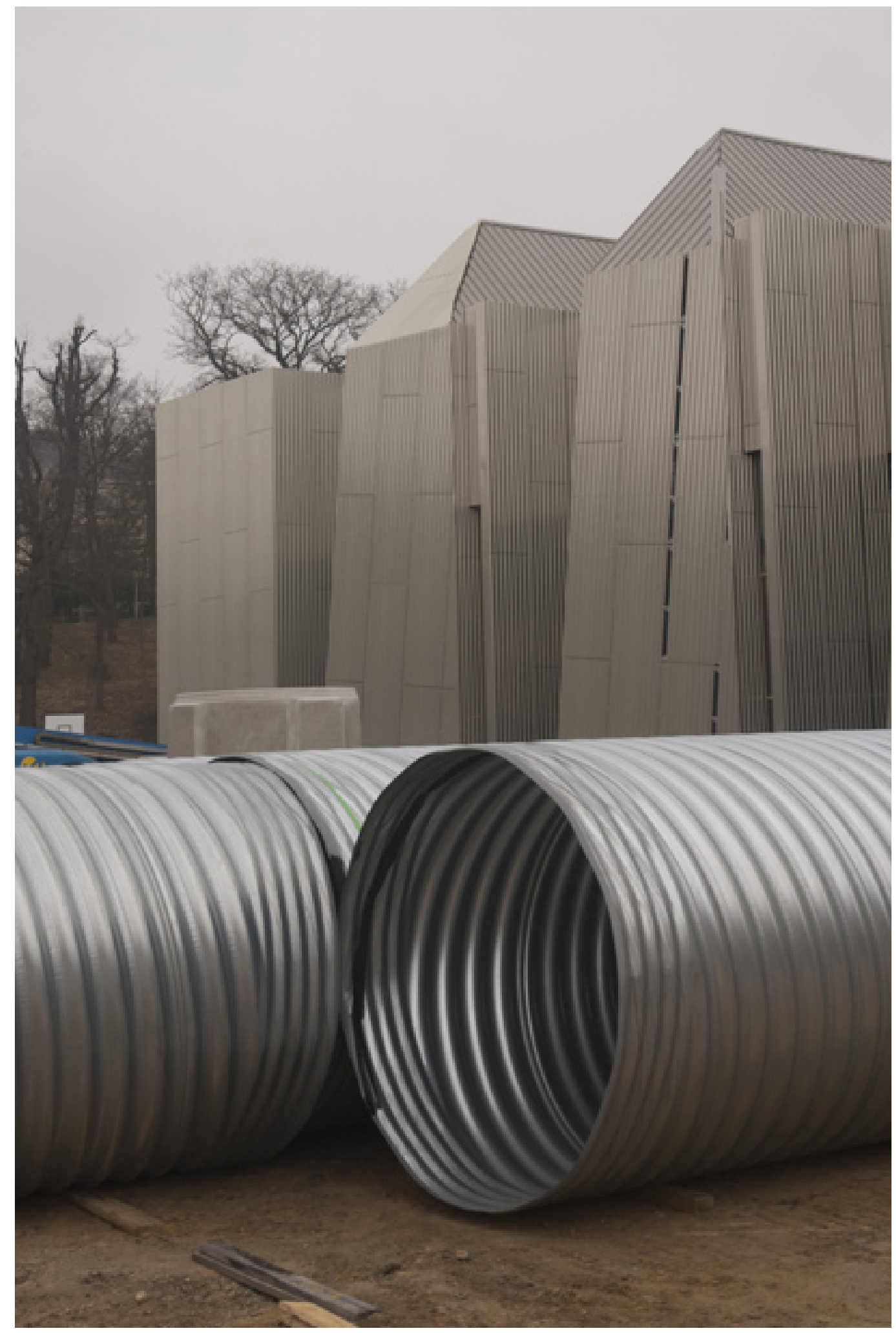


2009 | $13600 \mathrm{~m}^{2}$ | Architecte: Antoine Stinco

2008 | $3491 \mathrm{~m}^{2}$ | Architecte: Babel

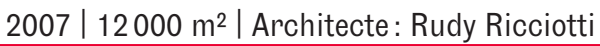

1994 | 1750 m² $^{2}$ Architecte: François Lobjoy

2009 | $4761 \mathrm{~m}^{2}$ | Architecte: Chabanne et partenaires

2006 | $2600 \mathrm{~m}^{2}$ | Architectes: Paul Chemetov et Borja Huidobro

1998 | $12839 \mathrm{~m}^{2}$ | Architecte: Pierre Riboulet

1993 | 3897 m² $^{2}$ Architectes: Fatus et Guillouët

Bibliothèque de la Roseraie, Angers $|2011| 800 \mathrm{~m}^{2}$ | Architecte: Pierre Chudeau

1996 | 8000 m² $^{2}$ Architectes: Emmanuelle et Laurent Beaudouin, Sylvain Giacomazzi et Hervé Beaudouin

$2008\left|2529 \mathrm{~m}^{2}\right|$ Architecte: Bruno Dumetier

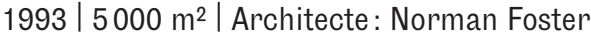

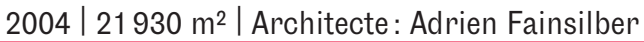

2005 | $4066 \mathrm{~m}^{2}$ | Architecte: François Lombard

$2011 \mid 17300 \mathrm{~m}^{2}$ | Architectes: Yves Lion et David Jolly

2007 | $2317 \mathrm{~m}^{2}$ | Architecte: agence Charon et Rampillon

2006 | $5500 \mathrm{~m}^{2}$ | Architecte: Thierry Van de Wyngaert

2007 | $2929 \mathrm{~m}^{2}$ | Architecte : Beal et Blanckaert

1995 | 5000 m² $^{\text {| Architecte: Cabinet MTA (Montrouge) }}$

2012 | $3000 \mathrm{~m}^{2}$ | Architecte: Badia Berger architectes 
Bibliothèque centrale de l'Université Diderot, Paris 00100

Médiathèque du Tilleul, Gérardmer 00100

Bibliothèque multimédia intercommunale Épinal-Golbey 00|00 Médiathèque Elsa-Triolet, Villejuif 00100

Bibliothèque de l'Université Paris 8, Saint-Denis 00100

Médiathèque de Lorient 00100

Bibliothèque de la Roseraie, Angers 00100

Médiathèque François-Mitterrand, Poitiers 00100

Médiathèque du $8^{\mathrm{e}}$, Lyon 00100

Carré d'Art Bibliothèque, Nîmes 00100

L'Alcazar - Bibliothèque de Marseille à vocation régionale 00100

Médiathèque de Biarritz 00100

Bibliothèque universitaire des langues et civilisations, Paris 00100

Médiathèque du Pôle culturel, Alfortville 00100

Bibliothèque universitaire Chevreul, Lyon 00100

Médiathèque L'Albatros, Armentières 00100

Bibliothèque multimédia, Valenciennes 00100

Bibliothèque universitaire des sciences, Versailles 00100

Lorem ipsum dolor sit amet, consectetur adipiscing elit. Suspendisse mollis porttitor est, quis sollicitudin risus eleifend elementum. Integer nulla nibh, vehicula vitae fringilla eu, bibendum vel velit. Duis tincidunt viverra nisi mollis adipiscing. Nulla ligula tortor, posuere et condimentum vitae, euismod sed sapien. Ut sit amet gravida nunc. Pellentesque ultrices eros ut nulla sodales mattis. Etiam at vestibulum ipsum. Mauris at elit ac lacus semper laoreet. Etiam in volutpat. 
$\theta$
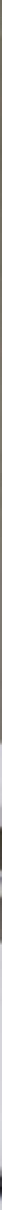